\title{
RECALIBRATING
}

REGULATION OF

COLLEGES AND

UNIVERSITIES

Report of the Task Force on

Federal Regulation of Higher Education

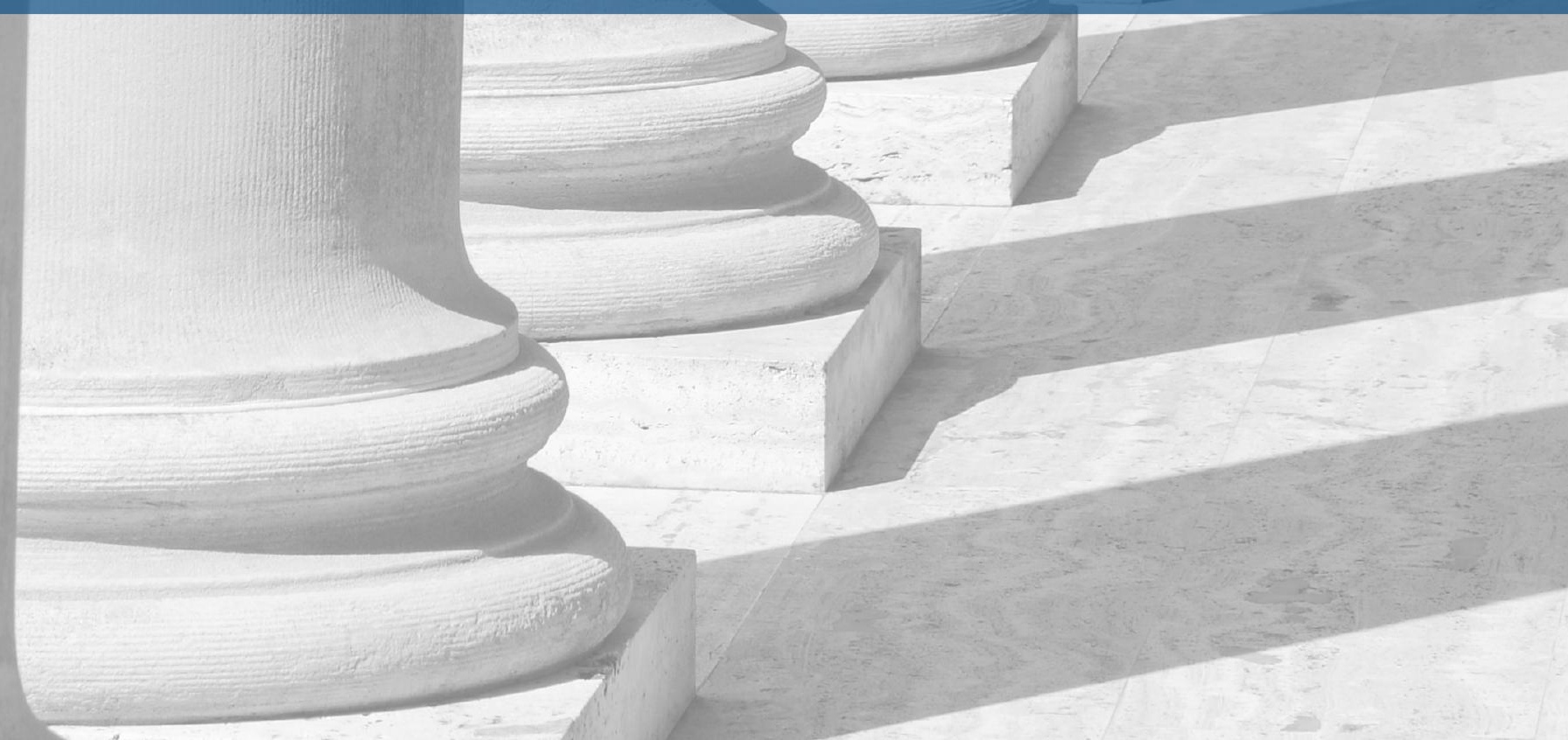


The Task Force thanks the American Council on Education for its dedicated work in hosting and organizing the meetings of the Task Force, and for its service in producing this report. In addition, we wish to thank Lumina Foundation for funding the three white papers on regulatory process reform that appear as appendices to this report. 


\section{Executive Summary}

The federal government's substantial fiscal investment in higher education recognizes that postsecondary education is a linchpin in the nation's social and economic strength. Through that support, the government helps ensure that colleges and universities continue to contribute broadly to the fabric of American society. To ensure prudent stewardship of federal support for higher education, the Department of Education ${ }^{1}$ is charged with developing procedures to carry out laws passed by Congress in regard to higher education and with overseeing institutional compliance. Institutions of higher learning recognize the important role regulations play in the oversight of federal investments.

Over time, oversight of higher education by the Department of Education has expanded and evolved in ways that undermine the ability of colleges and universities to serve students and accomplish their missions. The compliance problem is exacerbated by the sheer volume of mandates - approximately 2,000 pages of textand the reality that the Department of Education issues official guidance to amend or clarify its rules at a rate of more than one document per work day. As a result, colleges and universities find themselves enmeshed in a jungle of red tape, facing rules that are often confusing and difficult to comply with. They must allocate resources to compliance that would be better applied to student education, safety, and innovation in instructional delivery. Clearly, a better approach is needed.

In 2013, a bipartisan group of U.S. Senators recognized that the pending reauthorization of the Higher Education Act (HEA) creates an opportunity to consider these issues in depth. They established a task force of college and university presidents and chancellors to study federal regulation of higher education broadly and identify potential improvements.

Looking at the landscape of regulation of colleges and universities writ large, the Task Force on Federal Regulation of Higher Education identified a number of challenges that are particularly problematic. As described in Section II of this report, we concluded that many rules are unnecessarily voluminous and too often ambiguous, and that the cost of compliance has become unreasonable. Moreover, many regulations are unrelated to education, student safety, or stewardship of federal funds - and others can be a barrier to college access and innovation in education.

Based on extensive discussions, consultations with experts, and site visits to campuses, the Task Force identified specific regulations that are of major concern to higher education institutions. Section III details those concerns, which include problematic financial responsibility standards, confusion and inconsistency in reporting requirements for campus crime, overreach in authorization of distance education programs, inefficient rules concerning verification of financial aid eligibility, counterproductive micromanagement of the accreditation process, and policies that result in consumers being inundated with information of questionable value.

The Task Force also reviewed the processes by which higher education regulations are developed and implemented, and offers several specific ideas for improvement. Section IV outlines recommendations that include asking the Government Accountability Office to review the Department of Education's methodology for

1 Throughout this report, the phrases "Department of Education" and "the Department" are used interchangeably. 
estimating institutional costs of compliance with regulations; the creation of clear "safe harbors" for institutional compliance; the recognition of "good faith" efforts to comply; and several proposals for better practices by the Department.

To help policy makers think about the most effective and efficient way to regulate higher education, the Task Force developed the following Guiding Principles to govern the development, implementation, and enforcement of regulations by the Department:

- Regulations should be related to education, student safety, and stewardship of federal funds.

- Regulations should be clear and comprehensible.

- Regulations should not stray from clearly stated legislative intent.

- Costs and burdens of regulations should be accurately estimated.

- Clear safe harbors should be created.

- The Department should recognize good faith efforts by institutions.

- The Department should complete program reviews and investigations in a timely manner.

- Penalties should be imposed at a level appropriate to the violation.

- Disclosure requirements should focus on issues of widespread interest.

- All substantive policies should be subject to the "notice-and-comment" requirements of the Administrative Procedure Act.

- Regulations that consistently create compliance challenges should be revised.

- The Department should take all necessary steps to facilitate compliance by institutions.

The Task Force believes that adherence to these principles would help improve regulation of higher education, and urges their adoption.

Again, to be clear: Regulations serve an important role in ensuring institutional accountability. But requirements that have an excessive reach, or that are unnecessarily costly and difficult to implement-or worse still, that hinder student access to college and drive costs up-are counterproductive. Smarter rules are needed. In the context of the forthcoming reauthorization of the HEA, this report from the Task Force on Federal Regulation of Higher Education proposes many specific avenues to improve the regulation of higher education. 


\section{Contents}

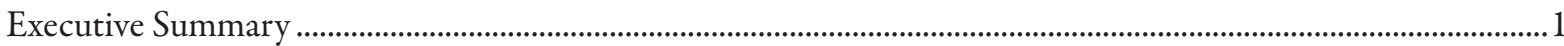

The Task Force on Federal Regulation of Higher Education ..................................................................................

Scope of Work and Task Force Activities .........................................................................................................5

Section I: The Increasing Burden of Federal Regulation of Higher Education.........................................................7

Section II: Challenges to Higher Education in the Current Regulatory Environment ....................................... 10

Regulations are Unnecessarily Voluminous.................................................................................................. 10

Compliance with Regulations is Inordinately Costly ......................................................................... 10

Regulations are Overly Complex .............................................................................................................. 12

Some Regulations Are Unrelated to Education, Student Safety, or Stewardship of Federal Funds ...... 13

The Department of Education Has an Increasing Appetite for Regulation ................................................. 13

The Department of Education Does Not Act In a Timely Fashion............................................................ 14

Regulation Can Be a Barrier to Innovation............................................................................................... 15

The Department of Education Appears Indifferent to the Regulatory Burden It Imposes ..................... 16

Section III: Specific Regulations of Concern ....................................................................................................... 18

Verification of Student Eligibility for Financial Aid ........................................................................................ 18

Return of Title IV Funds ("R2T4”)............................................................................................... 19

Financial Responsibility Standards .......................................................................................................... 20

Institutional Accreditation ................................................................................................................ 21

State Authorization of Distance Education Programs .................................................................................... 23

Uniform Definitions of Clery Crimes ........................................................................................................ 24

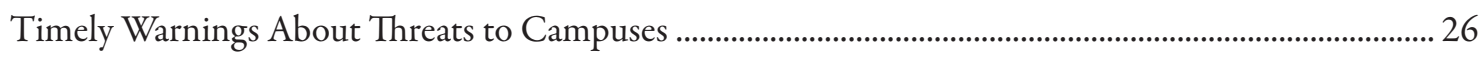

Definition of "Noncampus Property" ...................................................................................................... 27

Consumer Information .................................................................................................................... 28

Regulations Unrelated to Education, Safety, or Stewardship..................................................................... 29

Section IV: Recommended Improvements in the Regulatory Process................................................................... 32

Development of Formal Regulations at the Department .............................................................................. 32

Recommendations to Improve the Development of Regulations .................................................................. 33

Implementation of Regulations at the Department ..................................................................................... 36

Recommendation to Improve the Implementation of Regulations ............................................................... 37

Enforcement of Regulations at the Department.......................................................................................... 37

Recommendations to Improve the Enforcement of Regulations ................................................................... 37

Further Improvements to the Overall Regulatory Process................................................................................. 40

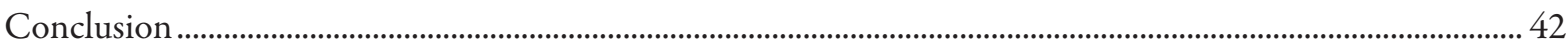

Appendices

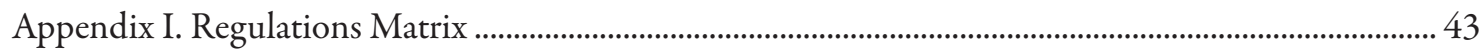

Appendix II. Regulations Process Reform Chart.................................................................................... 58

Appendix III. New Directions in Regulatory Reform ................................................................................. 59

Appendix IV. Enhancing the Use of Negotiated Rulemaking by the Department of Education ........... 90

Appendix V. The Challenges of Information Collection Burden in Higher Education........................... 126 


\section{The Task Force on Federal Regulation of Higher Education}

The pending reauthorization of the Higher Education Act (HEA) provides an opportunity for Congress to examine how institutions of higher education are regulated and to identify ways to streamline and simplify regulatory policies and practices. With that goal in mind, a bipartisan group of U.S. Senators-Lamar Alexander (R-TN), Barbara Mikulski (D-MD), Richard Burr (R-NC), and Michael Bennet (D-CO) created the Task Force on Federal Regulation of Higher Education in the fall of 2013 and directed it to consider these issues in depth.

The Senators articulated a three-part charge for the group:

1) Provide specific recommendations to consolidate, streamline, and eliminate burdensome, costly, and confusing regulations, laws, and reporting requirements;

2) Review and quantify the extent of all federal requirements with which institutions must comply, including estimates of the time and costs associated with specific regulations; and,

3) Provide recommendations for reform to ensure future regulations are promulgated in a manner that appropriately considers existing law and accurately examines the costs and benefits to taxpayers, institutions, and students.

The Senators appointed Task Force members representing institutions from across all sectors of higher education, and named Chancellors William E. Kirwan of the University System of Maryland and Nicholas S. Zeppos of Vanderbilt University (TN) as co-chairs. In addition to Chancellors Kirwan and Zeppos, the Task Force includes these members:

- William L. Armstrong, President, Colorado Christian University

- Bruce D. Benson, President, University of Colorado

- Molly Corbett Broad, President, American Council on Education (DC)

- Thomas V. Chema, President Emeritus, Hiram College (OH)

- Margaret L. Drugovich, President, Hartwick College (NY)

- Dana G. Hoyt, President, Sam Houston State University (TX)

- Brice W. Harris, Chancellor, California Community College System

- Jonathan A. Kaplan, Chief Executive Officer, Laureate Online Education (MD)

- Cornelius M. Kerwin, President, American University (DC)

- J. Michael Locke, Former CEO, Rasmussen College (IL)

- Harold L. Martin Sr., Chancellor, North Carolina Agricultural and Technical State University

- Claude O. Pressnell Jr., President, Tennessee Independent Colleges and Universities Association

- Thomas W. Ross, President, University of North Carolina

- Robert G. Templin Jr., President, Northern Virginia Community College 
In addition, the Senators asked the American Council on Education (ACE) to support the work of the Task Force.

\section{Scope of Work and Task Force Activities}

The word "regulation" can be viewed broadly or narrowly. Narrowly defined, federal regulation means only a requirement imposed on institutions through the Code of Federal Regulations, the codification of all the regulations promulgated by federal agencies. Considered more broadly, it means any requirement placed on colleges and universities in order to participate in the federal student aid program. For the purposes of this Task Force and our report, we use "regulation" in this broader sense.

The Task Force engaged in extensive consultations for this project and solicited insights from higher education associations, campus officials, and other organizations and stakeholders. To gather input from individuals on campuses who are responsible for implementing regulations, ACE staff conducted extensive site visits and met with representatives from more than 60 institutions around the country. ${ }^{2}$

Our aim was not simply to reduce the number of regulations imposed by the Department of Education, but rather to foster more effective and efficient rules that still meet federal objectives. To that end, we sought to accomplish these goals:

- Summarize the increasing burden of federal regulation on higher education.

- Identify regulations of particular concern to institutions of higher education, explain why they are problematic, and recommend changes to ameliorate them.

- Offer longer-term process improvements that would minimize similar concerns about regulations in the future.

Section I of this report frames the current regulatory landscape for higher education. Section II describes specific current challenges. Section III details 10 regulations that colleges and universities find especially problematic, and recommends solutions. ${ }^{3}$ Finally, Section IV proposes ways to improve the regulatory process.

Effective oversight can help colleges and universities keep costs down, keep students safe, focus on educating students, and be good stewards of federal funds. In that spirit, the Task Force developed the following Guiding Principles to help govern the development, implementation, and enforcement of regulations by the Department:

- Regulations should be related to education, student safety, and stewardship of federal funds.

- Regulations should be clear and comprehensible.

- Regulations should not stray from clearly stated legislative intent.

- Costs and burdens of regulations should be accurately estimated.

- Clear safe harbors should be created.

2 Our review was limited to regulations currently in effect, and not to those that were still in development. Since the Task Force began its review, however, the Department has released major rulemaking packages for gainful employment, the Violence Against Women Act, and teacher preparation, as well as hundreds of pages of new sub-regulatory guidance.

3 These regulations are derived from a lengthy matrix of problematic rules, appended to this report, that have been identified by the broader higher education community. 
- The Department should recognize good faith efforts by institutions.

- The Department should complete program reviews and investigations in a timely manner.

- Penalties should be imposed at a level appropriate to the violation.

- Disclosure requirements should focus on issues of widespread interest.

- All substantive policies should be subject to the "notice-and-comment" requirements of the Administrative Procedure Act.

- Regulations that consistently create compliance challenges should be revised.

- The Department should take all necessary steps to facilitate compliance by institutions.

We believe that these principles would help improve the regulation of higher education, and we urge their adoption.

While the primary focus of this report is on requirements imposed by the Department of Education, institutions of higher education are also regulated by every Cabinet-level agency, as well as many sub-Cabinet-level agencies. ${ }^{4}$ In that regard, we acknowledge the important work by other groups and organizations, including the National Research Council of the National Academy of Sciences and the National Science Board, to examine regulations stemming from other agencies, particularly in connection with federally funded research.

4 The Higher Education Compliance Alliance, http://www.higheredcompliance.org/matrix/. 


\section{Section I: The Increasing Burden of Federal Regulation of Higher Education}

The increasing size and reach of the federal government is an unmistakable sign of our times. In 1970, the federal budget totaled roughly $\$ 200$ billion; today it stands at $\$ 3.5$ trillion. The number of agencies in the president's Cabinet has grown from 11 to 15. The total number of individuals receiving benefits from Social Security and Medicare alone has jumped from 46 million to 100 million.

Federal aid to help students and families finance a college education has grown apace. In 1970-71, what was then the U.S. Office of Education awarded roughly 1.6 million grants and loans to low- and middle-income families. In 2013-14, the U.S. Department of Education reported nearly 20 million such awards. The amount of money disbursed grew from $\$ 1.6$ billion to more than $\$ 160$ billion. Over that same time period, federal support for research at the National Institutes of Health increased from approximately $\$ 1$ billion to roughly $\$ 30$ billion, while funding for the National Science Foundation rose from about $\$ 465$ million to nearly $\$ 7$ billion.

As the activities and scope of the federal government have expanded, so have its rules and directives. Between 1970 and 2014, the Code of Federal Regulations grew from 55,000 pages to 175,000. ${ }^{5}$ At one level, this expansion is not surprising. Increased federal support necessarily precipitates more oversight. Federal funding of higher education is not exempt, nor should it be.

At the same time, however, the cost and compliance burdens imposed by federal rules and the disincentives created by regulatory practices have become a significant matter of public concern. Indeed, a recent poll by The New York Times concluded that a clear majority of Americans now believe that over-regulation is a problem that may interfere with overall economic growth. ${ }^{6}$

While that survey focused on all federal regulation, it parallels a strong sense among college and university leaders that federal oversight of higher education has become too costly and complex and often creates negative incentives, and that significant streamlining of rules could protect the public and consumers while simplifying compliance and reducing its associated costs. From procedures institutions must follow to return "unearned" federal student aid funds when a student withdraws to the collection of crime statistics from foreign law enforcement agencies, colleges and universities face a daunting and ever-growing list of detailed federal requirements. According to an analysis of data provided by the Mercatus Center at George Mason University, the number of federal requirements placed on colleges and universities grew by 56 percent between 1997 and 2012.7

Most college and university leaders believe that the rate of increase in government-issued regulations has grown significantly in the last five years. Indeed, in 2013 and 2014, the two years since the Mercatus Center

5 The George Washington University Regulatory Studies Center, http://regulatorystudies.columbian.gwu.edu/reg-stats.

6 Sorkin, Andrew Ross, \& Megan Thee-Brenan, "Many Feel the American Dream is Out of Reach, Poll Shows," The New York Times, December 10, 2014, available at: http://dealbook.nytimes.com/2014/12/10/many-feel-the-american-dream-is-out-of-reach-pollshows/?_r=0.

7 Mercatus Center, George Mason University: http://www.regdata.org. 
study, the U.S. Department of Education has released new rules or directives addressing 10 new sets of issues. ${ }^{8}$

Two examples highlight the increasing complexity of the Department of Education's reach. First, in the early 1950s, accrediting agencies qualified for recognition by the U.S. Office of Education by meeting five straightforward criteria. Today, however, statutory requirements fill nine pages of the HEA, and the Department's application for agencies seeking recognition has expanded to 88 pages. Any agency that seeks initial or renewed recognition must expect to devote several person years to filing the appropriate federal paperwork. Another example is the expansion of data collection mandates imposed on colleges and universities. The Integrated Postsecondary Education Data Survey (IPEDS) was first implemented as a voluntary activity in 1985-86. Today, participation in IPEDS is mandatory and requires completion of nine separate surveys that together exceed 300 pages.

Given the amount of federal money spent on higher education, the government has an unambiguous responsibility to ensure that it is well spent. Concomitantly, colleges and universities have a clear obligation to be accountable for those funds. When conducted the right way, government oversight provides essential protections for students and taxpayers. But there are no benefits to unnecessary and excessively complex regulations. To the contrary, such rules impose a costly and unwelcome burden. At best, institutions must hire additional staff to comply with federal mandates. At worst, compliance consumes resources that would be better spent educating students and supporting innovative research that can help drive U.S. economic competitiveness.

While much of this report examines the Department's approach to regulation with a critical eye, there are areas where the Department performs its oversight responsibilities well. For example, the Department is charged with the monumental task of processing millions of financial aid transactions every year and overseeing the distribution of more than $\$ 160$ billion in grant and loan funds to students. In general, it manages those responsibilities effectively, carefully distributing federal dollars to students and institutions in a timely and accurate way. The Department's Office of Federal Student Aid regularly engages campus financial aid administrators in online and in-person training opportunities that enhance knowledge of financial aid processes and help facilitate compliance by school officials.

Equally important, there are cases where the Department of Education has used a regulatory process that has led to sound oversight of complex topics. The Satisfactory Academic Progress regulations issued in 2010 are one such example. Those rules outline the academic progress that students must achieve to continue to receive Title IV assistance and the steps that schools must take to document it. As a result of regulations developed through an effective negotiated rulemaking process, the Department developed standards that met the agency's objectives while giving institutions the flexibility necessary given the huge variation in academic programs across the thousands of institutions now participating in federal student aid programs.

These examples illustrate that the Department has the capacity to ensure that federal policy objectives are met

\footnotetext{
8 The 10 issues are: final regulations for the Violence Against Women Act/Clery Act, program integrity/direct loan (DL) PLUS credit check, and gainful employment; proposed rules for teacher preparation programs; and sub-regulatory guidance on program-level reporting for the 150 percent interest subsidy limit on Stafford loans, the effect of budget sequestration on annual DL and TEACH grant amounts for students, additional Net Price Calculator requirements and guidance, specific requirements for FAFSA verification, implementing the Supreme Court ruling on the Defense of Marriage Act, and a 53-page Q\&A on Title IX and campus sexual assault.
} 
in a way that facilitates campus understanding and compliance. Unfortunately, the fact that examples like this are rare underscores the infrequency with which it does so.

The overarching goal of the federal government with respect to regulation of higher education should be the creation of a regulatory framework and specific mandates that ensure full institutional accountability in a way that facilitates campus compliance. Rather than treating regulatory requirements as a "free good," the Department should accurately analyze compliance costs and seek to minimize them. The system should provide important and accurate information for students and families without imposing enormous data collection burdens on institutions. Rather than impeding institutional productivity and innovation, federal regulation ought to be facilitating it. 


\section{Section II: Challenges to Higher Education in the Current Regulatory Environment}

At the start of its review, the Task Force gathered information to develop a comprehensive understanding of the impact of federal regulations on colleges and universities. Based on our analysis, we have identified a number of broad problems confronting institutions.

\section{Regulations Are Unnecessarily Voluminous}

Higher education institutions are subject to a massive amount of federal statutory, regulatory, and sub-regulatory requirements, stemming from virtually every federal agency and totaling thousands of pages. ${ }^{9}$ Focusing solely on requirements involving the Department of Education, the HEA contains roughly 1,000 pages of statutory language; the associated rules in the Code of Federal Regulations add another 1,000 pages. Institutions are also subject to thousands of pages of additional requirements in the form of sub-regulatory guidance issued by the Department. For example, the Department's 2013-14 Federal Student Aid Handbook, a guidebook for administering student aid that amplifies and clarifies the formal regulations, is more than 1,050 pages. The Department's Handbook for Campus Safety and Security Reporting ${ }^{10}$ (also known as the "Clery Handbook") contains approximately 300 pages, and will soon expand significantly in light of new regulations issued in 2014. In 2012 alone, the Department released approximately 270 "Dear Colleague" letters and other electronic announcements-this means that more than one new directive or clarification was issued every working day of the year.

Among the many federal rules with which colleges and universities must comply, information disclosure mandates are particularly voluminous. Section 485 of the HEA, which details institutional disclosures on a host of issues, runs some 30 pages of legislative text and includes 22 separate "information dissemination" requirements. Of course, information disclosure is not limited solely to Section 485 and can be found throughout the law and the Department's rules. The Federal Student Aid office at the Department publishes a summary chart of the various consumer information disclosures. Although this chart is designed to provide consumer disclosures "At-a-Glance," it is currently 31 pages long. Between crime reporting and policy disclosures, the Clery Act and related departmental guidance require more than 90 separate policy statements and disclosures. In sum, the sheer number of regulatory provisions that affects institutions of higher education constitutes a voluminous and expanding burden. ${ }^{11}$

\section{Compliance with Regulations Is Inordinately Costly}

While government regulation can confer significant benefits and protections, the costs associated with heavyhanded and poorly designed regulations can be enormous. Unfortunately, calculating the precise benefits and costs of regulation is both difficult and time-consuming. One reason for this is that duties and functions associated with a new regulation are usually absorbed by staff who already perform other duties, simply

\footnotetext{
9 The Higher Education Compliance Alliance Compliance Matrix, http://www.higheredcompliance.org/matrix/, provides a comprehensive look at key federal laws and regulations affecting colleges and universities. The matrix identifies more than 80 different federal statutes.

10 The handbook provides departmental guidance for complying with the requirements of the Jeanne Clery Disclosure of Campus Security Policy and Campus Crime Statistics Act, commonly known as the Clery Act.

${ }^{11}$ Colleges and universities are also subject to a host of state and local laws and regulations, which add significantly to the volume of regulation, but are outside the scope of this report.
} 
adding to their workload. Similarly, estimates of the cost of complying with a new regulation may fail to take into account the complicated interplay between new and existing requirements. Regulations do not exist independently of each other, and the interplay of multiple requirements can add exponentially to the cost of compliance.

For these and other reasons, attempts to systematically quantify these costs have been few and far between. One early effort to estimate costs was undertaken by Stanford University in 1997. It estimated that even by a conservative accounting, the university incurred about $\$ 29$ million yearly in ongoing regulatory compliance costs. Stated another way, Stanford spent 7.5 cents of every tuition dollar on compliance. ${ }^{12}$ Given the increased volume of federal mandates, those costs are undoubtedly higher today.

A more comprehensive and recent effort to quantify these costs was undertaken by Hartwick College in 2011-12. A self-audit prepared over the course of a year at the direction of Hartwick's president revealed that for a modestly sized institution, compliance-related activities cost the college $\$ 297,008$ annually ${ }^{13}$ and required more than 7,200 labor hours for data collection and filing of required reports and forms. ${ }^{14}$ Hartwick estimates that the actual cost of compliance could be as much as 7 percent of its non-compensation operating budget. This study provides an important model that other colleges have used in their efforts to estimate the costs of regulation.

Another far-reaching analysis was launched by Vanderbilt University in 2014. Initial findings reveal that approximately 11 percent, or $\$ 150$ million, of Vanderbilt's 2013 expenditures were devoted to compliance with federal mandates. ${ }^{15}$ Nearly 70 percent of these costs were absorbed into different offices, affecting a broad swath of faculty, research staff, administrative staff, and trainees in academic departments. Vanderbilt is currently working with other institutions to test its methodology on different campuses.

In addition to these institution-specific efforts, other research shows that the cost of institutional compliance with regulations is rising, both monetarily and in terms of time. A recent publication by the American Action Forum found that the number of individuals in higher education with the title of "compliance officer" has grown by 33 percent in the past decade. Using publicly available data, the Forum also determined that institutions spend 26.1 million hours annually completing Department of Education-mandated forms. ${ }^{16}$ This figure did not include regulatory burdens that go beyond completing forms, meaning, for example, that efforts like the time required to develop and implement compliance policies were not considered.

Cass Sunstein, a former senior official in the White House Office of Management and Budget (OMB), observed that it is too easy to assume that regulations are a free good:

${ }^{12}$ Casper, Gerhard, "A Discussion with Members of the National Commission on the Cost of Higher Education," October 16, 1997, available at: http://web.stanford.edu/dept/pres-provost/president/speeches/971016collegecost.html.

13 See Zack-Decker, Kelly, "Compliance at Hartwick College: A Special Report to the President of the College," Dec. 2012, pg. 4, available at: http://www.naicu.edu/docLib/20130315_Compliance-HartwickColl-12-12.pdf.

${ }^{14}$ It is important to remember that small to moderate size colleges and universities must create the same data collection, monitoring, and reporting structures and mechanisms as larger institutions, even though this burden is spread over a smaller number of financial aid staff, institutional researchers, and other key administrators.

15 These estimates did not include regulations related to clinical activities, such as hospital-related expenditures at the Vanderbilt University Medical Center.

16 Batkins, Sam, Chad Miller, \& Ben Gitis, "Rising Tide of Education Rules Increases Costs," April 30, 2014, available at: http:// www.americanactionforum.org/research/rising-tide-of-education-rules-increase-costs. 
"[W]e recognized (and this is a critical point, sometimes overlooked by progressive groups) that when high costs are imposed on the private sector, it is not only some abstraction called 'business' that pays the bill. Consumers may pay too, in the form of higher prices..." ${ }^{\prime 17}$

Unfortunately, in the case of higher education, Sunstein's observation has proven axiomatic. The costs imposed by federal regulations are almost always passed on to the consumer in the form of higher prices. And when costs are not passed on, there is likely to be a loss of services as resources are redirected toward compliance mandates.

\section{Regulations Are Overly Complex}

Regulatory complexity causes great uncertainty for colleges and universities. Lack of clear guidance is one factor. Frequent issuance of sub-regulatory guidance by the Department, although intended to clarify, often leads to further confusion. In addition, as a result of this uncertainty, and out of an abundance of caution, institutions sometimes go beyond what is technically required in an attempt to avoid negative audit findings.

Every year, the Department identifies the most frequent problems encountered by institutions of higher education in complying with student financial aid regulations. These findings have been consistent for several years. Between 2010 and 2013, the top problems included the return of Title IV funds when a student withdraws ("R2T4"); verification of information provided by students and families on the Free Application for Federal Student Aid (FAFSA) form; Pell Grant over- or underpayment; failure to resolve issues with student credit balances; and errors associated with student loan exit counseling. These same errors occur on a regular basis, year after year, even after frequent training and guidance from the Department. The consistency in the list over time strongly suggests that these regulations are overly complex and present difficult compliance challenges.

In at least one case, a guidance document meant to clarify uncertainty only led to more confusion. A 2011 "Dear Colleague" letter on Title IX responsibilities regarding sexual harassment contained complex mandates and raised a number of questions for institutions. As a result, the Department was compelled to issue further guidance clarifying its letter. This took the form of a 53-page "Questions and Answers" document that took three years to complete. Still, that guidance has raised further questions. Complexity begets more complexity. ${ }^{18}$

In another case, Congress passed a law in 2012 that limited the eligibility for subsidized federal student loans to 150 percent of a given program's length. The concept is straightforward enough-a student enrolled in a traditional four-year bachelor's program would only be eligible for six years of subsidized loans. However, in practice, implementation has been challenging. In particular, institutions must now track student borrowing at an extremely granular "program" level. Unfortunately, it appears unlikely that the problems associated with the implementation of this provision, including the resources necessary to comply, will be resolved anytime soon.

${ }_{17}$ Sunstein, Cass. Simpler: The Future of Government, 2013, p. 8.

18 As another example of complex regulations leading to more complexity, since the issuance of the original regulations on "gainful employment" in 2010, the Department has already issued more than 45 "Dear Colleague" letters, electronic announcements, and other clarifications. 


\section{Some Regulations Are Unrelated to Education, Student Safety, or Stewardship of Federal Funds}

As leaders of institutions of higher education, we expect to be regulated in relation to the expenditure of financial aid funds and for the health and safety of our students. However, an increasing amount of federal oversight has little to do with these responsibilities and has more to do with pursuing broader governmental goals.

To cite several obvious examples, Selective Service registration, detailed voter registration requirements, peerto-peer file sharing, and foreign gift reporting are unrelated to the central areas of federal concern in higher education. While the policy objectives are worthwhile, the responsibility for pursuing them should not fall to institutions. We believe, for example, that individuals should be held accountable for whether they register with the Selective Service, not the college or university where they happen to be enrolled. Further, while some rules may be tangentially related to higher education, such as disclosing institutional policies on candles in dormitories and student vaccinations, they are not of sufficiently widespread interest to warrant a federal mandate.

Such mandates can have a tangible economic impact. Compliance requires colleges and universities to become expert in unfamiliar topics or to hire outside consultants with such expertise. That means redirecting funds that could be better devoted to student success. Moreover, for some of these regulations, colleges and universities must already meet state and local requirements on the same topic, making the federal requirements redundant.

\section{The Department of Education Has an Increasing Appetite for Regulation}

In recent years, the Department of Education has been especially active on the regulatory front. The significant growth in the volume and velocity of regulations at the Department has led some to question whether it has exceeded its authority. The fact that this increase comes at a time when there have been very few statutory changes from Congress only heightens concerns about possible overreach. In recent years, negotiated rulemaking sessions have addressed topics as varied as accreditation, college teacher preparation programs, PLUS Loans, debit cards, gainful employment, state authorization, and the credit hour-all undertaken solely at the Department's initiative without any prior Congressional action. In several recent cases, federal courts have ruled that the Department's regulatory zeal had, indeed, exceeded its legal authority.

The creation of a federal definition of "credit hour" and the "gainful employment" regulations illustrate this point. In the case of the credit hour, the Department created by fiat the first-ever federal definition of this term. "Credit hour" is an academic term that varies by necessity across campuses and continues to evolve as new learning modalities emerge. Recognizing the academic nature of this determination and the need to preserve flexibility, Congress and previous Departments have wisely declined to specify a uniform federal mandate. Nonetheless, and despite the unanimous opposition of higher education institutions, the Department imposed its definition in 2010.

Similarly, with respect to gainful employment, ${ }^{19}$ the Department first issued a complex and lengthy set of rules on this topic in 2010. However, following a court challenge that struck down the Department's pro-

19 Typically, "gainful employment" programs are certificate programs and other non-degree programs at public and nonprofit institutions and virtually all programs at for-profit institutions. 
posed metrics for judging gainful employment programs, it began a new negotiated rulemaking session. Final regulations stemming from this second effort were issued in October 2014. The 2014 final rule is almost 950 pages long, including a 610-page preamble and more than 50 tables and charts. In deciding to proceed with a second rulemaking on this topic, the Department was undeterred by both a federal court decision and by the passage of legislation in the House of Representatives blocking further regulation in this area until Congress considered the issue. We strongly support the goal of ensuring that programs of a vocational nature prepare students for employment in the fields in which they study. However, in this case, the Department has used the regulatory process to set its own policy agenda in the absence of any direction from Congress, and in the face of clear opposition to that policy from one house of Congress.

The Department has also made frequent use of sub-regulatory guidance to impose requirements on institutions. Such guidance is extremely helpful when it provides needed clarity around technical issues and addresses unintended consequences of various policies. However, it should not be used to create new mandates. And because sub-regulatory guidance lacks the formal opportunity for stakeholders to comment on the proposed guidance, it is doubly important that this process be used sparingly.

For example, the Department of Education has opted to rely almost exclusively on sub-regulatory guidance on Title IX as its preferred method for its oversight of institutions, a process that does not ensure robust feedback on and consideration of its proposals. In fact, the Department has not issued formal regulations on this law in more than eight years.

In addition, the Clery Handbook instructs institutions to report crimes that occur during institutionsponsored stay-away trips. Practically speaking, this means that if an institution sends an intercollegiate sports team out of town, it must report on all crimes that occur in rooms rented by the institution and in common areas of the hotel during the students' stay, regardless of whether the crimes affect students. Similar mandates are placed on trips to international destinations, requiring institutions to obtain crime statistics from foreign law enforcement agencies. The obligation to report on these trips cannot be found in any statute or formal rule-instead, it comes from the handbook and a "Help Desk" email issued by a Department of Education contractor.

These and other examples show that the Department uses regulation and sub-regulatory guidance to introduce changes in long-standing practices and, in doing so, impose new mandates. By operating in a vacuum, with no guidance from Congress, it is unlikely that these requirements will reflect Congressional intent. Congress, of course, creates policy, and it is then incumbent on the Department to use regulations to effectuate those policies-but not to use those processes to pursue its own policy objectives that go beyond the statute.

\section{The Department of Education Does Not Act in a Timely Fashion}

The Department has a challenging set of responsibilities, seeks to fulfill a broad mission, and serves a remarkable diversity of stakeholders. However, none of this is adequate justification for the Department's inability or unwillingness to act expeditiously. This problem presents itself in two ways.

First, the Department often fails to provide rules and guidance in a timely fashion, even when directed to do 
so by statute. For example, the HEA explicitly requires the Secretary of Education to issue final regulations within 360 days of the date of enactment of any legislation affecting these programs. ${ }^{20}$ The Department almost never meets this deadline.

As part of the Higher Education Opportunity Act, Congress mandated that the Department produce a "compliance calendar" to assist institutions in complying with the Act's various requirements. After six years, the Department still has not published this calendar. We can only speculate what sanctions the Department might apply to an institution that failed to make any effort to comply with the law for six years.

Second, the Department often takes years to resolve enforcement proceedings. Several examples are telling:

- In May 2013, Yale University was ordered to repay financial aid funds based on a Department of Education audit undertaken in 1996. The University of Colorado received a similar demand based on a 1997 audit. Even though the universities appealed in a timely fashion, it took 17 and 16 years, respectively, for the Department to take action.

- In 2004, the Department investigated Yale for Clery Act reporting violations in 2001 and 2002_but did not issue a fine until 2013.

- Following the mass shooting at Virginia Tech in April 2007, the Department conducted a program review to determine whether the institution had complied with federal requirements under the Clery Act. It was not until 2011 - four years later-that the Department levied its first fines against the institution. It is unclear what took the Department so long to conduct its investigation, especially since it did not consult with a single institutional representative about the tragedy, nor did it ever visit the campus.

\section{Regulation Can Be a Barrier to Innovation}

Excessive regulation can limit the ability of institutions to innovate in ways that benefit consumers. The Department's definition of credit hour, discussed above, is one such example. By relying on the concept of "seat time," the Department's definition has discouraged institutions from developing new and innovative methods for delivering and measuring education, such as competency-based models. ${ }^{21}$

Another example is the Department's policy regarding state authorization, which has discouraged institutional efforts to expand distance education offerings. Although the specific regulation was vacated by a federal court, the Department continues to insist that institutions must meet state requirements in any state where students reside as a condition of federal aid eligibility. ${ }^{22}$ This has led some institutions to restrict their educational offerings in certain states, creating barriers for students in accessing higher education.

When Vanderbilt University attempted to expand its online programing, it encountered extensive authorization requirements in several states. The demands of North Carolina, for instance, were so onerous that Vanderbilt simply stopped enrolling students from that state. Other institutions have discontinued out-of-

\footnotetext{
${ }^{20}$ See 20 U.S.C. $\$ 1232(\mathrm{e})$.

${ }^{21}$ Historically, credits for courses were assigned based on the assumption that students would spend two hours preparing for each hour of in-class work. So a three credit-hour class assumed that, in the institution's judgment, the student would spend six hours on the class outside the classroom every week.

${ }^{22}$ See question 7 in the Department's July 27, 2012 "Dear Colleague” letter at http://ifap.ed.gov/dpcletters/attachments/ GEN1213Attach.pdf.
} 
state internship programs rather than seek costly state authorization.

Departmental actions have led some states to use the authorization process to generate revenue. For example, in Minnesota, state regulators attempted to require Coursera-a Massive Open Online Course (MOOC) provider-to register and pay a fee in order to provide free non-credit courses to Minnesota residents. After significant public backlash, the state reversed its decision.

Finally, the Department's failure to approve new programs in a timely way is also a barrier to innovation. Publicly, the Department encourages the development of new programs that are relevant to current market needs, and institutions are eager to respond. In practice, though, new program applications to the Department can languish for months even after earning necessary accreditation approvals. Even more frustrating, the Department does not allow institutions to submit more than one new program request at a time, so one pending application creates a complete bottleneck.

The bottom line is simply that many of the Department's recent actions have had a chilling effect on institutions' ability to respond creatively and flexibly to meet the evolving educational needs of their students and surrounding communities.

\section{The Department of Education Appears Indifferent to the Regulatory Burden It Imposes}

It is easy for the Department to view regulation as a free good and overlook the costs that federal mandates impose. ${ }^{23}$ While the Department is required to estimate the burden for every regulation, these estimates rarely reflect the actual impact of a given rule.

An analysis prepared for the Task Force confirms these concerns. ${ }^{24} \mathrm{~A}$ sample of financial aid administrators was asked to estimate the time spent complying with federal requirements in two areas: enrollment verification and satisfactory academic progress. Comparing their calculations to those of the Department suggested that official estimates could be inaccurate by as much as 2.2 million hours.

A recent example can be found in the pending notice of proposed rulemaking on teacher education programs, published on December 3, 2014. According to the Department of Education, the total cost to states and institutions to implement the proposed regulation over 10 years is between $\$ 42.0$ and $\$ 42.1$ million. These estimates — given the extent and detail of the information being demanded —are almost certainly low. The California State University, for example, extrapolating from its estimate of the costs to implement the requirements at its own campuses, projected the nationwide 10-year costs at $\$ 312$ million—or roughly eight times the Department's national estimate. ${ }^{25}$ Meanwhile, the state of California projected the cost of developing and implementing the new data system required to meet the regulatory requirements at $\$ 233$ million for the Golden State alone. ${ }^{26}$

The process by which the Department arrives at its estimates is totally opaque. While intimating that it consults professionals in the field in developing its calculations, we have been unable to locate a single institutional official who has ever been contacted by the Department for this purpose. Even more telling, we

${ }^{23}$ Congress can also be guilty of underestimating compliance costs.

${ }^{24}$ See Carlo Salerno, The Challenges of Information Collection Burden in Higher Education, located in Appendix V.

${ }^{25}$ See https://www.insidehighered.com/sites/default/server_files/files/BYoung_Teacher\%20Prep\%20NPRM_12-29-14.pdf.

${ }^{26}$ See https://www.insidehighered.com/sites/default/server_files/files/Title\%20II\%20CA\%20Memo.pdf. 
have been unable to locate any institutional official who has heard of anyone else ever being contacted for this purpose. The Department has never publicly explained how it arrives at these costs in a fully transparent and comprehensive fashion. It needs to do so. 


\section{Section III: Specific Regulations of Concern}

Some Department of Education regulations present much greater challenges for colleges and universities than others. This section highlights some of the most problematic regulations according to campus officials. We have grouped them into four broad categories: The first deals with student financial aid programs; the second addresses institutional eligibility requirements to participate in the federal aid programs; the third examines the complexity of rules surrounding student safety; and the final category deals with disclosures provided to consumers. A more comprehensive list of problematic regulations that surfaced during our deliberations is included in an appendix to this report.

\section{Verification of Student Eligibility for Financial Aid}

Summary: Making sure that financial aid is awarded to students who are genuinely in need of such assistance is of paramount importance, but current regulations, particularly in terms of verifying student eligibility, are problematic. The process could be greatly streamlined if the Department moved with greater speed to fully align verification with a targeted student-by-student approach, and if aid eligibility were based on "priorprior" year financial information.

Background: Ensuring the accuracy of student aid applications is a joint responsibility between the Department and the postsecondary institution where the student is enrolled. Under a heavily regulated process, some data elements reported on the FAFSA that determine the student's expected family contribution must be verified. The Department of Education selects the applicants and specifies the data elements to be confirmed. Then the institution verifies the accuracy of the data by collecting additional information from families. This approach places primary responsibility on colleges and universities to ensure the accuracy of the financial and household information submitted by students and their parents.

The Department extensively overhauled the regulations governing verification of student aid application information in 2010, effective with the 2012-13 award year. The new process, focused on individual data elements rather than forcing a review of entire applications, is designed to reduce the burden on applicants and institutions. However, even under the new system, institutions continue to be responsible for ensuring the accuracy of FAFSA data.

Many of the other problems associated with verification are related to timing and stem from the fact that students and families are applying for federal aid while they are in the process of filing or finalizing their tax returns for the prior tax year. Consider the following example: A student who applied for aid in early 2014 for the upcoming school year used tax filing records for 2013 that were not officially due until April 15, 2014, and perhaps not actually finalized until well after that date. This timeline is very common, but student financial aid packages cannot be completed until the tax records are finalized. This means that those decisions may be made very late in the enrollment process. The combination of these circumstances creates a situation that might lead to errors or incomplete applications and would, therefore, generate a verification demand.

Recommendations: Modifying existing policy to use financial information from the "prior-prior" year would minimize the need for a complex verification process. Such a move would allow applicants, the government, and the institution to all use financial data already deemed accurate. Based on the above example, use of 
"prior-prior" financial data would have been based on 2012 income tax returns, and that information would be in the Internal Revenue Service (IRS) databases by the start of 2014, obviating the need to ask applicants for their tax returns and creating more certainty about the aid package much earlier in a student's decisionmaking process.

Alternatively, absent such a policy change, the Department could leverage its experience interacting with the IRS in the online FAFSA process (acquiring tax return information from IRS systems via the IRS Data Retrieval Tool) to reduce the administrative burden of verification on institutions and families. Indeed, the federal government has the capability to ensure the accuracy of FAFSA data much more efficiently than the current system, which requires an applicant to respond to his or her institution's request for information. Congress should consider whether verification should be done directly by the Department of Education.

\section{Return of Title IV Funds ("R2T4")}

Summary: Title IV funds not "earned" by a student who withdraws must be returned to the government. Unfortunately, the regulations needed to implement this simple mandate are extraordinarily complex. They need to be simplified and clarified and individual institutions should be given more discretion in several related areas.

Background: A student who withdraws from college before completing the period for which Title IV aid was awarded is entitled to only a portion of those funds, based on the time that the student was actually in the classroom. The remainder of the money must be returned to the federal government based on the percentage of time the student was enrolled prior to withdrawing.

The most fundamental problem in the R2T4 process is determining whether and when the student actually has withdrawn. Although some institutions take attendance, most do not. Existing rules make determining a student's withdrawal date and "last date of attendance" tremendously complicated for institutions that do not take attendance. When attendance is not taken, a withdrawal date can be identified for students who follow institutional procedures to officially withdraw. However, a date is more difficult to determine for students who drop out without notifying the institution.

After a withdrawal date is determined, the institution can calculate the percentage of the enrollment period that the student attended, and in turn, the percentage of aid "earned." If a student received less aid than "earned," the college or university must determine whether any undisbursed aid is permitted to be disbursed. But if a student received more aid than earned, the institution must determine who bears liability for returning the excess, or "unearned," funds to the Title IV programs.

While summarized above in the simplest terms, the rules around R2T4 are tremendously complex, requiring more than 200 paragraphs of regulatory text, supplemented by over 200 pages in the Federal Student Aid Handbook. In 2011, two changes related to R2T4 required 25 additional "Q\&As" on the Department's website. While some of the guidance is a result of questions asked by institutions and their representatives, the degree to which guidance has increased restrictions and decreased institutional discretion and flexibility has made the R2T4 process extraordinarily complicated and prescriptive. 
Recommendations: While the basic concept underlying a prorated approach is certainly valid for R2T4, the details need to be simplified, the meaning of "required to take attendance" needs to be more realistic, and universities should be given more discretion. Students who simply leave without notifying the institution should be subject to institutional policy, as long as that policy has been made clear to students. ${ }^{27}$

Given the complexity of this issue, we recommend that the Department of Education be required to report to Congress on ways to make the R2T4 process less burdensome. The Department should also be required to hold a dedicated R2T4 negotiated rulemaking session-limited to only that topic - with a view to starting over and striving for simpler interpretations and more discretion for schools.

\section{Financial Responsibility Standards}

Summary: The Department of Education is responsible for making accurate assessments of institutions' financial well-being. However, the agency has incorrectly interpreted and implemented the accounting definitions and standards used to calculate the financial responsibility composite scores for private nonprofit, and for-profit institutions. It has also failed to follow the statutory requirement to consider the overall financial health of an institution and has deemed institutions as failing based solely on these composite scores. These policies need to be revised to promote greater transparency about the method by which the Department reaches its determinations and a process that allows institutions to challenge them. This would include allowing schools to submit additional evidence of their overall financial health.

Background: The federal government has an obligation to ensure that colleges and universities that receive student aid are financially healthy. The primary purpose of Section 498(c) of the HEA is to guard against the harmful effects of the precipitous closure of postsecondary institutions for financial reasons. It was enacted following the unannounced closure of several for-profit institutions in the late 1980s that damaged students and taxpayers.

The current financial responsibility regulations were developed in 1996-97 with input from knowledgeable accountants and support from the broader higher education community. The composite score formulas remain, but the Department has not kept up with recent changes in accounting practices in applying them. The failure to update these rules has forced colleges and universities to take costly and unnecessary steps to demonstrate appropriate levels of financial responsibility.

Problems with the Department's accounting methods were dramatically brought to light with the economic downturn that began in 2008. At that time, more than 100 private nonprofit institutions failed to receive passing financial responsibility composite scores. A 2012 analysis of the reasons for the failure by the National Association of Independent Colleges and Universities (NAICU) found that Department of Education regulators were not using generally accepted accounting standards, as required by law, in calculating the financial ratios from nonprofit institutions' audited financial statements. ${ }^{28}$ As a result, well-performing and financially stable institutions were subject to administrative and financial penalties, including having to purchase expensive letters of credit to ensure their ability to receive financial aid.

27 We should also note that federal statutes on this issue should be limited to undergraduates, and universities should be given flexibility to address problems that may arise for graduate students.

${ }^{28}$ Report of the NAICU Financial Responsibility Task Force, November 2012. Available at: http://www.naicu.edu/docLib/20121119_ NAICUFinan.Resp.FinalReport.pdf. 
While the NAICU report identified several specific problem areas with the Department's accounting practices, the one that became the most obvious amid the economic crisis was the mischaracterization of endowment losses. Financially viable schools failed because the Department treated the decline in endowment value as an annual operating expense. As a result, some schools with significant endowments received lower scores than schools with little or no endowments.

In a 2011 example, the Department did not take into account the "spendability" of one college's temporarily restricted net assets. The Department held that the college did not have access to endowment earnings to cover current expenses because board approval would have been required. ${ }^{29}$ Despite the fact that its endowment was triple the size of its operating budget, the college had to spend $\$ 56,000$ on a letter of credit to address the situation. The institution in question has an operating budget of only $\$ 25$ million and an enrollment of approximately 500 students.

In this case, the 200-year-old private liberal arts college, which had received passing financial responsibility composite scores continually from the time that the current regulations took effect in the late 1990s, was surprised to learn it had received a failing score from the Department of Education in 2011. It was even more surprised when the Department retroactively changed the college's 2010 score from passing to failing. Using the Department's own formula, the college's independent auditor's calculation showed the college actually earned passing scores in both cases.

We are concerned that the financial responsibility standards are not meeting their statutory purpose. Moreover, in some instances, they are, in fact, harming well-performing and stable institutions by imposing financial costs associated with letters of credit and provisional Title IV eligibility status requirements, while failing to help the Department identify financially unstable institutions that the standards are meant to target. For example, in 2014, the Department failed to identify Corinthian Colleges' financial weaknesses in a timely fashion, resulting in the precipitous need to sell or close its campuses and creating massive uncertainty for 70,000 students.

Recommendations: The statutory language and the regulations for determining financial responsibility need to be reviewed and, where needed, revised to ensure they clearly meet their intended purpose - that is, to protect students and taxpayers against an institution's precipitous closure.

Correcting problems with the financial responsibility process may require Congressional action. The actions Congress can take include: requiring that institutions receive their composite scores in advance, creating a process to appeal the Department's determinations, establishing an advisory board of objective accounting experts to provide technical assistance to the Department, and ensuring that the Secretary of Education is fully implementing the legal requirement under Section 498(c)(3)(C) of the HEA to examine the "total financial circumstances" of institutions that fail the ratios test before requiring letters of credit or taking other actions.

${ }^{29}$ Changes to the Uniform Prudent Management of Institutional Funds Act eased access to such assets, a development overlooked by the Department. 


\section{Institutional Accreditation}

Summary: The Department has increasingly used the process by which it "recognizes" accrediting agencies as a lever to insert itself into details of the accreditation process. This development greatly complicates accreditation's quality assurance role and increases costs for institutions. Congress should reestablish proper boundaries for the Departmental oversight of institutional accrediting agencies and limit its interference in activities that fall outside the authentic purposes of accreditation.

Background: Accreditation is a voluntary, non-governmental process designed to promote and enhance student learning, improve institutional performance, and encourage educational innovation. It protects institutional autonomy and academic freedom while providing valuable information for self-improvement and quality assurances for the public. Because accreditation is centered on the mission of each individual school, it preserves the diversity of campuses that is a hallmark of American higher education.

Ever since the HEA was enacted in 1965, accreditation has played a gatekeeping function in federal financial aid eligibility; institutions must be accredited in order to participate in federal student aid programs. In turn, accreditors must be recognized by the Secretary of Education on the basis of the standards and review processes they apply to institutions.

Over the years, as public interest in institutional accountability has grown, the federal use of accreditation has evolved in ways not always consistent with its fundamental characteristics and purposes. The Department has increasingly imposed unnecessarily bureaucratic procedural requirements on accrediting agencies as part of the recognition process. Rather than focusing on agencies' reviews of activities related to educational quality, the Department has created a checklist approach, often giving even the most mundane paperwork requirement almost the same weight and consideration as an accrediting agency's overall ability to judge student learning and academic quality.

Under current rules, accrediting agencies are tasked with reviewing activities and issues completely unrelated to educational quality and student learning. For example, the Department requires accreditors to review institutional compliance with fire safety codes, regardless of the fact that they have no expertise on this matter. The Department also requires accreditors to review institutional compliance with Title IV regulations, even though the Department clearly has better tools and greater expertise for this purpose. Recent regulations require accreditors to ensure that institutional credit hour determinations are consistent with both a newly created federal definition and with commonly accepted practices. Tasking accreditors with these additional functions leaves them less time and fewer resources to focus on institutional quality and student learning.

Along with the Department, the National Advisory Committee on Institutional Quality and Integrity (NACIQI) reviews applications from accrediting organizations for recognition and offers recommendations to the Secretary of Education. Many of the concerns about the Department's intrusion into the accreditation process are manifested in its micromanagement of NACIQI, a body created by Congress to serve as an independent advisory committee. The Department's over-involvement in the everyday activities of accrediting bodies and of the accreditation process as a whole has bled over to NACIQI: The Department expects NACIQI to follow equally extensive processes when reviewing accreditors for recognition. 
Recommendations: First, Congress and the Department should use accreditation primarily to hold institutions accountable for educational quality, student learning, and institutional innovation, the fundamental purposes of accreditation. Clear boundaries between appropriate and inappropriate tasks for accreditors should be re-established. For example, accreditors should not be tasked with things such as reviewing institutional compliance with fire codes and Title IV regulations.

Second, Congress and the Department should restore proper boundaries for the oversight of institutional accrediting agencies through the recognition process. Over the years, the terms of recognition by the federal government have become increasingly specific and compliance-oriented. The Department's current tendency to micromanage institutional and programmatic accreditors is unnecessary and undesirable. The bureaucratic, prescriptive regulations surrounding recognition distract accreditors from the larger goals of accreditation and undermine the ability of institutions to innovate.

Finally, the capacity of accreditors to conduct "differentiated reviews" needs to be clarified. There is disagreement as to whether accreditors have the legal authority to allow institutions that have records of exceptional quality and performance to undergo a less arduous set of procedures and processes. Clarification of this capacity would enable accreditors to focus on those institutions that need additional assistance and minimize the burden on high-performing institutions. Congress should ensure that accreditors have the explicit authority to conduct differentiated reviews. ${ }^{30}$

Although it may be feasible to resolve many of the specific accreditation problems with a set of targeted fixes, the role and place of accreditation in the federal eligibility process would benefit from a careful rethinking. Over time, Congress and the Department have both assigned more tasks to accreditors, some of which they are not well suited to perform. Educational quality, student learning, and responsible innovation are the areas where accreditors can and should play the greatest role.

\section{State Authorization of Distance Education Programs}

Summary: On October 29, 2010, as part of its program integrity rulemaking package, the Department issued final rules that inappropriately altered state authorization requirements on distance education programs. The regulations were scheduled to take effect on July 1, 2011, but were blocked by a federal court. ${ }^{31}$ Undeterred, the Department still seeks to implement policies that would fundamentally shift longstanding procedures with respect to distance education. Congress should clarify that requirements on institutions to meet state authorization requirements apply only to states in which an institution is physically located.

Background: Prior to the issuance of the 2010 regulation, it was considered well-settled law that federal requirements for state authorization were limited to the state where the institution was physically located. The Department's 2010 plan would have required institutions to be authorized by every state in which a single student was located. ${ }^{32}$ This marked a fundamental shift in policy, and one that has since proven to be enormously controversial and burdensome.

${ }^{30}$ This is an example of a "risk-informed" regulatory approach that is discussed in more detail in Section IV.

${ }^{31}$ Association of Private Sector Colleges and Universities (APSCU) v. Duncan, D.D.C. July 12, 2011.

32 See 34 C.F.R. 600.9 (c): "If an institution is offering postsecondary education through distance or correspondence education to students in a State in which it is not physically located or in which it is otherwise subject to State jurisdiction as determined by the State, the institution must meet any State requirements for it to be legally offering postsecondary distance or correspondence education in that State." 
Even though the rule was blocked, it nonetheless has had an effect. Many states now regard federal Title IV state authorization requirements as a revenue generator, and the cost to institutions can be quite high. A public institution with a well-established online program estimated the costs at nearly $\$ 800,000$. One private institution has estimated that it will cost $\$ 290,000$ and take up to 2,000 hours annually to deal with the changes. The regulation has led some schools to restrict both online offerings in certain states and critical experiences, such as internship opportunities, clinical rotations, and student teaching-all of which hurt students.

This fundamental shift in policy was done without any guidance from Congress. In 2012, a federal appellate court upheld the original decision to vacate the regulation due to the Department's failure to properly give notice of this issue in its pending notice of proposed rulemaking and provide stakeholders with a meaningful opportunity to comment on the policy. ${ }^{33}$ Despite the court's ruling, the Department continues to pursue this policy. ${ }^{34}$

For example, state authorization for distance education was included as a topic for its 2013-14 program integrity negotiated rulemaking. At the session, negotiators were shocked to see that the Department's distance education rules had ballooned from the two sentences originally proposed in 2010 to more than 14 paragraphs. It is unclear when a proposed rule will be published for comment.

Recommendation: Consistent with long-standing interpretation, Congress should clarify that federal requirements on institutions to meet state authorization requirements apply only to the state in which an institution is physically located. States may elect to place additional requirements on institutions that serve students in their state through distance education, and indeed several states have already done so. The Department should be prohibited from publishing regulations on this topic.

\section{Uniform Definitions of Clery Crimes}

Summary: The Clery Act requires institutions to report incidents using definitions that can conflict with the Uniform Crime Reporting (UCR) definitions and the updated National Incident-Based Reporting System (NIBRS), creating confusion for campus law enforcement. To improve uniformity and effectiveness in reporting crime statistics under the Clery Act, the Department should rely on the expertise of the Department of Justice (DOJ) to establish common definitions for crimes, and Clery Act reporting should be consistent with these definitions.

Background: The Clery Act, enacted in 1990, has an important goal: to improve safety on campus. The impetus for the law was the rape and murder of Jeanne Clery, a Lehigh University freshman, in her dorm room by a fellow student. Under the law, colleges and universities must, among other things, count and report crimes that occur on campus and publish an Annual Security Report to advise students accordingly. We support the dissemination of this important safety information. Over time, however, burgeoning reporting requirements and policy disclosures added to this legislation have become onerous and confusing, diverting institutional resources away from student safety and toward compliance reporting.

${ }^{33}$ APSCU v. Duncan, D.C. Circuit, June 5, 2012.

${ }^{34}$ See question 7 in the Department's July 27, 2012 “Dear Colleague" letter at http://ifap.ed.gov/dpcletters/attachments/ GEN1213Attach.pdf. 
The Clery Act has been expanded to require institutions to report on a number of incidents that are not "crimes" under the DOJ's UCR program or NIBRS. Without a single and consistent form for reporting, campus officials spend significant time attempting to determine whether and how a particular incident should be reported in the Annual Security Report required by Clery. In addition, conflicting definitions and determinations, based on incidents that are not crimes outside of Clery reporting requirements, result in inaccuracies and inconsistencies in the data and mean that campus crime statistics cannot be compared with crime statistics gathered from other state and local law enforcement agencies across the country, as the law intended.

For example, both the Clery Handbook and the UCR handbook define "burglary" and "larceny-theft" over a number of pages by the use of examples. However, because the guidance varies in important ways, incidents with particular fact patterns are classified as burglary under one system and larceny under another. Adding to the confusion, under Clery, institutions do not report larcenies unless they occur as part of a hate crime. They are only required to report burglaries.

Task Force staff visited with safety officials from several campuses to discuss this confusion. The police officers were asked, "If someone were to come into the room and steal a laptop, would that be a burglary or a larceny under Clery?" Intense debate ensued, and no consensus was reached among the various campus security officials about how it should be classified for the Department of Education. By contrast, there was instant and unanimous agreement that the theft would be classified as a larceny for purposes of the UCR.

In addition, the 2013 amendments to the Violence Against Women Act require institutions to report on stalking, domestic violence, and dating violence, none of which are defined in the UCR as crimes. As a result of this statutory change and the 2014 regulations issued by the Department, universities must deal with two issues: Reporting on incidents that are crimes only under the Clery Act, and using Department of Education definitions for crime reporting that vary significantly from state law. Stalking, for example, is normally defined as a crime in state statutes, but the definitions vary across jurisdictions and do not match the definition in the new regulations released by the Department. Domestic violence is referenced in many state laws but not normally as a standalone crime. Dating violence is absent from virtually all state criminal statutes. Thus, campus safety officers must now interpret incidents not listed in the UCR as crimes for Clery purposes, and they must use federal definitions that can conflict with their own state laws. Given this complexity, reporting errors are inevitable.

Campus law enforcement officials rely on training they receive regarding UCR/NIBRS crime reporting and their home state's definitions of crimes. When the Clery requirements for reporting crimes stray from these conventions, campus officials must spend substantial extra time trying to determine how to report the crime properly for the Department's purposes. Each time the Department or Congress deviates from the UCR/ NIBRS framework, Clery crime reporting becomes less consistent and less accurate, statistics become more difficult to compare to local and national crime data, and the time officials need to spend on complianceinstead of patrolling-increases.

Recommendations: The federal government should rely on the expertise of the Department of Justice in creating the standard definitions for crimes, and the Clery Act should require reporting on crimes as they are defined in the UCR or NIBRS. This would allow for statistics that are comparable across institutions 
and provide useful information to consumers, while also ameliorating the need for campus police to juggle competing definitions of crimes.

If Congress believes campuses should report on other "crimes" that are not currently a part of the UCR or NIBRS, it should instruct DOJ to modify the UCR/NIBRS to include these definitions. This would ensure that new crime definitions would be developed by experts in law enforcement and crime reporting protocols, and would provide a common definition for both local police and campus security officials.

\section{Timely Warnings About Threats to Campuses}

Summary: The Clery Act mandates that colleges and universities send out Timely Warnings to the campus community to notify students and employees about "serious or continuing" safety threats based on reported crimes. However, in order for these warnings to be most effective, institutions need greater deference about when they are appropriate and what information they should include.

Background: Each school must have a Timely Warning notification process for Clery crimes considered by the institution to be a serious or continuing threat to other students and employees that occur anywhere in the boundaries defined by the Clery Act. To aid in the prevention of similar occurrences, such warnings must be issued "as soon as the pertinent information is available." Warnings are typically issued via email or text message and are posted on campus web pages. ${ }^{35}$

The Timely Warning notification process can be an important tool for helping ensure safety on campus. Unfortunately, however, the Department's regulations and guidance surrounding Timely Warnings has created substantial confusion, which can undercut the student safety purpose they were designed to serve.

Two specific points in this area are important. First, there is lack of clarity about the conditions constituting a "continuing threat" that would warrant a Timely Warning. As a result, many institutions issue Timely Warnings in an abundance of caution, concerned about a retrospective audit finding. That can render certain notifications moot-some Timely Warnings are issued even if the perpetrator of the event in question has already been apprehended or has been suspended and banned from campus. Furthermore, it can be nearly impossible to issue a warning that is truly "timely" when a reportable crime happens on noncampus property—often, institutions do not learn of these incidents for several days or weeks. Because institutions are concerned about the Department issuing fines in hindsight, seemingly without acknowledging the circumstances at the time, they often send out notices they feel are not necessary, such as the instances noted above. Campus security officials fear that too-frequent issuance of Timely Warnings creates "warning fatigue," a condition where students and staff become somewhat inured to these alerts because they receive so many of them. ${ }^{36}$

Second, the rules around timing are not clear: How quickly must the warnings be released in order to be

35 The Clery Act requires institutions to have two separate procedures to notify a campus community of potential dangers. In addition to the Timely Warning process, each institution must also have an Emergency Notification procedure, used for dangerous situations that may threaten the health or safety of the campus community. Such notifications are issued "immediately upon confirmation that a dangerous situation or emergency exists or threatens" and are sent via text, email, siren or alarm systems, and campus bulletins. This discussion only relates to the Timely Warning requirement.

${ }^{36}$ For example, see "Students, Faculty Don't Always React Quickly to Emergency Alerts," by Jake New, Inside Higher Ed, December 9, 2014, available at: https://www.insidehighered.com/news/2014/12/09/students-faculty-dont-always-react-quickly-emergency-alerts. 
compliant with the rules? Despite good faith efforts on the part of colleges and universities to get important messages out to the campus community expeditiously, the Department second-guesses the judgment of campus officials and appears to have unreasonable expectations. Virginia Tech's Timely Warning was issued two hours after the initial shooting on campus in April 2007, as soon as the university was able to verify the relevant facts, and the Department found the university in violation of the Clery Act because that was not fast enough. ${ }^{37}$ Sometimes, there can be negative consequences when notifications are released too quickly. In at least one case, a Timely Warning tipped off a potential perpetrator of a sexual assault on campus that an investigation was under way, thereby interfering with an investigation by local police. In that case, the Timely Warning strained the relationship between campus police and local law enforcement authorities. Another institution sent a Timely Warning after a tragic incident involving the death of a student in an off-campus homicide. Even though the primary suspect was in custody, a notification including the name of the deceased was released so quickly that family members had not yet been informed. By forcing institutions to issue warnings before they are ready, the Department undermines standards of good police work.

Recommendations: Campus law enforcement should have clear authority to use their own expert judgment to determine when a serious or continuing threat exists and when they have the appropriate information to issue a Timely Warning. The Department, except in cases of clear negligence, should give deference to the judgment of the law enforcement professionals who implement these rules on campus day in and day out, and it should acknowledge good faith efforts by institutions to protect their campus communities by appropriately informing them of safety threats.

\section{Definition of "Noncampus Property"}

Summary: The definition of "noncampus property" is unclear and overly broad, and should be narrowed to make it more meaningful and useful.

Background: The Clery Act requires colleges and universities to report the crimes that occurred on campus in an Annual Security Report. They also must report incidents occurring on "noncampus property," defined as a building or property owned or controlled by an institution and used in direct support of or in relation to the institution's educational purpose. However, this broad definition has created enormous confusion, and guidance from the Department has created many instances where institutions have had to spend considerable time obtaining information from third parties, such as hotels abroad and police departments across the country and around the world.

Guidance from the Department both in the Handbook for Campus Safety and Security Reporting and subsequent directives indicate that colleges and universities must report crimes that happen in any building or property they rent, lease, or have any written agreement to use (including an informal agreement, such as one that might be found in a letter, email, or hotel confirmation). Even if no payment is involved in the transaction, any written agreement regarding the use of space gives an institution "control" of the space for the time period specified in the agreement. The handbook requires colleges and universities to disclose statistics for crimes that occur during the dates and times specified in the agreement, including the specific area of a

\footnotetext{
37 That determination was ultimately overturned and Virginia Tech was fined under a different, albeit equally flawed, rationale. Please also note that the Emergency Notification requirement was not included in the law until 2008, largely as a result of these tragic events.
} 
building used (e.g., the third floor and common areas leading to the spaces used, such as the lobby, hallways, stairwells, and elevators). Department guidance mandates that schools report on study abroad locations when the school rents space for students in a hotel or other facility, and on locations used by an institution's athletic teams in successive years (e.g., the institution uses the same hotel every year for the field hockey team's away games).

As a consequence, institutions must attempt to collect crime data from dozens, if not hundreds, of locations where students may reside or study for short periods of time if the institution uses the space in successive years or if students are present there for what the Department calls a "stay of long duration." (While advising campuses that they must report stays of "long duration," the Department has not offered a definition of this term.)

The result is that institutions expend significant time and resources tracking these myriad locations and gathering crime data annually, only to have to settle for incomplete data. One institution has indicated that it requests data from 69 police departments, covering 348 locations in 13 states and five countries, including police at airports and on military bases. The mandate that colleges and universities must collect data from foreign entities is particularly troublesome. Apart from the administrative burdens that such regulations create, many foreign law enforcement authorities often simply ignore requests from institutions. In response to one such request, a foreign government accused a U.S. institution of espionage.

Because noncampus crime statistics are reported in the aggregate (a single number), the data provide little useful information for consumers. For example, when the Annual Security Report states that "four burglaries" took place in a noncampus location last year, a prospective student or parent has no way of knowing whether that crime occurred in a research facility on an island in the South Pacific, at a building the institution rents across town, at a study abroad location, or at an off-campus sorority house. Clarification of what data must be collected - and, particularly, why they are important to collect, what value they will provide and to whom, and how they should be reported-could improve current practices.

Recommendation: The definition of "noncampus property" should be clarified and narrowed to focus more directly on property that is a core part of a college or university. At a minimum, it should exclude all foreign locations ${ }^{38}$ as well as short-term stays in domestic hotels.

\section{Consumer Information}

Summary: Institutions of higher education overload consumers with an enormous amount of federally mandated information. Some of it is useful, and some of it is relatively trivial. Congress and the Department should ensure that the required information is of interest to a significant number of consumers.

Background: Institutions of higher learning are required to collect and disclose increasing amounts of information to students and prospective students. The goal is admirable - to equip students and families with valuable information about an institution. Too often, however, meeting current requirements means that institutions provide considerable information that is of marginal value or very limited interest. ${ }^{39}$

\footnotetext{
${ }^{38}$ Some universities have branch campuses overseas. Clery Act reporting is appropriate for those foreign locations.

39 Ben-Shahar, Omri. More Than You Ever Wanted to Know: The Failure of Mandated Disclosure, 2014.
} 
A few examples from the current list of requirements illustrate this point. Universities must disclose the number of supervised fire drills they hold in a given year. They must publish more than 30 gainful employment disclosures for each program they offer. In addition, institutions must counsel departing student borrowers on any of the seven different federal loan repayment programs applicable to them, even though the vast majority of borrowers use either the standard 10-year or the extended 30-year program. Despite the extensive counseling they receive, few borrowers understand the differences among the various income-based repayment programs.

Even well-intentioned efforts by the government to provide information may overload consumers. The Department has encouraged colleges and universities to adopt the Financial Aid Shopping Sheet, which was designed as a consumer tool to simplify the data that incoming students receive about costs and financial aid. Unfortunately, this initiative has proven extremely confusing for students, and the material provided is largely irrelevant for graduate and professional students.

In addition to sometimes receiving too much information, consumers are also often given information that is not very accurate or meaningful. For example, the "graduation rate" of an institution as defined by the federal government takes into account only first-time, full-time students who remain at their initial institution. This means that part-time students and transfer students are not counted. Most beginning college students are not first-time, full-time students, especially at community colleges and for-profit institutions. Even at four-year institutions, the federal graduation rate may not be meaningful—as one example, IPEDS graduation data do not capture approximately one-third of all graduates from the University of North Carolina system.

Recommendation: Congress and the Department should make sure that information and data being collected from institutions and provided to consumers will actually be useful before imposing additional information and data requirements. We encourage Congress and the Department to carefully test any new disclosures before they are imposed.

Focus group testing, for example, might help distinguish information that consumers really need from that which is merely trivial. However, the OMB has interpreted the use of focus groups with 10 or more persons as an information collection request, meaning that each time an agency seeks to use such a focus group, it would require a lengthy $\mathrm{OMB}$ approval process. Congress should encourage the $\mathrm{OMB}$ to grant categorical approvals for such requests to prevent unnecessary delays in the use of focus groups.

Finally, institutions should not be subjected to new information collection requirements from Congress or the Department when the same or substantially similar information is already in the possession of other federal agencies. Instead, the Department should be required to work with other federal agencies to obtain the necessary information.

\section{Regulations Unrelated to Education, Safety, or Stewardship}

Summary: Many federal regulations have little or nothing to do with educating students, protecting them on campus, or ensuring proper stewardship of federal funds. These requirements should be reviewed with an eye to determine whether they should be struck so that limited resources can be focused on more important efforts. 
Background: Policy makers have increasingly relied on colleges and universities and, in particular, eligibility for federal student aid, as a way to pursue policy goals that are entirely outside of higher education's purview. While these goals may be desirable, the question remains whether it is appropriate to use colleges as the means to achieve them and whether the purported benefits outweigh the costs imposed on institutions and ultimately students. Although the demands of any one requirement may be modest, as a collection they divert attention and resources. Among many other examples that we could cite, the following list is representative:

- Selective Service. In order to be eligible for federal financial aid, male applicants must have registered with the Selective Service before the age of 26. If there is a discrepancy in terms of whether an applicant has met the registration requirements, the burden falls on institutions to reconcile the difference. Student financial aid officers should not be tasked with enforcing this requirement.

- Link between drug convictions and Title IV eligibility. Under the HEA, a student convicted of some drug offenses while receiving federal student aid can lose eligibility to receive aid. ${ }^{40}$ At its core, this provision represents an inappropriate attempt to address an unrelated broader social issue through the student financial aid process. Moreover, while drastically increasing the complexity of the application process for those individuals involved, the provision has very little impact and affects only a handful of students every year.

- Voter registration. Institutions are required to distribute a voter registration form, in a federally specified timeframe and format, to each student enrolled and physically in attendance at the institution. We strongly support civic participation, especially voting. However, this is an overly prescriptive requirement with a modest benefit at best.

- Foreign gift reporting. Under a provision added to the HEA in 1986, institutions are required to report gifts or contracts from a foreign source (government, company, or individual) that total more than $\$ 250,000$ or that are conditional gifts of any amount. ${ }^{41}$ While there may be some who take a keen interest in such donations, this information is not of widespread interest. In many cases, there are other ways to locate this information, such as through public information and open records laws.

- Peer-to-peer file sharing. Colleges and universities are required to have institutional policies concerning illegal file sharing, educate students on the laws and the penalties of such actions, and have explicit plans to combat unauthorized distribution of copyrighted material. ${ }^{42}$ Advances in technology, such as the prevalence of legal and low-cost options for downloading music and movies, have made this requirement obsolete.

- Vaccination policies. Institutions must disclose their vaccination policies in order to be eligible for Title IV funding. ${ }^{43}$ While arguably related to student health, information about an institution's policy does not make students any safer, and is unlikely to be a consideration for any prospective students or parents when they select a college.

Recommendations: Congress should use the upcoming HEA reauthorization as an opportunity to review all the Act's provisions, identify the federal purpose behind their inclusion, and strike requirements that are

${ }_{40}$ See 20 U.S.C. $\$ 1091(\mathrm{r})(1)$.

${ }^{41}$ See 20 U.S.C. $\$ 1101 \mathrm{f}$.

${ }^{42}$ See 20 U.S.C. $\$ 1092(a)(1)(P) ; 20$ U.S.C. $\$ 1094(a)(29)$.

${ }^{43}$ See 20 U.S.C. $\$ 1092(\mathrm{a})(1)(\mathrm{V})$. 
not clearly related to the core mission and responsibilities of higher education. Congress and the Department should refrain from regulating in these areas and give colleges and universities more latitude to determine the most effective way to deliver information to students and families. 


\section{Section IV: Recommended Improvements in the Regulatory Process}

Effective and efficient regulations are critical to ensuring that federal resources for higher education are used in the intended manner and that students and taxpayers are protected. How those rules are framed, implemented, and enforced is of critical importance. Effective regulatory systems are predicated on several elements, including clear and comprehensible rules, accurate estimates of costs and burdens associated with the regulations, clear safe harbors, and recognition when institutions have made good faith efforts.

In Section III, we highlighted some of the regulations we find most problematic and suggested solutions. However, even if the problems with individual rules are addressed, higher education will continue to face problems with the Department of Education's efforts absent further action to change the processes by which those regulations are created and enforced.

The regulatory process can be divided into three distinct phases: development, implementation, and enforcement. The Task Force believes that changes are needed in each of these areas. Accordingly, we have identified a number of different ways to improve each phase. We discuss these ideas further in this section, and we provide other process reform ideas in a chart appended to this report. ${ }^{44}$

\section{Development of Formal Regulations at the Department}

All federal agencies must follow the processes prescribed by the Administrative Procedure Act (APA) in developing formal regulations. ${ }^{45}$ Among other requirements, the APA mandates that an agency provide the public an opportunity to participate in its rulemaking activities, a step known as "notice and comment." 46 Once a rule is in place, agencies often provide supplemental, sub-regulatory guidance when they believe more clarification is needed but does not require public participation.

The Negotiated Rulemaking Act of 1990 provides agencies the option to supplement (but not replace) APA requirements for rulemaking by conducting a process known as "negotiated rulemaking." ${ }^{47}$ Negotiated rulemaking is a way to bring an agency together with various interest groups affected by its regulations for the purpose of discussing — and ideally reaching agreement on - the text of a proposed rule before it is issued. While the use of negotiated rulemaking by agencies is typically optional, the HEA requires the Department of Education to use it when proposing modifications or establishing new regulations for programs authorized under Title IV of the HEA. The Department of Education is the only federal agency that must routinely use this process.

\footnotetext{
${ }^{44}$ We noted at the beginning of the report that "regulations" should be viewed broadly, inclusive of requirements beyond those emanating from formal regulations issued by the Department. While we are deeply appreciative of Congress' long history of support for higher education, we must acknowledge that it shares responsibility for creating some of the regulatory problems faced by institutions. In the process reform discussion that follows, therefore, while most of our recommendations are framed in the context of the Department, some apply equally well to Congress.

45 See 5 U.S.C. $\$ \$ 500$ et seq.

46 See 5 U.S.C. $\$ 553$.

${ }^{47}$ See 5 U.S.C. \$\$561-570a.
} 


\section{Recommendations to Improve the Development of Regulations}

\section{- The methods by which individuals are selected to participate as negotiators and the use of facilitators in the negotiated rulemaking process should be improved.}

As noted above, negotiated rulemaking is a mandatory step in the process through which regulations related to student financial aid programs are developed and issued. When first adopted by the Department of Education during the 1990s, the process was less controversial than it has become in the last decade. More recently, the process has devolved to a point where the Department uses it as a lever to pursue its own policy objectives rather than as a channel to work with relevant stakeholders and to achieve workable regulations.

One of the most pressing problems with the Department's current approach is the process through which it selects negotiators. The original intent was that stakeholders would select their own representatives, and when negotiated rulemaking was first implemented, this is what happened. In recent years, however, the Department has been more involved in the selection process, choosing individuals to serve, including both a primary and alternate member for each constituency represented. This has proven problematic in several respects. First, this approach tends to create either double representation or, in some cases, incompatible representatives. Second, constituencies too often feel ill-represented. For example, a staff member who happens to work at a four-year public institution should not be chosen by the Department to represent the views of all public four-year institutions unless the individual has the clear authority to represent the views of that sector. By handpicking individuals it would like to talk with, the Department simplifies its workload but also undermines a key premise of negotiated rulemaking - that those parties with a clear interest have their own voice. At a minimum, the Department of Education should return to its original practice for selecting negotiators.

Another problem with the Department's approach to negotiated rulemaking is the selection and role of facilitators. As the individuals charged with running the negotiating sessions, facilitators should serve as guardians of the process. Unfortunately, that is not the case. In recent years, the Department has given facilitators a limited role, with little authority to resolve differences that arise. This part of negotiated rulemaking should also return to its original purpose, which involved facilitators who served as arbiters of fairness and who use their skills to help achieve consensus not by encouraging a particular substantive outcome, but by being more active in exploring areas of agreement.

\section{- The "bundling" of unrelated issues into a single negotiated rulemaking should be discontinued.}

The "bundling" of unrelated issues for consideration during a single negotiated rulemaking has become a serious problem. More specifically, the Department has too often grouped a host of unrelated issues into a single panel, choosing negotiators on a disparate set of issues and thus creating situations in which only a small number of negotiators are knowledgeable enough to engage on any given issue. In such cases, a very small number of negotiators may determine the outcome of rules with broad public policy implications.

The February-May 2014 negotiated rulemaking on "Program Integrity" illustrates this point. A single negotiating committee was tasked with reaching consensus on, among other issues, "cash management" of Title IV funds; state authorization of distance education programs; state authorization of institutions with foreign locations; "clock-to-credit-hour" conversion; the definition of "adverse credit" for borrowers in the PLUS Loan Program; and the retaking of courses. Given the range of individuals needed for such a panel, it was not 
surprising that most negotiators were knowledgeable about a limited number of these issues. It was even less surprising that no consensus was reached on the regulatory package.

The upshot of these practices is that the Department exercises an extremely high degree of control over the entire process, not only selecting all the committee members and limiting the role of the facilitators, but also doing all the drafting and taking a very strict view of what constitutes a consensus. These and additional concerns about the Department's process for negotiated rulemaking and other ways to improve the process are explored in a white paper appended to this report.

- Congress should ask the Government Accountability Office to review the Department of Education's methodology for estimating the burdens and costs that institutions will incur in meeting the requirements of regulations, as required by the Paperwork Reduction Act, and make recommendations for improvement.

By law, any federal agency that proposes a new regulation or revises an existing one must estimate the burdens and costs the rule will impose on the regulated entities. The higher education community believes that the Department of Education consistently and substantially underestimates the costs and burdens of its rules. Various groups, including the National Association of Student Financial Aid Administrators and the Congressionally created Advisory Committee on Student Financial Assistance, have raised concerns about the processes through which the Department derives estimates associated with its regulations.

The Government Accountability Office should be asked to examine the Department's processes and make recommendations that at least would make them less opaque. It should also retrospectively review the Department's estimates for a sample of regulations after implementation. Assuming such a review would identify areas for reform, the Government Accountability Office should make appropriate recommendations.

Additional ideas about how to address concerns about the burden- and cost-estimating processes at the Department are explored in a white paper appended to this report.

\section{- Clear regulatory safe harbors should be created in order to ensure a level of certainty for institutions.}

The Department's requirements are so complicated in many areas that it is impossible for colleges and universities to be certain they are in compliance, even when they take carefully considered steps they believe are necessary. Clear safe harbors-provisions in the law that will protect institutions from liability as long as certain conditions have been met-should be established to help institutions meet their compliance obligations. ${ }^{48}$

Safe harbors currently exist in other areas of law that apply to institutions of higher education. For example, colleges and universities hiring foreign nationals through the H-1B visa program must pay those individuals wages that are equal to or higher than the prevailing wage in the occupations for which they were hired. If an institution uses Department of Labor-determined prevailing wage levels, it has a safe harbor against challenges to its prevailing wages. The federal "deemed export" rules prohibit certain individuals from receiving controlled information and/or controlled technologies without the required license(s), exception, or exemption, even if those individuals are otherwise authorized to work within the United States. However,

${ }^{48}$ Definition adapted from Black's Law Dictionary Free Online Legal Dictionary, 2nd ed., available at: http://thelawdictionary.org/ safe-harbor/. 
the "fundamental research exclusion" creates a safe harbor from such requirements. ${ }^{49}$ In addition, under the terms of a government-wide policy, entities that receive federal funds above a certain amount must undertake an independent audit annually. This process, commonly referred to as an A-133 audit, was designed as a safe harbor against excessive audits by federal agencies.

Congress should instruct the Department to make use of safe harbors whenever possible.

\section{- The Department should not exceed legislative language or Congressional intent when issuing regula- tions.}

According to the basic tenets of administrative law, Congress passes laws, and it is up to the agencies to implement them. However, in recent years, the Department has increasingly used the regulatory process not in response to any specific legislative change enacted by Congress, but rather as a means to achieve its own policy objectives. Some of the increase in agency activity may result from gridlock in Congress. But regardless of its cause, without clear guidance from Congress about the policy direction to be pursued, the resulting regulations are often poorly designed.

As noted earlier, in 2010, absent any legislative mandate, the Department created a regulatory definition of "credit hour." Not surprisingly, the definition has proven problematic. "Credit hour" is an academic term that varies somewhat across campuses and continues to evolve as new learning modalities emerge. Congress has recognized the danger of having the Department define such concepts and explicitly prohibits it from intruding into academic matters. ${ }^{50}$ The Department simply ignored the views of non-federal participants at the negotiated rulemaking session-all of whom opposed this step.

A second example is the Department's attempt, starting in 2010, to implement a new and very complicated set of regulations designed to enhance accountability for "gainful employment" programs. We share the goal of ensuring that taxpayer money supporting these programs is well spent. However, based on a two-word phrase that has been part of the HEA for more than 40 years, the Department has created a highly complex set of new reporting requirements and metrics. We believe that by failing to regulate based on clear direction from Congress, the resulting process has been fundamentally flawed and has unnecessarily created heavy regulatory burdens.

The problem of agency overreach is not limited to rulemaking - it also appears in sub-regulatory guidance. ${ }^{51}$ "Dear Colleague" letters and similar guidance may provide technical assistance to institutions and assist them in their compliance efforts, but they should not be used to create new substantive legal obligations. For example, guidance from the Department has created a new obligation on institutions to report Clery crimes that occur during overnight trips, even though there is nothing in statutory or regulatory language to suggest this expansive reading is warranted.

\footnotetext{
${ }^{49}$ Fundamental research means basic and applied research in science and engineering, the results of which ordinarily are published and shared broadly within the scientific community, as distinguished from proprietary research and from industrial development, design, production, and product utilization, the results of which ordinarily are restricted for proprietary or national security reasons. See: http://www.ucop.edu/ethics-compliance-audit-services/compliance/international-compliance/on-campus-research-with-foreign-nationals.html.

50 See 20 U.S.C. $\$ 1232$ a.

${ }^{51}$ As discussed in the following section, the use of sub-regulatory guidance to achieve agency policy goals is doubly problematic since it prevents stakeholders from commenting on the new policy before it is issued.
} 


\section{- The Department should not make significant changes in policy without following the APA's notice and comment procedures.}

The APA's notice and comment procedures are a valuable, time-tested tool for developing good regulations. ${ }^{52}$ Soliciting public comments and incorporating this feedback ensures that the agency has considered a wide range of viewpoints and allows for the opportunity to address unanticipated consequences before the regulation is finalized. When developing formal regulations, the Department is usually careful to follow the APA's requirements. However, as it increasingly turns to sub-regulatory guidance to pursue its policy goals, the agency often imposes significant new requirements without the benefits afforded by the notice and comment process. The Department should always use the notice and comment process. If, in rare circumstances, it determines it cannot, it should articulate a reasonable basis for dispensing with it.

The history of Title IX regulations at the Department's Office for Civil Rights (OCR) is illustrative. In the more than 40 years since passage of Title IX, the Department has promulgated formal regulations on only three occasions: once, in 1975, when it issued the first set of regulations implementing the statute, and on two other occasions, in 2000 and 2006, when it issued technical clarifications on discrete issues. Since 2006, the Department has relied exclusively on OCR sub-regulatory guidance to create new Title IX requirements for institutions, with the 2011 "Dear Colleague" letter being the most frequently cited example. While OCR strenuously maintains that the letter does not add requirements to applicable law, the reality is that these standards impose serious additional responsibilities and break new policy ground. To be clear, the issue is not the substance of the requirements - colleges and universities must maintain a safe learning environment for all students free from discrimination. Rather, it is that OCR, through sub-regulatory guidance, has created new enforcement standards without any opportunity for public comment.

The Department's policies would be better informed and more effective with the benefit of formal comments from all interested parties. Therefore, it is critical that Congress ensure that agencies follow the procedures set forth in the APA so that the public is given a meaningful opportunity to comment before new mandates are imposed.

\section{Implementation of Regulations at the Department}

Once the regulations have been finalized, colleges and universities implement them. The Department uses many tools, including "Dear Colleague" letters, electronic announcements, handbooks, FAQs, and help desks to further explain its interpretation of the rules and provide assistance as institutions come into compliance.

As noted earlier, when sub-regulatory guidance exceeds legislative intent and creates new standards and requirements without public comment, the result can be problematic. However, when used properly, subregulatory guidance can be an important aid to institutions in their implementation efforts.

For example, the Office of Federal Student Aid offers technical advice to financial aid administrators via hotlines. This provides a valuable resource for institutions regarding the complex administration of federal student aid. Because the hotlines are not used for enforcement purposes, campus officials are more likely to

\footnotetext{
52 The "notice and comment" process has been adopted by a number of other countries, including China. Jeffrey S. Lubbers, "Notice-and-Comment Rulemaking Comes to China," Administrative and Regulatory Law News 32(1): 5-6, fall 2006, available at: http://www.law.yale.edu/documents/pdf/Intellectual_Life/ch_Lubbers-Administrative_comment.pdf.
} 
seek out this assistance, which leads to better compliance. We believe that this type of technical assistance is an important way to assist institutions with their implementation efforts.

\section{Recommendation to Improve the Implementation of Regulations}

- Congress should require the Department to publish the compliance calendar and update it every year as mandated by the Higher Education Opportunity Act.

Institutions of higher education have an obligation to comply with regulations that the Department of Education is obligated to enforce. Compliance is enhanced and the need for audits and fines is greatly reduced if institutions are made clearly aware of the requirements they face. That was the rationale behind the compliance calendar created by Congress in the 2008 HEA reauthorization legislation.

Under that legislation, Congress mandated that the Department of Education publish an annual "compliance calendar" that lists all compliance requirements and their corresponding deadlines. The goal is straightforward: Institutions should receive a clear checklist of regulatory and information collection deadlines that documents their regulatory obligations. Armed with this information, institutions-especially small, thinly staffed ones-will be in a much better position to comply than they are at present. Given that regulations and requirements continue to grow, the compliance calendar should be updated annually and made easily available to institutions.

\section{Enforcement of Regulations at the Department}

The Department uses a variety of mechanisms to ensure compliance with its rules. Outside auditors conduct annual audits of all institutions to review compliance with the administration of Title IV programs as well as an institution's financial statements. Results of the reviews are shared with the Department, which may, in turn, take action when a potential problem or an irregularity is reported. The Department's Office of Inspector General may also conduct an audit, in response to an indication of a problem.

Program reviews are more comprehensive examinations of institutional operations. The Office of Federal Student Aid uses a taxonomy of thresholds that takes into account statutory requirements and other indicators from the Department's administrative records to select institutions for review. These reviews are usually conducted by the Department's regional offices. Often in the context of Title IX or the Americans with Disabilities Act, OCR responds to complaints by conducting investigations, which may lead to fines or consent agreements. ${ }^{53}$

\section{Recommendations to Improve the Enforcement of Regulations}

\section{- The Department of Education should recognize when institutions are clearly acting in good faith.}

Very few violations of federal regulations are deliberate or reflect negligence by institutions. Nor are all violations equally serious. At present, minor and technical violations are not acknowledged as such by the Depart-

${ }^{53}$ In addition, there are other situations in which Department enforcement action is automatically triggered as a result of an institution crossing a specific threshold. This is the case with institutions exceeding the allowed cohort default rates, as institutions with default rates higher than 30 percent for three consecutive years are banned from the Pell and student loan programs and institutions with a rate higher than 40 percent in a single year are banned from the loan programs. 
ment. We believe that the Department ought to recognize when institutions have clearly acted in good faith.

In the summer of 2014, for example, the University of Nebraska at Kearney was fined \$10,000 for mistakenly misclassifying a 2009 incident involving the theft of $\$ 45$ worth of goods from an unlocked custodian's closet as a larceny rather than a burglary. ${ }^{54}$ Because the Clery Act does not require the reporting of larceny, ${ }^{55}$ the university did not report the incident on its Annual Security Report. In an audit, the Department ruled that the incident was a burglary and fined the institution for failing to report it. We believe that this is an example of an institution being overly penalized for a relatively minor technical violation. In such cases, the size of the sanctions imposed by the Department does not appropriately reflect the weight of the infraction involved. Fines that fail to distinguish the important from the trivial undermine the Department's credibility.

Following the tragic shootings at Virginia Tech in 2007, the Department fined the institution for a technical error in following its own internal policy; in this case, the campus warning was issued by the office of public information rather than the office of public safety. The issue is not whether the warning was released-it was. Rather, the fine was assessed based on which campus office issued the warning. We believe that the university was acting in good faith to comply with the law and that the Department should have recognized this. Second-guessing informed by hindsight does little to improve practices for similar events that may arise in the future.

Some agencies, including the Internal Revenue Service and Securities and Exchange Commission, utilize voluntary correction programs. Under those programs, regulated entities identify instances of non-compliance and report them to the agency. The agency then reviews the self-report, collects evidence of correction, and issues a confirming letter. Congress and the Department should consider the benefits of developing a similar voluntary program in appropriate circumstances-for example, in cases involving technical violations where an institution was acting in good faith.

\section{- The Department of Education should act in a timely fashion when conducting program reviews, inves- tigating and resolving complaints, and approving new programs.}

Under the HEA, colleges and universities are required to submit documents and other records requested by the Department within a prescribed amount of time. While institutions are required to adhere to strict timelines in terms of responding to the agency's requests, there are no time limits imposed on the Department in terms of issuing a final determination after a program review. ${ }^{56}$

Earlier in this report, we cited a short list of cases in which the Department has dragged out program reviews over many years, including cases in which institutions were ordered to remand funds more than a decade after the initial audits. We also noted that it took the Department nearly four years after the tragic shootings at Virginia Tech to issue the first fines against the institution, even though agency representatives never visited the campus or met with officials from the university.

\footnotetext{
${ }_{54}$ According to one article, the stolen items were a bag of potato chips, Little Debbie Nutty Bars, and a set of walkie-talkies. Ben Miller, Roll Call, August 25, 2014, available at: http://www.rollcall.com/news/how_unnecessary_data_reporting_requirements_ turned_a_44_theft_into_a_10000-235831-1.html?pg=1\&dczone=emailalert.

55 To be precise, larceny is only reported under Clery when it occurs in connection with a hate crime.

56 Federal Student Aid Programs, Program Review Guide for Institutions, 2009, available at: http://www.ifap.ed.gov/programrevguide/attachments/2009ProgramReviewGuide.pdf.
} 
It is not uncommon for investigation and resolution of a complaint by OCR to take four to five years. Ironically, when institutions receive a complaint, OCR requires them to complete their investigation promptly, typically within 60 days. According to some campus officials, this delay allows the agency to go far beyond the scope of the initial inquiry and what is necessary to assess whether a violation occurred. It also has the effect of paralyzing institutional efforts to improve policies, since it may be unclear what policy changes will satisfy OCR and will be required before investigations are completed and resolutions reached. The bottom line is simply that Congress should require the Department to conduct program reviews and issue fines in a timely manner.

The problems around timeliness are not limited to compliance and enforcement proceedings, but also appear in other contexts. As we noted earlier, many institutions report significant delays when seeking approval from the Department to offer new programs. These delays prevent schools from providing new education and training programs to students in a timely way. We believe Congress should re-examine the Department's process for approving new programs and require it to do so in a timely fashion.

\section{- The General Education Provisions Act (GEPA) provisions for Secretarial discretion in resolving viola- tions currently provided to the K-12 sector should be extended to postsecondary education.}

Several provisions of GEPA explicitly provide the Department significant and specific flexibility in recovering federal funds in the K-12 arena. For example, when dealing with violations of federal regulations by K-12 entities, the Department is able to consider mitigating circumstances and whether the entities acted in good faith, and to potentially waive the fines. However, GEPA explicitly exempts higher education from such flexibility.

The Department has told several institutions that, based on mitigating circumstances, it would have been likely to forgive a fine or a directive to return funds in question but could not do so given the GEPA restriction. The agency maintains that while it has the ability to reduce fines once they are levied, it cannot eliminate fines or waive a remand of funds under current law. There is no legislative history to clarify why such flexibility was prohibited with respect to colleges and universities. This is an illustration of the type of flexibility that the Department of Education wants and that colleges and universities would like it to have. Congress should extend the same provisions that currently exist for K-12 schools to postsecondary institutions.

\section{- Staff at Department of Education regional offices should be required to provide the same information and advice to institutions as the staff in Washington.}

Institutional officials often receive conflicting information from the Department's regional offices and its headquarters in Washington. Such inconsistency makes compliance with complicated regulations even more difficult. This problem can be exacerbated when institutions have campuses in multiple regions and receive conflicting information from different regional offices.

For example, in Section III we discussed the NAICU task force on financial responsibility standards. That group identified eight accounting elements applied inconsistently by the different regional offices, including losses on investments and interest rate swaps included in expenses; current maturities of long-term debt not included as part of long-term debt; and defined benefit plan liabilities excluded from "post-retirement benefit 
plan liabilities" for calculating expendable net assets. ${ }^{57}$

All regional offices should apply the same standards consistently. The Department should be required to make sure that the activities of its national and regional offices are in alignment. Expanded and enhanced training would go a long way toward meeting this goal.

\section{- Congress should ask the Government Accountability Office to review the Department of Education's rulemaking in light of Executive Order 13563, "Improving Regulation and Regulatory Review."}

On January 18, 2011, the President issued Executive Order 13563, "Improving Regulation and Regulatory Review." Section 6 of the Order calls for the retrospective analysis of existing rules, where agencies analyze existing rules that may be outmoded, ineffective, insufficient, or excessively burdensome, and, based on what was learned from the analyses, modify, streamline, expand, or repeal them.

Also as required by the Order, the Department published its preliminary plan for retrospective analysis of existing regulations on May 18, 2011, and it published its final plan on August 22, 2011. The final plan, which incorporated feedback from the public on the preliminary plan, lists the 11 factors and processes the Department will use in setting priorities for the retrospective review of its regulations. ${ }^{58}$

The Department has published seven reports describing its regulatory activities under the Order, which means that the agency is technically in compliance. However, the activities identified in these reports are largely limited to previously planned rulemaking actions. There are issues that are ripe for a retrospective review (such as financial responsibility standards), but the Department has yet to announce any plan to address them. Accordingly, we believe Congress should request that the Government Accountability Office undertake an examination of the Department's implementation of Executive Order 13563.

\section{Further Improvements to the Overall Regulatory Process}

In addition to the specific reforms identified above, several strategies could usher in broader improvements in the Department's approach to regulation.

\section{- Congress should consider developing and implementing "risk-informed" regulatory approaches where appropriate.}

All colleges and universities are regulated in the same manner, regardless of the level of risk involved. This forces the Department to expend energy on institutions that should command relatively little attention, while simultaneously skimping on those where more oversight is warranted. Painting all institutions with the same broad brush does not serve anyone well.

While a risk-informed regulatory system is not appropriate for every issue, there is growing consensus that institutions with greater levels of risk to students and taxpayers should be regulated by the Department more closely. After extensive consultations with the higher education community, Congress should require the

\footnotetext{
${ }^{57}$ Report of the NAICU Financial Responsibility Task Force, November 2012, available at: http://www.naicu.edu/docLib/20121119_ NAICUFinan.Resp.FinalReport.pdf.

${ }^{58}$ See http://www2.ed.gov/policy/gen/reg/retrospective-analysis/index.html.
} 
Department to develop and implement risk-informed regulatory systems wherever appropriate.

The ideas behind a risk-informed regulatory system and the areas where such a system might be appropriate are explored in much greater detail in a white paper appended to this report.

- Congress should order an independent review of the Department of Education's organizational practices with respect to issuing regulations.

The Task Force discussed regulatory practices at other agencies and looked at whether there were best practices or desirable organizational structures that might be transferable to the Department of Education. For example, several members cited the Small Business Administration's Office of Advocacy as a possible model that might merit further study. Others mentioned various federal advisory committee structures, such as the National Institutes of Health Advisory Committee to the Director, and suggested that a similar body at the Department of Education could be a source of advice and information to the Secretary of Education.

Before changes can be recommended in the Department of Education's organizational structure and practices, Congress should commission a review of the Department through an organization with expertise in these areas. At Congress' request, for example, the National Academy of Public Administration (NAPA) recently conducted an extensive review of the Social Security Administration and has undertaken reviews for many other parts of the federal government. NAPA might be well suited to assist in a similar review with respect to the Department. ${ }^{59}$ In addition to NAPA, Congress may also wish to ask the Administrative Conference of the United States to review the legal processes and procedures used by the Department. ${ }^{60}$

59 NAPA is an independent, nonpartisan, and nonprofit organization chartered by Congress to improve government performance. See: http://www.napawash.org/.

${ }^{60}$ The Administrative Conference of the United States is an independent federal agency focused on improving the administrative process through consensus-driven applied research, providing nonpartisan expert advice and recommendations for improvement of federal agency procedures. See: http://www.acus.gov/. 


\section{Conclusion}

American legal scholar and former OMB senior official Cass Sunstein notes that simplicity is possible without compromising the overall effectiveness of the government's oversight abilities. In his book Simpler: The Future of Government, Sunstein writes, “...without a massive reduction in its current functions, government can be far more effective, far less confusing, far less counterproductive, and far more helpful if it opts, wherever it can, for greater simplicity." 61

We need to be smarter about the regulation of higher education. To that end, we have summarized the current regulatory landscape, outlined some of the challenges that make compliance onerous, detailed many specific concerns that are particularly problematic, and suggested a number of reforms that could help improve the process of regulation.

The Task Force has also developed a set of Guiding Principles that we believe can help inform a constructive path forward in recalibrating the regulatory process for higher education. Apart from our interest in seeing that regulations are coherent and fair, these principles also reflect our belief that all stakeholders-students and taxpayers, as well as colleges and universities - reap the benefit of well-designed regulation. We want to keep costs down, keep students safe, focus on educating students, and be good stewards of funds. These principles will help us do that.

To underscore points that we have made several times in this report, institutions of higher education must be careful stewards of federal funds, the federal government must ensure that public resources are not squandered, and students and taxpayers must be protected. Regulatory oversight exercised in the right way provides these essential protections.

But unnecessary and complex regulations provide no benefits. Nor do regulations that have an excessive reach or are poorly framed, hard to comply with, or difficult to implement. Such regulations thwart student access to college, impede the pursuit of institutional organizational efficiencies, and constrain innovation. And, because they increase administrative burden, they drive up institutional operating costs.

Relief from some of the most burdensome or ill-founded regulations and a better process for developing new ones would help higher education advance its important goals. The Task Force looks forward to working with members of Congress to address these concerns and others in the upcoming reauthorization of the Higher Education Act.

${ }^{61}$ Sunstein, 2013, p. 11. Italics omitted. 


\section{APPENDIX I: Regulations Matrix}

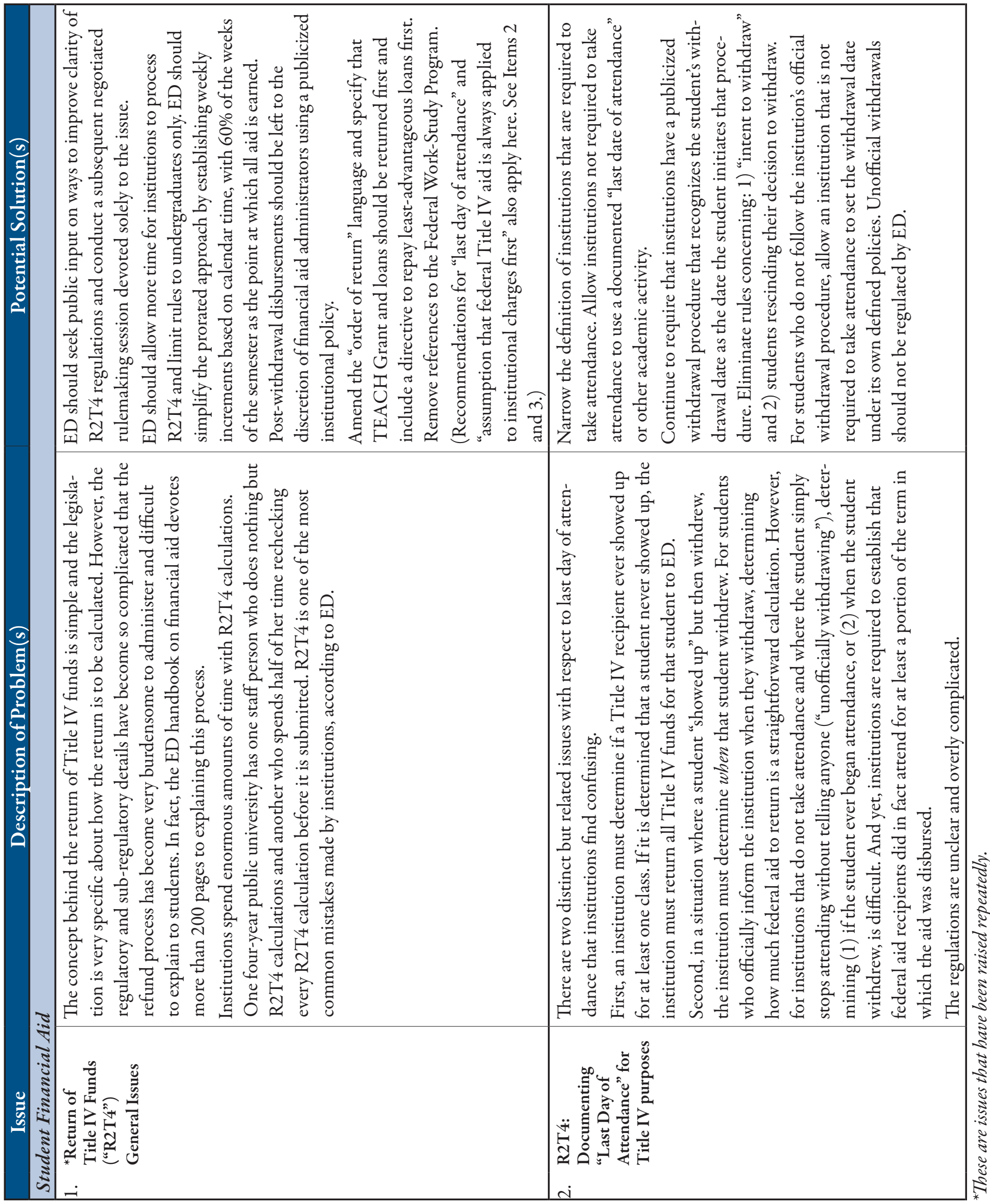




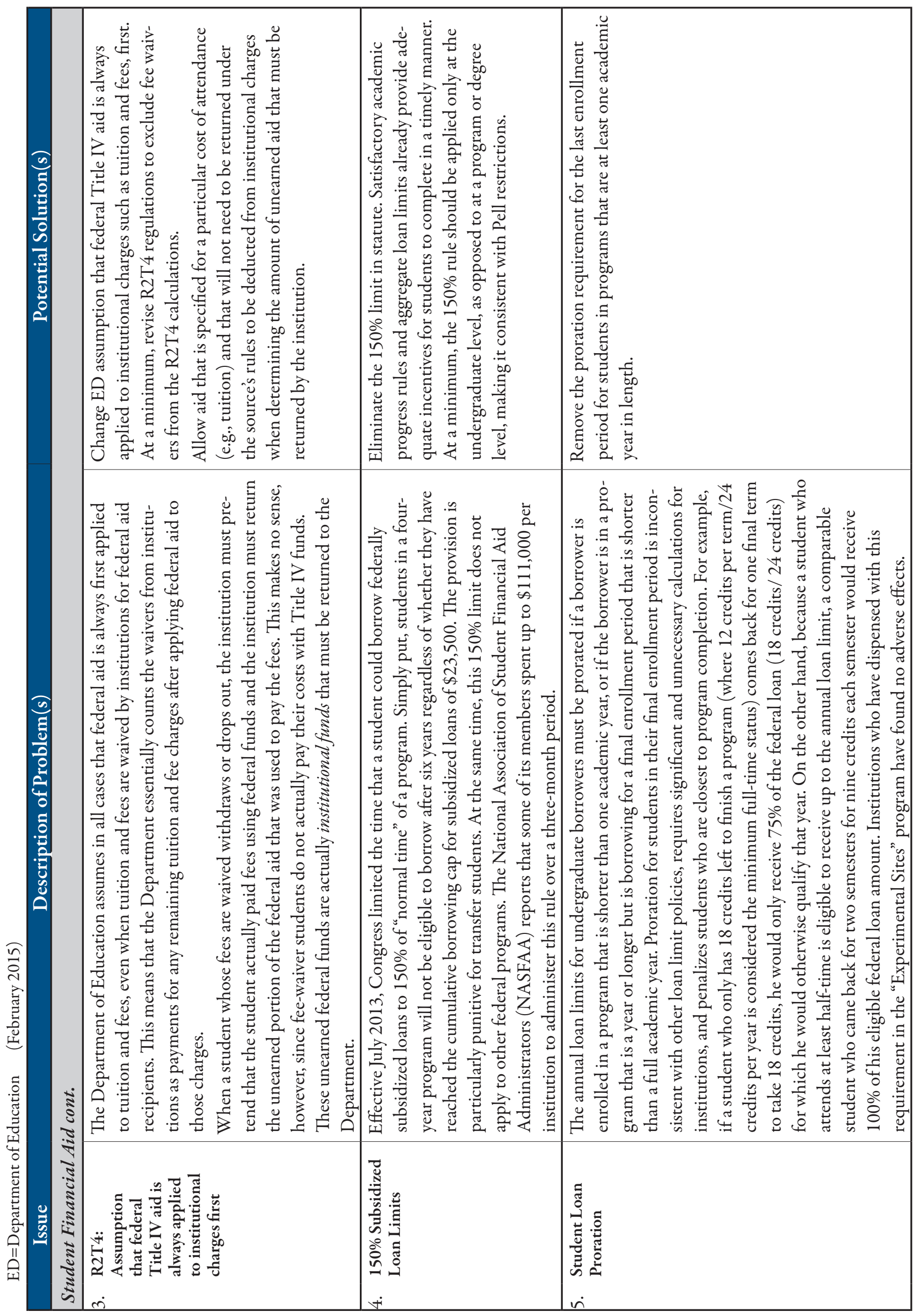




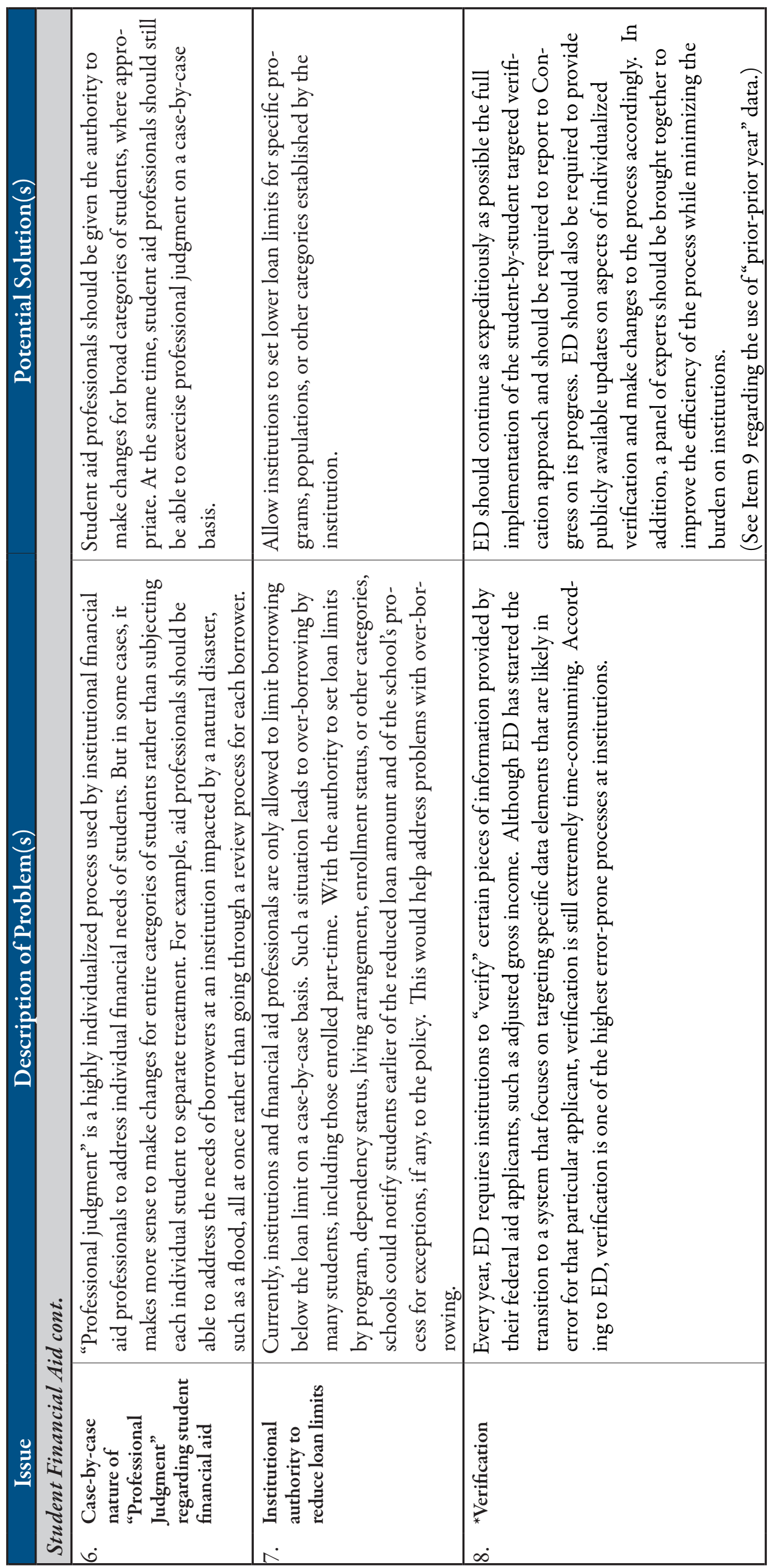




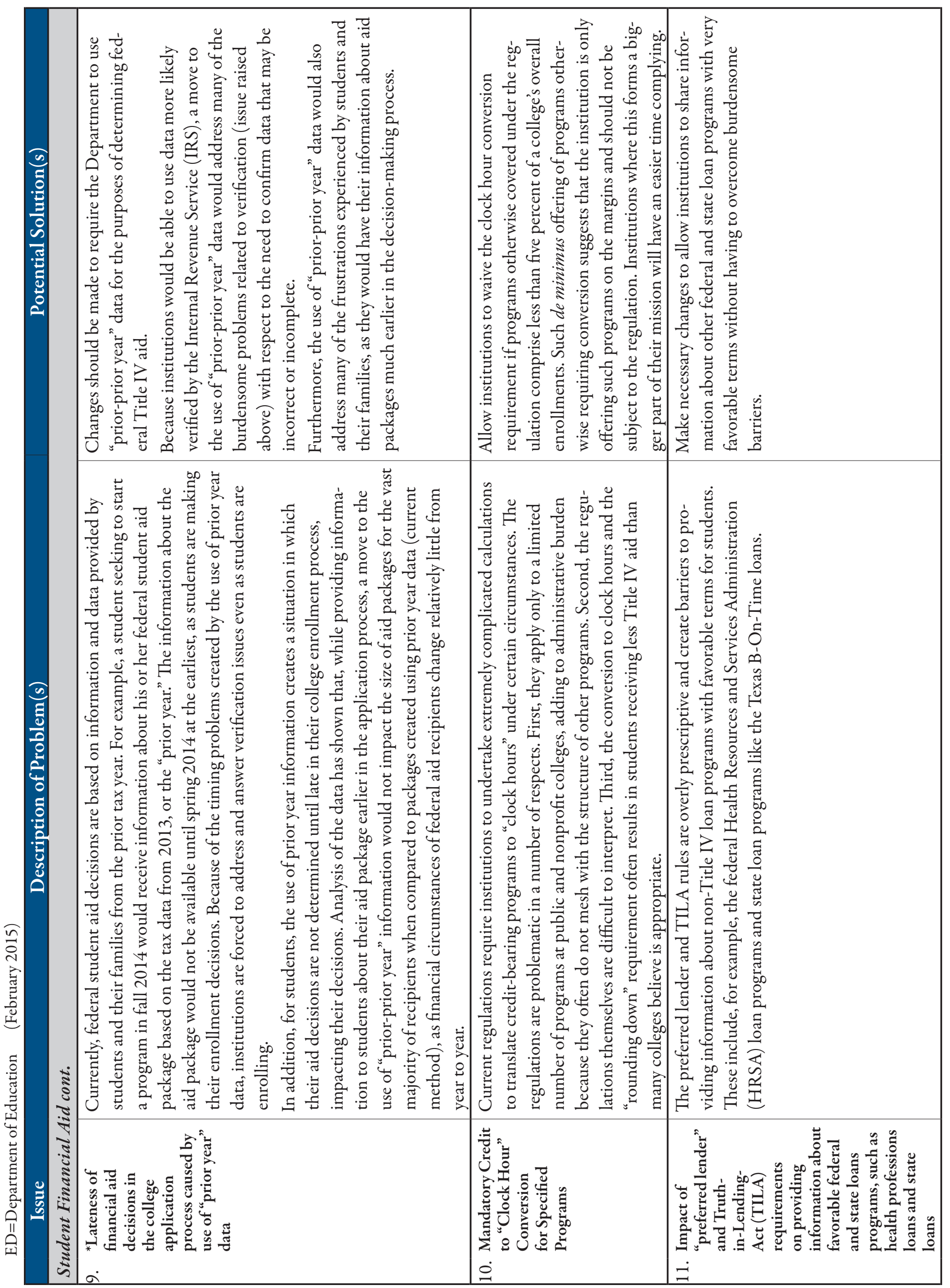




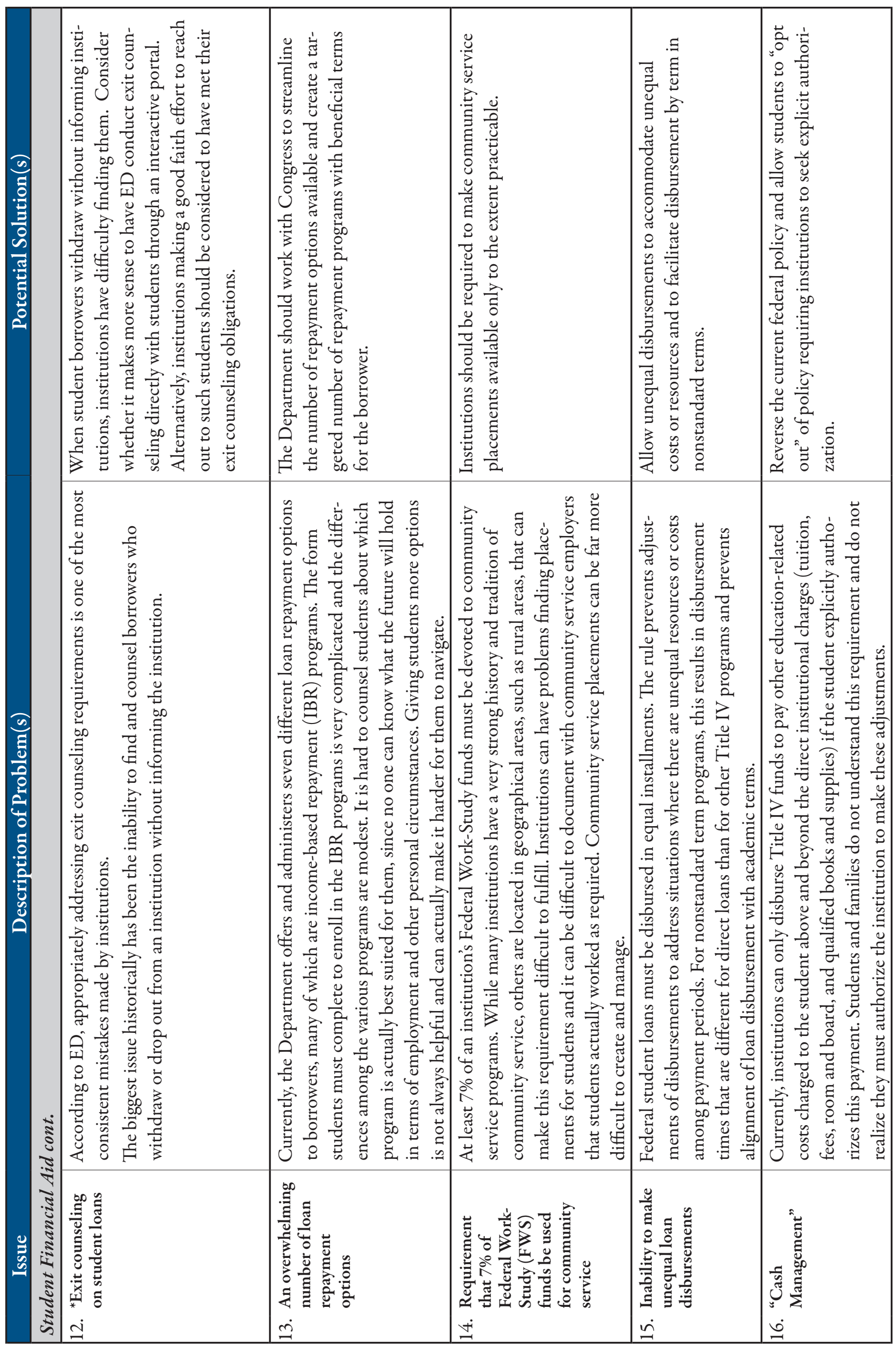




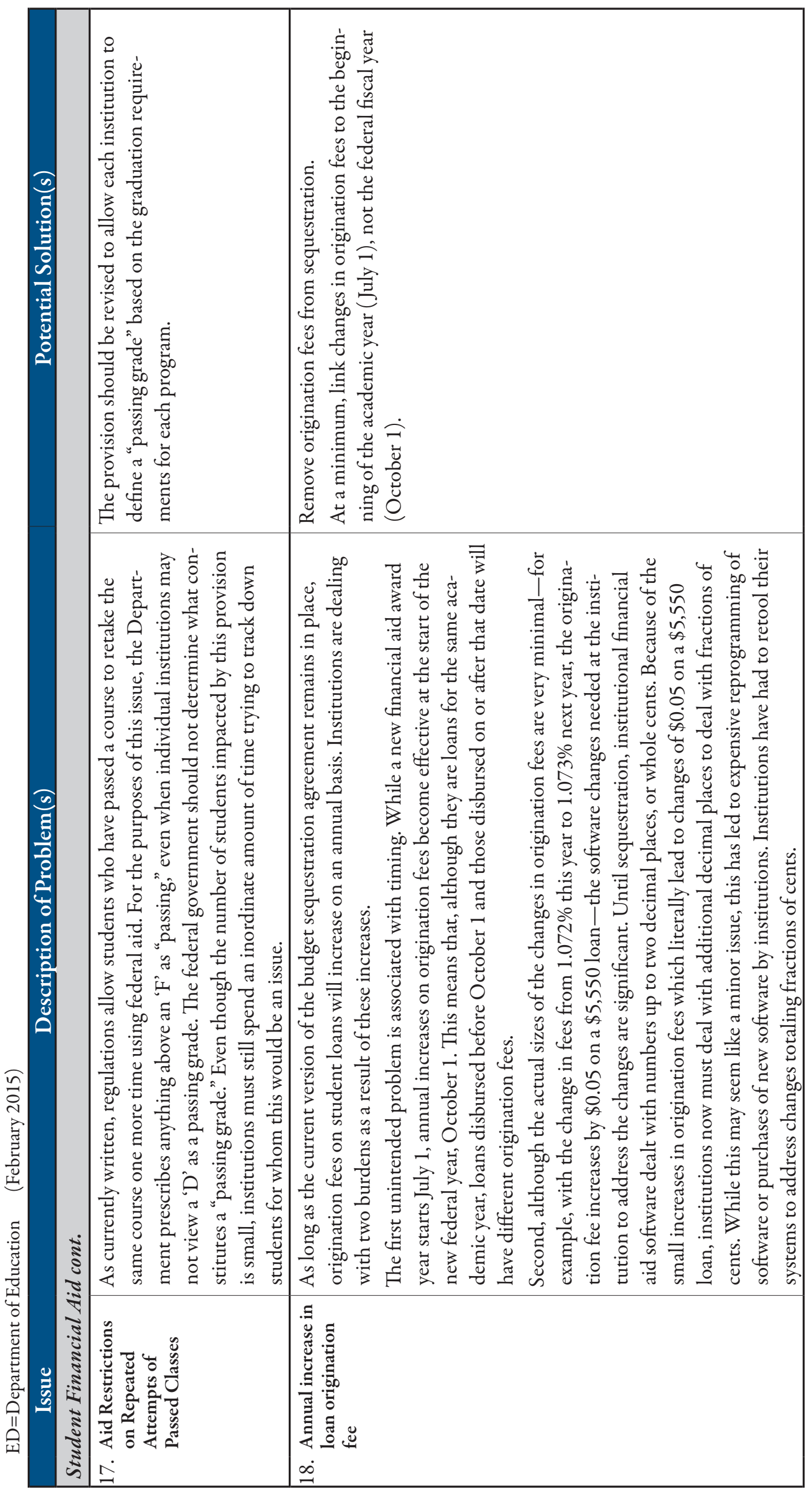




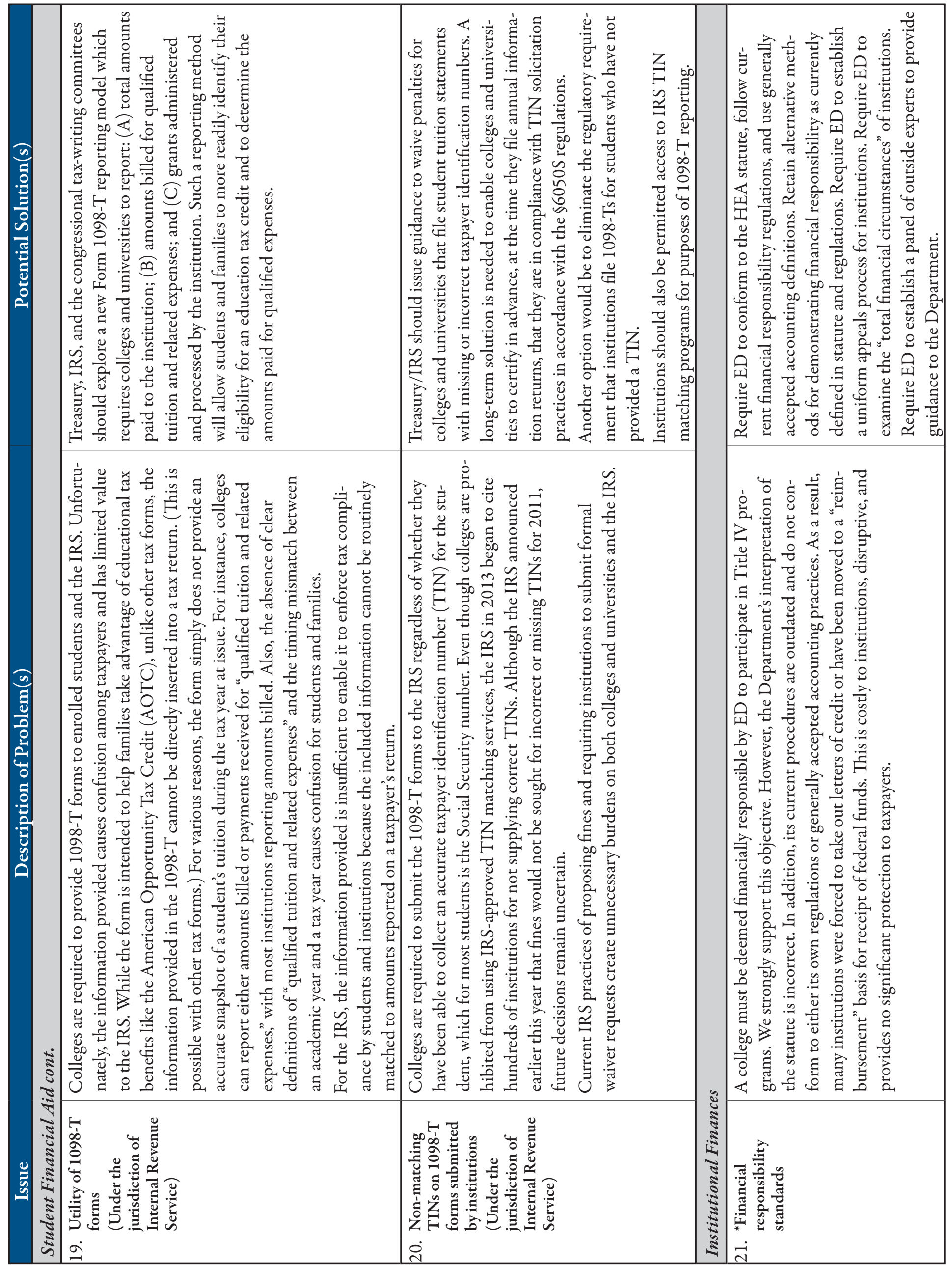




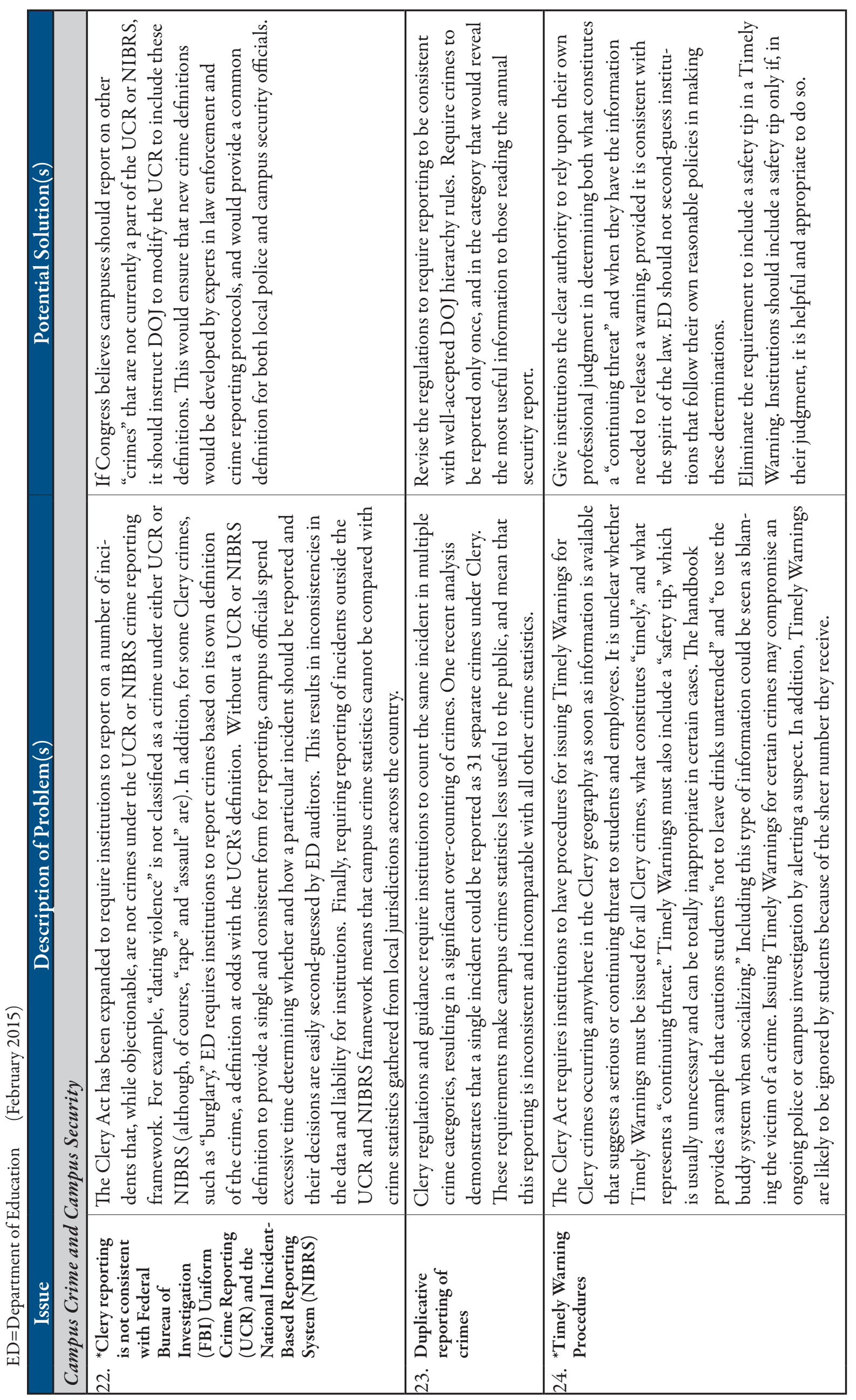




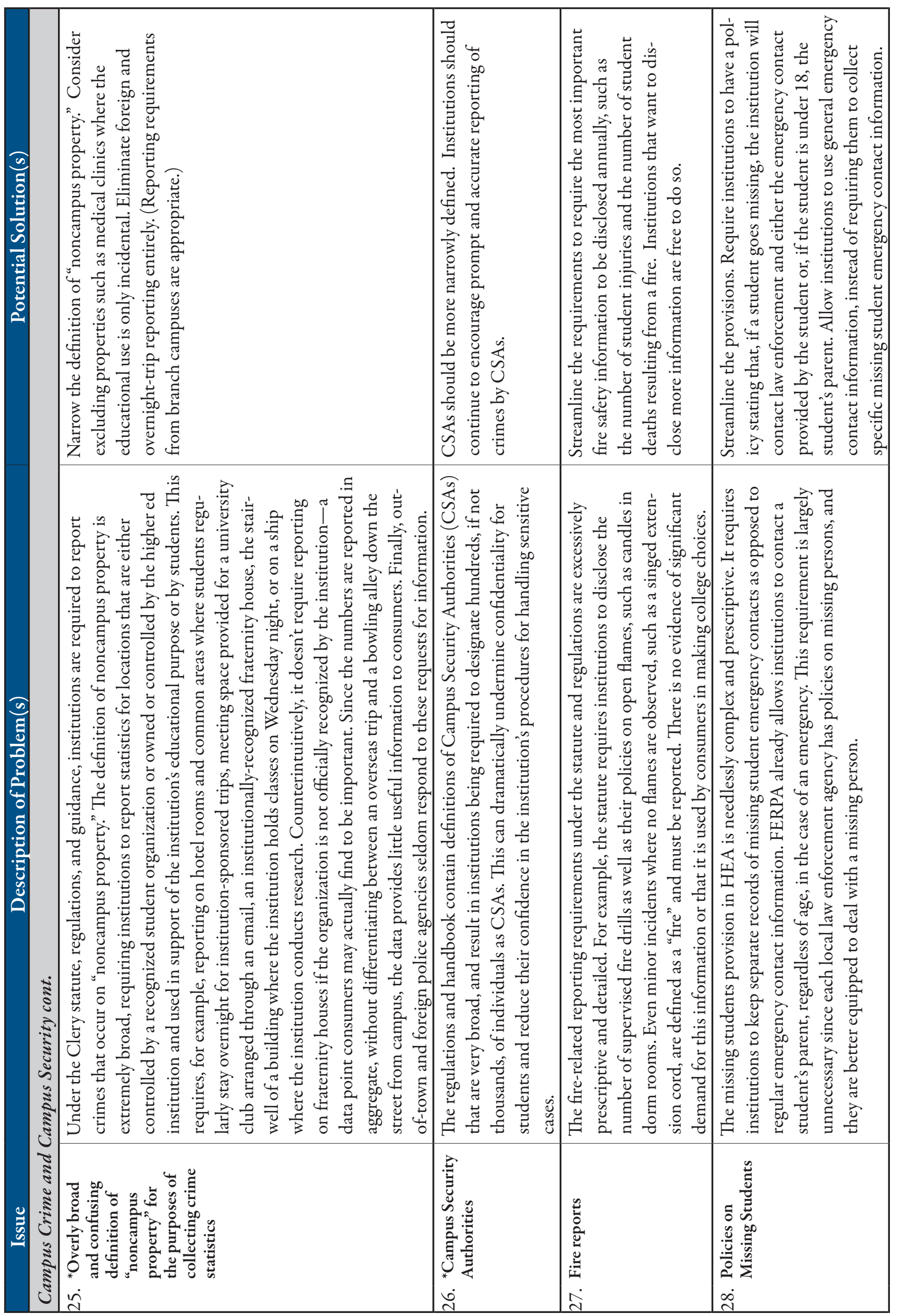




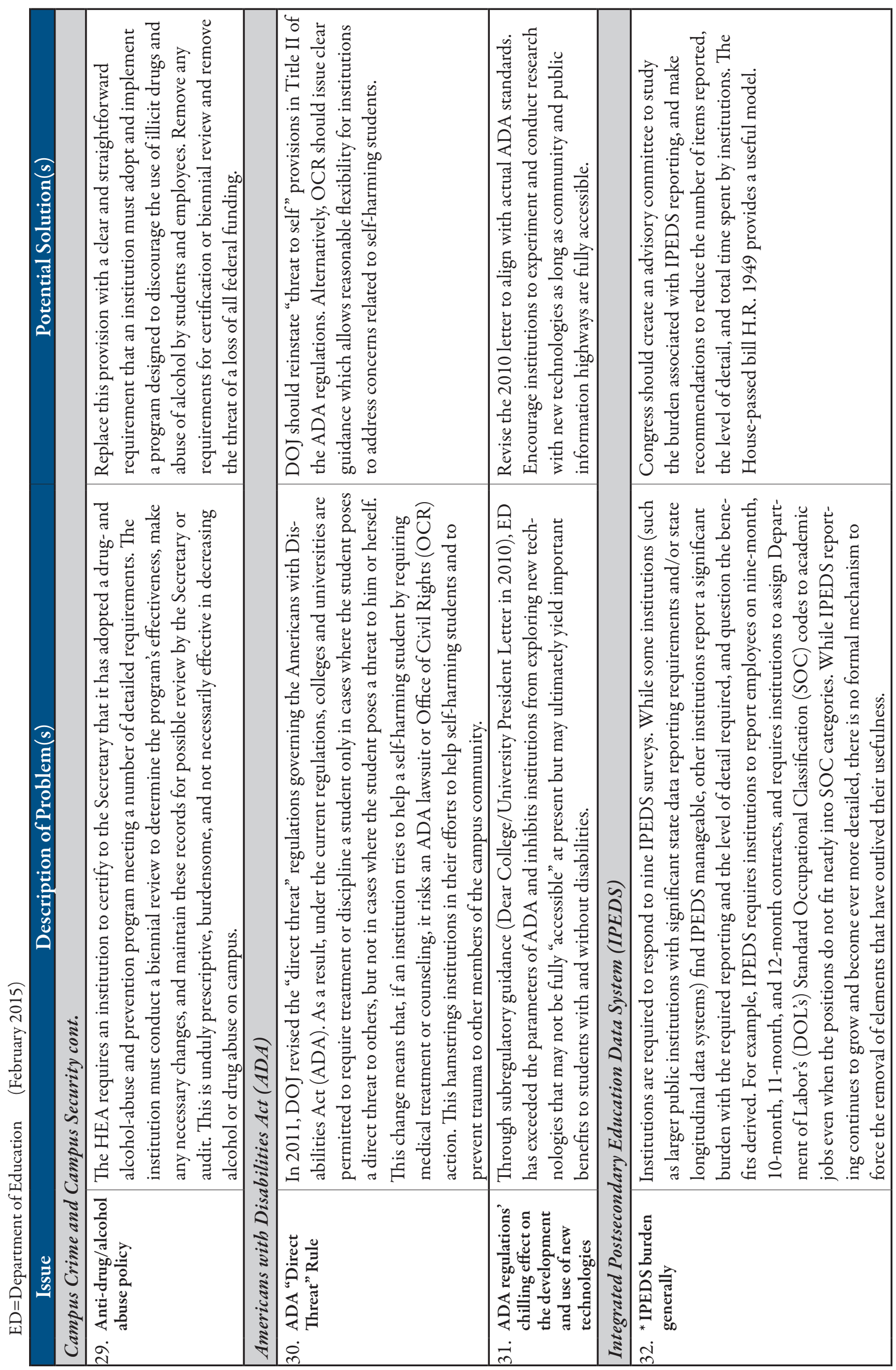




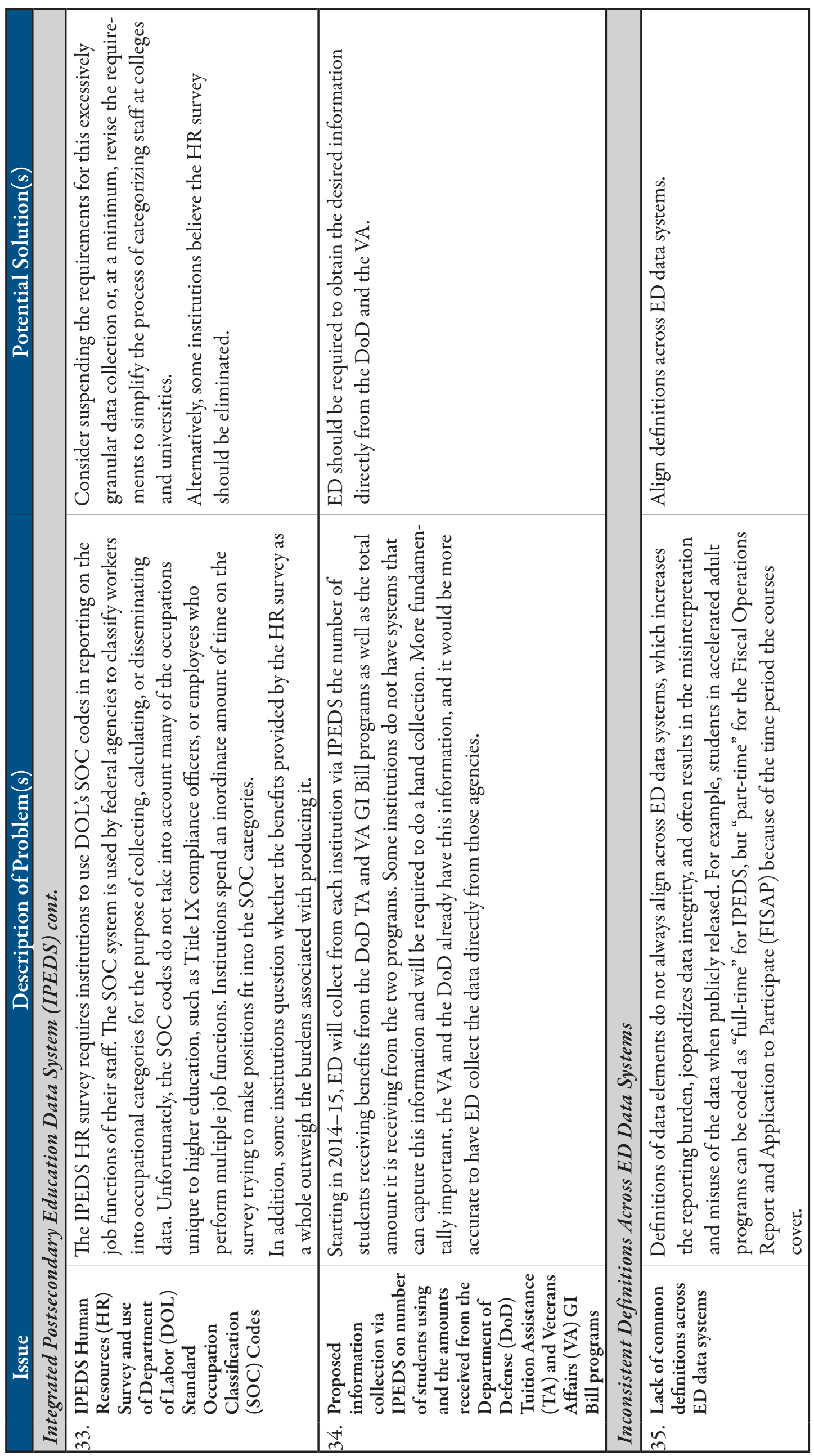




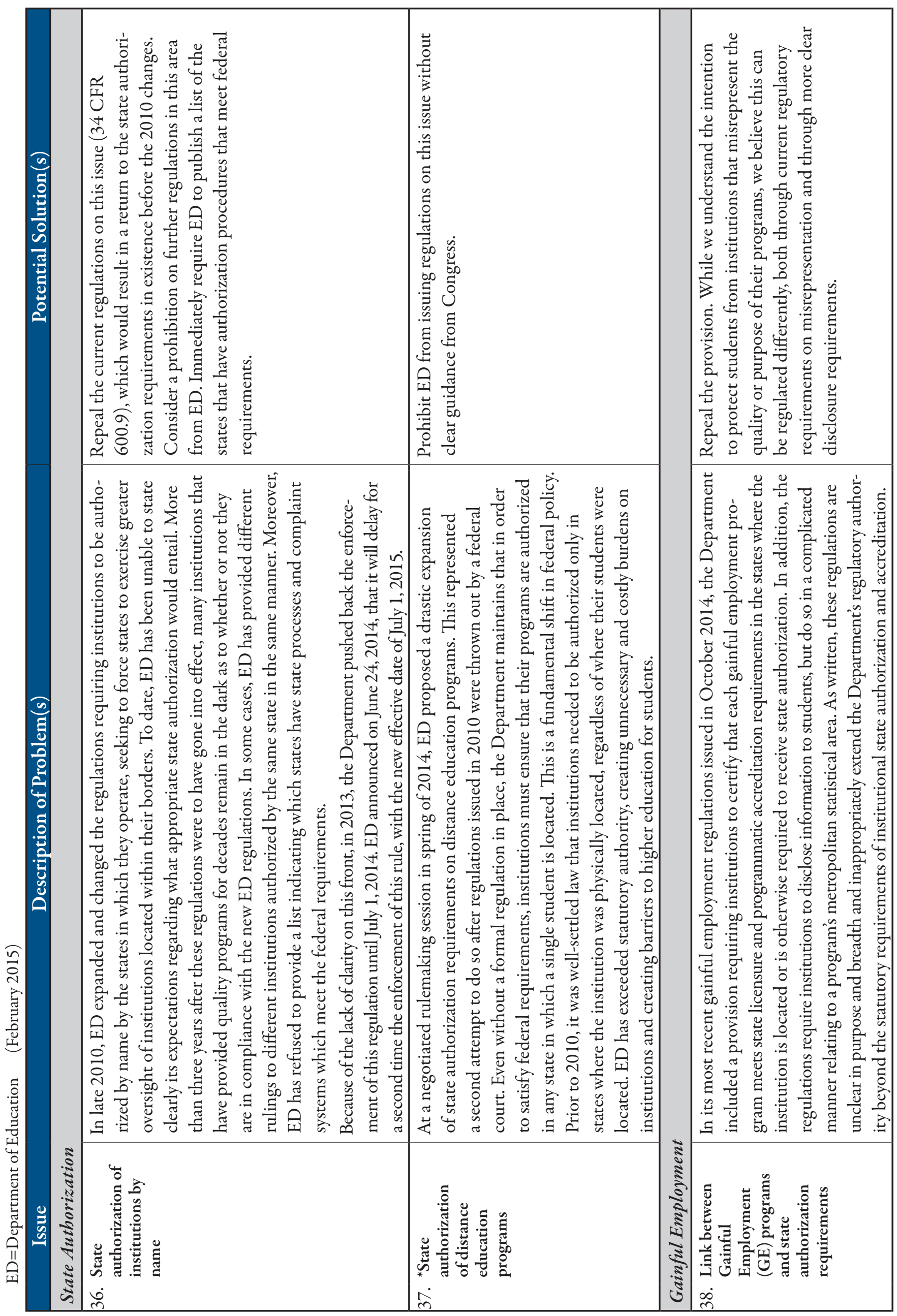




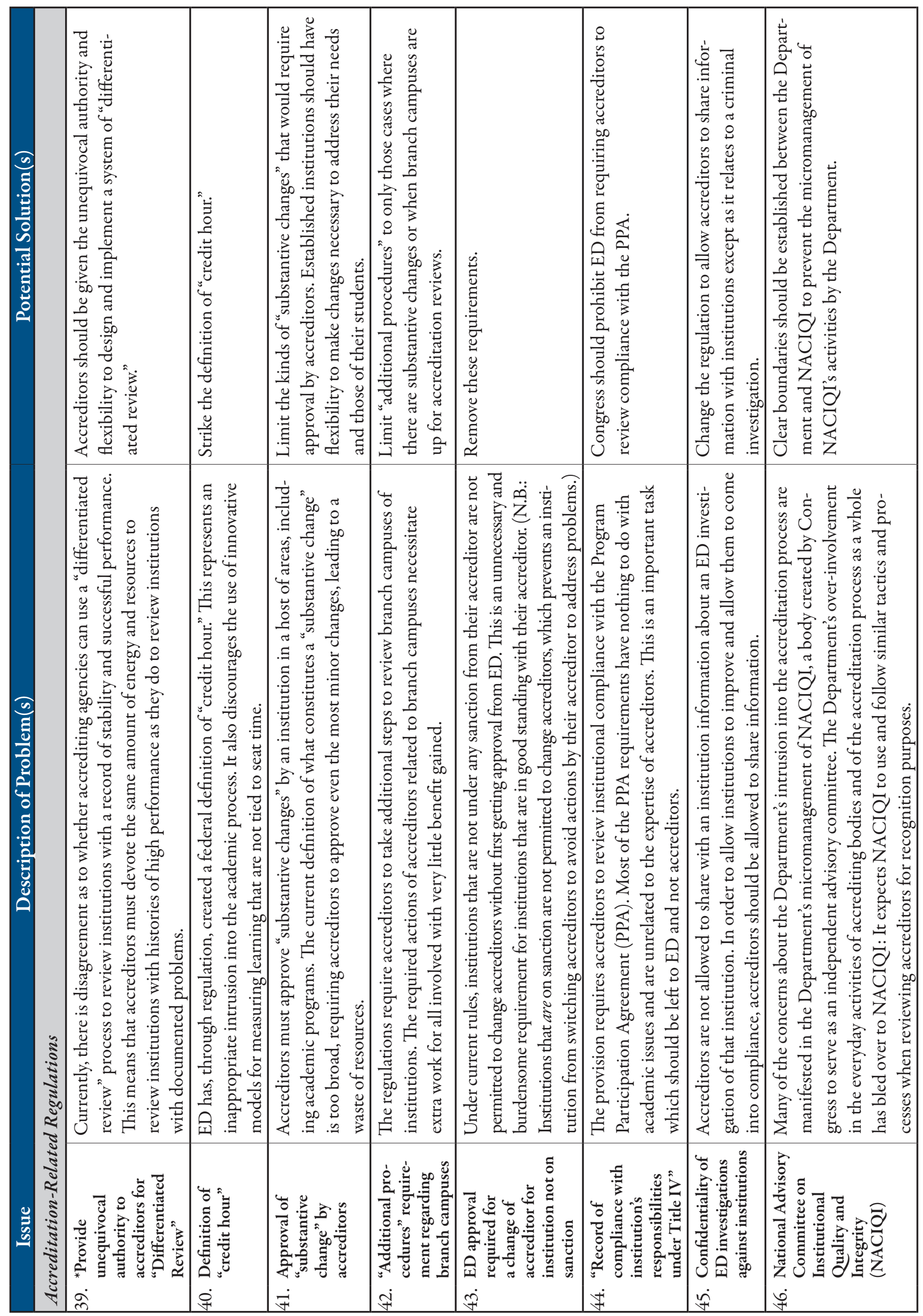




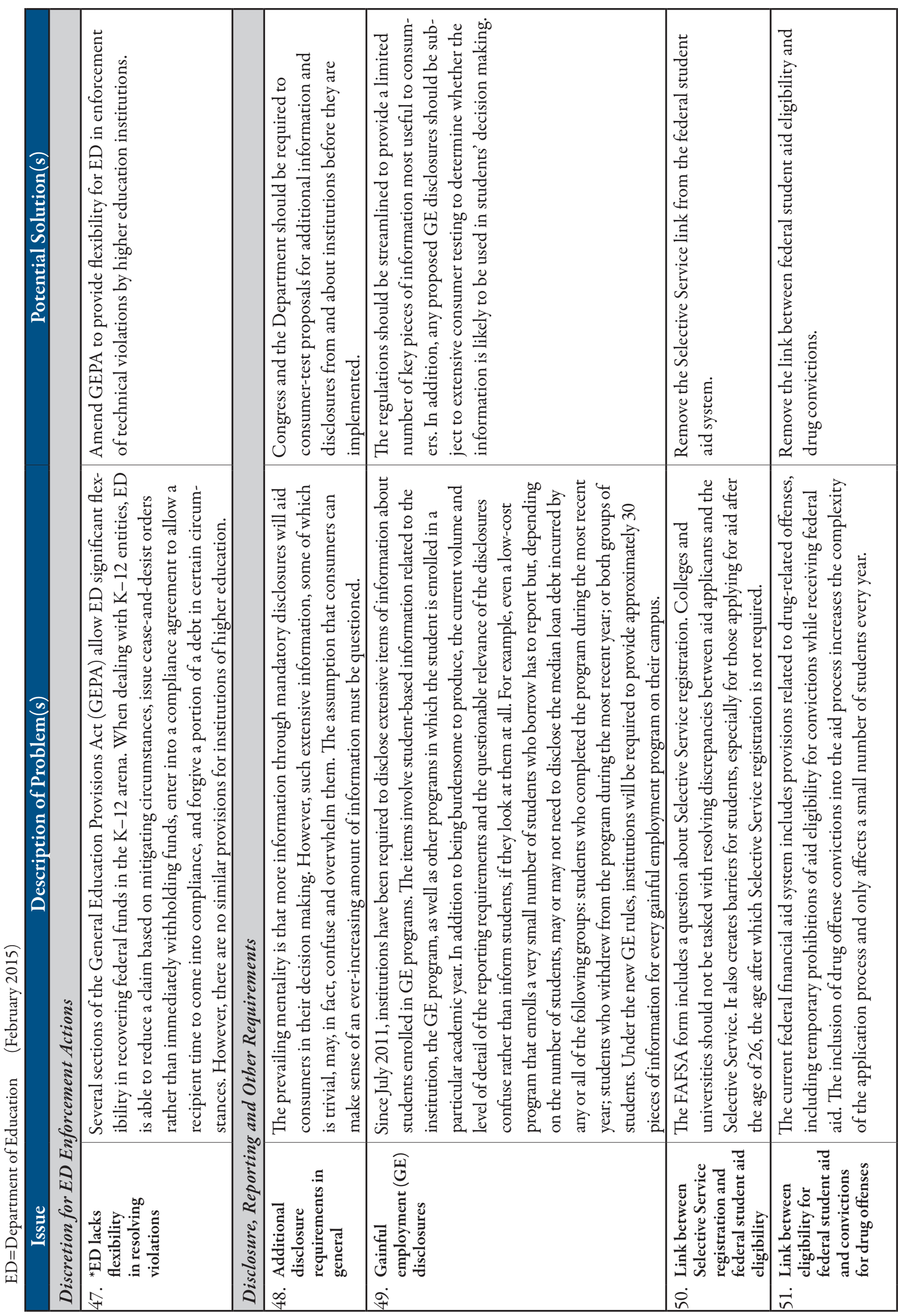




\begin{tabular}{|c|c|c|c|c|c|c|c|c|}
\hline & 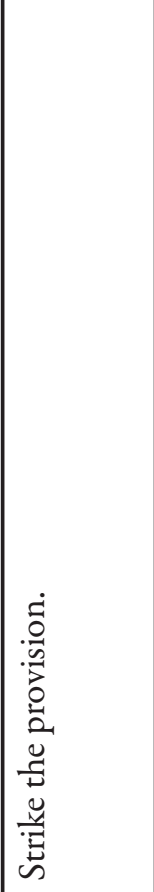 & 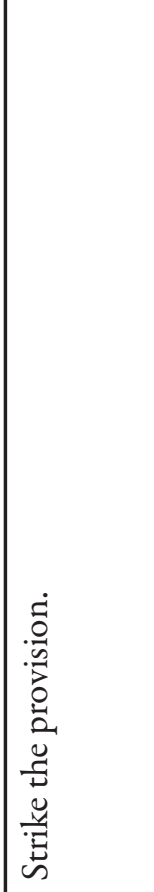 & 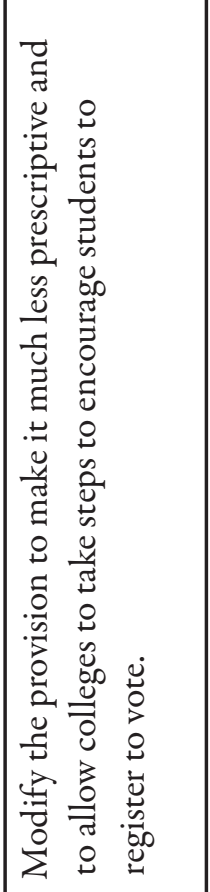 & 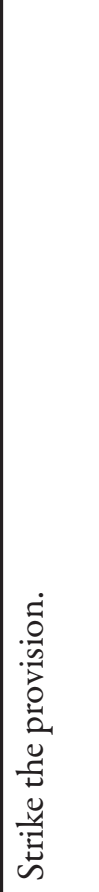 & 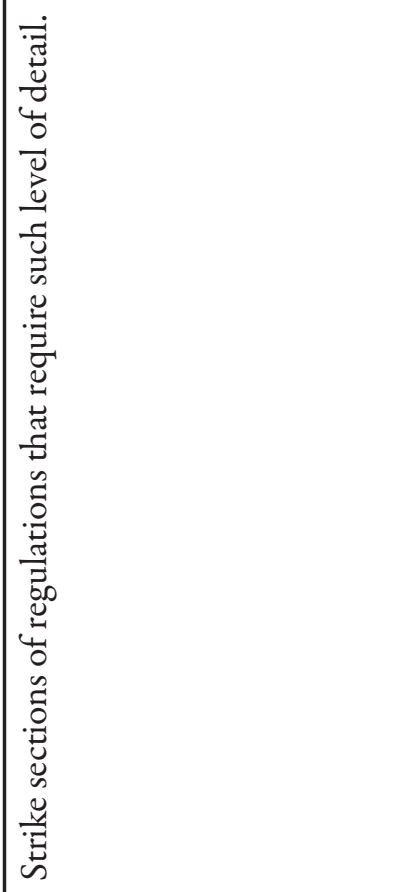 & 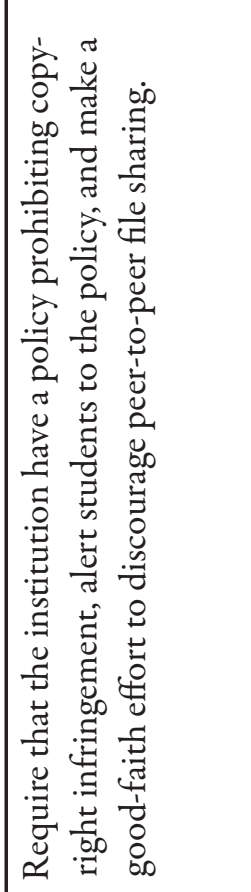 & 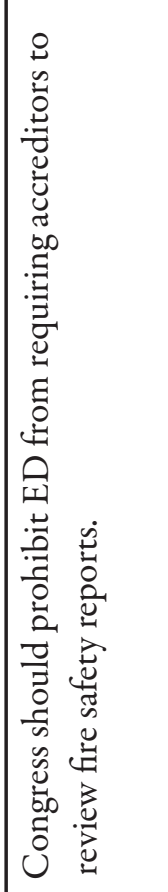 & 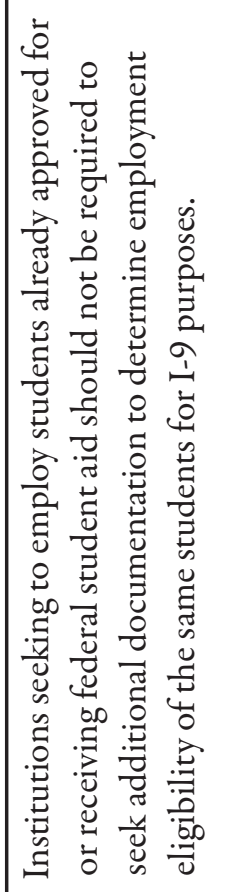 \\
\hline 8 & 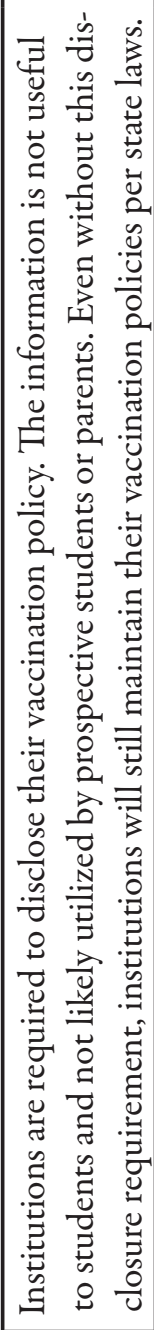 & 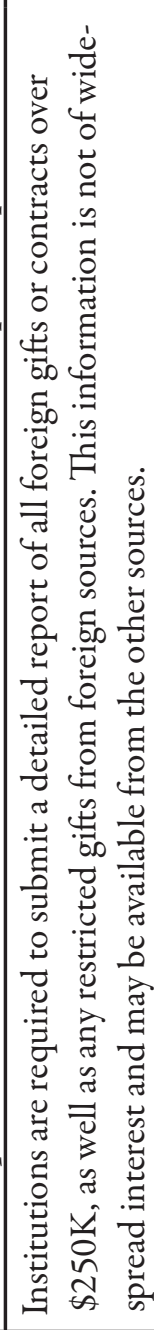 & 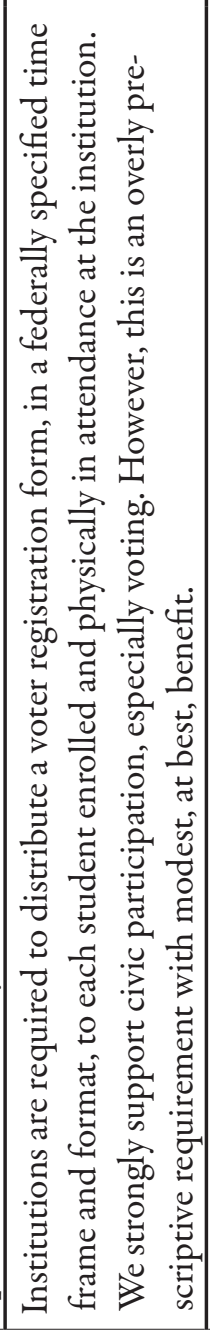 & 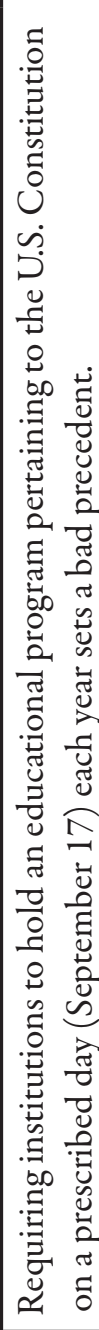 & 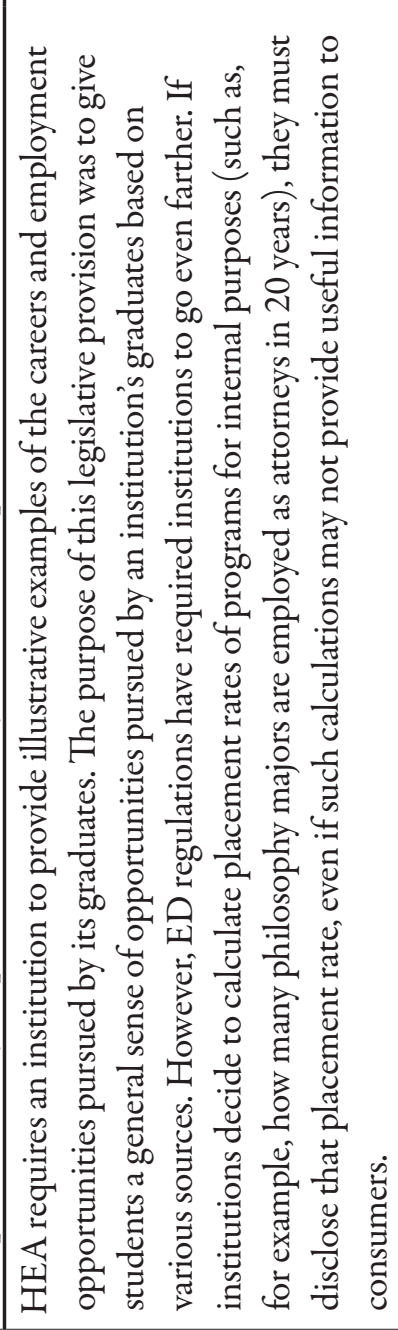 & 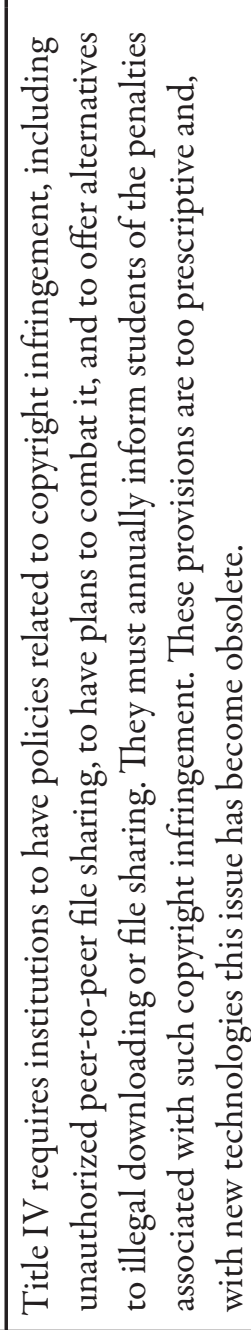 & 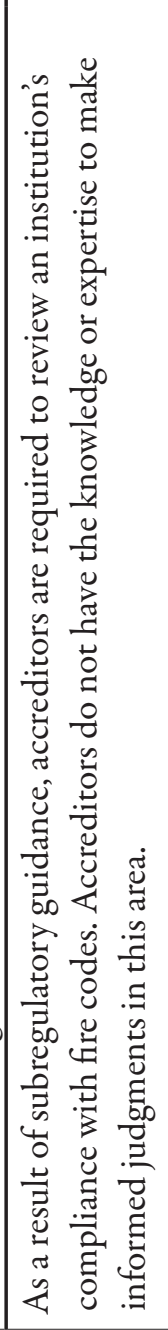 & 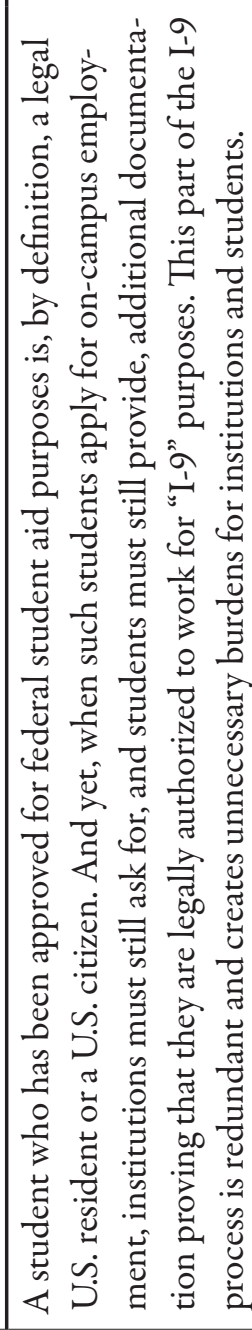 \\
\hline $\begin{array}{l}\approx \\
\text { है } \\
\text { है }\end{array}$ & 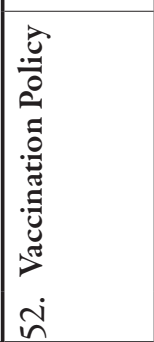 & 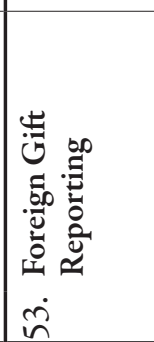 & 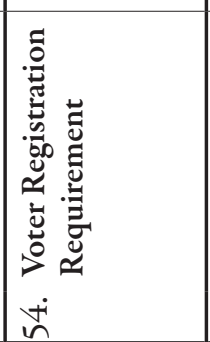 & 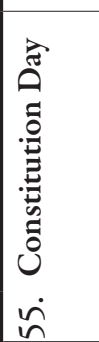 & 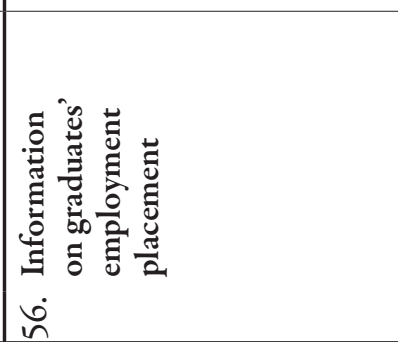 & 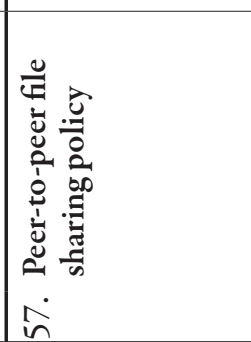 & 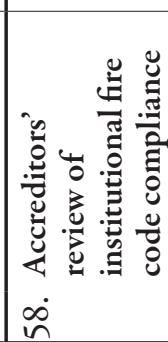 & 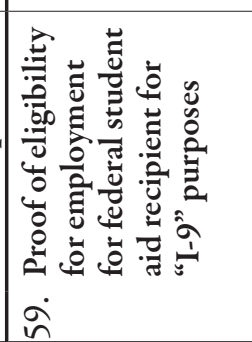 \\
\hline
\end{tabular}




\section{APPENDIX II: Regulations Process Reform Chart}

\section{Development of}

\section{Regulations}

- GAO should review ED methodology for estimating burden of regulations and make recommendations for improvement.

- “Neg Reg” improvements:

1. Change process for selecting negotiators.

2. Facilitators should serve as mediators and arbiters of fairness.

3. Minimize "bundling" of unrelated issues.

- Create regulatory "safe harbors."

- Regulations should not exceed legislative language or Congressional intent.

- The Department should follow "noticeand-comment" procedures when making significant policy changes.

- Write in plain language.

- Before any more consumer information is collected from institutions, focusgroup test all new collections for usefulness.

- Create an ombudsman to act as a "gobetween" for institutions and federal regulators, similar to the SBA Office of Advocacy.

- Establish a small advisory board of institutional officials to advise the Secretary on regulatory burden.

- Subregulatory guidance should not stray from underlying regulation/statute.

\section{Implementation of Regulations}

- Allow adequate time for implementation of regulations.

- Answer questions in a timely manner.

- Publish and then update compliance calendar every year.

- Require ED to give institutions at least nine months between the publication of final regulations and the initiation of any related data collection.

\section{Enforcement of}

\section{Regulations}

- Extend GEPA protections to colleges and universities.

\section{- Recognize "good faith"} by institutions.

- Require ED to provide the final report for a Program Review within 60 days of the receipt of the institution's response.

- Require ED to act in a timely fashion.

- Require GAO to examine whether the Department has retrospectively analyzed existing rules, as required by Executive Order 13563.

- Train regional staff appropriately and consistently.

\section{Changes That Could Improve Every Phase of the Process}

- Develop “risk-based” regulations where appropriate.

- Commission outside experts to analyze departmental structure and practices with respect to regulations. 


\title{
New Directions in Regulatory Reform: Prospects for Reducing Regulatory Bur- den Through Risk-Informed Approaches in Federal Law Governing American Higher Education
}

\author{
Arthur L. Coleman, Teresa E. Taylor, and Bethany M. Little
}

December 2014

\section{Acknowledgements}

This paper was significantly enhanced by the contributions of a diverse group of stakeholders in higher education, including representatives from colleges and universities in the United States and Australia, accrediting agencies, the U.S. Department of Education, and leading higher education organizations. Special thanks are owed to members of the Senate Task Force on Regulation of Higher Education and staff from the American Council on Education, whose ongoing guidance and counsel notably enhanced the draft.

About EducationCounsel, LLC

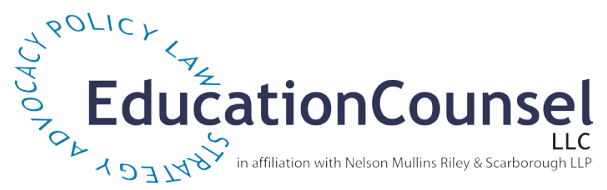

EducationCounsel is a mission-based education consulting firm that combines experience in policy, strategy, law, and advocacy to drive significant education improvements. Our team-including former U. S. Secretary of Education Richard W. Riley as senior partner-is a diverse and bipartisan group with a shared commitment to strengthen education systems, close achievement gaps, and expand access to educational opportunities. We work at the local, state, and national levels to develop and put into motion policy initiatives that close achievement gaps and lead to improved education outcomes from pre-K through postsecondary education. Our higher education practice focuses on access, quality, and completion, with particular emphasis on issues of diversity, enrollment and admission practices, accreditation, distance learning, federal accountability systems, desegregation, and federal compliance.

EducationCounsel is affiliated with Nelson Mullins Riley \& Scarborough LLP, which has more than 500 attorneys and other professionals in the District of Columbia, Florida, Georgia, Massachusetts, North Carolina, South Carolina, Tennessee, and West Virginia.

For more information, please visit our website, www.educationcounsel.com.

(C)ducationCounsel LLC. All rights reserved. 


\section{TABLE OF CONTENTS}

I. INTRODUCTION AND OVERVIEW ............................................................................................................................ 61

\section{THE RELEVANT EDUCATION LANDSCAPE AND}

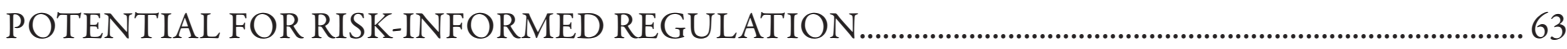

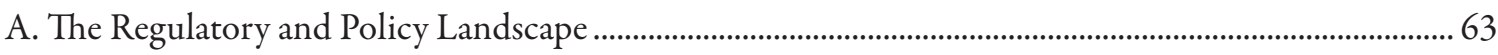

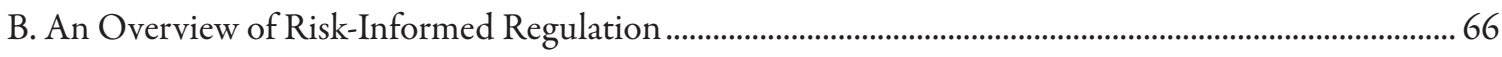

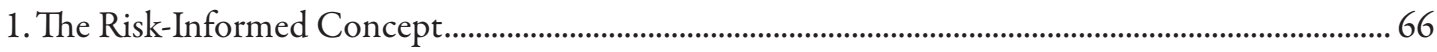

2. Core Functions Within Risk-Informed Regimes................................................................................... 68

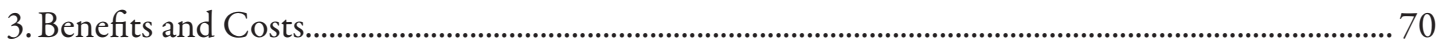

III. HOW RISK-INFORMED AND RISK-BASED REGULATORY

APPROACHES HAVE BEEN PURSUED AND APPLIED IN OTHER SETTINGS ............................. 71

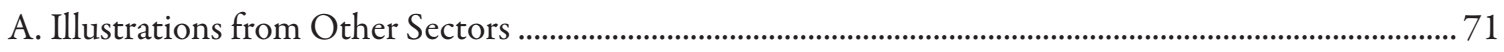

B. International Examples in Postsecondary Education .................................................................................... 73

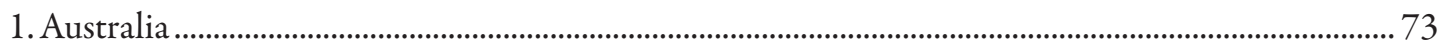

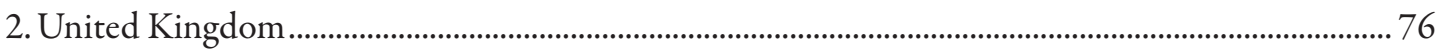

IV. PRINCIPLES TO GUIDE ACTION AND PROSPECTIVE RISK-INFORMED

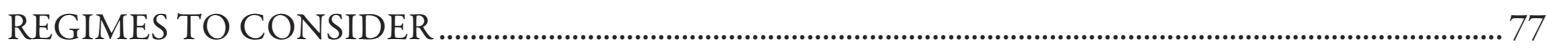

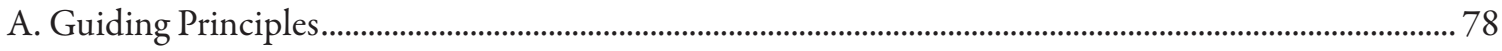

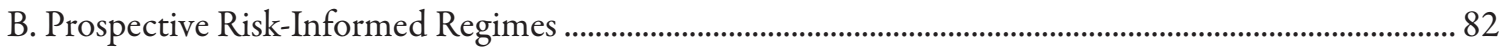

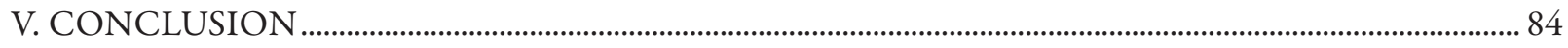

APPENDIX A: RISK-INFORMED PROCESS MAP …………………………………………………………….... 86

APPENDIX B: RECOMMENDED READING ON RISK-INFORMED REGIMES ........................................ 89 


\section{INTRODUCTION AND OVERVIEW}

The beginning of the 21 st century has brought unprecedented change to the higher education community. The last decade has produced significant increases in enrolled students, financial aid demands, numbers and variety of institutions, types of educational delivery methods, and employer expectations, to name a few. Technological developments are driving the pace of change on many fronts even more rapidly—a pace will likely increase in the years to come.

Meanwhile, regulatory systems are not keeping up. Decades of statutory and regulatory amendments have created a dense, labyrinthine thicket of rules and requirements that reflect competing priorities and changing compliance standards. Too much of the federal regulatory system relies on a one-size-fits-all reporting and enforcement regime that is out of sync with the broad diversity among American institutions of higher education and numerous interests and needs of students. As a consequence, the system too often fails to direct limited oversight and enforcement resources in the most effective, efficient manner. Without question, we need new regulatory strategies that can respond to these shifts and, as important, can prepare for the new changes on the horizon.

"Risk-informed" regulatory regimes have significant promise to correct some of the problems of the past and help prepare the system for today and tomorrow. These regimes present a fundamental shift in the regulatory paradigm. Instead of requiring the institution to comply with every requirement and regulation, institutions are required to comply with some baseline rules and submit to a preliminary risk assessment. When that assessment reveals a problem, regulators and/or their non-governmental partners may take additional action that ranges from requiring more information or participation in technical assistance programs, mandating corrective action, or - in worst case scenarios-applying sanctions. ${ }^{1}$ Risk-informed regimes reflect a hybrid of "deterministic" (one size fits all) and "risk-based" systems (regulatory action only applies when a regulated entity presents a certain level of risk, so some entities are not regulated at all).

Instead of requiring the institution to comply with every requirement and regulation, institutions are required to comply with some baseline rules and submit to a preliminary risk assessment.

When that assessment reveals a
problem, regulators may take
additional action that ranges from
requiring more information or
participation in technical assistance
programs, mandating corrective
action, or - in worst case scenarios -
applying sanctions

Incorporating risk assessment into regulatory regimes has been endorsed by leading higher education organizations ${ }^{2}$ and by both sides of the political aisle. ${ }^{3}$ Supporting organizations recognize the prospective efficiency, as

1 See Jonathan Coburn and Greg Weddle, Risk-Based Regulation: Learning from the Experience of Others, BioProcess Int'l $22-23$ (Sept. 2006).

2 See, e.g., Association of American Universities, AAU Submits Comments on Draft HEA Bill to Senator Harkin (Aug. 26, 2014), http://www.aau.edu/policy/article.aspx?id=15447; Peter McPherson, Association of Public and Land-grant Universities, APLU Comments on HEAA Discussion Draft (Aug. 22, 2014), available at: https://www.insidehighered.com/sites/default/server_files/files/ APLU\%20HEAA\%20Response\%20Final\%20082214.pdf; Molly Corbett Broad, American Council on Education, Recommendations from 39 Higher Education Associations for the Reauthorization of the Higher Education Act (Aug. 2, 2013), http://www.acenet.edu/ news-room/Documents/HEA-Reauthorization-Recs-080213.pdf.

3 For instance, a bipartisan group of Senators endorsed the concept behind the Food and Drug Administration's proposed risk-based approach to the regulation of medical devices, while the group also emphasized the importance of transparency in communicating to stakeholders to avoid confusion. Sens. Michael Bennet, Orrin Hatch, Tom Harkin, Lamar Alexander, Mark Warner, and Richard Burr, Letter to Commissioner Hamburg (March 18, 2014) ("Given that a large number of medical mobile applications could be actively regulated under the statute using this definition, we appreciate the FDA's decision to use a risk-based approach to regulation.”), http://www. help.senate.gov/newsroom/press/release/?id=2354f485-f387-40c4-80c9-158491f2fdla; see also discussion drafts of HEA reauthorization and the America COMPETES Act, infra notes 34-35. 
well as better deployment of resources that risk-informed regimes can promote. Most proposals, however, only include a brief reference to the concept without fully exploring the analytical foundations for successful adoption and implementation of risk-informed systems—or even clear and comprehensive definitions that precisely define the term.

This paper is intended to fill that void. It provides a vision and framework for prospective risk-informed federal regulatory reform affecting American higher education to create more effective and streamlined oversight and action aligned with the goals of the Higher Education Act (HEA). It is intended to inform and illustrate how risk-informed approaches could work in the regulation of postsecondary education as a foundation for further dialogue regarding specific recommendations that should be considered in the context of the reauthorization of the HEA. ${ }^{4}$ Within the paper:

- Section II provides an overview of the relevant policy landscape that should inform any evaluation of prospective risk-informed regulatory regimes in American higher education. It then provides a definition of risk-informed regulation, elaborating on differences from other regulatory approaches and key elements integral to the successful development of such a regime.

- Section III provides domestic and international illustrations of the incorporation of risk into various regulatory settings.

- Section IV distills key design, implementation, and evaluation principles derived from risk-informed experiences in other sectors and settings. It also provides a beginning list of sample policy areas where risk-informed reform might be undertaken in higher education.

- Section V concludes the paper with recommendations and key questions for policymakers to consider.

The paper also includes two appendices: a prospective "process map" to inform future policy deliberations and a recommended reading list.

To design and implement risk-informed regimes successfully, policymakers, advocates, and practitioners-working together-must be willing to think creatively and to return to first principles for federal regulation (maintaining provisions for strong enforcement when needed). Some existing regulatory provisions will need to make way for more efficient and effective regulatory regimes that can meet the challenges of today and tomorrow. (Meaningful regulation that ensures effective, impactful investment of federal funding in higher education should, of course, be preserved.) In addition, risk-informed regimes may be established in ways that align with performance-based regimes, which are currently the subject of significant exploration and pursuit among various higher education sectors and institutions. ${ }^{5}$

This paper focuses on identifying the models, conditions, and areas for exploration to guide future deliberations

\footnotetext{
4 This paper was developed with the support of Lumina Foundation at the request of the American Council on Education as part of its work with the Task Force on Government Regulation of Higher Education, made up 16 higher education leaders appointed by a bipartisan group of U.S. Senators. It is intended to serve as a resource for the Task Force and to complement its Final Report. In keeping with the Task Force's scope, the paper primarily focuses on the U.S. Department of Education's regulatory regimes under the HEA, but the principles and concepts within the paper may be applied in a variety of other contexts that affect institutions of higher education, such as requirements related to research grants funded by other federal agencies.

5 Although beyond the scope of this paper, the prospective alignment of federally-embedded risk-informed regimes in higher education with performance-based, outcome-centered policies merits further attention - particularly in the context of the much-anticipated reauthorization of the Higher Education Act. See Arthur L. Coleman, Bethany M. Little, Teresa E. Taylor, and Katherine E. Lipper, Getting Our House in Order (publication forthcoming in winter 2015).
} 
among policymakers and stakeholders in the higher education community. It does not propose that risk-informed regimes are a panacea for all regulatory woes. As with any regulatory regime, there are strengths and challenges to successful design, implementation, and evaluation. Those should be fully understood.

Correspondingly, the paper does not present an argument for an immediate and complete overhaul of the entire federal regulatory system to incorporate risk-informed regimes. The graphic below illustrates one way of clustering the major areas of federal compliance for higher education institutions. Only some of these are likely both appropriate and ripe for the incorporation of risk-informed regimes. In some cases, risk-informed systems will never be appropriate. Civil rights enforcement, for example, is based on constitutionally-guaranteed individual student rights - parameters that likely cannot and should not be adjusted based on the level of risk involved. In other cases, data sources and systems are not yet mature enough to support the development of accurate, meaningful risk assessments.

Illustrative Sectors of HEA Institutional Requirements

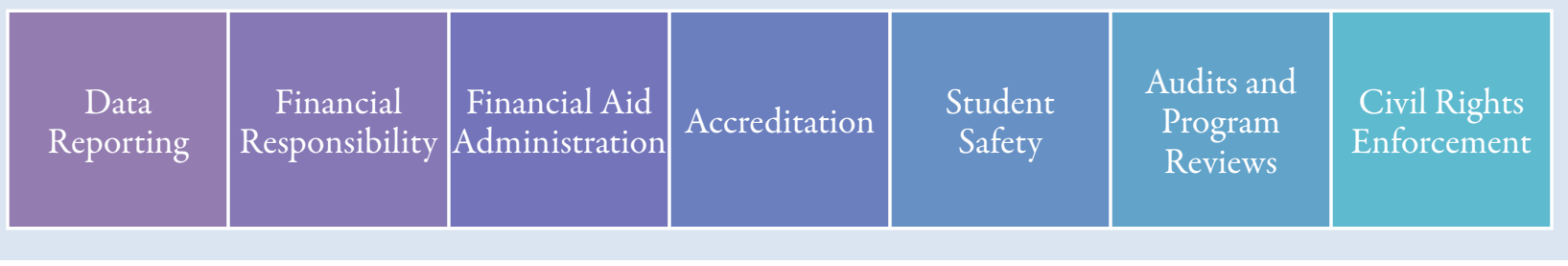

The paper strongly counsels that well-informed deliberation takes place before any risk-informed regime is adopted and implemented. The problems in today's regulatory environment for higher education institutions built up over decades; they will not be solved in a month—or a year. We hope that this paper, however, can serve as a foundation and resource for policymakers and stakeholders in higher education as risk-informed regimes are considered, designed, implemented, and evaluated.

\section{THE RELEVANT EDUCATION LANDSCAPE AND POTENTIAL FOR RISK-INFORMED REGULATION}

\section{A. The Regulatory and Policy Landscape}

American higher education is provided by a vibrant array of colleges, universities, and other providers. More than 7,000 institutions of higher education operate today-an increase of more than 500 in the past decade. ${ }^{6}$ In addition to growth in the sector, many institutions are expanding internally, creating new programs that leverage technology and can respond to the needs of students in a new way, such as competency-based learning models, distance learning opportunities, and prior learning assessments.

The population of students has grown, too, as postsecondary credentials have become increasingly important for sustainable employment. In the fall of 2012, there were 17.7 million undergraduate students and 2.9 million graduate students attending degree-granting IHEs in the U.S. — an almost threefold increase from the 5.9 million students enrolled in postsecondary programs when the HEA was originally passed in $1965 .^{7}$ This growth can be

\footnotetext{
6 Nat'l Ctr. for Educ. Statistics, Fast Facts: Educational Institutions, http://nces.ed.gov/fastfacts/display.asp?id=84 (last accessed Oct. 26, 2014).

7 IPEDS, Condition of Education Report (updated May 2014), http://nces.ed.gov/programs/coe/indicator_csb.asp; Thomas D. Snyder and Sally A. Dillow, Inst. of Educ. Scis, Nat'l Ctr for Educ. Statistics, Digest of Education Statistics 2012 319, t.221 (NCES 2014-015) (2013). The pace of growth has been particularly brisk recently: enrollment at degree-granting institutions increased 32 percent between 2001 and 2011, from 15.9 million to 21 million. Id. at 307. And USED expects overall postsecondary enrollments to increase by 14 percent from 2011 to 2022. U.S. Dep't of Educ., Projections of Education Statistics to 2022, NCES 2014-051, 19 (Feb. 2014), http:// nces.ed.gov/pubs2014/2014051.pdf.
} 
largely attributed to the fact that, in most of today's economy, postsecondary credentials are a pre-requisite to job security and long-term financial health. The pay gap between college graduates and non-college graduates reached a record high in 2013, as those with four-year degrees made 98 percent more an hour on average than people without one. ${ }^{8}$

The federal regulatory regime has also significantly grown and evolved since HEA's original passage - with both Congress and the U.S. Department of Education (ED) adding layers of complexity (and significant burdens) along the way. In exercising its regulatory oversight functions, ED tends to evaluate nearly all institutions in the same way. But consequential institutional differences should be taken into account in regulatory responses, even if systems are framed around common interests and metrics.

Enforcement tools tend to address deficits with blunt, one-size enforcement mechanisms, which can result in less targeted, timely, and effective action. The loss of Title IV eligibility, in particular, would have an enormous impact on students enrolled at an institution, and ED is often justifiably hesitant to use this enforcement tool. But that means that ED might only act in the most egregious cases, and not have the intermediate processes in place to take action that could help mitigate the impact of an identified problem.

Moreover, the regulatory landscape shifts frequently, creating an unstable environment that makes it more difficult for institutions and non-governmental partners to carry out their responsibilities under federal law.

\section{Despite capacity challenges and other limitations, the federal government's influence and involvement in higher education will not abate anytime soon as long as today's high demand for federal financial aid continues.}

\section{The challenge will be how to prioritize and direct federal attention to those areas that merit the most significant oversight. Incorporating risk assessments have significant potential to do just that.}

This uncertainty is pervasive and contributes to unnecessarily high costs and ineffective deployment of limited resources. In 2012 alone, through electronic announcements and Dear Colleague letters, ED issued at least 270 regulatory updates or modifications - more than one change per workday. ${ }^{9}$ At the same time, though Congress has provided ED with various oversight tools (including the authority to close a school immediately), ED uses these tools irregularly and idiosyncratically. In 2013, for example, the Department announced it would levy fines on institutions for alleged violations that occurred in 1995-so nearly two decades passed between the violation and ED's levying of fines. ${ }^{10}$

This complex, unsettled terrain has a significant impact on institutions and their ability to fulfill their primary missions of educating. Regulatory compliance burdens detract from their ability to focus more resources on academic programs and services that directly benefit students. Calculating the cost of federal regulatory com-

\footnotetext{
8 This represents an increase from 89 percent five years earlier, 85 percent a decade earlier, and 64 percent in the early 1980s. David Leonhardt, Is College Worth It? Clearly, New Data Say, N.Y. Times (May 27, 2014), http://mobile.nytimes.com/2014/05/27/upshot/iscollege-worth-it-clearly-new-data-say.html; see also U.S. Departments of Education and Treasury, The Economics of Higher Education 3 (Dec. 2012), http://www.treasury.gov/connect/blog/Documents/20121212_Economics\%20of\%20Higher\%20Ed_vFINAL.pdf (“The median weekly earnings of a full-time, bachelor's degree holder in 2011 were 64 percent higher than those of a high school graduate ( $\$ 1,053$ compared to $\$ 638$ ). The earnings differential grew steadily throughout the 1980 s and 1990 s.")

9 The gainful employment regulations alone spawned 43 separate Dear Colleague letters and electronic announcements further detailing institutional reporting and disclosure requirements. Broad, supra note 2, at 20.

10 Id. at 16.
} 
pliance is challenging-largely because requirements implicate a wide range of administrative staff, institutional leaders, and faculty members - but a few data points exist. A study of financial aid officers found that about two thirds reported that their financial aid office was facing a moderate or severe resource shortage that affected their ability to provide adequate personnel for administering Title IV programs and to provide adequate financial aid counseling for students. ${ }^{11}$ Eighty percent of respondents identified greater regulatory / compliance workload as a "major" factor behind the shortage. ${ }^{12}$ Hartwick College, a liberal arts college in New York, determined in 2012 that it spent about seven percent of its operating budget (nearly $\$ 300,000$ ) annually on federal compliance related activities. ${ }^{13}$ Similar studies have been launched at other institutions recently, including at Vanderbilt University.

It is important to recognize that ED is the smallest of Cabinet-level federal agencies, with limited staff resources. Though the federal aid programs have grown six fold since the early 1980s, ED only employs 0.1 percent of the total Executive Branch workforce, with the number of ED employees quite close to its levels in the late 1970s, before it was a Cabinet-level agency. ${ }^{14}$ Its partners in oversight and accountability—states and recognized accrediting agencies-also have significant capacity challenges. Regulatory breadth strains the system and ED lacks the capacity and expertise to do everything well and in a timely manner. And ED's efforts to delegate additional responsibilities to accrediting agencies has created new burdens that accrediting agencies are not always experienced or equipped to enforce. But the reality is that, despite these capacity challenges and other limitations, the federal government's influence and involvement in higher education will not abate anytime soon as long as today's high demand for federal financial aid continues. The challenge will be how to prioritize and direct federal attention to those areas that merit the most significant oversight. Incorporating risk assessments have significant potential to do just that.

11 Nat'l Ass'n of Student Financial Aid Administrators, Findings from the 2010 NASFAA Administrative Burden Survey (2011), http:// www.nasfaa.org/WorkArea/linkit.aspx?LinkIdentifier=id\&ItemID=3903.

12 Id.

13 This represents $\$ 192,874$ in salary costs, $\$ 30,900$ in direct costs, and \$1 1,515 accreditation costs. Kelly Zack-Decker, Compliance at Hartwick College: A Special Report to the President of the College 4 (Dec. 2012), available at: http://www.naicu.edu/docLib/20130315_Compliance-HartwickColl-12-12.pdf.

14 USED currently has approximately 4,200 employees, compared with 3,000 in 1979-far fewer than the 17,000 projected in 1980 when President Carter elevated USED to a Cabinet-level agency. White House, The Executive Branch, http://www.whitehouse.gov/our-government/executive-branch (last accessed Nov. 3, 2014); U.S. Dep't of Educ., An Overview of the U.S. Department of Education (Sept. 2010), http://www2.ed.gov/about/overview/focus/what_pg2.html; United Press International, Education Department Created, The Palm Beach Post (Oct. 18, 1979), available at: http://news.google.com/newspapers?id=0sZUAAAAIBAJ\&sjid=ejsNAAAAIBAJ\&p$\mathrm{g}=1984,3959160 \& \mathrm{dq}=$ department + of + education\&hl=en. 


\section{B. An Overview of Risk-Informed Regulation}

\section{The Risk-Informed Concept}

Risk-informed systems are best understood as part of a spectrum of regulatory approaches that ranges from subjecting all regulated entities to highly prescriptive requirements to only requiring entities deemed risky to regulatory oversight. ${ }^{15}$ This paper's recommended risk-informed approach is in the middle of this spectrum, as illustrated below. It is also important not to confuse a risk-informed system with a crisis management system, as the former focuses on prioritizing and managing risks while the latter concerns procedures that will be activated when a particular risk comes to fruition.

The more traditional or "deterministic" system uses the same rules and consequences for all regulated entities, regardless of the level of risk they pose. Most federal requirements related to accreditation of institutions of higher education qualify as deterministic. Historically, for instance, in order to grant accreditation status to institutions as a pre-requisite for participation in federal financial aid programs, accrediting agencies must have been recognized by ED, as advised by the National Advisory Committee on Institutional Quality and Integrity (NACIQI). Because an accrediting agency is either recognized or not recognized, all agencies seeking recognition have been required to submit the same documentation for the same level of review.

A fully risk-based system sets a threshold for acceptable risk and only subjects regulated groups to regulation if the regulatory body deems them risky. As a result, regulated entities deemed not risky can completely bypass oversight and enforcement. For example, all agencies in the federal government have used common audit standards that classify federal programs as "major" or "non major" (measured by the level of federal funding for the overall program and for the specific recipient) and then determine whether recipients qualify as "low risk" or "high risk." ${ }^{16}$ If a recipient is granted low-risk status, it is exempted from several federal audit requirements for as long as it undergoes no major changes. ${ }^{17}$ These rules allow auditors to avoid performing time consuming risk assessments for relatively small federal programs, focus their attention on those programs most likely to present problems, and relieve those with strong performance records of some regulatory burdens.

15 These ideas were drawn from a number of scholarly works, particularly Coburn and Weddle, supra note 1; Julia Black and Robert Baldwin, Really Responsive Risk-Based Regulation, 32 L.\& Pol'y 181, 184-85 (2010); and Peter May, Performance-Based Regulation, Jerusalem Papers in Regulation \& Governance Working Paper No. 2(April 2010), http://regulation.huji.ac.il/papers/jp2.pdf.

16 Auditors make a holistic determination of risk using factors including current and prior audit results (e.g., evidence of weak or multiple internal controls and prior audit findings indicates higher risk); results from oversight and monitoring by relevant federal agencies (e.g., monitoring that identified significant programs indicates higher risk; and the inherent risk of the program (e.g., greater program complexity or new programs indicates higher risk). OMB Super Circular $\$ \$ 200.518-520,78$ Fed. Reg. 78590, 78670-72 (Dec. 26, 2013), http://www.gpo.gov/fdsys/pkg/FR-2013-12-26/pdf/2013-30465.pdf.

17 Low-risk entities are only obligated to be audited for the following programs: (1) All major programs not identified as low risk; (2) all non-major programs identified as high risk; and (3) any additional programs to fulfill "percentage of coverage" rules. On the third group of programs, federal auditors are generally required to audit major programs that make up at least 40 percent of the total federal awards expended on the entity. If major programs do not comprise at least 40 percent, the auditor must select additional programs (either major or non-major) to include in the audit. For low risk auditees, the percentage is dropped to 20 percent, meaning that it is less likely that the auditor is required to include additional programs in the audit to fulfill the percentage of coverage rule. Id. at $\$ 200.518$ (f); see also Am. Inst. of CPAs, OMB Circular A-133 Audit Refresher -Major Programs (2008), http://www.aicpa.org/interestareas/governmentalauditquality/resources/ombcirculara133/ombcirculara-133auditrefresher-majorprograms/pages/default.aspx. 


\section{Understanding the Risk-Related Regulatory Design Spectrum}

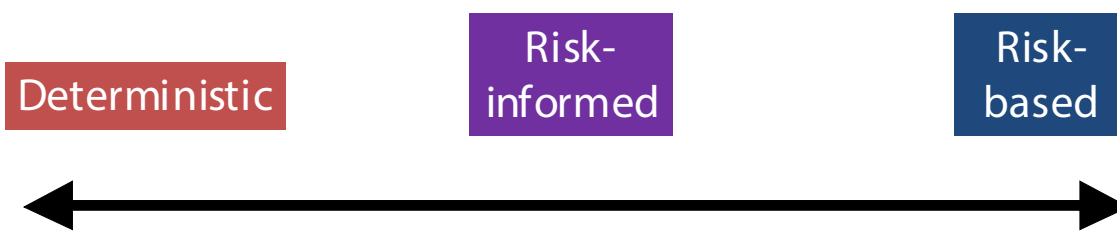

Uses the same rules
and consequences
for all regulated
entities, regardless
of the level of risk
they pose

\begin{tabular}{|} 
Requires all \\
regulated entities to \\
follow some \\
baseline rules, but \\
requirements will \\
differ based on the \\
nature of risk \\
presented by \\
different entities
\end{tabular}
Sets a thre shold for acceptable risk and only subjects regulated entities to regulation if deemed risky

A risk-informed system adopts a hybrid approach, combining risk-based enforcement mechanisms with baseline deterministic regulatory rules. All regulated groups must follow those baseline rules and submit to a preliminary risk assessment, but the regulatory response will differ based on the degree of risk presented by different groups. Systems vary, but risk-informed systems commonly involve targeting enforcement resources on the basis of assessment of risk that a regulated entity poses to the regulator's objectives—which may be paired with additional requirements for supplying information on those entities that pose greater risks. Several examples of this approach are provided in Section III.

To illustrate differences between these regimes, imagine an obstacle course that a set of Army recruits must complete to be eligible for active duty. The "risk" here would be that recruits would fail to perform in active duty, putting themselves and their fellow soldiers in danger. A traditional regulatory or deterministic system would require all recruits to complete the obstacle course regardless of past performance or ability. On the other end of the spectrum, a risk-based system would require only those recruits with certain risk factors to complete the obstacle course, such as failure to complete prior physical tests, existing health conditions, or other indicators that they may be less able to serve effectively as an active solider. Between the two extremes, risk-informed system would require all recruits to pass through a portion of the obstacle course, but require only those recruits with identified risk factors to complete a second portion. (This portion would be optimally designed to test different levels of risk for different recruits, such as an extra climbing exercise for recruits with a fear of heights, an extra weight lifting exercise for recruits with less demonstrated strength, or an extra leadership exercise for recruits who did not participate sufficiently in prior group activities.)

Extending this illustration to a higher education setting, a risk-informed system might require all institutions to overcome a baseline "obstacle" of key reporting and data collection requirements, as well as a confirmation of accreditation status and state authorization. For those institutions with indicators of risks of financial instability, additional assurances may be appropriate to ensure that the institution's financial health is sufficient to support its students. (Indeed, ED already has a requirement similar to this.) For institutions with a low graduation rate, additional information on transfer rates may help to overcome concerns about the institution's graduation rate. 


\section{Core Functions Within Risk-Informed Regimes}

Determining whether to pursue the development of a risk-informed regime requires comprehensive understanding of the primary functions in these systems. ${ }^{18} \mathrm{~A}$ review of the frameworks behind risk-informed regimes in several countries found that, despite significant variation in the details, five functions are common: ${ }^{19}$

1. Defining the purpose and goals of the system in terms of specific risks. It is important to distinguish overarching, big picture risks from the specific, measurable risks that go into a risk-assessment. Some risk will always be present within the system, and this step should focus on defining the precise risk that the regulatory regime seeks to assess and avoid. For example, ED's financial responsibility requirements for institutions (described in detail on page 24) are intended to assess the specific risk of imminent closurenot a general examination of whether an institution is financially responsible.

2. Determining the responsible agency or organization's own risk appetite. This step has proved to be "extremely challenging" for regulators and their non-governmental partners responsible for risk-informed regimes. ${ }^{20}$ Political risks-including reactions from politicians, the media, stakeholders, and the general public - are always present, and may be particularly strong in the design and early implementation stages.

3. Assessing the risk and its likelihood of occurrence. Two broad categories of risk are usually involved in a risk assessment: (1) risks inherent to activity within the sector; and (2) individual entities' efforts to manage and control those risks. ${ }^{21}$ Though they can be combined in different ways, inherent risks and management/control risks work together to provide a complete picture of the risks posed by an individual entity. Metrics for these risks should center on what really matters within the regime-and what is most appropriate for the responsible agency or regulatory partner. Some regimes are highly quantitative (e.g., financial responsibility ratios) while others may be more qualitative and, therefore, rely more on the informed professional judgment of those performing the risk assessment (e.g., accreditation). ${ }^{22}$

4. Assigning scores or ratings to regulated entities on the basis of risk assessments. Many systems use relatively simple "red," "yellow," and "green" categories to differentiate different levels of risk (one example of this is given on the next page). Others have a more granular system with many categories; the Financial Services Authority in the United Kingdom, for example, has 15 different categories. ${ }^{23}$ Ideally, data and information necessary for risk assessments can be acquired through existing mechanisms to avoid new compliance burdens.

\section{Linking regulatory responses and resources to scores or ratings categories (for individual regulated} entities and/or for system-wide issues. Regulatory responses should be targeted at providing support to address identified problems and imposing more significant consequences for egregious or repeat violations. Generally, requirements should be loosened when low risk is presented and should be tightened when medium or high risk is presented.

Additionally, ongoing monitoring and evaluation of the system and its effects is essential, with particular focus in early years to allow for fine-tuning.

\footnotetext{
18 These functions presuppose that an appropriate issue or program area for risk-informed regulation has been identified. Not all areas of a system will be optimal candidates for a risk-informed regime. Implementation should only take place in areas where appropriate foundations are present (e.g., legal authority, sufficient data systems, and stakeholder support).

19 Black and Baldwin, supra note 15, at 184-85.

20 Id. at 184 .

21 Id.

22 Id. at 185.

23 Id.
} 
Fully developed risk-informed systems are usually graphically depicted to illustrate how risk and regulatory response relate under different conditions. The Financial Services Commission of Ontario (FSCO) developed the graphic on the next page to show how impact and probability guide risk assessments and regulatory responses. ${ }^{24}$

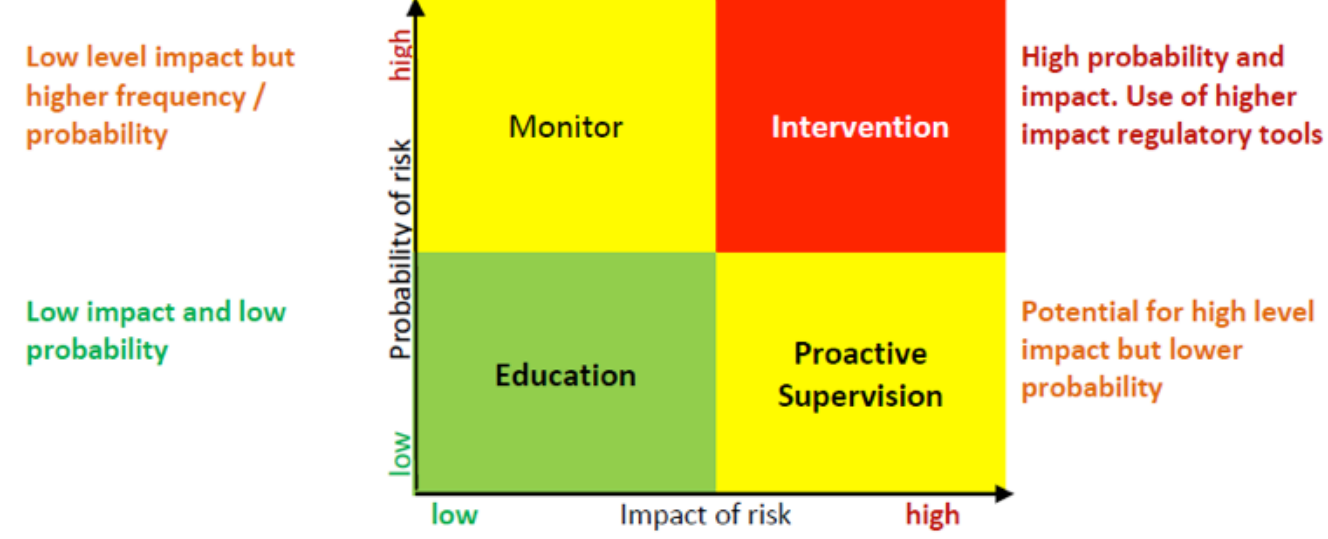

The FSCO defines "green" entities as those that present low probability and low impact risk. This group is required to support that determination, but—once that determination is made—need not do more. In such cases, FSCO only provides general updates and communications; no specific plan to engage individual entities within this category exists. For "yellow" entities that present low probability but high impact of risk, FSCO proactively supervises through ongoing monitoring, regular reporting, and possibly site visits. For the other "yellow" entities that present high probability but low impact risk, FSCO will monitor with less rigor that the low probability / high impact group (given that the impact of risk is lower), but will regularly monitor and engage on specific issues identified. "Red" entities present high probability and high impact risk. Because these entities present such a significant danger, they require the most FSCO time and effort through regular interactions, proactive measures to mitigate risks, site visits, and-in egregious cases—enforcement actions.

The regulation of scientific laboratories provides a useful illustration of these concepts. ${ }^{25}$ A laboratory with "high impact" risk involves experiments with highly hazardous materials such as plutonium or uranium. In those cases, the danger to the public is high enough to merit proactive regulatory supervision, even if the laboratory only has a handful of researchers. A laboratory with "high probability" risk might involve many researchers working on many experiments. These projects may not involve highly hazardous materials (so the impact of the risk is low), but the frequency and number of experiments increases the probability of something going wrong. In those cases, regulatory monitoring is appropriate to keep an eye on potential problems. When both risk conditions are present—highly hazardous materials with a large number of experiments and researchers involved—regulators and their non-governmental partners may need to intervene with stronger regulatory tools to protect public safety. But when neither risk condition is present-no highly hazardous materials and a smaller number of experiments and researchers involved-regulators likely only need to ensure that those laboratories receive appropriate education about regulatory changes and other key developments.

These concepts can also be applied to higher education. One example might involve assessing the risk of students

${ }_{24}$ Financial Services Commission of Ontario, Risk-Based Regulation: Framework Document 4 (2011), http://www.fsco.gov.on.ca/en/ pensions/fsco_consultations/Documents/Framework_Final.pdf.

25 The principles undergirding this simple illustration are reflected more robustly in several federal statutes, including the Occupational Safety and Health Act, the Resource Conservation and Recovery Act (which governs the safe generation, storage, transport, and disposal of hazardous chemical waste), and the Clean Air Act and Federal Water Pollution Control Act. See The Nat'l Acads Press, Prudent Practices in the Laboratory: Handling and Disposal of Chemicals 198 (1995). 
at an institution eventually defaulting on their loans. At a very basic level, those colleges and universities with a large number of students taking out loans would have a higher probability of default, while those with very high tuition or very high borrowing amounts would have a higher impact of default because repayment would be a more significant financial burden. (Additional risk indictors could be built into a system, but these indicators are provided simply for illustrative purposes.) Regulatory responses by ED and its partners could be designed to focus most on those institutions with both risk conditions present, while designing supportive monitoring and supervision efforts for those institutions with one of the risk conditions present.

\section{Benefits and Costs}

When considering the plausibility of pursuing a risk-informed regime, the potential benefits and challenges inherent to that model should be fully understood. ${ }^{26}$ Fundamentally, the approach provides an opportunity to realign regulatory requirements with the primary risks that rules and regulations are intended to prevent. Correspondingly, these regimes allow regulators and their non-governmental partners to acknowledge differences among regulated entities and to develop more systematic responses to the variety of unique circumstances presented within a regulatory area.

At the same time, however, these regimes require significant investment in the design process, particularly in identifying appropriate metrics and thresholds. Though most stakeholders are likely to embrace risk-informed regulation conceptually, that support can evaporate when the work of setting metrics and thresholds actually takes place - particularly if a metric or threshold is likely to place an entity or group in a higher risk category.

Finally, risk-informed regimes are intended to reduce burden for strong performers and to increase it when performance is lagging (according to a range of different responses). But this may implicate significantly more regulatory activity and responsibilities for regulators and their non-governmental partners, particularly in the early years of transition to the new system. These challenges do not negate the benefits-but policymakers should approach risk-informed regimes fully aware of the potential investments that are certainly implicated and the downsides that may be centrally relevant to any such endeavor.

26 This discussion was informed significantly by several scholarly sources, particularly Coburn and Weddle, supra note 1; Baldwin and Black, supra note 15; Financial Services Commission of Ontario, supra note 24; as well as the various U.S. and international models discussed in Section III infra. 


\section{Risk-Informed Decision Making in American Higher Education}

Incorporating risk into decision making is not foreign concept to American higher education. Indeed, many colleges and universities already embed risk assessments into strategic planning efforts and employ a chief risk officer. Many even develop their own impact versus probability charts similar to the graphic on page 10 to determine which risks to accept, monitor, or mitigate and control. And, as a response to institutions' tendency to focus on risk only in the negative, the University Risk Management and Insurance Association (URMIA) was founded by various U.S. institutions to promote a more positive view of risk management in universities.

Moreover, accrediting agencies - key actors within the federal regime who address issues of institutional and provide quality - have begun to incorporate risk into their accreditation decision making process. For example, the Western Association of Schools and Colleges Senior College \& University Commission (WASC Senior) has developed considerable variability in its responses to findings of accreditation reports similar to the "red-yellow-green" responses described earlier in this paper. Depending on the level of strength (and level of risk, determined holistically), WASC Senior varies the term of years before the next required accreditation review cycle from seven to ten years. For institutions demonstrating a need for close monitoring, WASC Senior has tiers of follow-on requirements (e.g., progress reports, special visits, and notices of concern).

These developments in the higher education community illustrate the appeal of incorporating risk into the regulation of higher education. The concept is already familiar to the regulated community of institutions and has been a useful tool for these complex organizations to bring greater prioritization and focus to their work. It comes as little surprise, then, that the concept has been endorsed in current postsecondary legislative proposals. One draft HEA reauthorization bill calls for ED to conduct "risk-based reviews" for at least two percent of IHEs for program reviews (and names several conditions for prioritization of reviews). And draft bill to reauthorize the COMPETES Act includes a provision that requires the study of risk-based regulatory procedures for determining requirements for evaluation requirements for federal research awards.

\section{HOW RISK-INFORMED AND RISK-BASED REGULATORY APPROACHES HAVE BEEN PURSUED AND APPLIED IN OTHER SETTINGS}

Before launching into recommendations for new risk-informed regimes in the regulation of higher education, a careful examination of more mature risk-informed systems is called for. At a basic level, these illustrations bring this paper's general discussion of the functions and design elements to life. And understanding these systems, both in design and execution, can significantly enhance perspectives regarding the prospective improvement of our higher education system - may help inform the identification of viable areas of higher education regulation that are strong candidates for adoption of new risk-informed systems. This section explores existing risk-informed and risk-based systems in multiple sectors in the U.S as well as risk-informed systems being developed in postsecondary regulatory systems in Australia and the United Kingdom.

\section{A. Illustrations from Other Sectors}

Risk-informed and risk-based systems have their origins in the latter decades of the 20th century, when industrialized nations became more interested in deregulation initiatives and a shift toward the private sector-style management methods including the use of cost-benefit analyses. The Nuclear Regulatory Commission provided early leadership in the field of American regulation, while the Basel Accords on requirements for capital systems 
led the way internationally through a voluntary series of agreements. Today, risk-informed approaches have been established or are emerging in a variety of sectors, including the regulation of scientific laboratories and health information technology firms.

Risk-informed regulation has been used in some form by the Nuclear Regulatory Commission (NRC) since the late 1970 s. $^{27}$ Its status as an early adopter and decades of experience with these systems make the NRC an appropriate starting point. Indeed, the NRC conducted a rigorous review of regulatory approaches before adopting its risk-informed system, which has served as guidance for this paper and for many others on risk-informed regimes. ${ }^{28}$ The NRC's risk policy mandates that the risk of cancer fatalities of people living near a nuclear power plant cannot exceed 0.1 percent of the sum of cancer fatality risks from all other sources, and licenses will only be given to power plants who meet the requirements in the policy for an acceptable level of safety to the public. ${ }^{29}$ The Commission complements these requirements with regulations based on probabilistic risk assessment (PRA) to assess the likelihood and consequences of severe reactor accidents.

The Federal Reserve Board oversees a risk-informed capital system that weighs the risks inherent in the different types of loans offered by a bank and determines how much capital a bank needs to possess in order to be protected upon default. This system is part of a voluntary, global effort that started in the 1970s in response the increasing internationalization of economies and capital flow—and the large foreign currency losses many banks were experiencing when the system allowed a bank to have three times the exposure in foreign markets than its available capital. ${ }^{30}$ Foundations were laid during a 1975 meeting of the G-10 countries, followed by successive Basel Capital Accords among many countries. ${ }^{31}$ "Basel III" is currently being implemented, which includes significant changes to respond to banking strategies that led to the global financial crisis. ${ }^{32}$ Notably, the same problem that led to Basel I-too much exposure and not enough capital—was a significant reason for the financial crisis in 2007-09. ${ }^{33}$ This history demonstrates the importance of remaining grounded in the original purpose of the system, but revising standards and metrics to meet new challenges.

The success of the Basel Accords has led to risk-based capital rules being expanded to financial institutions in the U.S. other than banks. The National Association of Insurance Commissioners, a standard-setting and regulatory support system created by the insurance regulators from each state, also employs a risk-based capital system based on the Basel Accords to ensure that insurance companies have adequate levels of capital. ${ }^{34}$ And other countries have expanded Basel principles even further, with some converting all financial regulation to a risk-based system.

Since 1976, the Food and Drug Administration (FDA) has used a risk-based approach to classify medical devices, using the degree of control necessary to assure the safety of effectiveness of the devices as a risk barometer. ${ }^{35}$ The

27 Coburn and Weddle, supra note 1.

28 William D. Travers, Risk-Informed and Performance-Based Regulation (March 1, 1999), http://www.nrc.gov/reading-rm/doc-collections/commission/srm/1998/1998-144srm.pdf.

29 U.S. Nuclear Reg. Comm'n, Fact Sheet on Nuclear Reactor Risk (June 30, 2014), http://www.nrc.gov/reading-rm/doc-collections/ fact-sheets/reactor-risk.html.

30 Bank for Int'l Settlements, History of the Basel Committee, http://www.bis.org/bcbs/history.htm (updated Oct. 28, 2014).

31 Id.; Capital Standards for Banks: The Evolving Basel Accord, Fed. Reserve Bulletin 395 (Sept. 2003).

32 Basel Comm. on Banking Supervision, Basel III: A global regulatory framework for more resilient banks and banking systems 2 (rev. June 2011), www.bis.org/publ/bcbs189.pdf.

33 Id.

34 Nat'l Ass'n of Insurance Comm'rs, Risk Based Capital General Overview 1 (2009) http://www.naic.org/documents/committees_e_capad_RBCoverview.pdf.

35 The statutorily created device classes are: (1) Class I devices are generally low risk and are mostly exempt from premarket review and are subject—unless exempt - to the requirements for reporting of adverse events, manufacturing and design controls, registration and listing, and other "general" controls. Surgical apparel and surgeon's gloves are examples of Class I devices. (2) Class II devices implicate 
FDA has created a comprehensive listing of about 1,700 types of medical devices, each of which has been assigned one of three risk categories. The success of this approach led Congress to instruct the FDA, in consultation with other relevant federal agencies, to propose a strategy and recommendations on "an appropriate, risk-based regulatory framework pertaining to health information technology, including mobile medical applications, that promotes innovation, protects patient safety, and avoids regulatory duplication for a health information technology (health IT) framework." ${ }^{6}$ The resulting report proposes to clarify oversight of health IT products based on a product's function and the potential risk to patients who use it. ${ }^{37}$ The report makes an instructive observation for many sectors in its discussion, "Ultimately, the Agencies recognize that any categorization scheme will be imperfect and may need to adapt over time. Nevertheless, we believe that this proposed functional categorization can both assist the Agencies in avoiding regulatory duplication and prompt meaningful policy discussions with stakeholders to identify and clarify unresolved areas of ambiguity." 38

\section{B. International Examples in Postsecondary Education}

Even though important contextual differences exist, experiences in other countries can be useful illustrations of how the design and implementation of risk-informed regimes has worked in practice. This section explores systems in Australia and the United Kingdom.

\section{Australia}

In Australia, the Tertiary Education Quality Standards Agency (TEQSA) began operating in 2012 as the national quality standards agency for the 37 public institutions, four private institutions, and 131 other providers that make up the Australian system of higher education. ${ }^{39}$ TEQSA's establishment followed on the opening of Australia's public institutions in 2009 to a "demand-driven" system as caps on bachelors-degree enrollment were removed and institutions were allowed to increase enrollment based on student demand. ${ }^{40}$

Under TEQSA, Australian degree-granting institutions have the authority to self-accredit their courses through academic boards or similar internal bodies. But they must do so under the Higher Education Standards Frame-

generally moderate or well-understood risks, are subject to general controls, are usually subject to premarket review, and subject to enumerated "special controls" that are closely tailored to the specific risks presented by that particular device type. Ear, nose, and chin prostheses are examples of Class II devices. (3) Class III: Devices that generally present high or poorly understood risks. In addition to general controls, Class III devices are subject to premarket approval and certain other regulatory controls. A special injectable paste designed to augment or reconstruct a vocal cord is an example of a Class III device. Food and Drug Admin. (FDA), Overview of Device Regulation, http://www.fda.gov/MedicalDevices/DeviceRegulationandGuidance/Overview/default.htm (last updated June 26, 2014); FDA, Device Classification Panels, http://www.fda.gov/MedicalDevices/DeviceRegulationandGuidance/Overview/ClassifyYourDevice/ucm051530.htm (last updated June 26, 2014); FDA, FCC, ONC, FDASIA Health IT Report: Proposed Strategy and Recommendations for a Risk-Based Framework 29, n.76 (April 2014), http://www.fda.gov/downloads/AboutFDA/CentersOffices/OfficeofMedicalProductsandTobacco/CDRH/CDRHReports/UCM391521.pdf.

36 FDASIA Health IT Report, supra note 42, at 3.

37 The three risk categories within the proposed system are: (1) Products with administrative health IT functions that pose little or no risk to patient safety and thus require little to no additional oversight or attention (e.g., software for billing, claims processing, and scheduling). (2) Products with health management heath IT functions that pose sufficiently low risk so they do not require significant oversight (e.g., software for health information and data management, electronic access to clinical results, and clinical decision support software). For this category, the FDA proposes relying primarily on coordinated regulatory activities among different agencies, supported by private sector capabilities, and tools for testing, certification, and accreditation. (3) A final group of products with medical device health IT functions that pose greater risks to patients if they do not perform as intended (e.g., computer-aided detection software, software for bedside monitor alarms, and radiation treatment software). The FDA proposes to continue regulating these products as it currently regulates all health IT functions. Id. at 11-13.

38 Id. at 11 .

39 Hon. Dr. David Kemp and Andrew Norton, Review of the Demand Driven Funding System -Final Report 77 (2014), http://docs. education.gov.au/system/files/doc/other/review of the demand_driven funding_system_report for_the website.pdf.

40 Discussion of the Australian system was informed by an interview with Andrew Norton, co-author of the report cited in note 34, and several representatives of Australian institutions, which took place on October 22, 2014. Notes from the interview on file with the authors. 
work and they must be registered annually with TEQSA. (TEQSA also approves each course at most non-institution providers through a separate process.)

TEQSA's actions represented a significant change for Australian institutions because, prior to 2012, most regulation was conducted through state governments. Though states took different regulatory approaches (some were more expansive than others), they generally adopted a very light touch regulatory approach. But in the first decade of the 21 st century, Australia - like the U.S. - saw a large expansion in the higher education and vocational training sectors driven by growing student populations (particularly international students) and demand for financial aid. The failure of some new institutions and some questionable student recruitment practices led to increased scrutiny of oversight regimes for institutions. A review in 2008 of Australia's postsecondary funding system triggered a broader legislative effort to create a more rigorous national system of regulation by enhancing requirements that public institutions participate in a national quality agency's review process as a condition for qualifying for student aid from the national government. Policymakers also saw a more rigorous quality control system as a precondition for expanding aid programs to students at private institutions.

Notably, risk assessment was embedded in the TEQSA bill by the Australian Parliament on the recommendation of the higher education community. ${ }^{41}$ An early bill would have created a much more prescriptive agency to mirror Australian agencies in other sectors. The Australian higher education sector responded by proposing that regulation be determined in proportion to risk. The final law was initially seen as a victory by Australian institutions.

Under that law, TEQSA's review process for degree-granting institutions includes an initial review using three guiding principles: risk assessment, proportionality, and intervention only when necessary. Through its risk assessment framework and the use of risk assessments, TEQSA aims to:

- Reduce regulatory burden by using risk assessments to inform a differentiated approach to evidence and reporting requirements;

- Strengthen the protection of students' interests and the sector's reputation by monitoring key aspects of providers' operations during review periods;

- Encourage TEQSA case managers and providers to engage early with providers about emergent issues; and

- Support quality improvement by sharing information with providers about potential risks and good practices in the sector. ${ }^{42}$

Importantly, TEQSA uses risk assessments to identify potential risks of non-compliance (or "leads" that warrant additional consideration by TEQSA case manager) — not to draw conclusions about compliance with regulatory or other legal standards. ${ }^{43}$ Instead, TEQSA uses the risk assessment as a basis for determining how to respond to providers based on the issues identified in the risk assessment.

TEQSA defines risk in four key areas: (1) regulatory history and standing; (2) student profiles and outcomes (measured by student load, student attrition rate, progress rate, completions, student satisfaction, and graduate

41 Incorporation of risk in TEQSA's process was partially due to the fact that, during the global financial crisis, Australia's banking system survived mostly intact - which much of the Australia public attributed to Australia's risk-based financial regulatory system. This public sentiment influenced the Australian government's reauthorization of higher education-related legislation in 2011. TEQSA, A Snapshot of TEQSA (2013); Self-Accrediting Authority, TEQSA (2012), http://www.teqsa.gov.au/for-providers/self-accrediting-authority.

42 Australian Government Tertiary Education Quality and Standards Agency, TEQSA's Risk Assessment Framework Version 2.02

(March 2014), http://www.teqsa.gov.au/sites/default/files/publication-documents/TEQSARiskAssessFramework2014_0.pdf.

43 Id. 
destination); (3) academic staff profile (measured by qualifications of senior academic leaders, student to staff ratio, and academic staff on casual work contracts); and (4) current and historical financial viability. TEQSA has developed a list of specific risk indicators for each area ${ }^{44}$ and TEQSA's evaluation uses a simple rating system of high, moderate, or low risk (represented by traffic colors) for each.

Risk thresholds are considered in the context of other information and are not the sole determinants of risk. For annual risk assessments of institutions, TEQSA considers past and present documentation and reference material, statistical analysis of the sector, experience from previous risk cycles, and any special considerations related to the nature of the indicators. ${ }^{45}$ TEQSA keeps the actual numeric thresholds confidential, but does publish its standard thresholds. ${ }^{46}$ Providers are thus aware of general expectations and what data and information will be assessed, but are unaware of the precise point at which their risk drops below a risk threshold.

TEQSA combines the information from these sources and makes a judgment about the risks of the provider against the identified threshold. Importantly, TEQSA's overall evaluation examines both risk to an institution's students and risk to its financial position. ${ }^{47}$ TEQSA calculates risk holistically, meaning even when a higher education provider falls below a threshold, success in other priority areas may balance the provider's overall quality, eliciting less or no regulatory response from TEQSA. ${ }^{48}$ From this rating, TEQSA takes one of the following five steps:

1. Formal regulatory action outside the scheduled review process, e.g., undertaking a compliance assessment or imposing formal conditions on registration for institutions

2. Consideration of issue during scheduled regulatory review

3. Formal request for information

4. Recommendation that the institution carefully monitor and/or put into place appropriate controls or improvement strategies

5. No action ${ }^{49}$

TEQSA keeps its risk assessments confidential, and only shares them with providers if the institution receives an overall moderate or high risk rating, has significant gaps in data (or otherwise causes TEQSA to have no confidence in the data), requests a copy, or faces registration renewal. ${ }^{50}$ Because of this—and the fact that TEQSA relies on existing information in its systems (e.g., providers' annual reporting requirements) - burdens on providers are limited. In many cases, providers do not have any responsibilities to interact with unless there is an identified issue. In other words, low-risk providers have very low burdens related to TEQSA's risk assessment.

TEQSA's early years have not been without controversy. Australian institutions broadly endorsed these design elements (including the incorporation of risk-informed regimes), but believed that TEQSA pushed an overly prescriptive interpretation of statutory requirements, mandating significant new reporting requirements and pouring significant staff time into institutional reviews that went beyond the intentions of the Parliament. ${ }^{51}$

44 Id. at Appendix 1.

45 Id. at 6.

46 Id.

47 Id. at 5 .

48 Id.

49 Id. at 8.

50 Id. at 4 .

51 Part of the challenge for the longstanding public institutions is that they had long enjoyed very light regulation and a reputation for quality. But, when TEQSA was established, institutions suddenly had to provide data and information to support their claims of quality. 
Another challenge was that TEQSA had been established before Australia's national standards for postsecondary quality were revised (a process that has now been initiated), meaning that TEQSA lacked important foundations to justify its more outcomes-oriented approach. As a result, the Australian Parliament commissioned a study of TEQSA's performance, which concluded, “TEQSA, while subject to criticism for bureaucratic over-reach, is now effectively preventing sub-standard higher education courses in both public and private institutions. The existence of a system of standard setting, with appropriate monitoring and enforcement, has a significant bearing on any decision to expand the scope of the demand driven system." 52

As a result of the report and mounting political pressure, several actions were taken to reduce burdens on institutions and to streamline TEQSA processes. TEQSA deemed 2013-14 the "year of reform" and reduced evidence requirements by tailoring assessment processes for low risk providers; reduced timelines for completing course accreditation and re-accreditation assessments; and reduced annual risk assessment requests for information by drawing on existing data. ${ }^{53}$ TEQSA has also increased its efforts to engage with the higher education sector. Finally, significant personnel changes have taken place in 2014, with the founding chief commissioner of TEQSA placed on leave in June 2014 and the agency staff significantly downsized-deliberate decisions to force TEQSA to focus its review process on the most essential elements.

Notably, the concept of risk within the TEQSA system has not been the target of critics and remains a regulatory concept that both the government and institutions support. ${ }^{54}$ The challenge for TEQSA now will be to develop proportional procedures that reduce burdens on low risk providers and focus agency resources on high risk providers.

\section{United Kingdom (U.K.)}

The British context mirrors that in Australia in two key ways. First, the U.K. is currently moving toward a more "market-based" system of higher education that allows for enrollment in institutions to be based not on pre-allotted quotas but on student demand. Second, Higher Education Funding Council for England (HEFCE) — a public body not situated in any government department or agency—is moving toward a risk-informed system in which regulators will conduct fewer and less frequent reviews on institutions that have long records of quality in higher education and more thorough and frequent review of institutions with short records or records lacking quality. ${ }^{55}$

HEFCE acts as a broker between institutions and the U.K. government with authority to determine the conditions for government funding for institutions and to distribute those funds. ${ }^{56}$ Under a new framework released in

52 Kemp and Norton, supra note 46, at 3. Other specific findings from the report included:

- All existing institutions "aware that their actions and performance, including any rapid expansion under the demand driven system, are potentially subject to scrutiny from TEQSA."

- Though not a formal complaint resolution agency, TEQSA keeps records of complaints and, when "multiple credible complaints suggest there may be a significant problem, TEQSA is able to investigate further."

- New institutions and providers face "a very significant barrier to entering the higher education system" by virtue of TEQSA's registration process.

- TEQSA's standards are rigorous, and the body "has rejected provider registration and course approval requests that do not meet the standards and has applied conditions to other approvals to ensure that the standards are met." The report concludes, "This third-party scrutiny contributes to our confidence that Australia's higher education system can accommodate increasing numbers of students and higher education providers without compromising quality."

53 Australian Government Tertiary Education Quality and Standards Agency, TEQSA Annual Report 2013-14 2 (tabled in Parliament Oct. 24, 2014), http://www.teqsa.gov.au/sites/default/files/publication-documents/TEQSA2014AnnualReport_FullReportWeb.pdf.

54 Norton et al. interview, supra note 47.

55 UK Dep't of Bus., Innovation and Skills, Higher Education: Students at the Heart of the System 10 (2011).

56 HEFCE, Memorandum of assurance and accountability between HEFCE and institutions: Terms and conditions for payment of 
the summer of 2014, HEFCE includes confidential risk assessments as conditions of funding. These assessments use institutions' annual accountability reports (a requirement for funding eligibility), outputs of the institution's internal and external auditors, information from other public bodies, and HEFCE's own audit and assurance work..$^{57}$ Results are provided to the applicable institutional leaders. ${ }^{58}$ These risk assessments will normally remain confidential for three years, and then be released to the public. HEFCE considers this three-year period to be an appropriate period of time to allow institutions found to be high risk to address issues and reduce its classification. $^{59}$

HEFCE judges an institution to be "at higher risk" when, on the basis of all available evidence, it:

- Faces threats to the sustainability of its operations, either immediately or in the medium term,

- Has serious problems relating to value for money, propriety or regularity (that is, whether funds are used for the purpose intended), or

- Has materially ineffective risk management, control, or corporate governance.

When it judges that an institution "does not meet" or "requires improvement to meet" its standards then fails to make the necessary improvements through a relatively low-burden follow-up process, HEFCE will step in and require regular meetings. HEFCE has explained that its greater involvement in such cases is justified "because it has a clear regulatory interest to ensure that [institutions] in receipt of public funds provide value for money and are responsible in their use of these funds." ${ }^{60} \mathrm{HEFCE}$ expects institutions in this process to improve. If improvements do not occur, however, HEFCE may apply sanctions in "exceptional" cases, including the withdrawal of some or all HEFCE funding.

Implementation has gone more slowly than initially proposed due to the concern from the field that the categorization and ranking of higher education institutions could pose political challenges, could create a large burden from initial investment as regulated groups compile the necessary data, and could place more regulatory burdens on new institutions than under the old regulatory scheme. ${ }^{61}$ Though HEFCE has implemented the new risk assessments, it is still working with stakeholders to determine appropriate risk thresholds. ${ }^{62}$

\section{PRINCIPLES TO GUIDE ACTION AND PROSPECTIVE RISK-INFORMED REGIMES TO CONSIDER}

Developing effective risk-informed regimes that are a net benefit to regulators, their non-governmental partners, and the regulated community requires a significant investment of time and resources from many different stakeholders. Any new regimes will likely take many months to be designed and many years to mature. Moreover, new or enhanced risk-informed regimes are likely to require traditional regulatory structures to give way to new requirements and processes. And they will need to be coherently integrated into a larger regulatory regime that

HEFCE grants to higher education institutions 1 (June 2014), http://www.hefce.ac.uk/media/hefce/content/pubs/2014/201412/ HEFCE2014_12.pdf.

57 Id. at 20-21.

58 Id.

59 HEFCE does allow for limited release of risk assessment results before the three years have elapsed in two exceptional cases: (1) if other public funders and other regulators to need the results to make their own assessments of risk, or (2) if the National Audit Office needs to discuss the results at the Public Accounts Committee or disclose them in a published report. Additionally, HEFCE will make results public (after notifying institutions) at any stage if it has "strong grounds for believing that it is in the collective student or the public interest to do so." Id. at 4-5.

60 Id.

${ }^{61}$ Roger King, The Risks of Risk-Based Regulation: The Regulatory Challenges of the Higher Education White Paper for England 3-7 (2011).

62 See HEFCE, supra note 63. 
will likely include other non-risk-informed provisions. In addition, regulators and the regulated community must have confidence in each other that the new regime will be designed and implemented - and responded to by institutions -in good faith. Otherwise, prospects for success are likely slim. Policymakers should initiate this process, therefore, with clear eyes about what new legislation or regulation will precipitate and what investments and commitments from various stakeholders will be required.

This section provides guiding principles for developing risk-informed systems, starting with the conditions that must be in place before starting the process and then exploring key factors for system design, implementation, and evaluation and improvement. ${ }^{63} \mathrm{~W}$ ith these principles in place, the second half of this section identifies prospective opportunities for risk-informed regimes within the current federal postsecondary regulatory system.

\section{A. Guiding Principles}

Based on the theory associated with risk-informed regulation and lessons that have emerged during the implementation of other regimes, we have identified the following principles to inform the assessment of necessary prerequisite conditions and to guide action for the development, implementation, and continuous improvement of specific risk-informed regimes. These principles are intended to be applied in specific, discrete regulatory contexts-not to guide the complete overhaul of the federal regulatory system for institutions of higher education.

And it is important to understand the difference between the fundamental risk in the federal regulation of higher education and the specific risks that provide the foundation for risk-informed regimes. The fundamental risk entailed in the federal regulation of higher education is tied to the federal investment in financial aid and the desire to protect students and to be a good financial steward for the taxpayers' dollars. In other words, the overall risk in the system is that students use federal financial aid (and, therefore, taxpayer dollars) to pay for low quality postsecondary programs that do not enhance their professional prospects. This broad risk should motivate all of federal regulation of institutions. But it is essential to distinguish this broad risk from the specific risks that must be identified for risk-informed regulatory regimes. In those cases, the risk must be related to a more specific problem that is directly tied to a particular area of regulation, e.g., the risk of mismanaging federal financial aid dollars through problematic disbursement or refund processes.

Necessary prerequisite conditions (i.e., conditions that must be in place before any risk-informed regime is even considered)

- A risk-informed regulatory regime should only involve areas where regulators have clear authority to develop a risk-informed regime or significant discretion in determining regulatory response. Granting accrediting agencies flexibility to establish risk-informed review procedures (as explored in more detail later in the paper) is likely to be an appropriate area, while using a risk-informed system to enforce federal civil rights laws is not, given the legally mandated statutory and constitutional rights and protections associated with individual student rights that dictate permissible regulatory parameters.

- Risk should be defined very precisely and concretely. The examples of successful risk-based and risk-informed systems described above started first with the question of the risk or danger to be avoided (e.g., cancer rates for nuclear power plants), and built the system from there.

\footnotetext{
63 These principles were distilled from a range of scholarly sources, interviews with practitioners, and policy best practices, particularly Coburn and Weddle, supra note 1; Baldwin and Black, supra note 15; Financial Services Commission of Ontario, supra note 24; as well as the various domestic and international models discussed in Section III supra.
} 
- The regulatory area should have some type of prospective risk involved. ${ }^{64}$

- The regulatory area should implicate a risk that is measurable through existing data sources. ${ }^{65}$

- There should be some evidence that regulated entities are likely to fall under each level of risk defined. In other words, the risk thresholds should relate to known variances in performance related to the risk in question, even though the precise lines between thresholds should not be drawn at the outset.

- Regulators should be able to develop a range of potential regulatory responses that are specifically tailored to the different levels of identified risk. This process likely provides an opportunity for regulators and their non-governmental partners to be more systematic and strategic in how they allot technical assistance, make requests for additional information, and impose more severe consequences.

Potential key questions to assess necessary prerequisite conditions:

- Is the risk in question real and easily understood? Does it implicate a specific area of regulation?

- Do the likely benefits of the prospective risk-informed regime outweigh the likely challenges (both in the short and long term)?

- Does stakeholder support exist for the concept of shifting to a risk-informed regime and are stakeholders committed to the hard work of turning the concept into an actual regulatory regime?

System design

- The system should incorporate the five key functions present in mature regimes (from pages 8-9):

1. Defining the purpose and goals of the system in terms of specific risks

2. Determining the responsible agency or organization's own risk appetite

3. Assessing the risk and its likelihood of occurrence

4. Assigning scores or ratings to regulated entities on the basis of risk assessments

5. Linking regulatory responses and resources to scores or ratings categories (for individual regulated entities and/or for system-wide issues)

- The type of risk in question and the different thresholds for performance should be clearly defined by regulators (and, in some cases, enforcement partners such as accrediting agencies), with the input of the full range of stakeholders.

- Data and information sources to determine and monitor risk should be clearly defined before any assessment of risk takes place.

- Thresholds should be based on accessible and reliable data and information sources-and collection should be based on existing sources and through existing collection methods wherever possible to avoid duplication of existing reporting requirements.

\footnotetext{
${ }^{64}$ A risk-informed system would be inappropriate for retroactively adjusting the regulatory response for violations that have already occurred. In the higher education context, a risk-informed system would be inappropriate for re-designing USED's procedures for assessing fines for past violations by institutions of federal rules. The fact that USED's fine assessment procedures might benefit from greater flexibility - an objective shared by risk-informed regimes-does not mean that the entire regulatory action can be designed according to the principles in this paper because the two regulatory functions are fundamentally different (creating conditions for monitoring, as opposed to imposing consequences when violations are made).

65 This is not to say that new data sources should not be developed to build a smarter, more effective regulatory system. Indeed, new prospects for risk-informed regimes may emerge in time. But this paper focuses squarely on the prospect of developing viable risk-informed systems today (and not on how to develop new data sets), meaning that existing data sources are an appropriate necessary condition.
} 
- Regulatory responses should be tiered and should be defined in direct relation to the types of risk that they are intended to address.

- If systems are defined as "opt in" by institutions, every effort should be made to avoid the creation of multiple regulatory regimes that may conflict or overlap with one another.

- Regulated entities and other stakeholders should be given multiple opportunities to contribute to and comment on the proposed system design elements.

Potential key questions to assess system design:

- What body is the most efficient and effective entity to maintain oversight or control over the contemplated risk informed regime?

- What are the risk variables at the top of the hierarchy? Are the metrics that are incorporated into the risk determination primarily outcome measures that related directly to the defined risk areas for the regime?

- Do proposed metrics and thresholds appropriately allow for differences in institutional mission and students served? Are all institutions implicated by the regime responsible under similar performance standards that may nevertheless be applied by regulators in a way that appropriately accounts for different contexts?

- Who should be responsible for defining the risk and identifying appropriate metrics and thresholds? And based on what process?

System implementation

- The primary oversight body and enforcer of the new risk-informed regime should be prepared for an initial investment of time and resources to set up the regime, to provide information and technical assistance, and to conduct a baseline assessment for regulated institutions. Regulated institutions will also need to invest resources into understanding and complying with the new requirements.

- Piloting of the system for a small number of regulated entities may be an important foundation for informing how risk is defined and assessed over time. No binding regulatory response should take place for at least the early phase of the pilot.

- Regulated entities and other stakeholders should be given multiple opportunities to comment on the implementation process to inform final processes and system elements.

Potential key questions to assess system implementation:

- Are all system participants prepared for the initial investment of time, effort, and resources-and clear about the longer-term payoff for this investment?

- Are regulators prepared and empowered to make mid-course corrections when problems arise?

System evaluation and improvement

- Regulators should regularly review overall system performance, with special attention to tracking how institutions are categorized on the basis of risk and what types of regulatory responses are most common. Adjustments should be made as appropriate.

- Regulatory burden should also be regularly assessed, both for regulated institutions and for regulators. Adjustments should be made as appropriate. 
- The definition of risk, how it is assessed, and how regulators respond should be regularly revisited and revised.

Potential key questions for system evaluation and improvement:

- How can the regime mitigate unanticipated, unforeseen, or misunderstood elements of the definition of risk, the identified thresholds and metrics, and the appropriate regulatory responses? Can these be mitigated?

- Does the regime tend to affect certain types of institutions in unique ways? Are any institutions experiencing negative consequences due to student demographics and other factors outside the institutions' control?

\section{ED's Financial Responsibility Standards}

ED has a risk-informed system for assessing private nonprofit and for-profit institutions' financial viability for purposes of Title IV funding eligibility. In the late 1990s_based on a congressional mandate in the 1992 amendments to the HEA-ED worked with a variety of stakeholders and commissioned a task force and expert report to inform methods of calculating financial ratios to identify financially troubled institutions. The process of calculating these ratios was intended to provide an "initial screening" through which ED could "appropriately allocate its limited resources to more financially at risk institutions." This initial design and implementation process was largely considered a success by the higher education community.

The current system is largely unchanged from what was established in the late 1990s. One key measure is the "financial ratios test," which draws on institutions' annual financial statements to create a ratio for each institution on a scale of -1.0 to 3.0. Those institutions with a score of 1.5 or above are considered financially responsible, and no other requirements apply. Institutions with scores between 1.0 and 1.4 may continue to receive federal funding, but are required to submit to additional monitoring and oversight requirements. Institutions with scores below 1.0 only remain eligible for Title IV funding if they provide additional surety, such as a letter of credit equal to a minimum of 10 percent of the Title IV aid received in the institution's most recent fiscal year.

After the financial downturn of 2008-09, more than 100 non-profit colleges unexpectedly "failed" the financial ratios test by receiving scores under 1.5 , due in large part to decreases in endowment funds. Many of these colleges were forced to obtain letters of credit to maintain their Title IV eligibility, which can be an expensive, time-consuming endeavor. As a result, the National Association of Independent Colleges and Universities (NAICU) to establish its Financial Responsibility Task Force to review the ED's process for determining institutions' fiscal viability. In November 2012, the Task Force released its final report, which called into question ED's financial review procedures. The report made several recommendations, including that ED's financial responsibility system be revised to reflect generally accepted accounting principles that have been revised since the 1990s, particularly with regard to the assessment of changes in endowment funds, and that ED should convene a new panel of accounting experts to provide technical guidance in that effort.

Though these issues have yet to be fully resolved, this experience illustrates the importance of regularly engaging with stakeholders and technical experts to ensure that risk-informed systems remain current and relevant over time. It also shows the difference between the viability of a risk-informed regulatory approach from challenges or problems that may be part of the implementation and continuous improvement of such an approach. 


\section{B. Prospective Risk-Informed Regimes}

Building on the principles explored in the preceding section, the following discussion provides a beginning list of sample policy areas where risk-informed reform might be undertaken in higher education. Each of these areas meets the "necessary prerequisite conditions" identified — though, in some cases, changes in regulations or statute may be necessary. These prospective regimes also represent opportunities to reduce compliance burdens significantly and to direct ED's enforcement efforts more meaningfully. Significant stakeholder engagement will be necessary for the successful design and implementation of any of these regimes, and this list is intended only to provide concrete examples of potentially ripe areas for risk-informed regulation in the existing federal regulatory system for colleges and universities.

Requirements for financial aid reporting could be restructured around a risk-informed regime. The bulk of the reporting burden for institutions in reporting student financial aid information is not necessarily the annual reporting that takes place through IPEDS for accountability, completion, and other purposes. Instead, the bulk of the burden comes through the bimonthly updates that financial aid offices are required to submit through the NSLDS system for Direct Loan compliance and with the Department of Defense for financial aid programs for veterans. These updates are intended to track the changes in enrollment that may cause students to fall out of eligibility for federal financial aid programs (and, therefore, the institution is in improper receipt of federal funds after the funds have been disbursed to students). For institutions that have stable student populations and/or a history of sound financial accounting practices and appropriate return of federal funds (among other indicators), a risk-informed system could reduce the frequency of reporting requirements. For example, institutions deemed low risk might be subjected to only the annual accounting process, those deemed medium risk could have quarterly reports due, and those deemed high risk could continue to be subjected to the bimonthly updated reports.

- The risk. The risk is that institutions are promoting fraud in the use of federal funds in cases where students fall out of eligibility for some or all of their federal financial aid during the semester or school year.

- Benefits. This system could significantly reduce compliance burdens for both low risk institutions and for ED.

- Challenges. The system would mean that at least some institutions would be providing much less frequent reports to $\mathrm{ED}$, which may prompt regulatory oversight concerns.

Accrediting agencies could have clear authority to develop risk-informed approaches to reviewing and taking action regarding institutions. ${ }^{66}$ Approaches could encompass new policies for both strong performers (e.g., expedited review) and low performers (e.g., consequences other than removal of accreditation status) - guided by a system for differentiating between levels of institutional performance. It should be noted that accrediting agencies have already explored and implemented some risk-informed concepts, including tiered consequences based on review findings. The prospective regime contemplated here, however, would allow accreditors to develop more robust systems that could tie to new, more nuanced requirements in the HEA. In other words, rather than a determination of "accredited or not" for Title IV purposes-leaving aside the more nuanced judgments accrediting agencies make within their peer review processes described above-systems could potentially allow for strong performing, low-risk institutions to receive an expedited review and/or for low-performing, high-risk institutions to be targeted and supported more effectively through the accreditation process.

\footnotetext{
${ }^{66}$ The application of this prospective regime (at least for expedited review for strong performers) has been endorsed by ACE, AAU, and APLU, among others, in recent comments submitted to the Senate HELP Committee on Senator Harkin's discussion draft bill. See note 2, supra.
} 
- The risk. The central risk implicated is that of the accreditation process failing to identify weak institutional performance and take action before students are unduly harmed.

- Potential benefits. Accrediting agencies already make very context-specific assessments of institutional performance as part of the accreditation process; developing more systematic risk-informed systems may reduce burdens for institutions with a history of strong performance, allow accreditors to be more systematic in targeting resources, and provide additional transparency in the accreditation process. And because they work with groups of relatively similar institutions (either in terms of region/geography or institutional sector) accrediting agencies can work more quickly and more closely with their institutions on new approaches than if ED attempted to design and implement a risk-informed system for all of higher education. These approaches also promise to reduce burden on institutions that present low risk, thereby freeing more of their resources to go toward students.

- Potential challenges. Most importantly, developing new risk-informed systems within accrediting agencies may be a significant new burden for ED, for accrediting agencies, and for institutions, at least in the design and early implementation process. Also, the approaches developed by different accrediting agencies may differ in key areas. For example, accrediting agencies (particularly the regional accrediting agencies), accredit a wide variety of institutions, which may make it challenging to develop metrics and thresholds that can apply in a variety of institutional contexts.

\section{ED could establish a risk-informed regime for the program reviews conducted by the Federal Student Aid} (FSA) office. Approximately 300 reviews are undertaken each year, and encompass assessments of whether the institution under review meets requirements for institutional eligibility, financial responsibility, and administrative capability for purposes of Title IV compliance ${ }^{67}$ The HEA identifies a few prospective triggers for a program review, but leaves significant discretion to ED. ${ }^{68} \mathrm{ED}$ currently does not publish how it selects the institutions to undergo program reviews. Policymakers have already identified this area of ED's authority as ripe for potential risk-informed systems, as demonstrated, for example, in Senator Harkin's draft HEA reauthorization bill that would direct ED to build in "risk-based" program reviews annually for two percent of institutions participating in Title IV. ${ }^{69}$

- The risk. The risk is that institutions are inappropriately using federal financial aid funding, to be primarily measured by student outcomes. Some metrics may include those already embedded in the HEA: a cohort default rate over 25 percent; a cohort default rate in the top 25 percent of all institutions; significant fluctuation in Stafford Loan, Direct Loan, or Pell Grant volume; identified deficiencies or financial aid programs identified by the relevant state or accrediting agency; and high annual dropout rates. ${ }^{70}$

\footnotetext{
67 During a program review, reviewers evaluate the school's compliance with requirements, assess liabilities for errors in performance, and identify actions the school must take to improve its future administrative capabilities. Federal Student Aid, Program Reviews, https:// studentaid.ed.gov/about/data-center/school/program-reviews (last accessed Oct. 26, 2014).

68 HEA $\$ 498$ A, 20 U.S.C. $\$ 1099$ c; see also Federal Student Aid, Program Review Guide for Institutions (2009), http://www.ifap. ed.gov/programrevguide/attachments/2009ProgramReviewGuide.pdf.

69 Specific considerations may include large increases in funding over a five-year period, a large proportion of overall federal funding, significant fluctuation in federal funding, sharp increases in enrollment, high default rates, high student default risk, high proportion or rate of complaints, low graduation rates, poor financial health, large proportion of funding toward recruiting and marketing, large profit margins [for proprietary institutions], negative action by an accrediting agency, prior compliance problems, large amounts of federal funds returned, and change in ownership [for proprietary institutions]). The bill allows USED to determine the final specific criteria as well as the processes for conducting for such reviews. Harkin HEA Reauthorization Discussion Draft (June 25, 2014), Sec. 498A(b)(3), http://www.help.senate.gov/imo/media/doc/HEAA\%20Discussion\%20Draft\%20Language\%206.25.14.pdf.

70 HEA $\$ 498$ A, 20 U.S.C. $\$ 1099$ c; see also Federal Student Aid, Program Review Guide for Institutions (2009), http://www.ifap. ed.gov/programrevguide/attachments/2009ProgramReviewGuide.pdf
} 
- Potential benefits. The program review function is an important accountability tool controlled by ED, but it is currently used in a way that is opaque and not clearly defined in terms of risk. Creating a clear definition of risk and prioritizing certain factors may be a way for this accountability tool to be used in a more meaningful, transparent way. Systems also might be designed in a way to complement activity by other members of the triad; if accreditors were also using risk-informed regimes, for example, the risk factors and consequences between those regimes and ED's program reviews may make for more effective and aligned overall accountability systems.

- Potential challenges. ED has limited resources to conduct program reviews, and the risk factors for program reviews should not be so broad as to implicate more institutions than ED can effectively review in a single year. (Senator Harkin's bill, for example, has been estimated to implicate thousands of institutions per year-a number far beyond FSA's current capacity. ${ }^{71}$ ) And program reviews can be a significant burden for institutions undergoing them; any risk-informed systems must be developed in a way that complements (rather than duplicates) efforts by other regulatory bodies and regulatory partners (i.e., states and accreditors).

\section{CONCLUSION}

While certain areas within the HEA may be ripe for exploration of new risk-informed regimes, others simply are unlikely to be appropriate or ready for such pursuits. As policymakers explore the adoption of new risk-informed regimes, they should take care to balance the burdens and expected benefits of these new regimes within the overall context of the importance of effectively regulating a sector that receives billions of dollars in taxpayer and student dollars every year. Creating a system that supports deterministic and risk-informed regimes is entirely possible-but care must be taken not to create greater burdens by layering new regulatory approaches on top of existing requirements, nor to abandon critical protections of student and taxpayer investments.

Moreover, policymakers must be clear on the goal of creating new risk-informed regimes. Is the intention that an entire area of regulation be replaced by a new risk-informed regime? Or should some parts of the regime remain deterministic while others become risk-informed? Should the new approach apply to all institutions? Or should the risk-informed regime be applied only to a subset of institutions (at least as a pilot for the initial period of implementation)? Though the latter approach may provide an opportunity for less complexity and controversy at the outset, it may also create a regulatory environment that is even more complex and confusing than what we have today. A primary interest should be to do no harm.

The current policy environment requires ED to develop strategies for using its resources effectively and efficiently-particularly to allow for better responsiveness to the unique circumstances presented by different institutions in various regulatory contexts. ED's efforts should be targeted at the areas most in need of federal oversight and enforcement, in light of a realistic assessment of capacity and expertise. Federal resources should not be spread so thin that enforcement mechanisms are ineffective and regulatory requirements impose burden on institutions often without real impact (particularly when compliance burdens siphon institutional resources away from functions essential to student success). Risk-informed regimes hold significant promise to aid in this effort, but ED may need additional capacity with new skill sets to ensure these new regimes are effective.

So what's next? First, the higher education community should come together to identify the most viable regula-

71 Molly Corbett Broad, Letter on the Harkin Higher Education Act Reauthorization Discussion Draft 3 (Aug. 29, 2014), http://www. acenet.edu/news-room/Pages/Letter-on-the-Harkin-Higher-Education-Act-Reauthorization-Discussion-Draft.aspx. 
tory area(s) for new risk-informed regimes. Additional papers should explore which areas are most ripe and lay out design option. A commission, task force, or other body made up of a variety of stakeholders-in collaboration with ED and Congress - may be an appropriate body to decide on the best areas to determine risk-informed approaches, design specific systems, and make recommendations on key decisions about metrics, thresholds, and regulatory response strategies. Congress may want to hold hearings to $r$ understand the ripeness, fit, and impact of implementing risk-informed regimes in various areas of higher education regulation. And, in the meantime, ED can assess where it might make changes without legislation and explore whether there is a more effective regulatory strategy that could be deployed within its existing authority. The potential payoff of a well-designed risk-informed regime to create more effective regulation is significant enough to merit the pursuit of these important steps.

\section{Questions on the Horizon}

This paper is intended to be an important early step in a long-term conversation about the prospect for the incorporation of risk-informed regimes within the regulatory system for institutions of higher education. Some important questions include:

1. Within the full range of federal regulations of higher education (at least within the context of compliance with federal financial aid programs in Title IV), what areas may be ripe for risk-informed regulation-and what areas are not?

2. What should institutions and regulators expect in terms of initial investments and long-term benefits? For example, would the adoption of risk-informed regimes truly lead to meaningful lower burdens for high performers with low risk?

3. Would the adoption of risk-informed regimes help ED (and other regulatory partners such as accrediting agencies) allocate their enforcement resources more accurately?

4. In the context of institutional quality, what metrics should factor into a risk assessment, how should thresholds be determined, and who is responsible for making these decisions?

5. How can Congress, ED, and other stakeholders be able to trust one another to design, carry out, and comply with risk-informed regimes, particularly when these regimes require removing other requirements or safeguards? 


\section{APPENDIX A: RISK-INFORMED PROCESS MAP}

The following table aligns with the guiding principles for the design, implementation, and continuous improvement of risk-informed regimes in EducationCounsel's 2014 white paper, New Directions in Regulatory Reform: Prospects for Reducing Regulatory Burden Through Risk-Informed Approaches in Federal Law Governing American Higher Education. This appendix is intended to serve as a standalone resource that may be used to inform future discussions among policymakers and stakeholders about new regimes to explore.

\begin{tabular}{|c|c|c|}
\hline Process step & Key concepts & Potential key questions \\
\hline $\begin{array}{l}\text { Necessary prereq- } \\
\text { uisite conditions }\end{array}$ & $\begin{array}{l}\text { A risk-informed regulatory regime should only involve } \\
\text { areas where regulators have clear authority to develop } \\
\text { a risk-informed regime or significant discretion in } \\
\text { determining regulatory response. Granting accrediting } \\
\text { agencies flexibility to establish risk-informed review } \\
\text { procedures (as explored in more detail later in the } \\
\text { paper) is likely to be an appropriate area, while using a } \\
\text { risk-informed system to enforce federal civil rights laws } \\
\text { is not, given the legally mandated statutory and consti- } \\
\text { tutional rights and protections associated with individ- } \\
\text { ual student rights that dictate permissible regulatory } \\
\text { parameters. } \\
\text { Risk should be defined very precisely and concretely. } \\
\text { The examples of successful risk-based and risk-informed } \\
\text { systems described above started first with the question } \\
\text { of the risk or danger to be avoided (e.g., cancer rates for } \\
\text { nuclear power plants), and built the system from there. } \\
\text { The regulatory area should have some type of prospective } \\
\text { risk involved. } \\
\text { The regulatory area should implicate a risk that is mea- } \\
\text { surable through existing data sources. } \\
\text { There should be some evidence that regulated entities } \\
\text { are likely to fall under each level of risk defined. In } \\
\text { other words, the risk thresholds should relate to known } \\
\text { variances in performance related to the risk in ques- } \\
\text { tion, even though the precise lines between thresholds } \\
\text { should not be drawn at the outset. } \\
\text { Regulators should be able to develop a range of poten- } \\
\text { tial regulatory responses that are specifically tailored } \\
\text { to the different levels of identified risk. This process } \\
\text { likely provides an opportunity for regulators to be more } \\
\text { systematic and strategic in how they allot technical } \\
\text { assistance, make requests for additional information, } \\
\text { and impose more severe consequences. }\end{array}$ & $\begin{array}{l}\text { Is the risk in question real and } \\
\text { easily understood? Does it impli- } \\
\text { cate a specific area of regulation? } \\
\text { Do the likely benefits of the } \\
\text { prospective risk-informed regime } \\
\text { outweigh the likely challenges } \\
\text { (both in the short and long } \\
\text { term)? } \\
\text { Does stakeholder support exist } \\
\text { for the concept of shifting to a } \\
\text { risk-informed regime and are } \\
\text { stakeholders committed to the } \\
\text { hard work of turning the concept } \\
\text { into an actual regulatory regime? }\end{array}$ \\
\hline
\end{tabular}




\begin{tabular}{|c|c|c|}
\hline Process step & Key concepts & Potential key questions \\
\hline System design & $\begin{array}{l}\text { The system should incorporate the five key functions } \\
\text { present in mature regimes: } \\
\text { Defining the purpose and goals of the system in terms } \\
\text { of specific risks } \\
\text { Determining the responsible agency or organization's } \\
\text { own risk appetite } \\
\text { Assessing the risk and its likelihood of occurrence } \\
\text { Assigning scores or ratings to regulated entities on the } \\
\text { basis of risk assessments } \\
\text { Linking regulatory responses and resources to scores or } \\
\text { ratings categories (for individual regulated entities and/ } \\
\text { or for system-wide issues) } \\
\text { The type of risk in question and the different thresholds } \\
\text { for performance should be clearly defined by regula- } \\
\text { tors (and, in some cases, enforcement partners such as } \\
\text { accrediting agencies), with the input of the full range of } \\
\text { stakeholders. } \\
\text { Data and information sources to determine and moni- } \\
\text { tor risk should be clearly defined before any assessment } \\
\text { of risk takes place. } \\
\text { Thresholds should be based on accessible and reliable } \\
\text { data and information sources-and collection should } \\
\text { be based on existing sources and through existing col- } \\
\text { lection methods wherever possible to avoid duplication } \\
\text { of existing reporting requirements. } \\
\text { ment on the proposed system design elements. } \\
\text { Regulatory responses should be tiered and should be } \\
\text { defined in direct relation to the types of risk that they } \\
\text { are intended to address. } \\
\text { If systems are defined as "opt in" by institutions, every } \\
\text { effort should be made to avoid the creation of multiple } \\
\text { regulatory regimes that may conflict or overlap with } \\
\text { one another. }\end{array}$ & $\begin{array}{l}\text { What body is the most efficient } \\
\text { and effective entity to maintain } \\
\text { oversight or control over the con- } \\
\text { templated risk informed regime? } \\
\text { What are the risk variables at } \\
\text { the top of the hierarchy? Are the } \\
\text { metrics that are incorporated } \\
\text { into the risk determination } \\
\text { primarily outcome measures that } \\
\text { related directly to the defined } \\
\text { risk areas for the regime? } \\
\text { Do proposed metrics and } \\
\text { thresholds appropriately allow } \\
\text { for differences in institutional } \\
\text { mission and students served? Are } \\
\text { all institutions implicated by the } \\
\text { regime responsible under similar } \\
\text { performance standards that may } \\
\text { nevertheless be applied by regu- } \\
\text { lators in a way that appropriately } \\
\text { accounts for different contexts? } \\
\text { Who should be responsible for } \\
\text { defining the risk and identi- } \\
\text { fying appropriate metrics and } \\
\text { thresholds? And based on what } \\
\text { process? }\end{array}$ \\
\hline
\end{tabular}




\begin{tabular}{|c|c|c|}
\hline Process step & Key concepts & Potential key questions \\
\hline $\begin{array}{l}\text { System imple- } \\
\text { mentation }\end{array}$ & $\begin{array}{l}\text { The primary oversight body and enforcer of the new } \\
\text { risk-informed regime should be prepared for an initial } \\
\text { investment of time and resources to set up the regime, } \\
\text { to provide information and technical assistance, and } \\
\text { to conduct a baseline assessment for regulated insti- } \\
\text { tutions. Regulated institutions will also need to invest } \\
\text { resources into understanding and complying with the } \\
\text { new requirements. } \\
\text { Piloting of the system for a small number of regulated } \\
\text { entities may be an important foundation for informing } \\
\text { how risk is defined and assessed over time. No binding } \\
\text { regulatory response should take place for at least the } \\
\text { early phase of the pilot. } \\
\text { Regulated entities and other stakeholders should be } \\
\text { given multiple opportunities to comment on the imple- } \\
\text { mentation process to inform final processes and system } \\
\text { elements. }\end{array}$ & $\begin{array}{l}\text { Are all system participants pre- } \\
\text { pared for the initial investment } \\
\text { of time, effort, and resources - } \\
\text { and clear about the longer-term } \\
\text { payoff for this investment? } \\
\text { Are regulators prepared and } \\
\text { empowered to make mid-course } \\
\text { corrections when problems arise? }\end{array}$ \\
\hline $\begin{array}{l}\text { System evaluation } \\
\text { and improve- } \\
\text { ment }\end{array}$ & $\begin{array}{l}\text { Regulators should regularly review overall system } \\
\text { performance, with special attention to tracking how } \\
\text { institutions are categorized on the basis of risk and what } \\
\text { types of regulatory responses are most common. Adjust- } \\
\text { ments should be made as appropriate. } \\
\text { Regulatory burden should also be regularly assessed, } \\
\text { both for regulated institutions and for regulators. } \\
\text { Adjustments should be made as appropriate. } \\
\text { The definition of risk, how it is assessed, and how regu- } \\
\text { lators respond should be regularly revisited and revised. }\end{array}$ & $\begin{array}{l}\text { How can the regime mitigate } \\
\text { unanticipated, unforeseen, or } \\
\text { misunderstood elements of the } \\
\text { definition of risk, the identified } \\
\text { thresholds and metrics, and the } \\
\text { appropriate regulatory responses? } \\
\text { Does the regime tend to affect } \\
\text { certain types of institutions } \\
\text { in unique ways? Are any insti- } \\
\text { tutions experiencing negative } \\
\text { consequences due to student } \\
\text { demographics and other factors } \\
\text { outside the institutions' control? } \\
\text { How can best practices and } \\
\text { lessons learned be memorialized } \\
\text { and shared? }\end{array}$ \\
\hline
\end{tabular}




\section{APPENDIX B: RECOMMENDED READING ON RISK-INFORMED REGIMES}

General information about risk-informed models and design theory:

- Julia Black and Robert Baldwin, Really Responsive Risk-Based Regulation, 32 Law \& Policy 181, 184-85 (2010)

- Jonathan Coburn and Greg Weddle, Risk-Based Regulation: Learning from the Experience of Others, BioProcess Int'l 22-23 (Sept. 2006)

- Peter May, Performance-Based Regulation, Jerusalem Papers in Regulation \& Governance Working Paper No. 2 (April 2010), http://regulation.huji.ac.il/papers/jp2.pdf

- William D. Travers, Risk-Informed and Performance-Based Regulation (March 1, 1999), http://www.nrc. gov/reading-rm/doc-collections/commission/srm/1998/1998-144srm.pdf

U.S. models in other sectors:

- Basel Committee on Banking Supervision, Basel III: A global regulatory framework for more resilient banks and banking systems (rev. June 2011), www.bis.org/publ/bcbs189.pdf

- Food \& Drug Administration, Federal Communications Commission, and Office of the National Coordinator for Health Information Technology, FDASIA Health IT Report: Proposed Strategy and Recommendations for a Risk-Based Framework (April 2014), http://www.fda.gov/downloads/AboutFDA/ CentersOffices/OfficeofMedicalProductsandTobacco/CDRH/CDRHReports/UCM391521.pdf

Australian and U.K. models in postsecondary regulation, including technical information about metrics, thresholds, and methods of calculation:

- Australian Government Tertiary Education Quality and Standards Agency, TEQSA Annual Report 2013-14 (tabled in Parliament Oct. 24, 2014), http://www.teqsa.gov.au/sites/default/files/publication-documents/TEQSA2014AnnualReport_FullReportWeb.pdf

- HEFCE, Memorandum of assurance and accountability between HEFCE and institutions: Terms and conditions for payment of HEFCE grants to higher education institutions (June 2014), http://www. hefce.ac.uk/media/hefce/content/pubs/2014/201412/HEFCE2014_12.pdf 


\section{Enhancing the Use of Negotiated Rulemaking by the U.S. Department of Education}

\section{By Jeffrey S. Lubbers ${ }^{*}$}

December 5, 2014

As the Alternative Dispute Resolution (ADR) movement made its way from the courts to the agency hearing rooms in the 1980s, negotiated rulemaking (sometimes called "regulatory negotiation" or simply "reg-neg") also emerged on a parallel track as an alternative to traditional procedures for drafting proposed regulations.

This exemplar of "regulatory reform" was based on two insights: (1) that the usual Administrative Procedure Act (APA) process of written notice-and-comment rulemaking ${ }^{2}$ has an intrinsic limitation because stakeholders engaged in it do not interact with each other or with the agency, and (2) in certain situations it is possible to bring together representatives of the agency and the various affected interest groups to negotiate the text of a proposed rule. If stakeholders are able to negotiate a consensus on a draft proposed rule, the resulting final rule is likely to be issued more quickly, easier to implement, and less likely to be subsequently challenged in court. Moreover, even in the absence of consensus on a draft rule, the process may be valuable as a means of better informing the regulatory agency of the issues and the concerns of the affected interests. For these reasons, negotiated rulemaking was seen as an appropriate application of ADR principles to the rulemaking process.

After its development in recommendations by the Administrative Conference of the United States (ACUS), ${ }^{3}$ its use was codified by the Negotiated Rulemaking Act (NRA), enacted in 1990 and made permanent in $1996 .{ }^{4}$ Both the ACUS recommendations and the NRA make clear that its use is only advisable in certain circumstancesafter the agency concerned used a "convener" to explore whether the proposed rulemaking lends itself to a successful negotiation. The NRA established a basic statutory framework for agency use of negotiated rulemaking. It serves to supplement the rulemaking provisions of the APA, largely codifies the practice of those agencies that had previously used the procedure, and incorporates relevant ACUS recommendations. ${ }^{5}$ It does not require use of the technique; rather, it was intended to clarify agency authority and to encourage agency use of the process, allowing each agency the discretion whether to employ it.

There was an initial groundswell of agency interest in the 1990s, but as I have lamented, its use has waned in the 2000s. ${ }^{6}$ Nevertheless, Congress has continued to require its use in certain narrow areas of regulation through

1 'Professor of Practice in Administrative Law, Washington College of Law, American University. Former Research Director of the Administrative Conference of the United States (ACUS) at the time when ACUS developed the concept of negotiated rulemaking. This white paper was written in my capacity as consultant to the American Council on Education (ACE), but any errors are mine.

2 As prescribed in 5 U.S.C. $\$ 553$.

3 See ACUS Recommendation 82-4, Procedures for Negotiating Proposed Regulations, 47 Fed. Reg. 30,708 (1982); ACUS Recommendation 85-5, Procedures for Negotiating Proposed Regulations, 50 Fed. Reg. 52,895 (1985).

4 Pub. L. No. 101-648, 104 Stat. 4969 (codified at 5 U.S.C. $\$$ 561-570). The NRA was permanently reauthorized in 1996, Pub. L. No. 104-320 \$11, 110 Stat. 2870, 3873.

5 See supra, note 2. See also Administrative Conference of the United States, Negotiated Rulemaking Sourcebook (2d ed. 1995).

6 See Jeffrey S. Lubbers, Achieving Policymaking Consensus: The (Unfortunate) Waning of Negotiated Rulemaking, 49 S. TEx. L. REv. 987 (2008) (tracking the use of reg-neg from 1991 to 2007). See also Peter H. Schuck \& Steven Kochevar, Reg Neg Redux: The Career 
specific legislation. One of those areas is Section 492 of the Higher Education Act, as amended by the Higher Education Amendments of 1998, ${ }^{7}$ which requires that all Title IV regulations promulgated after the enactment of the Amendments of 1998 be subject to a negotiated rulemaking process. The process mandated by this legislation differs in some significant ways from "classical reg-neg" envisioned by ACUS and the Negotiated Rulemaking Act. This paper will explore how it is has worked at the U.S. Department of Education (ED) and suggest some ways of making it work better.

\section{OVERVIEW OF "CLASSICAL" NEGOTIATED RULEMAKING ${ }^{8}$}

As mentioned above, when an agency goes forward with a negotiated rulemaking, the agency, with the assistance of its convener, assembles a committee of representatives of all identifiable affected interests willing to negotiate the proposed rule. The goal of the process is to reach consensus on a text that the agency and all the stakeholders can accept. The agency is supposed to be represented at the table by an official who is sufficiently senior to be able to speak authoritatively on its behalf. Negotiating sessions, however, are chaired not by the agency representative, but by a neutral mediator ("facilitator") skilled in assisting in the resolution of multiparty disputes.

Although the NRA sets forth some basic public notice requirements, most of the language is permissive. ${ }^{9}$ It sets forth several criteria to be considered when an agency determines whether to use reg-neg. ${ }^{10}$ These include: (1) whether there are a limited number of identifiable interests - usually not more than twenty-five, including any relevant government agencies - that will be significantly affected by the rule; (2) whether a balanced committee can be convened that can adequately represent the various interests and negotiate in good faith to reach a consensus on a proposed rule; (3) whether the negotiation process will not unreasonably delay issuance of the rule; (4) whether the agency has adequate resources to support the negotiating committee; and (5) whether the agencyto the maximum extent consistent with its legal obligations-will use a committee consensus as the basis for a proposed rule. These criteria are based on the ACUS recommendations and actual agency experience using the process.

In "regular" rulemaking, absent special circumstances, the APA requires an agency planning to adopt a rule on a particular subject to publish a proposed rule in the Federal Register and to offer the public an opportunity to submit written comments. ${ }^{11}$ However, the APA does not specify who is to draft the proposed rule nor any particular procedure to govern the drafting process. It is purely an institutional decision; ordinarily agency staff performs this function, with discretion to determine how much opportunity for public input to allow. Any agency contacts with regulated parties or the general public while the agency is considering or drafting a proposed rule are usually informal and unstructured, and some agencies bar such "ex parte" contacts after the issuance of the notice of proposed rulemaking. ${ }^{12}$ Typically, there is no opportunity for interchange of views among potentially affected parties,

of a Procedural Reform, 15 Theoretical InQ. L. 417 (2014) (updating my figures from 2007 to 2013 and finding a further "gentle" decline).

7 Pub. L. No. 105-244, codified at 20 U.S.C. $\$ 1098$ a. See also the Native American Housing Assistance and Self-Determination Act of 1996 Pub. L. No. 104-330, \$106(b) (2), 110 Stat 4030, codified at 25 U.S.C. $\$ 4116($ b)(2), mandating that "all regulations required under this Act shall be issued by a negotiated rulemaking procedure."

8 Much of this initial overview is adapted from Jeffrey S. Lubbers, A Guide to Federal Agency Rulemaking 190-94 (5th ed.) (American Bar Ass'n 2012).

9 See Tex. Office of Pub. Util. Counsel v. FCC, 265 F.3d 313, 327 (5th Cir. 2001) ("The plain language of the statute undermines the notion that the NRA's procedures are mandatory.").

10 See 5 U.S.C. $\$ 563(\mathrm{a})$.

11 See 5 U.S.C. $\$ 553$.

12 See, e.g., Department of Transportation Order No. 2100.2 (1970). Ex parte communications are discouraged after the end of the comment period. After the notice of proposed rulemaking is published, all communications must be reduced to writing and promptly placed 
even where an agency chooses to conduct an oral hearing.

The dynamics of the normal rulemaking process tend to encourage interested parties to take extreme positions in their written and oral statements-in pre-proposal contacts as well as in comments on any published proposed rule. They may choose to withhold information that they view as damaging. A party may appear to put equal weight on every argument, giving the agency little clue as to the relative importance it places on the various issues. There is usually little willingness to recognize the legitimate viewpoints of others. This adversarial atmosphere often contributes to the expense and delay associated with regulatory proceedings, as parties try to position themselves for the expected litigation. What is lacking is an opportunity for the parties to exchange views and to focus on finding constructive, creative solutions to problems. This is what reg-neg is intended to provide.

However, it should be remembered that negotiated rulemaking is a supplement to the rulemaking provisions of the APA. This means that the negotiation sessions generally take place prior to issuance of the notice and the opportunity for the public to comment on a proposed rule. In some instances, renewed negotiations may be appropriate at a later stage of the proceeding. But negotiated rulemaking does not reduce in any way the agency's obligations to follow the APA process, to produce a rule within its statutory authority, or to adequately explain the result.

\section{THE CLASSICAL NEGOTIATED RULEMAKING PROCESS}

The Negotiated Rulemaking Act authorizes use of a convener to report on the feasibility of undertaking a negotiated rulemaking. ${ }^{13}$ If the agency decides to go forward, its public notice announcing its intent to use the procedure is supposed to provide an opportunity, for at least 30 days, for members of the public who believe they are inadequately represented on the negotiating committee to apply for membership or better representation, though the agency retains discretion as to whether to grant such requests. ${ }^{14}$ If, after considering the public responses to the published notice of intent to establish a negotiating committee, the agency determines not to do so, the agency should publish a notice of that fact and the reasons for the decision. ${ }^{15}$

The agency must comply with the Federal Advisory Committee Act (FACA) ${ }^{16}$ in establishing and administering the negotiating committee, ${ }^{17}$ although other agency procedural actions relating to establishing, assisting, or terminating the committee are not subject to judicial review. ${ }^{18}$ However, the otherwise available judicial review of a rule is not affected by the fact that it resulted from a negotiated rulemaking, and the Negotiated Rulemaking Act even specifies that a reviewing court is not supposed to accord such a rule any greater deference merely because of the procedure followed. ${ }^{19}$

in the public docket. Summaries should include list of participants, summary of discussion, and statement of commitments made by Department of Transportation personnel.

13 See 5 U.S.C. $\$ 563($ b). For a good example of such a report, see EPA, Final Convening Report on the Feasibility of a Negotiated Rulemaking Process to Develop the All Appropriate Inquiry Standard Required under the Small Business Liability Relief and Brownfields Revitalization Act (Dec 17, 2002) (prepared for EPA by Susan Podziba \& Associates), available at http://podziba.com/ sites/all/themes/ppm/pdf/projects/brownfields/2.3AAIFinalReport.pdf; and U.S. Department of Energy, Convening Report on the Feasibility of a Negotiated Rulemaking to Revise the Certification Program for Commercial Heating, Ventilating Air Conditioning and Commercial Refrigeration Equipment (Oct. 2, 2012) (prepared for DOE by Alan W. Strasser), available at https://www1.eere. energy.gov/buildings/appliance_standards/pdfs/convening_report_hvac_cre_1.pdf.

14 S U.S.C. $\$ 564$.

$15 I d . \$ 565(\mathrm{a})$.

16 Pub. L. No. 92-463, 86 Stat. 770 (1972) (codified at 5 U.S.C. App. 2).

17 5 U.S.C. $\$ 565(\mathrm{a})$.

185 U.S.C. $\$ 570$. See also Ctr. for Law \& Educ. v. Dep’t of Educ., 396 F.3d 1152 (D.C. Cir. 2005) (denying an advocacy group standing to challenge final rule on the basis of an alleged defect in the composition of a negotiated rulemaking committee).

195 U.S.C. $\$ 570$. However, courts obviously know that a rule has been a product of negotiated rulemaking. See, e.g., Steel Joist Inst. v. 
It is assumed that the agency will be represented on the committee, but committee meetings are to be chaired by an impartial "facilitator" who assists the committee in its deliberations. ${ }^{20}$ If the committee reaches consensus on a proposed rule, it transmits to the agency a report containing the proposal. ${ }^{21}$ Consensus is defined as unanimous concurrence among the interests represented, unless the committee agrees on a different definition. ${ }^{22}$ If the committee does not reach consensus on a rule, it may transmit to the agency whatever information, recommendations, or other material it considers appropriate. ${ }^{23}$ The agency may keep a negotiating committee in existence until promulgation of the final rule, but earlier termination is permitted if the agency or the committee so chooses. ${ }^{24}$

Agencies may contract with private parties or may use government employees to act as facilitators, or to assist the agency in the "convening" process. ${ }^{25}$ Agencies are authorized to pay expenses of certain committee members in accordance with the FACA, and agencies are authorized to accept outside funds and use them in planning or conducting negotiated rulemakings if no conflict of interest is created. ${ }^{26}$

For reg-neg to be successful there should be a number of diverse issues that participants can rank according to their own priorities, so that each of the participants may be able to find room for compromise on some of the issues as an agreement is sought. However, it is essential that the issues to be negotiated not require compromise of principles so fundamental to the parties that meaningful negotiations are impossible. Parties must indicate a willingness to negotiate in good faith, and no single interest should be able to dominate the negotiations.

The existence of a deadline for completing negotiations, whether imposed by statute, by the agency, or by other circumstances, has been found to impart a degree of urgency that can aid the negotiators in reaching a consensus on a proposed rule. On the other hand, where the participants feel that they have a strong "BATNA" (best alternative to a negotiated agreement), ${ }^{27}$ such as hope of obtaining a better result from the agency or Congress through the political process, the chances of an agreement are reduced.

If a consensus is achieved by the committee, the agency ordinarily would publish the draft rule based on that consensus in a notice of proposed rulemaking — and the agency would have committed itself in advance to doing so. Such a commitment is not an abdication of the agency's statutory responsibility, for there would not be a consensus without the agency's concurrence in the committee's proposed rule. ${ }^{28}$ Even negotiations that result in less than full consensus on a draft rule can still be very useful to the agency by narrowing the issues in dispute, identifying information necessary to resolve issues, ranking priorities, and finding potentially acceptable solutions. ${ }^{29}$

\footnotetext{
Occupational Safety \& Health Admin., 287 F.3d 1165, 1166 (upholding a rule and noting that it was "based on a consensus document submitted by a rulemaking advisory committee in a negotiated rulemaking"); Cent. Ariz. Water Conservation Dist. v. EPA, 990 F.2d 1531, 1544 (9th Cir. 1993) (upholding a negotiated sulfur dioxide emission rule designed to improve visibility at the Grand Canyon).

26 Id. \$ 569, amended, Administrative Dispute Resolution Act of 1996, Pub. L. No. 104-320, \$11, 110 Stat. 3870, 3873. This provision was modified to take account of the then-recent (but later rescinded) closure of ACUS, which previously was authorized to accept and pay out such funds. See Administrative Conference of the United States, Building Consensus in Agency Rulemaking: Implementing the Negotiated Rulemaking Act-A Report to Congress (1995).

27 See Roger Fisher, William Ury, \& Bruce Patton, Getting To Yes 97-106 (2d. ed. 1991) (describing the concept of BATNA).

28 Nor would such an agreement undercut the agency's authority to make changes at the final rule stage. See Natural Res. Def. Council v. EPA, 859 F.2d 156, 194-95 (D.C. Cir. 1988).

29 There remains a lively debate on the pros and cons of negotiated rulemaking. See generally, Symposium, Twenty-Eighth Annual
} 


\section{DEPARTMENT OF EDUCATION NEGOTIATED RULEMAKING}

\section{Statutory Requirements}

Section 492 of the Higher Education Act, as amended by the Higher Education Amendments of $1998,{ }^{30}$ requires that, absent good cause for not doing so, ${ }^{31}$ all Title IV regulations promulgated after the enactment of the Amendments of 1998 be subject to a negotiated rulemaking process. ${ }^{32}$ This represented an expansion of the statutory mandate to use reg-neg (introduced for some aspects of Title IV in the 1992 Amendments) to all of Title IV. In place of the convening activity that would precede a decision to undertake a classical reg-neg, the statute mandates a consultation process.

More specifically, before engaging in the actual negotiation of a proposed regulation, the Secretary must first "obtain advice and recommendations from individuals and groups involved in student financial assistance... such as students, legal assistance organizations that represent students, institutions of higher education, state student-grant agencies, guaranty agencies, lenders, secondary markets, loan servicers, guaranty agency servicers, and collection agencies" and must provide for a comprehensive discussion and exchange of information concerning the implementation of Title IV of the HEA. ${ }^{33}$ This requirement "to obtain advice and recommendations" has been implemented in practice by the Department through a series of "pre-reg-neg" public hearings that are held before proposals are put before a negotiating committee.

According to the statute, all published proposed regulations must conform to any agreements resulting from the negotiated rulemaking process unless the Secretary reopens the negotiated rulemaking process, or provides a written explanation to the participants in that process why the Secretary has decided to depart from the agreements.

\footnotetext{
Administrative Law Issue, 46 Duke L.J. 1255 (1997). Several critics have argued that negotiated rulemaking allows agencies to transfer too much control to private parties. See William Funk, Bargaining Toward the New Millennium: Regulatory Negotiation and the Subversion of the Public Interest, 46 Duke L.J. 1351 (1997); Susan Rose-Ackerman, Consensus Versus Incentives: A Skeptical Look at Regulatory Negotiation, 43 Duke L.J. 1206 (1994); William Funk, When Smoke Gets in Your Eyes: Regulatory Negotiation and the Public Interest-EPA's Woodstove Standards, 18 Envtl. L. 55 (1987) (arguing that EPA's negotiated woodstove emissions rule went beyond the bounds of the Clean Air Act). Cary Coglianese has challenged empirically the basic assumption that regulatory negotiation has produced faster and less litigated rules. See Cary Coglianese, Assessing the Advocacy of Negotiated Rulemaking: A Response to Philip Harter, 9 N.Y.U. Envtl. L.J. 386 (2001); Cary Coglianese, Assessing Consensus: The Promise and Performance of Negotiated Rulemaking, 46 Duke L.J. 1255 (1997).

On the other hand, the authors of several empirical studies have strenuously rebutted the critics. See Philip J. Harter, A Plumber Responds to the Philosophers: A Comment on Professor Menkel-Meadow's Essay on Deliberative Democracy, 5 Nev. L.J. 379 (200405) (summarizing his arguments in response to critics of regulatory negotiation); Philip J. Harter, Assessing the Assessors: The Actual Performance of Negotiated Rulemaking, 9 N.Y.U. Envtl. L.J. 32 (2000) (rebutting Professor Coglianese); Laura I. Langbein \& Cornelius M. Kerwin, Regulatory Negotiation Versus Conventional Rule Making: Claims, Counterclaims, and Empirical Evidence, 10 J. Pub. Admin. Res. \& Theory 599 (2000) (finding that participants felt negotiated rules were superior, and more likely to be implemented, than conventional rules); Jody Freeman \& Laura I. Langbein, Regulatory Negotiation and the Legitimacy Benefit, 9 N.Y.U. Envtl. L.J. 60 (2000) (finding significant legitimacy benefit); see also Andrew P. Morriss, Bruce Yandle \& Andrew Dorchak, Choosing How to Regulate, 29 Harv. Envtl. L. Rev. 179, 195-202 (2005) (finding good arguments on both sides, but generally siding with Coglianese on empirical debate with Harter).

30 Pub. L. No. 105-244, codified at 20 U.S.C. $\$ 1098$ a.

31 See 20 U.S.C. $\$ 1098 \mathrm{a}(\mathrm{b})(2)$, specifying that negotiated rulemaking is not required if "the Secretary determines that applying such a requirement with respect to given regulations is impracticable, unnecessary, or contrary to the public interest (within the meaning of section 553 (b)(3)(B) of title 5)."

32 I note that this paper covers ED rulemaking under the Higher Education Act. The Department is also required to use reg-neg by a special provision of the No Child Left Behind Act, 20 U.S.C. \$6571(b). The Department failed to achieve consensus in its one reg-neg under this Act, and only held one committee session. Its attempt was criticized in Danielle Holley-Walker, The Importance of Negotiated Rulemaking to the No Child Left Behind Act, 85 NeB. L. Rev. 1015 (2007) (arguing that the Department improperly implemented the reg-neg requirement). The Department's reg-neg practices in that rulemaking were challenged in Ctr. for Law \& Educ. v. Dep't of Educ., 315 F. Supp. 2d 15 (D.D.C. 2004) (dismissed on standing grounds). I was told by one former ED official in the Higher Education Office that "we briefed them on how we did it, but they didn't follow our advice very well."

33 See 20 U.S.C. $\$ 1098 \mathrm{a}(\mathrm{a})$
} 
The Act is quite detailed concerning the selection of members of the reg-neg committee:

Participants in the negotiations process shall be chosen by the Secretary from individuals nominated by groups described [above], and shall include both representatives of such groups from Washington, DC, and industry participants. The Secretary shall select individuals with demonstrated expertise or experience in the relevant subjects under negotiation, reflecting the diversity in the industry, representing both large and small participants, as well as individuals serving local areas and national markets.

In addition, the Department must operate under several strict time constraints in issuing regulations. It is supposed to issue regulations implementing statutory changes within 360 days of enactment, ${ }^{34}$ and, accordingly, the Act specifies that the "negotiation process shall be conducted in a timely manner in order that the final regulations may be issued by the Secretary within the 360-day period." ${ }^{35}$ Even more significantly, the Department is also subject to a "master calendar" requiring that any final rules containing regulatory changes must be published by November 1 in order to be effective by July 1 of the following year. ${ }^{36}$ This means that a rule that misses the November 1 date may not go into effect for 19 months. These two requirements combine to put a lot of time pressure on the Department to complete the required negotiating phase of the process.

Unlike other agencies' reg-negs, the Department of Education's are exempted from the requirements of the Federal Advisory Committee Act; ${ }^{37}$ nevertheless the Department opens the negotiating meetings to the public. ${ }^{38}$

\section{The Department's Negotiated Rulemaking Practice}

After the 1992 Amendments but before the 1998 Amendments, the Department of Education had used negotiated rulemaking several times, ${ }^{39}$ but after the 1998 amendments, its use took off, and the Department has averaged about one negotiated rulemaking package (some containing numerous issues) every year. ${ }^{40}$ After 1998 , many of these rulemakings were legislation-directed, e.g., 1999 and 2000 (1998 Amendments to HEA), 2006-07 (Higher Education Reconciliation Act), 2007-08 (College Cost Reduction and Access Act), spring 2009 (2008 HEA reauthorization), and 2014 (implementing changes made to the Clery Act by the Violence Against Women Reauthorization Act of 2013). But in recent years there have been several ED-initiated rulemakings as well—in 2002 (the "FED-UP" initiative), 2006-07 (accreditation), and various program integrity issues, such as "gainful employment," and “teacher preparation” program issues beginning in the fall 2009 and continuing. A list of ED's

3420 U.S.C. $\$ 1232(\mathrm{e})$.

3520 U.S.C. $\$ 1098 \mathrm{a}(\mathrm{b})(1)$. It should be noted that the Department's violation of these deadlines does not negate its ability to issue rules after the deadline.

36 See 20 U.S.C. $\$ 1089$ (c) (November 1 deadline for rules applying to next award year), and 20 U.S.C. $\$ 1088$ (a) (defining "award year" as beginning on July 1$)$.

3720 U.S.C. $\$ 1098 \mathrm{a}(\mathrm{c})$.

38 The Negotiated Rulemaking Process for Title IV Regulations-Frequently Asked Questions, Question 4, http://www2.ed.gov/policy/ highered/reg/hearulemaking/hea08/neg-reg-faq.html.

39 I found five reg-neg committees in that period: Office of Postsecondary Education; The Higher Education Amendments of 1992; Negotiated Rulemaking, 34 CFR Chapter VI, 57 Fed. Reg. 62,533 (Dec. 31, 1992);

Office of Postsecondary Education; Direct Student Loan Regulations Negotiated Rulemaking Advisory Committee and the Guaranty Agency Reserves Regulations Negotiated Rulemaking Advisory Committee; 34 CFR Chapter VI (establishing two negotiated rulemaking committees), 58 Fed. Reg. 68,619 (Dec. 28, 1993);

Office of Elementary and Secondary Education; Title I-Helping Disadvantaged Children Meet High Standards; Request for Advice and Recommendations on Regulatory Issues Under Title I of the Elementary and Secondary Education Act, 34 CFR Parts 200, 201, 203, and 212, 59 Fed. Reg. 54,372 (Oct. 28, 1994);

Office of Postsecondary Education; Borrower Defenses Regulations Negotiated Rulemaking Advisory Committee; Establishment, 60 Fed. Reg. 11,004 (Feb. 28, 1995).

40 See the Department's archived information on its reg-negs in 1999, 2000, and 2002 at http://www2.ed.gov/about/offices/list/ope/ policyarchives.html, and from 2006-07 to the present, at http://www2.ed.gov/about/offices/list/ope/policy.html. 
reg-negs from 2007 to the present, and whether or not they achieved consensus, is in Appendix A.

The Department describes its practices for conducting its negotiated rulemakings on its website. ${ }^{41}$ Interviews with federal and non-federal participants provide the following picture of how reg-negs have been, and are conducted. It was interesting to note how little these procedures have changed over the years.

The process begins when the Department decides that new regulations or changes in existing regulations are needed-either due to a directive in legislation or due to a policy decision by the Department. In any given year, of course, there may be more than one such triggering event, and then the Department must decide whether it can bundle issues (the more related the better) into one rulemaking proceeding. Timing exigencies may lead to somewhat unrelated issues being bundled together, a practice that can obviously make it harder to negotiate the entire package.

But except for rare instances of good cause for avoiding the process, the Department must follow the statutorily mandated reg-neg process. To meet the needs of the master calendar, which requires a final rule by November 1 , the initial public hearings with stakeholder groups are normally held in the previous fall. After the committee members are selected and the facilitator is hired, the committee typically meets three times: January, February, and March. If consensus is achieved on the text of the proposed rule, the Department drafts the preamble (after providing it to the committee for its comments), publishes the proposed rule for comment in the Federal Register sometime in late spring or early summer, digests any comments received, and then publishes the final rule in the Federal Register usually on or just before November 1. If the committee reached consensus, this task is made easier because the participants agree in advance not to comment negatively on the proposal. ${ }^{42}$ If the committee was unable to reach consensus, the Department retains the option of drafting the text of the proposed rule (and preamble) itself to suit its own predilections, which might delay the publication of it in the Federal Register and would likely lead to more numerous and more contentious comments and a concomitant delay in publishing its final rule.

It is apparent from this schedule that unless the Department is willing to plan at the outset for a more distant effective date-something that it rarely willing to do-the November 1 deadline can compress the available time so that not much leeway is present for extended negotiations.

\section{Public Hearings}

The public hearings at the beginning of the process, used by the Department to allow the statutorily listed stakeholders to make oral statements to Departmental officials, are typically held both in Washington and in a couple of other cities. Because of the travel, and the practice of having them transcribed by a court reporter, they are rather costly. The main benefit of having these hearings from the Department's standpoint is to get a better handle on the sub-issues that might be involved in the upcoming reg-neg. But they don't seem to provide much useful new input on who should be named to the reg-neg committee. Moreover, the out-of-Washington hearings are often sparsely attended, and in some cases only Washington-based people appeared in those hearings anyway. One facilitator told me that when he was hired to do his first reg-neg for the Department he eagerly sat down with the transcript of the public hearings, only to discover that it was relatively useless in that most of the testimony was

41 The Negotiated Rulemaking Process for Title IV Regulations-Frequently Asked Questions, http://www2.ed.gov/policy/highered/ reg/hearulemaking/hea08/neg-reg-faq.html.

42 It is unclear whether participants who disagree with the preamble comment on that aspect, even if they feel bound not to comment on the proposed rule text. As explained above, the preamble is not negotiated although the Department solicits comments on it from the committee members. 
irrelevant to the issues actually to be negotiated. The consensus among my interviewees was that normally the hearing could be held in Washington only (perhaps with video technology allowing out-of-towners to participate) and that the money saved could be better spent elsewhere in the program. I should also point out that the Department is not statutorily obligated to hold these public hearings-only to "obtain advice and recommendations" from the named stakeholders, so perhaps the Department should take advantage of that flexibility and experiment with other ways of obtaining the public's views.

\section{Selection of the Committee Members}

The Department controls the selection of committee members. The statute, with its emphasis on regulation of financial matters in the world of higher education, dictates that individuals and groups "such as students, legal assistance organizations that represent students, institutions of higher education, State student grant agencies, guaranty agencies, lenders, secondary markets, loan servicers, guaranty agency servicers, and collection agencies" be selected. But the use of the phrase "such as" gives the Department more leeway in selecting committee members-which, of course is necessary when the rulemaking has little to do with financial matters (e.g., the Violence Against Women Act). Nevertheless, the Department feels it has to be faithful to this statutory directive, so this can potentially lead to a large number of committee members. The Department relies on nominations (including self-nominations) of persons to serve on the committee. It solicits these nominations in a Federal Register notice in which it identifies the constituencies it believes will be significantly affected.

The self-nomination process can create some issues. One association member complained that "Stakeholders don't get to 'choose' a representative; nominations are made and ED picks, so people who are nominated by groups representing hundreds of institutions now seem to have no leg up on people who nominate themselves." Another said, "Everybody and their uncle would like to have a seat at the table, but many participants don't have the resources, the time, the knowledge, or sometimes even the desire to be actively engaged. They see appointment to a reg-neg committee as a ceremonial honor, and are frequently net negatives in terms of their uninformed participation in discussions that they sometimes don't fully understand."

Moreover, the Department feels it is necessary to select an "alternate" member for each "primary" member-who has all the privileges of membership except that (s)he cannot vote unless the primary is absent. The alternates do not sit the main table, but have the same rights to speak, and in fact are treated as members in all other respects. ${ }^{43}$ It is notable that the Department selects the alternate, and doesn't rely on the primary to do so unless there are no nominations for that position. This can lead to the anomalous situation where the primary and the alternate are representing different constituencies or even hold opposing views.

The selection of committee members by the Department and the related issue of the make-up of the negotiating committees are quite controversial. Selection of committee members is obviously a crucial aspect of reg-neg more generally, and the normal convening process is designed to produce a committee with optimum balance, qualifications and ability to negotiate. ED's process lacks the convening stage and the Department does the selection in a rather opaque way, although its defenders point out that anyone can be nominated and that the committee itself can add new members (assuming everyone on the committee agrees). In addition ED representatives also aver that "We do pay attention to how well a person performed in a previous negotiation when we are deciding whether to choose him or her." But my interviews identified a number of issues, in addition to problems with

\footnotetext{
43 Indeed recent meeting summaries listed them all without even distinguishing between primary and alternates. See, e.g., U.S. Department of Education, Program Integrity and Improvement Negotiated Rulemaking Committee, Meeting Summary (April 23-25, 2014) (listing 31 non-federal members without affiliation or status as primary or alternate).
} 
primaries and alternates who don't agree with each other:

- I was told that during both the Bush II and Obama Administrations there has been a preference for appointing individuals with practical experience over people who work for associations. This may make sense for some topics where it's better to have a practicing financial aid officer or registrar at the table, but when the issue is a broad policy one like the Violence Against Women Act (VAWA), it is problematic not to have someone with a breadth of historical or industry-wide knowledge.

- One member was told (s)he was representing "all associations." Other times a particular official (e.g., a financial aid officer or a campus security officer) was supposed to represent his or her entire institution, or, worse, all such institutions. Too often a segment of the industry is "represented" by a "surprise" selectee who is unfamiliar with the relevant association's policy development process and often cannot represent smaller schools' interests well. One upshot is that affected groups may not feel bound by a consensus formed by such non-representative members.

- Partly because of the "doubling" created by the status given to alternates, and partly due to the statutory enumeration of members, some proceedings become imbalanced with a surfeit of consumer-oriented representatives. For example, in rulemakings dealing with for-profit institutions there were multiple consumer representatives (state attorneys general, students, consumer protection organizations) compared to a few representatives of the institutions. This problem was compounded, according to one of my interviewees, who felt "chilled" by the presence of law enforcement personnel (state AGs) on the committee who had the power to investigate the institutions or associations of such institutions if something was said in the committee meeting that might imply some sort of wrongdoing. Whether or not that person would have really behaved differently without the State AGs present (since the meetings are public anyway), it does seem clear that one side of the "ledger" should not be overloaded.

- In proceedings with multiple bundled issues, there were too many single-issue members selected for the committee who didn't know or care about most of the other issues. This can make achieving consensus impossible.

- The facilitators (even experienced ones) are not consulted by ED officials about the selection of representatives.

\section{Bundling of Issues}

Due to the ever-present Master Calendar and resource constraints, the Department has a great incentive to try to combine as many issues as it can into a single rulemaking, which of course means one reg-neg (albeit sometimes with separate subcommittees). This can make consensus more elusive as the sheer number of issues to negotiate (normally in three meetings) can make it difficult to give enough attention to all the issues. Moreover, it can lead to the selection of more "single issue" members who might not know or care about many of the issues and may become more dug in on their issue.

For example, in November 2013 the Department announced its intent to do a negotiated rulemaking on the broad topic of "Program Integrity and Improvement," and in the notice listed the following issues to be negotiated:

- Cash management of funds provided under the title IV Federal Student Aid programs, including the use of debit cards and the handling of title IV credit balances. 
- State authorization for programs offered through distance education or correspondence education

- State authorization for foreign locations of institutions located in a state.

- Clock-to-credit-hour conversion.

- The definition of "adverse credit" for borrowers in the Federal Direct PLUS Loan Program, an issue of special concern to Historically Black Colleges and Universities (HBCUs).

- The application of the repeat coursework provisions to graduate and undergraduate programs. ${ }^{44}$

Given the diversity of issues in this rulemaking, it is not surprising that the notice listed 20 separate "constituencies as having interests that are significantly affected" by these topics. ${ }^{45}$ Ultimately the Department selected "primary" representatives (and with one exception, alternates) for 16 of these constituencies - still leading to an unwieldy group of 31 members of the committee. ${ }^{46}$ Not surprisingly, although quick agreement was reached on several issues, and the committee did reach consensus on the issues of concern to HBCUs, consensus was not reached on the cash management or state authorization issues.

An even larger committee was necessary in the 2009 "Negotiated Rulemaking for Higher Education-Team V-General and Non-Loan Programmatic Issues." ${ }^{37}$ The protocol listed 46 members. It also included an unusual provision: "Single-issue members will participate for the purpose of determining consensus only for the single issue that they have been chosen to negotiate." This seems to be an acknowledgement by the Committee that some members should not vote on the whole package - which is certainly a significant departure from the normal type of ED reg-negs, much less classical reg-negs. But even this unusual provision failed to produce consensus. ${ }^{48}$

Ideally, the Department should take steps to break up these bundles into separate, but narrower, severable proceedings. One way to do that would to try to identify those issues where time is not of the essence. These issues might be broken off into a proceeding that could end after November 1. I realize that this may require more staffing of these spin-off reg-negs, but it would certainly increase the chance of achieving more consensus outcomes.

\section{Selection and Use of Facilitators}

The Department has, over the years, used a relatively small number of facilitators. In the beginning it hired facilitators who believed in being pro-active in terms of achieving consensus through their own communications with

4478 Fed. Reg. 69,612, 69,613 (Nov. 20, 2013).

45 Id. at 69,614.

46 See http://www2.ed.gov/policy/highered/reg/hearulemaking/2012/programintegrity.html. The list was:

1. Students

2. Legal assistance organizations that represent students

3. Consumer advocacy organizations

4. State attorneys general and other appropriate State officials

5. Financial aid administrators

6. Business officers and bursars at postsecondary institutions

7. Minority serving institutions

8. Two-year public institutions

9. Four-year public institutions

10. Private, non-profit institutions

11. Private, for-profit institutions

12. Institutional third-party servicers

13. Distance education

14. Business and industry

15. Lenders, community banks, and credit unions

16. Accrediting agencies

47 See http://www2.ed.gov/policy/highered/reg/hearulemaking/2009/gen-program.html.

48 Notice of proposed rulemaking, General and Non-Loan Programmatic Issues, 74 Fed. Reg. 42,379, 42,382 (Aug. 21, 2009) (“'Team V did not reach consensus on the proposed regulations."). 
committee members. For example, one anecdote I heard about that took place in the early days of the program was a situation where one of the more active facilitators successfully defused a rancorous morning discussion by inviting a few people on each side to have lunch with him. They ordered pizza, readily agreed on the toppings, proceeded to have convivial lunch, and the afternoon sessions were much more collegial and productive. This was told to me by someone who had been at the Department at the time and felt it was an example of a skillful facilitator at work. But I have reason to doubt that the Department would encourage that sort of behavior by its facilitators now.

There is at least a perception among some participants that the Department now prefers more passive and less independent facilitators. In 2006, one potential facilitator was told by ED's subcontractor, which was soliciting potential facilitators, that he could not even count on having free communications with members of the committee but would have to go through the Department's political officers. He declined the offer. In 2009 he was solicited again by the same contractor and was then given assurances that he could have such communications. However, another facilitator told me he thinks he that some of his (post-2009) activism in resolving acrimony and urging a little more time for negotiations may have annoyed the Department so much that he has not been asked back despite some successful results.

Indeed several of the recent facilitators I spoke with told me they were aware of this perception and took pains to be neutral, to be equally "tough" on the Department's representative, and to be careful to avoid any actions that might give rise to a feeling that they were overly chummy with the Department. Nevertheless, one participant said: "They need to be Switzerland—with a great deal more independence from the Department than recent facilitators have shown. In the last 10 years, the Department has chosen facilitators that defer to the Department far too much." On the other hand, former or current Departmental officers said that the real problem was that the former facilitators simply became too expensive, given the Department's increasingly severe budget constraints.

ED reg-neg facilitators have another handicap - the lack of a convening stage. Because ED reg-neg is mandatory, the only pre-negotiation phase is the public hearing stage, but I was told that in some proceedings facilitators were hired not only after the public hearings, but less than three weeks before the first committee meeting. This is not enough time to allow the facilitator to get sufficiently up to speed on the issues or to talk intelligently to the committee members before the first meeting.

In this connection, I spoke to a retired agency regulator who was involved with negotiated rulemaking at his Department and is now engaged in facilitating reg-negs for another Department (not ED). In his first one, he had the benefit of an extensive convening report written by a separate convener and he told me he learned a lot from it and from his conversations with the convener. He was also able to call the committee members before the meeting. In the second one, due to special circumstances there was no convening report, and although he said he was well briefed by Department staff, he felt his lack of prior knowledge about the issues and the participants made him uncomfortable, reduced his stature in the eyes of the participants, and made it harder to understand the areas of disagreement within the committee.

Obviously the skill of the facilitators is crucial to a successful negotiation. I would hope that the Department could afford to pay for the best facilitators, although most participants I talked to were not overly critical of most of the recent ones. But, regardless of their facilitating "style," it also seems clear that the Department could make better use of its facilitators. To be more specific: 
- Facilitators should be given more time to prepare, and should be hired before the public hearing if possible.

- If the Department wishes to maximize the chances of achieving consensus, it should encourage facilitators to use their skills to attempt to achieve consensus, not by encouraging any particular substantive result, but by being more active in exploring areas of agreement.

- Facilitators should either draft or be closely involved in drafting the meeting agendas. In one instance the facilitator was in the dark about the Department's agenda for the committee meeting session until the morning of the session.

- Unless the matter is extremely sensitive, facilitators should be kept better informed about relevant aspects of a rulemaking, such as concerning Departmental policy or developments pertaining to the positions of the Office of Management and Budget (OMB), the White House, or Members of Congress. If they are left uniformed about these matters, as has apparently happened, this undermines their ability to facilitate the meeting.

- The Department should consult with facilitators early and often (especially experienced ones), because they may be able to provide useful substantive or procedural advice (e.g., who should be appointed to the committee, or whether it is worth having another meeting). At present the Department rarely if ever consults them on such matters.

- The Department should diversify its roster of facilitators. Given some of the topics of recent reg-negs (e.g., HBCUs, VAWA) and the pervasiveness of social media, it is problematic that ED's current facilitators are all white men in their 60 s.

\section{Departmental Negotiators}

Departmental interviewees made clear that, with a few exceptions, the Department purposely chooses to assign the role of Departmental negotiator to a career (non-political) official—and usually a non-lawyer. Most interviewees who had been participants, in general, praised their capabilities. One said that "on the whole, the ED representatives are professional, knowledgeable, and handle their role with aplomb." Several, however, did complain that they too often had to clear their positions with political officials not in the room. To my mind, that comes with having a career person as the negotiator. I suspect that many non-federal participants also have to check with their superiors before making commitments.

A more troubling concern was that with the departure of senior people, "in recent years, the quality has suffered and the Departmental representative lacked knowledge of the relevant policy and history." This seems to largely be a function of resource and staffing concerns.

I would be open to using political appointees more often, especially in proceedings where it can be anticipated that there will be otherwise be a frequent need to seek political guidance. Secondly, I suspect that there are some talented career lawyers who could be brought out from behind the curtain to take on this role-and this could make it more feasible for the Department to have more numerous, narrower reg-negs in order to reduce bundling problems.

\section{Definition of Consensus}

Everyone I talked to agreed that the Department takes a firm position on what "consensus" means. Not only do the reg-neg protocols define it to mean unanimity in the sense of lack of dissent (as it is defined in many classical 
reg-negs too), Departmental practice is to require unanimity on every issue. Thus, to take an extreme example, if the proceeding had 50 issues and the group agreed on the text of the proposed rule for 49 of the issues, with one member being a holdout on issue number 50, the Department would consider that consensus was not reached. The upshot would be that the Department would not feel bound to propose the language agreed to on the 49 provisions-even if number 50 could reasonably be seen as severable. This is not to say that the Department might not go ahead on the proposed text for some or all of the 49, but it does not feel obliged to do so. My impression is that it often does, but not always.

This stance has two ramifications - it tends to reduce the incentive for the Department to achieve full consensus, while perhaps putting more pressure on the non-federal participants to, say, agree to all 50 . The last ramification may be somewhat salutary, but the problem is that any one participant can derail this. I did hear one complaint that in one of these mega-issue proceedings, the Department itself seemed to be moving the goalpost on one of the last issues in such a way that consensus could not be achieved. I also heard that in another proceeding, where a fourth (phone) meeting was added and it appeared that a little more time might get the group to the finish line, the Department "pulled the plug." These anecdotal references hardly amount to an indication that the Department is playing games to avoid full consensus on any regular basis. Nor does the Department ever seem to be the lone hold-out in a negotiation, and I was assured by current and former officials that the Department highly values consensus, but there is still a perception that in some cases the Department is less interested in a full consensus than it might be. This may, of course, be a function of the fact that the Department has to use reg-neg in every rule and has limited time and resources to do so.

On the other hand, a former official pointed out that one important benefit of consensus was that OMB would let rules go through when a consensus was reached but might very well raise questions on a rule that was not founded on consensus. ${ }^{49}$ Moreover, I did hear a counter example in which a particular committee member who was the lone dissenter on an issue was allegedly invited by Departmental personnel (unsuccessfully) to resign from the committee, indicating that the Department was truly (and perhaps overly) interested in achieving consensus on that proposed rule at least.

A separate issue regarding consensus is the Department's policy of requiring unanimity even on procedural matters, such as whether to add another constituency to the committee, to form a subcommittee, to bring an outside expert, or to make adjustments in the organizational protocols. Perhaps such procedural steps could be taken with a "consensus" amounting to a super-majority but short of unanimity.

\section{Caucuses/Subcommittees/Use of Outside Experts to Speak to the Committee}

Use of caucuses, subcommittees, and outside experts were relatively non-controversial aspects of ED's reg-negs and my impression is that this aspect is relatively similar to the way it works in classical reg-negs, although ED's time pressures may limit its ability to take advantage of these techniques. The facilitators I spoke to seemed to think that this was not a problematic area. With respect to use of experts, one did say that he thought ED tended to use more of its own experts from other parts of the Department than outside experts, due to cost considerations. One mentioned that officers from the Consumer Financial Protection Bureau came to a meeting and provided useful information. A participant mentioned that a subcommittee on campus security and fire issues brought in several technical experts who were quite helpful.

\footnotetext{
49 Under Executive Order, 12,866, the Office of Information and Regulatory Affairs (OIRA) in OMB is charged with reviewing proposed and final significant rules of all executive agencies. ED takes pains to keep OIRA (and OMB's budget side) apprised of the progress of negotiation of rules that are subject to such review.
} 
As for caucuses, I received conflicting views. One Departmental person told me that they are used regularly, and are mostly closed, but when the caucus members come back to the table they report in public. This conforms to classical reg-neg. Usually the Department representative is not included in the caucus, but occasionally a subgroup will ask to caucus with the Department. One participant opined that this was "an area of potential improvement and efficiency that hasn't been utilized well, but that's mostly the non-federal negotiators' fault, not the Department's." However, one participant did complain that "During the teacher preparation negotiations, the federal negotiators, at the urging of Department officials, refused to allow non-federal negotiators to caucus with the associations representing the broad sectors. It undermined the caucuses' purpose and outcome."

\section{Logistics}

The Department now uses its own conference room in the Office of Postsecondary Education at $1990 \mathrm{~K}$ Street NW. It formerly used hotels, but its current practice saves money-although I heard that in a few years this facility may not be available. I also heard a few relatively minor complaints about the room: It lacks a guest Wi-Fi network. There is no live or archived streaming of meetings or use of Skype. The temperature cannot be controlled by the facilitators or anyone else - this was an oft-expressed complaint. There apparently is no dedicated copy machine, so that when documents are introduced in the meeting, too few copies are sometimes provided, and attendees regularly complain about this to the facilitators. Finally, whether or not by design, the Department does not use a projector/screen to help the negotiators discuss draft language. This technique can be useful as demonstrated by an ongoing (classical) reg-neg of energy efficiency standards I learned about where the group worked on a set of PowerPoint slides throughout a series of meetings that resolved issues and formed the basis for agreements on regulatory language..$^{50} \mathrm{~A}$ secretarial assistant sat in the meeting and made the changes and highlighted relevant text as the discussion proceeded.

The Department would do well to upgrade these aspects of the process.

\section{Transparency}

Many meetings have a high degree of public interest, with investors and other policy mavens seated in the public seats (or the overflow room).

Because ED reg-negs are exempt from the Federal Advisory Committee Act, the Department can avoid formally chartering the committee, submitting data to the General Services Administration FACA database, or having a federal officer take minutes or recordings. Accordingly the Department made the decision early on not to have transcripts taken. As one former Departmental officer explained, "we didn't want lots of 'he said, she said." Nevertheless, in at least two instances the Department included provisions for a transcript in its draft protocol only to have it vetoed by a number of committee members.

Social media's advance may be making this issue moot. A Departmental participant pointed out with some annoyance that observers were increasingly attempting to plug in their tape recorders into the room's microphone system to aid in the production of a transcript after the committee rejected transcribing, but "it is unclear how that can be prevented completely as these are public meetings." On the other hand, the Department may have good reasons to want a transcript. As one former official said, "Trade press routinely records the negotiations and can produce transcripts but ED can't. This has caused problems in litigation. ED can't produce a transcript or recording but, at least in theory, the other side could by seeking a court order to turn over the recording."

50 See http://www.regulations.gov/\#!documentDetail;D=EERE-2011-BT-CE-0077-0066. 
The facilitators are tasked with writing meeting summaries, but they have almost no substantive content. One facilitator joked that "there is no 'there' there." Participants invariably laughed when I brought up these summaries. But another facilitator stoutly defended the extremely barebones summaries as appropriate under the circumstances. He didn't think it was a useful use of the facilitators' time to write up detailed minutes, especially when attendees were tweeting out summaries anyway. Moreover, he felt if the facilitators did do that, it could just become another bone of contention at the next meeting.

A former ED official conceded that live blogging and "Twitter wars" have become a problem since he left. He said these are mostly being waged by those not at the table, and said he doesn't know how you contain that. He pointed out that the producers of the PBS Frontline piece, "College Inc., asked to film the negotiation. "We asked them not to because it would turn a negotiation into theater. They ultimately agreed not to film the negotiations and we negotiated an arrangement that satisfied them. But how do you negotiate with the Twitterverse?" As one participant concluded, "I think it's too soon to know what the long-term effects will be although it seems to render the requirement of negotiators not to speak to the media obsolete."

Personally, if the Department is unwilling to push for (and pay for) a transcript, I would like to see better summaries or minutes prepared, with an opportunity for members of the committee to review them and suggest changes before they are finalized and approved by the Committee. Facilitators should be in charge of this, and should be permitted to hire an assistant to help with this task.

\section{Overall Departmental Control of the Process}

It seems clear that the Department exercises a high degree of control over the reg-neg process. Not only does it choose the issues, the participants, the facilitator, and the agenda for the meetings, it also maintains firm control of the drafting. As one former official acknowledged:

The Department does all the drafting. In the first meeting, the Department brings its list of issues (already published in the Federal Register) and short briefing papers on each one. Occasionally additional issues are accepted, but not often. During the process Department will refine drafts, and then present them. The facilitator doesn't participate in this, but can suggest language."

Another former official agreed that "ED is primarily responsible for writing the rule. Most of the writing is done in the program office (OPE) and not by lawyers. Lawyers review."

One participant stated that "The Department exercises complete control over the initial draft (the negotiating document) and extends that control through the selection of negotiators who support its point of view." Another characterized the control over the drafting as "enormous." Another said the "other members can make suggestions and work on language but ED only takes what they want." These complaints are not new; an early critique of the process complained that "by controlling and principally defending the text of the proposed regulations, the Department assumed a dominant position and was not just one of the negotiating parties." ${ }^{\text {1 }}$ This is certainly a different approach from that used by other agencies in classical reg-neg, where it is the committee (including, of course, the agency representative) that drafts the text of the proposed rule, often with the help of the facilitator.

But it bears repeating that the mandatory nature and the other constraints on ED make this a different "animal" than classical reg-neg. As one of the facilitators opined, the mandatory model "produces some odd incentives and perhaps unintentional consequences, but it still produces benefits for the Department and the participants, not-

51 See Mark L. Pelesh, Regulations Under the Higher Education Amendments, 57-Aut. Law \& Contemp. Probs. 151, 154 (1994). 
withstanding its warts. It manages to force the Department to actually sit down with, learn from its stakeholders, and exchange views with them." He also said that his view as facilitator is that "it is the Department's process and he is there to try to make it work, or put another way, to help the parties pursue the best possible deal in the time available." Ultimately, he also said that he obviously does not agree with every aspect of the way the Department does it, but he understands why they do it the way they do, and that he might not do it all that differently if he were given that statute to implement. He also thought it was best not to get involved with drafting the proposed rule text. He felt it was ultimately the Department's rule and that it was appropriate for it to come out with its new draft seven days before each meeting, and that everyone had two cracks at the draft before the final Committee decision, plus an opportunity to comment on the draft preamble of the proposed rule before ED finalized it.

It is hard to disagree with this point of view, although committee members would undoubtedly feel better about the process if they thought they had more say in the final result.

\section{We Must Remember the Constraints under which the Department Is Operating}

It is tempting to criticize the Department's reg-neg process as "violating" the tenets of classical reg-neg. ${ }^{52}$ One participant went so far as to argue that the reg-neg label was a misnomer and that it was not really a true negotiation. It clearly is far from a classic reg-neg, but to some extent the Department has been dealt a difficult hand-in having to use reg-neg for every rulemaking, within difficult time and financial constraints—and is playing it in an understandable way.

As one former official pointed out, "Don't forget, the Department has no dedicated resources for rulemaking activities. The funds used to negotiate come from the program administration account so the program office has to compete against other demands for funding to operate the application system and loan servicing." Moreover, the Office of Postsecondary Education is apparently losing staff, especially senior staff, at an alarming rate.

These constraints go far in explaining why the Department exercises as much control as it does over the processwhy it tends to bundle too many issues into one rulemaking, limits the number of committee meetings, prefers cheaper and less active facilitators, does all the drafting, and may not be overly concerned when it doesn't achieve full consensus.

Nevertheless, although these incentives are understandable, from a good government standpoint, there are improvements that can and should be made.

\section{General Feeling that the Process is Valuable in Many Rulemakings}

Given some of the complaints discussed above, I was surprised that nearly everyone believed the process was generally beneficial, at least as compared to regular notice-and-comment rulemaking, and would not want Congress to remove it. One former ED official stated, "Frankly when reg-neg was expanded to virtually all Title IV rulemakings, top officials at the department were not so supportive (didn't want to 'share' power), but I think staff will grudgingly admit that the process produces a better result. It does have costs of money, time, and compression. But it's worth it."

The costs of doing these are not negligible. Another former official estimated the costs as follows: "My estimate is that it costs between $\$ 600,000$ and $\$ 1$ million more to convene a committee when facilitators, non-federal negotiators, and staff time are considered than public comment rulemaking. ED has had to cut back some of

52 See an early criticism of this type in Pelesh, $i d$. at 161 ("The negotiated rulemaking conducted by the Department was clearly flawed. It departed extensively from the 'classic' model of negotiated rulemaking that has evolved since [Philip] Harter's article in 1982, and it failed to follow the precepts set forth in the Administrative Conference's Recommendations as mandated by Congress."). 
those costs." In addition the Department pays the expenses of student participants. Counting extra staff time may not be correct, since in regular rulemakings, staff must deal with more extensive drafting and review of comments than would normally be the case in a reg-neg. Still, given that the Department lacks a dedicated appropriation for rulemaking, these extra front-end costs are a significant concern.

Nevertheless, the process enjoys support among some current and past officials of the Department, although there was wide agreement that the mandatory nature of it deserves to be reconsidered. While the Department apparently does not have an official position whether or how the program should be continued, my talks led me to believe that Departmental officers who have worked with the program feel that it adds value to the regular rulemaking in several respects, both as to the merits of rules and in making the process visible to the stakeholders. At a minimum it gives the Department a window to see how a rule could work-what the consequences and problems might be in the field, and even if consensus is not achieved, it provides some confidence that there will be a high degree of tolerance in the field for what is being proposed.

Among the non-federal participants there was also a general feeling that the process was valuable, even among those who were critical of the Department's practices. One association representative told me it was a misnomer to call it a negotiation or a true effort to achieve consensus, and suggested it should be eliminated in favor of a true consultation process. But that person was an outlier among the people I talked to. One association representative said:

When we can participate (or are assured of appropriate participation by our college and university members) we feel it is worthwhile. Even in the current less-than-optimal negotiating environment, we have tended to feel that it is a useful way for the Department to gain insights into how campuses work, and what they can and cannot do.

Another suggested that even when consensus is not reached, "it appears to inform and make a positive contribution to rulemaking." Another said, "I think the final rules are greatly improved by the [reg-neg] process and avoid implementation problems that might have occurred otherwise." Another gave it "high marks":

I've been generally happier with regulations developed through reg-neg than those without. It has tended to be an educational experience for both the Department and the stakeholders. In some cases the process is actually therapeutic. The participants gain a better understanding of each other's positions. I've been through contentious reg-negs that, contrary to expectations, produced consensus and those that, contrary to expectations, didn't. In both cases, I'd say that the outcome was better than it would have been without reg-neg.

In sum, it seems like both the Department and most stakeholders have come to appreciate the benefits of sitting down at the same table to discuss their concerns. And while stakeholders may not be thrilled with the substance of the ensuing regulations, and would like to see changes in some of the Department's practices, they would not like to see reg-neg disappear from the Higher Education Act. For its part, the Department has learned to live with the process, and given its ability to control it, and the lack of "penalty" for not achieving consensus, seems content to continue it-if they can obtain the resources to do so.

But Maybe an Opt-Out Provision for Certain Types of Rules or Circumstances Would Be Beneficial As mentioned, reg-neg under the Higher Education Act is mandatory for every rulemaking (including amend- 
ments to existing rules), unless there is good cause for not doing so. ${ }^{53}$ But the Act's good cause exemption specifically invokes the similar exemption in the APA from notice-and-comment rulemaking-it must be shown to be "impracticable, unnecessary, or contrary to the public interest." This APA language has been very strictly construed by the courts-the rule has to be a true emergency or a very trivial one.

I was told that the Department's Office of General Counsel has also felt constrained to interpret this provision narrowly and has only invoked this exemption once-in an interim-final rulemaking where the statutory deadline was really short, and even in that one a reg-neg group was convened to do the "final-final" rule.

But keeping in mind the basic tenet of classical reg-neg - that it should only be attempted when a convener determines that the circumstances are propitious-perhaps it is time to advocate an expanded opt-out provision.

The Negotiated Rulemaking Act itself contains the classic factors, as recounted in the introduction of this paper, and it seems clear that in some of ED's rulemakings, these factors will not all be present. There is also the more fundamental question of whether ED, virtually alone among all Departments and agencies, should have to do all of its rulemakings through negotiated rulemaking.

As one former ED official said:

While I think reg-negs have worked well in a number of circumstances, and I would choose to voluntarily do them perhaps more than some of my colleagues, I think it is fundamentally inappropriate for any agency to have to do them for all rules. I can think of a situation ( $9 \frac{1}{2}$ Rule) where it would have taken us a year and half to change a policy that was requiring us to pay excess subsidies if we had to go through reg-neg. Its rigors have prevented the Secretary from taking rapid action that could have saved the taxpayers money.... I think there should be an opt-out provision. That would be a legitimate recommendation.

When I broached this idea in my other interviews, no one disagreed with this, so long as the opt-out provision was properly drafted.

So I believe Congress should consider an opt-out provision that is broader than the current good cause provision. I think that the Secretary should have to certify that (and explain why) certain conditions are present (or not present) that makes the use of reg-neg inadvisable. One example might be an amendment to an existing rule that would not significantly increase the regulatory burden on affected institutions or significantly decrease the protections afforded to students. Another condition might be that a delay in the rulemaking would require significant expenditures of government funds. Another might be a rulemaking with an especially short statutory deadline. To avoid delays caused by judicial review of such certifications, I would prohibit or narrowly limit such review. Of course, when opting out of using reg-neg, the Department would still ordinarily have to use regular notice-andcomment procedures.

\section{RECOMMENDATIONS}

The general approach of these recommendations (based on the preceding report) is to urge Congress to reduce the time and resource constraints on the Department of Education's use of negotiated rulemaking ("reg-neg") and to concomitantly urge the Department to cede a bit of its control to the negotiating committee.

53 See note 30, supra. 


\section{Recommendations to Congress}

1. If Congress wishes to retain the "master calendar" requirements currently applicable to rulemaking under the Higher Education Act, it should (1) eliminate the general 360-day time limit now applicable to some such rules, and (2) consider extending the master calendar deadline from November 1 to December 1.

2. Congress should amend the Act's negotiated rulemaking provision to allow the Department to choose to use APA notice-and-comment rulemaking instead of negotiated rulemaking. This provision should be broader than the current "good cause" provision, but should require the Secretary to have to certify that (and explain why) certain conditions are present (or not present) that makes the use of reg-neg inadvisable. Congress should make clear that such an opt-out provision should not be used as a basis for not using reg-neg where the matter is of significant public concern, but instead would be used in circumstances such as:

a. When the Department wishes to propose an amendment to an existing rule that would not significantly increase the regulatory burden on affected institutions or significantly decrease the protections afforded to students;

b. When the Department certifies that a delay in the rulemaking would require significant expenditures of government funds;

c. When there is a rulemaking with an especially short statutory deadline.

Such certifications should not be subject to judicial review.

3. Congress should consider revising (and making more general) the list of stakeholders that are supposed to be invited to participate in negotiated rulemakings.

4. Congress should provide dedicated, adequate funds in the Department's appropriations to be used for the purpose of conducting negotiated rulemakings, including the use of a dedicated conference room for this purpose.

\section{Recommendations to the Department of Education}

\section{Public Hearings}

1. The Department should consider other ways than its current practice of holding several public hearings in Washington and in the field to meet its statutory obligation to "obtain advice and recommendations" prior to undertaking a reg-neg. It should experiment with using video conferencing to avoid the expense of field hearings and transcripts, and in some cases should try collecting written views instead of hearings.

\section{Selection of the Committee Members}

2. The Department should relax its control over the selection of committee members.

a. It should make the initial selection of constituencies to be represented but should allow each constituency to nominate its own primary and alternate members, and should accept those nominations unless there is a good reason not to.

b. It should use Federal Register notices to solicit additional interested constituencies, and ask the committee to suggest the absence of key constituencies.

c. In any event, it should end its practice of choosing alternates for all "primary" committee members who are now given all the privileges of membership except the vote. This creates either double representation or in some cases incompatible representatives. Alternates should be true 
alternates (who sit at the table only in the absence of the primary), and they and other attendees should be able to speak only with the committee's permission (which should not be unreasonably withheld).

d. It should strive for balance and a manageable number of members, without over-representing one "side" of the issue. In the event that similar groups seek to have their own representation, and that would create overloading, the Department should ask those groups to select a representative for the larger group.

e. It should have no blanket preference for "practitioners" over association representatives. The elimination of the doubling effect of the current "alternate" policy should enable the selection of more of both practitioners and association representatives as the issues warrant.

f. It should maintain its practice of taking into account the nominee's negotiating behavior in previous reg-negs, and should also consult experienced facilitators in identifying constituencies and accepting nominations.

\section{Bundling of Issues}

3. The Department should avoid bundling unrelated issues into a single reg-neg. It is hoped that a relaxation of time and resource constraints would allow use of separate reg-negs for clearly separate issues.

\section{Selection and Use of Facilitators}

4. Facilitators should be given more time to prepare, and, if possible, should be hired before the public hearing-if those are to be continued.

5. If the Department wishes to maximize the chances of achieving consensus, it should encourage facilitators to use their skills to attempt to achieve consensus, not by encouraging any particular substantive result, but by being more active in exploring areas of agreement.

6. The Department should allow the facilitators to either draft or be closely involved in drafting the meeting agendas.

7. Facilitators should be kept better informed about relevant aspects of a rulemaking, such as applicable Departmental policy or developments pertaining to the positions of OMB, the White House, or Members of Congress, unless such matters are extremely sensitive.

8. The Department should consult with facilitators early and often (especially experienced ones), because they may be able to provide useful substantive or procedural advice (e.g., who should be appointed to the committee, or whether it is worth having another meeting). At present the Department rarely if ever consults them on such matters.

9. The Department should diversify its roster of facilitators.

\section{Departmental Negotiators}

10. The Department should consider using its political appointees as its negotiator in reg-negs more often, especially in proceedings where it can be anticipated that there will be a frequent need to seek political guidance. When using career officials, it should also consider using its experienced lawyers in this role.

\section{Definition of Consensus}

11. If the Department is forced to continue its practice of bundling a number of unrelated, severable issues into one rulemaking, it should make clear that if a consensus is reached on some of these issues, the 
Department will agree to publish the agreed-upon text of those proposals in its proposed rule.

12. On procedural matters, such as whether to add another constituency to the committee, to form a subcommittee, to bring an outside expert, or to make adjustments in the organizational protocols, the Department should allow the Committee to take actions with a "consensus" amounting to a super-majority but short of unanimity.

\section{Caucuses/Subcommittees/Use of Outside Experts to Speak to the Committee}

13. The Department should continue to allow (and if resources permit, encourage) the use of caucuses and the bringing in of outside experts to educate the committee.

\section{Logistics}

14.The Department should strive to continue to use its own dedicated space for reg-neg meetings, but should upgrade the space and modernize the meetings by (a) installing a guest Wi-Fi network, (b) allow live and archived streaming of meetings or use of Skype, (c) installing a room thermostat to allow temperature control, (d) providing a dedicated copy machine, and (e) using a projector/screen to help the negotiators discuss draft language.

Transparency

15. The Department should consider requiring that either a transcript or better summaries/minutes are prepared of each meeting, with an opportunity for members of the committee to review them and suggest changes before they are finalized and approved by the Committee. Facilitators should be in charge of this, and should be permitted to hire an assistant to help with this task.

\section{Drafting}

16. The Department should consider experimenting with allowing the committee (aided by the facilitator) to play a greater role in drafting the text of the proposed rule-especially when the rulemaking is statutorily mandated. 


\section{APPENDIX A}

\section{NEGOTIATED RULEMAKING BY DEPARTMENT OF EDUCATION SINCE 2007}

Thank you to Susan Hattan of National Association of Independent Colleges and Universities (NAICU) for pulling this information together.

This is a very rough, unofficial compilation of Department of Education-negotiated rulemaking sessions since 2007. "No consensus" is generally the outcome when the negotiated rulemaking process does not stem from recently enacted legislation. Examples include Accreditation (2007), Program Integrity (2010), Teacher Preparation (2012), and Gainful Employment (2013).

YEAR

2007

2008

2009

2010

2012

2013

2014
TOPIC

Accreditation

Loans

TEACH Grants

Loans

Loans

Accreditation

General Provisions

Outreach Programs

Program Integrity

Foreign Schools

Loans

Teacher Preparation

Gainful Employment

VAWA/Clery

Multiple disparate topics

[State authorization, PLUS loans,

cash management, clock-to-credit-hour conversion, retaking coursework]

\section{CONSENSUS?}

NO

YES

YES

YES

YES

YES

$\mathrm{NO}$

$\mathrm{NO}$

$\mathrm{NO}$

YES

YES

NO

NO

YES

NO 


\section{APPENDIX B}

\section{List of Interviewees}

\section{Current or Retired Longtime Former Department of Education Officials}

- David Bergeron, retired from ED after 34 years, at the Center for American Progress (CAP) for last 18 months.

- Daniel T. Madzelan, Associate Vice President for Government Relations, American Council on Education (ACE). Retired from ED after 30 years in 2012.

- Jamienne S. Studley, Deputy Under Secretary of Education since September 26, 2013, deputy General Counsel and General Counsel of the Department in the Clinton Administration.

- Brian Siegel, Attorney, Office of General Counsel for 27 years.

\section{Non-Federal Participants}

- Maureen Budetti, National Association of Independent Colleges and Universities (NAICU).

- Judith S. Eaton, president of the Council for Higher Education Accreditation (CHEA).

- Sarah Flanagan, head of Government Relations, National Association of Independent Colleges and Universities (NAICU).

- Anne C. Gross, Vice President, Regulatory Affairs, Advocacy and Issue Analysis, National Ass'n of College and University Business Officers (NACUBO).

- Susan Hattan, National Association of Independent Colleges and Universities (NAICU).

- Leah Matthews, Executive Director at Distance Education and Training Council (DETC).

- Barmak Nassirian, American Association of State Colleges and Universities (AASCU).

- Becky Timmons, retired from American Council on Education (ACE) in January 2014 after 40 years.

\section{Facilitators}

- Craig Bagemihl.

- Chip Cameron.

- Charles Pou Jr.

- Also Neil Eisner-Retired DOT regulatory lawyer, active in some DOT reg-negs, and currently active facilitator for Department of Energy. 
CASES AND ARTICLES DISCUSSING ED'S TITLE IV RULEMAKING SINCE 1992

\section{CASES}

Ass'n of Private Sector Colleges \& Universities v. Duncan, 2014 WL 4923023-F. Supp. -(D.D.C. 2014)

Facts. After the DC Circuit (in Ass'n of Private Sector Colleges \& Universities v. Duncan, 681 F.3d 427 (D.C. Cir. 2012, below) instructed the Department of Education to provide a reasoned explanation for two aspects of the incentive-based compensation regulation that affect for-profit colleges and universities, the Department supplemented the preamble to its regulations. Plaintiffs complain that the Department has once again failed to support its regulations with record evidence and substantiated assertions.

Holdings. Plaintiff's motion for summary judgment is granted.

- The Department has failed to explain and substantiate its wholesale ban on graduation-based compensation. In addition, the Department has not furnished an adequate response to the commenters' concerns about the impact of its regulations on minority recruitment.

- The Department basically relied on arguments already promulgated that the court had rejected as insufficient. Further, the Department's attorneys offered explanation during litigation, but those explanations were not in the preamble.

Ass'n of Private Sector Colleges \& Universities v. Duncan, 930 F. Supp. 2 d 210 (D.D.C. 2013)

Facts. In 2012, Association of Private Colleges and Universities successfully challenged (in part and briefed below) Dept. of Ed.'s rule that tested compliance with "gainful employment" requirement by examining debt, earnings, and debt repayment of program's former students and two related rules. After the rules were vacated, ED. moved to amend.

- In earlier action, the court vacated reporting requirements and debt measure rule. In this action, the Department argues that the disclosures required by upheld regulations (34 C.F.R. $\$ 668.6(\mathrm{~b})(1)(\mathrm{v})$ ) cannot be fully effective without the vacated reporting requirements (34 C.F.R. $\$ 688.6(\mathrm{a})$ ) and portions of the vacated debt measures (34 C.F.R. $\$ 688.7(\mathrm{a})(2),(\mathrm{b})$-(f)).

- The Department argued that 34 C.F.R. $\$ 668.6(\mathrm{~b})(1)$ (v) (upheld) required covered institutions to disclose to students the median loan debt incurred by graduated students as provided by the Secretary but the court vacated 34 C.F.R. $\$ 668.6(\mathrm{a})(1)(\mathrm{i})(\mathrm{C})(2)$, which required the institutions to report to the Department the amounts that any graduated student received from private education loans and the amount from institutional financing plans that the student owes the institution. The Dept. argues that it needs both pieces of information to provide covered schools with the median loan debt data they are required to disclose.

Holdings.

- ED's motion to amend is denied. ED could not expand the National Student Loan Data System (NSLDS) database to include detailed information about every student enrolled in a gainful employment program.

o The court notes that the Department's motion depends on the proper interpretation of 20 U.S.C. $\$ 1015 \mathrm{c}$ which prohibits the development of federal databases storing personally identifiable information on individuals receiving assistance, except when it is necessary for the operation of programs authorized by subchapter II, IV, or VII.

Thanks to my research assistant, Rose Monahan, Washington College of Law, Class of 2015, for her compilation of this Appendix. 
o Court finds that the data collection has not been authorized by Congress.

Ass'n of Private Sector Colleges \& Universities v. Duncan, 681 F.3d 427 (D.C. Cir. 2012) [reviewing Career College Ass'n v. Duncan, 796 F. Supp. 2d 108 (D.D.C. 2011), below]

Facts. Three requirements for qualification for Title IV programs are at issue: (1) the school authorization regulation (2) agreeing not to provide commission or other incentives on the success in securing enrollments or financial aid; and (3) requirement not to engage in substantial misrepresentation of the nature of its educational program, its financial charges, or the employability of its graduates.

- School authorization regulation: state must have a process to review and act on complaints and for online courses, authorization from all states in which students reside that require authorization.

- Commission/Compensation Rule: Closes loophole where schools were providing incentive payments.

- Misrepresentation: redefined to mean any statement that has the likelihood or tendency to deceive or confuse plus providing the Department with more enforcement options.

\section{Holdings.}

- Compensation Regulations do not exceed the Higher Education Act's (HEA) limits, but two aspects of regulations are remanded for want of adequate explanations.

o Misrepresentation regulations exceed the HEA's limits because: (1) allows enforcement without procedural protections; (2) proscribes misrepresentation to subjects not covered by the HEA; and (3) proscribes statements that are merely confusing.

o State Authorization Regulations are valid but the online education regulation is not a logical outgrowth of the Department's proposed rules.

Ass'n of Private Colleges \& Universities v. Duncan, 870 F. Supp. 2d 133 (D.D.C. 2012)

Facts. Association of private colleges and universities brought suit against ED challenging rule that tested compliance with gainful employment requirement by examining debt, earnings, and debt repayment of program's former students. To assess whether a program provides training that leads to gainful employment, ED proposed two tests: one based on debt-to-income ratios and the other based on repayment rates ("debt measures").

- Debt Measure Rule

o Plaintiffs argued that "gainful employment" simply means "a job that pays" and the Department's attempt to define the phrase in terms of debt and income exceeds its statutory authority.

o Plaintiffs also argued that the debt measure rule is not adequately explained, does not actually assess whether a program prepares a student for gainful employment, is arbitrarily or unconstitutionally retroactive, and lacks a reasoned basis.

- Reporting requirements

o Plaintiffs challenge required reporting as in violation of the HEA which prohibits "the development, implementation, or maintenance of a Federal database of personally identifiable information on individuals receiving assistance under this chapter."

- Disclosure

o Plaintiffs challenged rule requiring disclosure to students of employment placement rates and median loan debt for students. 


\section{Holdings.}

- Gainful employment regulations are a reasonable interpretation of an ambiguous statutory command.

- The debt repayment measure lacks a reasoned basis and is vacated as A\&C. Because the debt-to-ratio measure and repayment measure were meant to work together, the court cannot sever one from the others. Therefore, the entire debt measure rule must be vacated and remanded to the Department.

- The reporting rule is also remanded because the Department was relying on the debt measures rule to satisfy the exception to the information collection prohibition when information collection "is necessary for the operation of programs authorized" by Title IV. Since the debt measures are remanded, the reporting rule has no authorized program to rely upon.

- Disclosure rule is upheld because it is within ED's regulatory power to "make, promulgate, issue, rescind, and amend rules and regulations governing the manner of operation of, and governing the applicable programs administered by, the Department."

Career College Ass'n v. Duncan, 796 F. Supp. 2d 108 (D.D.C. 2011) (aff'd. in part \& rev'd. in part by Ass'n of Private Sector Colleges \& Universities v. Duncan, 681 F.3d 427 (DC Cir. 2012)).

Facts. Plaintiffs challenged ED's regulations prohibiting incentive-based compensation, the elimination of compensation "safe harbors," the misrepresentation regulations, and the state authorization requirement as outside the scope of the Department's statutory authority and the Constitution, and as arbitrary and capricious under the APA.

\section{Holdings.}

- Association had standing to pursue facial challenges, despite ED's argument that, without any enforcement record, claims were not ripe;

- New compensation regulations did not violate the HEA through their restrictions on incentive payments or senior management compensation;

- New misrepresentation regulations did not contravene the HEA's command that Secretary provide notice and opportunity to be heard prior to suspending or terminating school's eligibility status for Title IV funding or prior to imposing fine;

- New misrepresentation regulations did not impermissibly expand scope and type of statement that could be sanctioned as substantial misrepresentation;

- New misrepresentation regulations did not, on their face, create chilling effect on school's free speech rights;

- Secretary gave no prior notice of aspect of new state authorization regulations that would require distance educators to obtain authorization from every state in which they had students, and its adoption in final regulations violated the APA; and

- Association was not entitled to injunctive relief pending appeal.

American Ass'n of Cosmetology Schools v. Riley, 170 F.3d 1250 (9th Cir. 1999)

Facts. Plaintiffs challenge ED’s implementing regulations for 20 U.S.C. $\$ 1085$, concerning administrative procedures for hearing and appeal after notice of termination from eligibility for Federal Family Educational Loan (FFEL) participation, under Title IV. Ineligibility for FFEL is tied to an institution's "cohort default rate" (CDR) - the percentage of current and former students that enter repayment on their loans during a given fiscal 
year who default before the end of the following fiscal year. ED promulgated regulations on calculating CDRs, and then amended those regulations in November, but stated that the calculation that was most favorable to individual institutions would be used in adjudication. Plaintiffs allege:

- The Secretary in fact has acted in accordance with his statement in only two CDR loan servicing appeal decisions and has otherwise applied only the standards of the November regulations.

- That the retroactive application of the November regulations without adequate notice violated due process.

- The Secretary's failure to require uniformly a day-specific method of determining the repayment date of Stafford loans is in violation of 20 U.S.C. $\$ 1078(\mathrm{~b}), 1232$ (c).

- The short and strict administrative deadlines do not give institutions that opportunity to review the loan servicing records of the affected borrowers in CDR appeals.

Holding. District court's order granting the Secretary's motion for summary judgment (made on the merits) is vacated, and case is remanded so that it may enter judgment dismissing the action for lack of jurisdiction.

- $\quad$ Relief plaintiffs were seeking was barred by the anti-injunction provision of 20 U.S.C. $\$ 1082$.

Mission Group Kansas, Inc. v. Riley, 146 F.3d 775 (10th Cir. 1998)

Facts. Nonprofit educational organization operating post-secondary vocation institution sought declaratory and injunction relief against the Sec. of Ed. to enjoin imposition of the $85 / 15$ rule, requiring proprietary institutions of higher education to derive 15 percent of tuition revenues from nonfederal sources to be eligible for federally guaranteed financial aid programs. The district court agreed with Mission that the Secretary's action contravened the plain language of the HEA, and granted the requested declaratory and injunctive relief against imposition of the $85 / 15$ rule.

\section{Holding.}

- Contrary to the district court's view, the statute does not plainly contravene the Secretary's action in this case.

- But the administrative action taken by the Secretary here cannot be regarded as within the legitimate interpretive scope of the regulations upon which he purports to have acted. Therefore the Secretary is entitled to no deference under the Seminole Rock-Cheuron standard.

- Even when evaluated under the less deferential Skidmore standard, the record before us appears insufficient to evaluate properly whether the $85 / 15$ rule survives review as a valid statutory "interpretative rule." We therefore remand to the district court for further proceedings.

Coalition of New York State Career Schools, Inc. v. Riley, 129 F.3d 276 (2d 1997)

Facts. Association of trade schools brought action challenging refund regulation promulgated by Sec. of Ed. under the HEA. The district court entered a permanent injunction barring enforcement on the theory that it represented an impermissible modification of the refund formula set forth in the governing statute.

Holding. Regulation governing refund of federal aid money when student's program of study ends prematurely was reasonable although it did not permit institution to retain amounts owed by student when calculating refund under state law or accrediting agency formula. Overturns district court: injunction vacated and complaint dismissed. 
- 20 U.S.C. $\$ 1091 \mathrm{~b}$ set forth the minimum amount that must be refunded to a student in order for an institution's policy to be considered fair and equitable. Nothing in the statute precludes the Secretary from determining that a larger amount must be refunded in certain instances. Nor does the statute dictate that the government, rather than the education institution, should bear the risk of student non-payment.

- Notes that this court is agreeing with the D.C. Circuit and not the 9th Circuit.

California Cosmetology Coalition v. Riley, 110 F.3d 1454 (9th Cir. 1997)

Facts. Association of cosmetology schools sought injunction against ED's enforcement of amendments to tuition refund regulations under the HEA. Regulations governed the amount of tuition and other fees postsecondary schools must refund when a student receiving Title IV federal aid withdraws from classes before completing the term for which those fees have been charged. District court found that the regulations contradicted 20 U.S.C. $\$$ $1091 \mathrm{~b}$.

- Under the Final Regulations, the school would have to include in its reimbursement to the government the amount still owed by the student. The institution would then have to pursue the student for unpaid sums. For students receiving full grants, this turns grants into personal debt.

Holding. ED exceeded its authority in promulgating tuition refund regulations; district court affirmed.

- Congress was unambiguous when it listed three criteria for when an institution's refund policy will "be considered fair and equitable."

- Disagrees with the D.C. Circuit's holding on the same issue because the D.C. Circuit assumed that Congress had inadvertently overlooked the problem of unpaid charges.

Career College Ass'n v. Riley, 74 F.3d 1265 (DC Cir. 1996)

Facts. Appellants raise five challenges to regulations promulgated by ED:

- (1) The regulations amending the Student Assistance General Provisions (34 CFR Part 668) is ineffective for the award year 1994-95 because it was not promulgated "in final form" by May 1, 1994 as required by the Master Calendar Provision.

- (2) The required refund of federal funds when a student withdraws from an institution prematurely (challenging two regulations).

- (3) The "Cohort Default Rate Rule" as exceeding the Secretary's authority because it conflicts with various statutory provisions.

- (4) The "Thirteen Week Rule," which required that institutions calculate the placement rate for any award year based on the number of students who, within 180 days of the day they received their degree obtained gainful employment and on the date of this calculation are employed or have been employed for at least 13 weeks following receipt of the credential from the institution. Challenged at arbitrary and capricious because it is "virtually impossible to meet."

- (5) The "Five Day Rule" which applies to non-term based, credit-hour schools and defines a week of instruction time to be any week in which at least five days of regularly scheduled instruction, examinations, or prep for exams occurs. Challenged as unsupported by the record and unjustified due to the severe effect on evening students.

Holdings. 
- Regulations were promulgated in proper form within time limit set by master calendar provision.

- Regulation pertaining to refund of "unearned tuition" upon withdrawal of student properly required institution to add to federal refund amount of student's unpaid scheduled cash payment.

- Regulation that determined institution administratively incapable of administering financial aid program if institution had cohort default rate of more than 25 percent for any of three most recent financial years was proper.

- Secretary's explanation for implementation of the 13-week rule was reasonable.

- Regulation that defined "week of instructional time" for purposes of vocation school eligibility in student aid program to be five days of class was not arbitrary or capricious.

Career College Ass'n v. Riley, 82 F.3d 476 (DC Cir. 1996)

Facts. Career College Association petitions for rehearing of court's determination that the refund regulation (34 C.F.R. $\$ 668.22(\mathrm{~g}))$ is a reasonable interpretation of conflicting statutory mandates. The refund regulation puts the risk of non-collection on the institution, which must first pay the government and then seek money from the student.

Holding. Upon withdrawal of student during enrollment, school is to pay the government first and is not allowed to assume that government will be repaid indirectly by the student; and the Secretary's explanation of regulations was not a post-hoc rationalization such as not to be entitled to deference.

Connecticut Student Loan Foundation v. Riley, 948 F. Supp. 156 (D. Conn. 1996)

Facts. State guarantee agency under the Guaranteed Student Loan Program brought declaratory judgment action challenging ED's regulation requiring that loans be guaranteed at a rate of 98 percent of their total amount.

Holding: The agency had standing; the statute requiring agencies to insure loans at "no less than 98 percent" was ambiguous, and the regulation requiring guarantee at no less and no more than 98 percent was reasonable.

Career College Ass'n v. Riley, Civ. A. N. 94-1214, 1994 WL 396294 (D.D.C. July 19, 1994)

Facts. Plaintiffs sought injunctive relief arising out of final regulation ED promulgated on April 29, 1994, which defined a "proprietary institution of higher education" as requiring that institutions derive at least 15 percent of their revenue from sources that are not derived from funds provided under Title IV. Plaintiffs argued that the regulations violated the APA. Plaintiffs' arguments:

- Secretary's decision to apply the substantive requirements of the 85 percent rule with no lead-in time was arbitrary and capricious (A\&C).

- Only allowing revenues to Title IV-eligible programs to be counted in the 85 percent rule was A\&C.

- Requiring institutions to apply a cash method of accounting to report revenue in the denominator was $\mathrm{A} \& \mathrm{C}$.

Holding. Injunction denied

- The 85 percent rule was not arbitrary and capricious.

- Congress granted the Secretary express discretion to implement the substantive requirements of the 85 
percent rule and it was reasonable to give immediate effect.

- Secretary's discussion of the possible limitations on what revenues could be considered provides an adequate basis for the choice he ultimately made.

- Congress left a clear gap as to which accounting method would be used in calculating the revenue formula and the Secretary's cash method is reasonable.

Ponce Paramedical College, Inc. v. U.S. Dep’t of Education, 858 F. Supp. 303 (D.P.R. 1994)

Facts. Proprietary institutions brought action for injunction and declaratory relief challenging new regulations promulgated by ED for eligibility of Title IV loan funds. Plaintiffs argued that they received insufficient notice prior to publication of agency's final rules, that the regulations were not a reasonable interpretation by the agency of Congress' intent and therefore A\&C. Plaintiffs also argued that a taking of both property and liberty without due process and violations of the Equal Protection Clause, the Contracts Clause, and the nondelegation doctrine.

- Like Career Colleges Ass'n v. Riley, plaintiffs were challenging the 85 percent rule [15 percent of revenues had to be from sources other than Title IV funds to qualify as a proprietary institution of higher education]. ED had to define "revenue." Expert testimony at trial asserted that 14 of the 24 plaintiffs would not be able to comply with the Department's 85 percent rule using the revenue definition in the regulations.

\section{Holdings}

- Regulations were not A\&C.

- Regulations were finalized in accordance with notice-and-comment provisions.

- Secretary was not required to delay implementation date.

- Regulations did not constitute a taking of liberty and property interests under the Fifth Amendment.

- Amended statute did not violate Equal Protection Clause, Contract Clause, or nondelegation doctrine.

Career College Ass'n v. Dep’t of Education, 1992 WL 233837 (D.D.C. Aug. 31, 1992)

Facts. Plaintiffs seek to preliminarily enjoin ED from finding schools with high loan default rates ineligible to participate in a federal student loan program without pre-termination notice and review, alleging a violation of the plaintiffs' Fifth Amendment due process rights. Plaintiffs also allege that disqualifying schools from participating in the program for more than one fiscal year violates the plain language of the statute.

\section{Holding.}

- PI is denied because plaintiffs couldn't show irreparable injury.

- Because denial of even "some kind" of pre-termination process violates plaintiffs' due process rights, plaintiffs are entitled to judgment as a matter of law.

o Although a full evidentiary hearing prior to termination is not required, some kind of process is required.

Ass'n of Accredited Cosmetology Schools v. Alexander, 979 F. 2d 859 (DC Cir. 1992)

Facts. Plaintiffs challenged ED's regulations implementing the Student Loan Default Prevention Initiative Act. The regulations stated that institutions would lose their eligibility to participate in the GSL programs if the institution's cohort default rate, for each of the three most recent fiscal years, is equal to or greater than 35 percent 
(for years 1991 and 1992) or 30 percent (all fiscal years after 1992). Termination became effective eight days after official notice and terminated the school from eligibility for the next two subsequent fiscal years.

\section{Holding.}

- Interpretation of the Student Loan Default Prevention Initiative Act by the Secretary of Education as permitting application of 35 percent threshold default rate to fiscal years 1987-89 is a permissible one;

- Act and its implementing regulations are not impermissibly retroactive, even though future eligibility for participation in Guaranteed Student Loan (GSL) program depends on schools' past default rates; and

- Congress has not waived its power to alter contractual terms with respect to program participation agreements entered into pursuant to the GSL program.

\section{ARTICLES}

Kamille Wolff Dean, Foreclosures and Financial Aid: Mind over Mortgages in Closing the Plus Loan Gap, 4

Colum. J. RaCe \& L. 129 (2014)

- Addresses an array of inherent problems with the current student loan industry, particularly as the student aid system relates to the federal Parent Loan for Undergraduate Students (PLUS) loan program.

- $\quad$ Suggests certain best practices including

o PLUS loan reform, specifically addressing minorities.

o Financial Aid Eligibility.

o Bankruptcy Protection.

Mark Andrew Nelson, Note, Never Ascribe to Malice That Which is Adequately Explained by Incompetence: A Failure to Protect Student Veterans, 40 J. Coll. \& Univ. L. 159 (2014)

- This article specifically focuses how on for-profit educational institutions have engaged in manipulative and deceitful recruitment practices at the expense of student veterans.

- It does focus on educational funding programs, including Title IV of the Higher Education Act and ED regulations.

Jake A. Kasser, Note, Professional Integrity: Why the DOE Should Apply Debt Measures to Law Schools, 43 U. Mem. L. Rev. 805, 806 (2013)

- Argues that the debt-burden on students graduating from for-profit institutions that have prompted ED regulation is not unlike the debt-burden of law graduates. For ED to fulfill its policy initiatives articulated in the most recent rulemaking, the new gainful employment-debt measures should be expanded to encompass law school institutions.

Julian T. Miller, Note, Program Integrity and the Implications of the Corporate Identity in Higher Education, 7 Brook. J. Corp. Fin. \& Com. L. 509, 511 (2013)

- Article is organized into five parts: (1) historical emergence of for-profit universities; (2) current context and practice of for-profit institutions; (3) current legislation and regulatory context of the for-profit education industry and impetus behind increases in borrowing and default; (4) approach taken by ED to 
address for-profit institutions and the potential impact it could have had on the rise of student default, reduction of student loan debt, and improvement of institutional performance; (5) illustrate for-profit institutions contemplated when the industry was granted Title IV eligibility.

- The article is addressing how the regulations would have played out if not vacated by the DC District Court.

- Argues that regulatory reforms were unlikely to make much of a change. For instance, under the "gainful employment" regulation, it was expected that 97 percent of institutions were providing programs that lead to gainful employment. Only the worst actors would be addressed - making the game more fair but still substantially unfair.

Jean Braucher, Mortgaging Human Capital: Federally Funded Subprime Higher Education, 69 WASH. \& LeE L. REV. 439 (2012)

- This article focuses on the "Gainful Employment Rule" promulgated by ED. The author compares the bubbles in for-profit higher education and subprime mortgages, arguing that both involve federal encouragement of high risk taking to achieve the American Dream.

- Spends time outlining the business model of for-profit colleges.

- Ultimately questions the policy of relying on for-profit higher education as a means to expand to universal higher education.

o Questionable whether they produce educated citizens with degrees at lower the cost than alternatives.

o Debt levels are prohibitively high, especially among for-profit institution graduates.

Amanda Harmon Cooley, The Need for Legal Reform of the for-Profit Educational Industry, 79 Tenn. L. Rev. 515 (2012)

- Examines the recent attempts at increased government oversight, on both federal and state levels, as well as the trends within the litigation involving for-profit colleges and universities.

- Argues for more effective control measures concerning for-profit institutions, particularly greater transparency, stronger federal and state legislation and regulation, increased accreditation associations reform, and improved internal self-regulation.

- Examines the areas of concern that have become the most problematic for the for-profit educational industry: student recruitment methods, amount of loan debt their students accrue, and the future career prospects for graduates.

- Specifically focused on ED's recruiter compensation regulations, the misrepresentation regulations, and the gainful employment regulations.

Anthony J. Guida Jr \& David Figuli, Higher Education's Gainful Employment and 90/10 Rules: Unintended "Scarlet Letters" for Minority, Low-Income, and Other at-Risk Students, 79 U. CHI. L. REv. 131, 132 (2012)

- Argues that existing legislative and regulatory policies directed at proprietary institutions due to allegedly disproportionally higher numbers of student borrowers and defaulters at proprietary institutions have unwittingly restricted minority and at-risk students' access to higher education.

- Takes issue with two ED rules in particular: the new "gainful employment" rule and the "90/10" rule. "If, 
as the data and analysis suggest, it is the type of student enrolled, as opposed to the quality of the program offered or the institution offering it, that is the primary cause of low graduation rates, excessive debt, and student defaults, then it is pointless to shift these students from proprietary institutions to nonprofit and public colleges." Argues for the elimination for both ED rules in favor of policies that will apply to all institutions and designed to ensure student access and success, require transparency and comparability, consider institutional mission where appropriate, measure student outcomes normalized against populations served, and treat at-risk students equitably no matter what institution they choose to attend.

- The article outlines Title IV of the HEA of 1965 , the role of proprietary institutions, regulatory constraints for low-income and minority students, while focusing specifically on how ED rules make things worse.

Grant MacQueen, Note, Closing Doors: The Gainful Employment Rule As over-Regulation offor-Profit Higher Education That Will Restrict Access to Higher Education for America's Poor, 19 GeO. J. on POverty L. \& PoL'y 309 (2012).

- Specifically focuses on the "gainful employment" regulation, projecting likely impacts.

- Argues that the gainful employment rule will adversely affect low-income students and proposes a system wherein applicants take a placement exam and all institutions of higher education make a series of mandatory disclosures to allow applicants to make informed enrollment decisions.

o The placement test would be required for all students seeking federal funding in order to gauge whether particular students are prepared for higher education. Further, there would be a section measuring individual strengths, in order to create a better fit between students and their chosen fields.

o Current disclosure only allows students to compare failing to non-failing schools, which isn't particularly useful. Average income ten years after graduation should also be disclosed (does not address collection issue).

Matthew A. McGuire, Note, Subprime Education: For-Profit Colleges and the Problem with Title IV Federal Student Aid, 62 Duke L.J. 119 (2012)

- This article focuses on ED's Title IV regulations and for-profit educational institutions.

- Examines the interaction between federal student-aid policy and for-profit institutions, arguing that the noble goals of modern federal student-aid policy enable the very practices that lead to negative outcomes for many students by creating a lucrative market for "subprime education."

- Argues that the problems surrounding federal financial aid and for-profit organizations will only be resolved by deemphasizing the student-oriented aid model in favor of an institution-center model that is focused on reducing the price of education.

o The author supports direct federal funding to the institutions themselves.

Jaclyn Patton, Comment, Encouraging Exploitation of the Military by for-Profit Colleges: The New GI Bill and the 90/10 Rule, 54 S. Tex. L. Rev. 425, 427 (2012)

- The article is focused on how for-profit institutions have specifically targeted veterans. The author explores the 90/10 rule and how it incentivizes for-profit institutions to enroll the highest number of military members possible because for every service member a school enrolls, it may enroll nine students who pay 
for their education with nothing but federal student aid.

- Ultimately argues that because for-profit schools have a fiduciary duty to their shareholders, they cannot act in the best interest of students or taxpayers. As a result, for-profit institutions should have minimum access to GI bill funds.

James Audette, Note, Defining "Gainful Employment" and Other Reforms in Federal Educational Lending, $38 \mathrm{~J}$. Coll. \& Univ. L. 167, 168 (2011)

- The paper analyzes ED's recent rule change regarding the definition of "gainful employment."

- Addresses criticisms and critiques of the new rule and attempts to predict the rule's real-world impact.

Cheryl L. Auster, Comment, Promising A Better Future but Delivering Debt: Understanding the Financial and Social Impact offor-Profit Colleges and the Effect of the New Program Integrity Rules, 13 SCHOLAR 631, 632 (2011)

- This article focuses on ED's regulations geared towards transparency and misrepresentations, particularly addressing: (1) misrepresentation and marketing; (2) fraud in connection with the value of the degree; and (3) fraud relating to financial matters.

- Also addresses ED's regulations which strengthen the ban on incentive compensation for admissions representatives for for-profit colleges.

- Notes that ED has not created a private cause of action to respond to misrepresentations and ED has discretion regarding enforcement, but is generally supportive of ED efforts to require disclosures and transparency.

Gayland O. Hethcoat II, For-Profits Under Fire: The False Claims Act As A Regulatory Check on the for-Profit Education Sector, 24 Loy. Consumer L. Rev. 1, 2 (2011)

- Recognizing the regulatory reform enacted by ED in response to for-profit educational institutions, the article advocates for the use of the False Claims Act as another tool aimed at for-profit reform.

- Acknowledges that the question whether an institution that knowingly breaches its PPA can be liable for fraud under the False Claims Act has divided the courts.

Nicholas R. Johnson, Phoenix Rising: Default Rates at Proprietary Institutions of Higher Education and What Can Be Done to Reduce Them, 40 J.L. \& EDuc. 225 (2011)

- This article is focused on the student loan default rates at for-profit institutions of higher education, exploring the regulatory scheme and gaps therein. Regulatory issues discussed include:

o ED's failure, until recently, to define "gainful employment."

o Problems with the calculation of the cohort default rate.

o Lack of job placement and graduation rate information.

o Loopholes in federal rules that generally prohibit incentive payments to loan enrollment officers based on the number of students enrolled.

- Discusses ED's recent regulatory efforts and makes recommendations to "plug the gaps," mostly focusing 
on greater enforcement and information gathering.

Robert S. Eitel \& Kent D. Talbert, The U.S. Department of Education's Federal Student Aid Program Integrity Final Regulations, 12 Engage: J. Federalist Soc'y Prac. Groups 16 (2011)

- The paper focuses on whether the Department of Education has exceeded its statutory authority under the HEA concerning the following regulations:

o The misrepresentation regulation-prohibits misleading statements by eligible institutions to students, prospective students, members of the public, any accrediting agency, a state agency, or to the Secretary.

$\otimes \quad$ Argues that the Department punishing eligible institutions for misrepresentation for even minor infractions without notice and hearing is not supported by the HEA.

o The incentive compensation regulation-expands the kinds of compensation prohibited by the HEA and the class of compensated persons encompassed within those provisions.

$\otimes \quad$ The incentive compensation regulations bar payments that the HEA arguably permits.

o The state authorization regulations - a specific framework for authorizing eligible institutions to provide a postsecondary program of study.

$\otimes \quad$ The effort to compel a specific authorization and enforcement scheme is without foundation in the HEA's provisions governing state responsibilities.

Joseph Sipley, Note, For-Profit Education and Federal Funding: Bad Outcomes for Students and Taxpayers, 64 Rutgers L. REv. 267 (2011)

- Argues that the "gainful employment" regulations do not go far enough and that several additional reforms are needed to rein in for-profit institutions.

- The article spends time describing the history of federal involvement in higher education and the rise of for-profit schools.

- The note mostly focuses on the current regulations, specifically the "gainful employment" regulation and what more can be done.

Stephen S. Dunham, Government Regulation of Higher Education: The Elephant in the Middle of the Room, $36 \mathrm{~J}$. Coll. \& Univ. L. 749, 750 (2010)

- This piece has a historical purpose, spending much time discussing the development of higher education regulation.

- Discusses the costs and benefits of government regulation of higher education, suggesting that the industry may do better without regulation.

- Also discusses in-house compliance at higher education institutions, arguing that the role of counsel is conflicting: advising and defending the institution on one hand and acting as an in-house regulator to ensure compliance from that same institution.

For-Profit Colleges: Undercover Testing Finds Colleges Encourages Fraud and Engaged in Deceptive and Questionable Marketing Practice, U.S. GAO (Aug. 4, 2010), http://www.gao.gov/new.items/d10948t.pdf 
- GAO report discussing undercover tests at fifteen for-profit colleges, finding that four colleges encouraged fraudulent practices and that all fifteen made deceptive or otherwise questionable statements to GAO's undercover applicants, including:

o Applicants encouraged to falsify their financial aid forms to qualify for financial aid.

o Exaggeration of potential salary after graduation and failure to provide clear information about the college's program duration, costs, or graduation rate.

o Pressuring contracts for enrollment before the applicant had a chance to talk with a financial advisor.

Matt G. Smith, Comment, Tuition: \$5,000. Textbooks: \$600. Having Your Federal Student Aid Applied to December's Rent in August: Priceless, 43 Idaho L. Rev. 767, 768 (2007)

- Discusses 34 C.F.R. 668.164(d), ED's financial aid disbursement regulation that allows institutions of higher education to require students living on campus to prepay an entire semester's rental expenses.

- Argues that the common law-which generally supports the proposition that rent does not accrue as a debt until the tenant has enjoyed the use of the land for the period for which it is payable - prohibits ED's regulation.

- Argues that Congress did not intend for ED to preempt state law.

Lisa P. Baar, The Higher Education Amendments of 1992: Resolving the Conflict over Diversity Standards and Institutional Eligibility for Title IV Aid, 30 HARV. J. ON LEGIS. 253 (1993)

- The article discusses the controversy that led Congress to amend the Higher Education Act in 1992 and discuss possible consequences of the Amendments.

- Focused on the accreditation requirements, particularly the relationship between the accrediting agencies and the federal government and the ambiguity regarding the Secretary's authority to control accrediting agency standards.

o Discusses the implications of the private accrediting agency relationship to the federal government (inherent tension) and legislative response for continued autonomy of accrediting agencies and future conflicts between ED and accrediting agencies over standards.

- Briefly discusses possible Establishment Clause problems with the allocation of federal funds through Title IV aid to religiously affiliated schools and the new "Religious Institution Rule." 


\section{APPENDIX V}

\section{The Challenges of Information Collection Burden in Higher Education}

\section{Carlo Salerno}

October 24, 2014

\section{EXECUTIVE SUMMARY}

This paper was commissioned as part of the Task Force on Regulation of Higher Education and is one of a series of white papers looking at regulatory process reform ideas. This paper focuses on the challenges that colleges and universities may face when information collection burden estimates do not necessarily match reality. The study's research questions were designed to evaluate: 1) the extent to which the U.S. Department of Education's practices for estimating information collection burden differ from other federal departments and agencies, and 2) how representative of the actual time, effort, and cost existing estimates may be.

The findings indicate that the Department's processes for justifying information collection burden are neither more nor less transparent than those at other federal agencies. They also suggest that agencies provide varied levels of justification and are inconsistent in terms of both how activities are distinguished as well as in how costs are measured. The most commonly omitted information in the packages that federal agencies provide to the Office of Information and Regulatory Affairs (OIRA) was, in fact, justification for how the estimates themselves were derived. Even within the Department of Education, information collection justifications were found to be remarkably diverse.

The findings also indicate that, at least in the case of federal financial aid, the aggregate information collection burden is highly sensitive to minute adjustments in time-on-task estimates and greatly understates the true effort needed to maintain compliance as assessed by the relevant institutional staff. When activities like Enrollment Verification and Satisfactory Academic Progress (SAP) were evaluated, rounding error adjustments suggest that the true effort needed to maintain compliance across all higher education institutions for these two activities alone could be understated by as much as one million hours of staff time.

When financial aid administrators were asked to review the Department of Education's (ED) estimates, the findings suggest that the true effort needed to maintain compliance across all higher education institutions for just these two activities could be understated by as much as 2.2 million staff hours. The bulk of these additional hours seem to come as a result of much greater time needed to adjust to changing standards, as well greater time needed to work with and resolve student issues with students.

From these findings come the following recommendations:

1. The Department of Education and other federal agencies should consider adopting more definitive and activity-based information collection standards that focus on clearly defined activities.

2. OIRA should consider requiring federal departments and agencies to incorporate additional justification 
elements into their information collection request packages, including estimates for data collection and storage, as well as data validation.

3. The Department of Education should consider exploring ways to foster a more collaborative relationship with higher education institutions on burden efforts. This could involve a petition-style process that obligates the Department to review and potentially revise information collection burdens when a minimum threshold of higher education institutions requests it. It could also involve establishing standing panels of school experts who can assist the Department in making informed burden estimate calculations.

4. OIRA should consider requiring federal departments and agencies to incorporate information collection standards that require burden measurements based on the size of the public entity being affected.

5. The Department of Education should consider engaging in a thorough review of areas where data that is already being collected can be re-purposed to reduce information collection burden on higher education institutions.

6. The Department of Education should consider exploring ways in which private sector technology solutions can help reduce the information collection burden on higher education institutions.

7. Congress should have the U.S. Government Accountability Office conduct a retrospective study of select ED regulations in order to determine the accuracy of ED's information collection request estimates.

\section{INTRODUCTION}

At the core of regulatory action, at least to those responsible for its execution, is recordkeeping, reporting out to federal and/or state bodies, or disclosing information to the general public. The extent to which activities like these permeate the postsecondary education industry landscape was made particularly clear in 2008 with the passage of the most recent reauthorization of the Higher Education Act. That legislation imposed a record number of new reporting and disclosure requirements on American higher education institutions. ${ }^{1}$

In light of the growing attention paid to streamlining federal regulations affecting colleges and universities, this project was designed to help policymakers better understand the challenges that arise when higher education institutions are tasked with information collection burdens that may not accurately reflect the financial and time costs expended. The purpose here is to address the transparency of the Department of Education's process for calculating burden estimates. It is also to understand the extent to which total burden may be sensitive to minute increases in activity time as well as consider what kinds of recommendations may improve the process by which information collection burden estimates are established.

\section{STUDY QUESTIONS}

The particular questions this study will address are:

1. To what extent does the Department of Education provide the same type of information/data to the Office of Management and Budget (OMB) as other federal departments and agencies when it comes to estimating the administrative burden of proposed/existing regulations?

2. What is the potential impact on higher education institutions of inaccurate burden estimates from the

\footnotetext{
1 A comprehensive listing of the various reporting and disclosure requirements, up to and including the most recent reauthorization of the Higher Education Act, can be found here: http://nces.ed.gov/pubs2010/2010831rev.pdf.
} 
Department of Education?

\section{METHODOLOGY}

The Office of Information and Regulatory Affairs (OIRA), within the Office of Management and Budget (OMB), is responsible for overseeing the implementation of the Paperwork Reduction Act of 1995, the overarching legislation that guides how federal departments and agencies should look to minimize administrative burden. ${ }^{2}$ As a matter of public service, OIRA maintains a searchable, online Information Collection Review database that includes all of the documentation that agencies must file in order to get approval for imposing public burdens related to information recordkeeping, reporting, or disclosure. ${ }^{3}$

The first question was addressed by creating a cross-agency list of Information Collection Requests (ICRs) from the database. This list was created by filtering records to include: 1 ) on-going activities (e.g., those that are currently active and not yet expired), 2) across all federal departments and agencies, 3) applicable to recordkeeping, reporting, and disclosure activities, 4) that received public comments, and 5) that affect higher education. ${ }^{4}$ This limited the review to 34 records, a list of which can be found in Appendix A. From this listing, the information burden justification documentations each agency provided was retrieved, analyzed, and compared.

Even focusing on just higher education, the Department of Education alone includes a number of separate offices (e.g., Federal Student Aid, Office of Postsecondary Education, National Center for Education Statistics), each of which submits ICR packages as part of its own regulatory action. As a secondary check, a random collection of just Department of Education ICRs was separately analyzed in order to determine the extent to which these different sub-offices utilized different justification methods when completing ICR packages.

To address the second question, college administrators, national higher education advocacy organizations, and private sector education service providers were contacted and asked to help identify ongoing ICRs that: 1) affected most if not all higher education institutions, 2) required substantive effort towards record-keeping or reporting to the Department of Education, and 3) focused on where school officials believed that burden requests understated the actual effort needed for compliance. From these discussions it was determined to focus attention on the Student Aid Verification process as well as the monitoring and reporting related to students maintaining Satisfactory Academic Progress (SAP). ${ }^{5}$

The first step involved establishing baseline estimates for Verification and SAP from the documentation that ED provided to OIRA. The next step involved fractionally adjusting baseline estimates upward for activities where time-on-task is clearly could not be precisely defined down to the second in order to better understand how sensitive total burden was to minor changes or adjustments in the estimates. Lastly, the baseline estimates were adjusted again, this time by reflecting financial aid staff members' perceptions about the actual time needed to complete such activities.

In general, it is important to note that the number of ICRs reviewed for this project was small; it may be the case that another set of filters (e.g., focusing only on ICRs that needed to be adjusted before approval or focusing on

2 See also: http://www.nasfaa.org/WorkArea/linkit.aspx?LinkIdentifier=id\&ItemID=3903.

3 See http://www.reginfo.gov/public/ for further information. The actual database can be found here: http://www.reginfo.gov/public/ do/PRASearch.

4 Part of the search filter process allows individuals to filter on the type of business entity affected, as well as a particular sub-function. For this study, "education" was selected as the primary business entity and "higher education" was selected as the relevant sub-function.

5 See the findings section of this paper for additional references to further information on what these activities involve. 
new requests compared to extensions) could yield altogether different results. In addition, utilizing just federal financial aid examples may not necessarily capture the breadth and scope of practices that affect all higher education institutions; there is the risk that the issues identified are simply unique to financial aid. What is more, it may also miss important factors or considerations that could help shape policy going forward.

\section{$\underline{\text { FINDINGS }}$}

\section{Question \#1}

As part of the package of information submitted to OIRA, all federal agencies must complete a supplementary statement that is designed to answer a number of questions related to information collection burden and how it is estimated, as well as additional questions related to other pertinent issues including duplicative data, use of technology and frequency of collection. Question \#12 of this document asks agency respondents the following:

12. Provide estimates of the hour burden of the collection of information. The statement should:

- Indicate the number of respondents by affected public type (federal government, individuals or households, private sector-businesses or other for-profit, private sector-not-for-profit institutions, farms, state, local or tribal governments), frequency of response, annual hour burden, and an explanation of how the burden was estimated, including identification of burden type: recordkeeping, reporting or third party disclosure. All narrative should be included in item 12. Unless directed to do so, agencies should not conduct special surveys to obtain information on which to base hour burden estimates. Consultation with a sample (fewer than 10) of potential respondents is desirable. If the hour burden on respondents is expected to vary widely because of differences in activity, size, or complexity, show the range of estimated hour burden, and explain the reasons for the variance. Generally, estimates should not include burden hours for customary and usual business practices.

- If this request for approval covers more than one form, provide separate hour burden estimates for each form and aggregate the hour burdens in the ROCIS IC Burden Analysis Table. (The table should at minimum include Respondent types, IC activity, Respondent and Responses, Hours/Response, and Total Hours)

- Provide estimates of annualized cost to respondents of the hour burdens for collections of information, identifying and using appropriate wage rate categories. The cost of contracting out or paying outside parties for information collection activities should not be included here. Instead, this cost should be included in Item 14.

The review of ICR documentation for the sample did not reveal any systematic differences between ED and other federal departments/agencies when it came to providing justification for the amount of burden hours requested. Instead what was found was a great deal of variability in the type of justification information provided across all agencies. The ICR packages all provided a minimum level of information listing out the number of respondents, activity types, hours per response, and total hours incurred. Beyond this though, it was not possible to identify any particular documentation patterns. Cost estimates were sometimes included and sometimes not. Where costs were included, some covered labor, some capital (e.g., postage or data entry) and some covered both. What is more, activity types were almost invariably broken out by task, rather than by any uniform activity standards that comprised those tasks (e.g., instruction review and document retrieval.)

Surprisingly, even though the instructions are very explicit, the most commonly omitted information was how the 
burden estimates themselves were constructed. The lack of explanation provided by agencies is important because it is the main inquiry of this study, but it is also important for what it highlights: a lack of federal standards for units of work. Tasks across agencies are, by design, unique in their needs; still, the activities supporting information collection are basic processes. For example, while many activities require individuals and businesses to review policy changes or read instructions, there do not seem to be measures of how long activities like this should take (e.g., how long it should take, in minutes, for an individual to read 100 words and then multiplying that by the number of words in the instructions). Similarly, while many activities require individuals and institutions to exchange financial and personal information, here too there do not seem to be agreed upon standards for how long it should take to retrieve bank, tax or retirement documentation.

\section{Within the Department of Education}

Even within the Department of Education ICRs vary considerably in the level of justification provided. Consider, for example, Appendix B, which documents the Supplementary Statement question \#12 answers for two currently approved requests: the Student Support Services Program (SSSP) Annual Performance Report and the College Accessibility and Transparency List Explanation Form (CATEF).

The SSSP document simply highlights that it will take 15 hours (or two full business days) and nearly half a million dollars in just staff costs each year to complete. No further information is offered except that 80 percent of the work is anticipated to be done by "professionals" (without a definition of what a professional is in this context) and the remainder is clerical.

Contrast this with the burden estimate in the same appendix for the CATEF. In this case the submitting group actually documents the time needed to complete each individual section, lists ranges based on how answers are provided, and offers a cost measure that not only breaks out labor and capital costs, but also includes a cost-of-living adjustment as well.

\section{Question \#2}

\section{Verification}

Each year, as part of the financial aid process, colleges and universities are required to conduct checks on the information that students provide, which helps determine the amount of federal grant and loan aid they may be eligible for. This process is known as "verification." Each year ED selects approximately one-third of all aid applicants for verification. While some schools only verify those students they are asked by the Department to verify, in some cases an institution will conduct verification activities on all of its students that receive federal financial aid as a matter of quality assurance. ${ }^{6}$

Table 1 below shows a comparison between the amount of time that ED estimates schools and students will need to complete the various verification activities and what financial aid office professionals estimate they need for the same activities. As the data shows, the expectation from ED is that institutions will need approximately two hours per year to review new verification items and update their systems to retrieve any information accordingly. It further estimates that students will spend an additional 7.2 minutes locating the necessary documentation and an additional 4.8 minutes (10.2 for institutions) actually updating that information. Finally, it estimates that, for those students selected for verification, the institution will have approximately 2.5 interactions at approximately 7.2 minutes per interaction to collect the necessary information and resolve any issues.

\footnotetext{
${ }^{6}$ For more information on the verification process, please see: http://ifap.ed.gov/fsahandbook/attachments/1415AVGCh4.pdf.
} 


\section{TABLE 1.-Comparison between Department of Education estimates of the amount of time students and insti- tutions need to complete verification of financial aid information requests and financial aid office professionals' estimates for the same activities}

\begin{tabular}{|c|c|c|c|c|c|}
\hline \multirow[b]{2}{*}{ Activity } & \multirow[b]{2}{*}{ Responses } & \multicolumn{2}{|c|}{$\begin{array}{c}\text { Department of Education } \\
\text { Estimates }\end{array}$} & \multicolumn{2}{|c|}{$\begin{array}{c}\text { Financial Aid Office } \\
\text { Estimates }\end{array}$} \\
\hline & & $\begin{array}{l}\text { Minutes per } \\
\text { response }\end{array}$ & Burden hours & $\begin{array}{r}\text { Minutes per } \\
\text { response }\end{array}$ & Burden hours \\
\hline \multicolumn{6}{|c|}{ Program updating } \\
\hline For-profit & 2,199 & 120.0 & 4,398 & $2,400.0$ & 87,960 \\
\hline Private & 1,743 & 120.0 & 3,486 & $2,400.0$ & 69,720 \\
\hline Public & 1,896 & 120.0 & 3,792 & $2,400.0$ & 75,840 \\
\hline \multicolumn{6}{|c|}{ Updating information } \\
\hline For-profit & 798,000 & 10.2 & 135,660 & 10.2 & 135,660 \\
\hline Private & 630,000 & 10.2 & 107,100 & 10.2 & 107,100 \\
\hline Public & 672,000 & 10.2 & 114,240 & 10.2 & 114,240 \\
\hline Individuals & $2,100,000$ & 4.8 & 168,000 & 4.8 & 168,000 \\
\hline \multicolumn{6}{|c|}{ Review request \& locate docs } \\
\hline For-profit & $2,394,000$ & 7.2 & 287,280 & 15.0 & 598,500 \\
\hline Private & $1,890,000$ & 7.2 & 226,800 & 15.0 & 472,500 \\
\hline Public & $2,016,000$ & 7.2 & 241,920 & 15.0 & 504,000 \\
\hline Individuals & $6,300,000$ & 7.2 & 756,000 & 7.2 & 756,000 \\
\hline \multicolumn{6}{|c|}{ Transactions to facilitate request } \\
\hline For-profit & $5,985,000$ & 7.2 & 718,200 & 7.2 & 718,200 \\
\hline Private & $4,725,000$ & 7.2 & 567,000 & 7.2 & 567,000 \\
\hline Public & $5,040,000$ & 7.2 & 604,800 & 7.2 & 604,800 \\
\hline Total & & $\mathrm{F}$ & $3,938,676$ & & $4,979,520$ \\
\hline
\end{tabular}

Source: Supplementary Statement documentation provided by the Department of Education to OIRA for verification information collection approval

It is unclear based on the documentation provided by ED to OIRA how the minute-per-response estimates for the individual activities were derived. What is clear, based on the numbers of responses, is how sensitive the overall burden will be to the minute-per-response estimates that ED employs. Indeed, each of the activities, with the exception of program updating, involve tasks that are highly variable in terms of time to completion, such as phone/email communication, but also document review, retrieval, verification, and submission. It is reasonable to suggest that any one of these activities could take, for example, an additional minute or two minutes to execute.

If an additional two minutes are added to each of the student/school interactions, it would add nearly half a million additional hours of burden and if all non-updating activities are included, it would require the nation's postsecondary institutions to take on nearly 637,000 additional hours of verification activities alone. In more relatable terms, this means employing an additional 315 individuals every year, or three weeks of additional work for one full-time staff member at the average institution. ${ }^{7}$

When financial aid office directors were asked about the reliability of verification burden estimates, there was widespread agreement that the two hours of reviewing changes and altering programming was several orders of magnitude off from the reality they experienced. Directors and staff suggested that it typically takes as much as 25 to 50 additional hours in preparation and adjustment plus additional staff hours in training (e.g., a 20-staff office would incur 20 additional hours of burden simply by all of them attending a one-hour update seminar).

7 This exercise assumes that only institutional burden is increased, not the amount of time it takes students to read instructions and secure the necessary information. 
While the people interviewed for this project suggested the amount of time needed to update documentation and interaction times were fair "on average," there was also near unanimity that it typically takes more than double the seven minutes that the Department estimates is needed to review requests and locate appropriate documentation.

As can be seen from Table 1, when financial aid office professionals' estimates of time to complete verification are considered, the difference between these estimates and those provided by ED across all higher education institutions adds up to more than one million hours of staff time. To the average institution, this is equivalent to approximately 4.5 additional weeks of work effort for one full-time equivalent staff member.

\section{Satisfactory Academic Progress}

As part of continued federal student aid eligibility, students must maintain minimum academic standards, and must demonstrate Satisfactory Academic Progress (SAP). Colleges and universities are required to evaluate all students and counsel those who do not meet the standards. ${ }^{8}$

Table 2 below shows the amount of time that ED estimates schools will need to meet SAP compliance. This includes approximately three hours per institution to account for annual changes to SAP policy. It also estimates that schools spend at least 1.2 minutes per student to identify those in compliance or not, and an additional 10.2 minutes to review cases where students do not meet SAP. It then estimates that a school will spend an additional 15 minutes on a consultative and evaluative basis with those students who do not meet the requirements.

8 For more information on SAP, please see: http://ifap.ed.gov/fsahandbook/attachments/1415Vol1Ch1.pdf. 
TABLE 2.-Comparison between Department of Education estimates of the amount of time students and institutions need to complete Satisfactory Academic Progress activities and financial aid office professionals' estimates for the same activities

\begin{tabular}{|c|c|c|c|c|c|}
\hline \multirow[b]{2}{*}{ Activity } & \multirow[b]{2}{*}{ Responses } & \multicolumn{2}{|c|}{$\begin{array}{c}\text { Department of Education } \\
\text { Estimates }\end{array}$} & \multicolumn{2}{|c|}{$\begin{array}{c}\text { Financial Aid Office } \\
\text { Estimates }\end{array}$} \\
\hline & & $\begin{array}{l}\text { Minutes per } \\
\text { response }\end{array}$ & Burden hours & $\begin{array}{r}\text { Minutes per } \\
\text { response }\end{array}$ & Burden hours \\
\hline \multicolumn{6}{|l|}{ Program updating } \\
\hline For-profit & 2,199 & 180.0 & 6,597 & 1200.0 & 43,980 \\
\hline Private & 1,743 & 180.0 & 5,229 & 1200.0 & 34,860 \\
\hline Public & 1,896 & 180.0 & 5,688 & 1200.0 & 37,920 \\
\hline \multicolumn{6}{|c|}{$\begin{array}{l}\text { Schools evaluating SAP at end of } \\
\text { payment periods }\end{array}$} \\
\hline For-profit & $8,789,254$ & 1.2 & 175,785 & 3.0 & 439,463 \\
\hline Private & $6,938,885$ & 1.2 & 138,778 & 3.0 & 346,944 \\
\hline Public & $7,401,477$ & 1.2 & 148,030 & 3.0 & 370,074 \\
\hline Individuals not meeting SAP & $1,619,074$ & 10.2 & 275,243 & 10.2 & 275,243 \\
\hline For-profit & 615,248 & 15.0 & 153,812 & 15.0 & 153,812 \\
\hline Private & 485,722 & 15.0 & 121,431 & 15.0 & 121,431 \\
\hline Public & 518,104 & 15.0 & 129,526 & 15.0 & 129,526 \\
\hline \multicolumn{6}{|c|}{$\begin{array}{l}\text { Schools evaluating SAP annually or } \\
\text { less frequently than end of } \\
\text { payment periods }\end{array}$} \\
\hline For-profit & $3,595,604$ & 1.2 & 71,912 & 3.0 & 179,780 \\
\hline Private & $2,838,635$ & 1.2 & 56,773 & 3.0 & 141,932 \\
\hline Public & $3,027,877$ & 1.2 & 60,558 & 3.0 & 151,394 \\
\hline Individuals not meeting SAP & 662,348 & 10.2 & 112,599 & 10.2 & 112,599 \\
\hline For-profit & 251,692 & 15.0 & 62,923 & 15.0 & 62,923 \\
\hline Private & 198,705 & 15.0 & 49,676 & 15.0 & 49,676 \\
\hline Public & 211,951 & 15.0 & 52,988 & 15.0 & 52,988 \\
\hline Total & & 一 & $1,627,548$ & & $\quad 2,704,544$ \\
\hline
\end{tabular}

Source: Supplementary Statement documentation provided by the U.S. Department of Education to OIRA for satisfactory academic progress information collection approval

Again, based on a review of the documentation provided by ED to OIRA it is unclear how the minute-per-response estimates for the individual activities were derived. Similar to the exercise done with verification, to examine the potential impact of even a small error in the Department's estimates, the SAP responses were adjusted upward by an additional two minutes, as were the minutes spent resolving SAP with students. The results suggest that this fractional increase would increase the SAP activities by more than half a million hours, which again translate into full-time work for more than 255 college staff members every year or just more than two weeks of additional work for a single full-time staff member at the average institution.

When financial aid office professionals were asked about the reliability of SAP burden estimates, respondents again pointed out that program updating often requires considerably more staff time, though there was general agreement that since SAP rules do not change as much from year to year, staff time costs are more dependent on the financial aid office's size (e.g., a 20-staff office will likely incur 20 hours of additional time if the entire office needs to engage in a one-hour "update" seminar).

Second, determining "meets or not meets" burdens are often a function of technology, including how student reports are stored, filed, and accessed. In some cases, the staff responding to this study believed that this activity could take up to five minutes per student. In addition, SAP appeals often tend to add a good deal more time, though the individuals that were interviewed for this project were unable to identify the frequency with which 
this typically occurs.

As can be seen from Table 2, when financial aid office professionals' estimates of time to complete SAP activities are considered, the difference between these estimates and those provided by ED across all higher education institutions adds nearly 1.1 million hours of staff time. To the average institution, this is equivalent to approximately 4.6 additional weeks of work effort for one full-time equivalent staff member.

\section{DISCUSSION/RECOMMENDATIONS}

The absence of systematic information collection burden reporting across federal agencies would at first glance suggest that both Congress and OIRA could do more to encourage or even require the kind of measurement standards necessary for accurately determining public burden. While it is evident that different information collection exercises have different purposes and, at least technically, no two requests are alike, the disparity in how federal agencies make their case is, for lack of a better phrase, consistently inconsistent. Given the time, effort and rigor associated with the regulatory process, it is strikingly odd that such an important aspect-the amount of time and effort needed by the public to comply — seems to be guided by little more than historical practice.

However, it also must be acknowledged that an undertaking like this would be difficult to execute for numerous reasons. Each year OIRA not only reviews thousands of ICRs, but also accomplishes this one particular task as part of a much, much larger portfolio of activities. What is more, establishing government-wide reporting standards would not only require a very high level of cross-agency agreement, but the exercise would impose its own administrative burden on the federal government itself. This cost would have to be weighed against a not-well-defined set of benefits.

Still, this paper reveals that a great deal of effort goes into documenting the amount of burden that information collection creates but practically no effort into actually justifying the underlying calculations. How long does it take to read a paragraph or a one-page form? How much time does it take to input a single data entry? How long does it take to find last year's tax forms? How much time to make a phone call, navigate a voice-mail tree, and discuss an issue with someone else (be it from the perspective of the student or from a financial aid office)?

These are the factors that shape time and effort spent. They are the activities that either force businesses to bring on more resources or find ways to do more with less-yet they also seem to be the one aspect of a well-defined regulatory process that has no reasonable basis. Policymakers need to consider how information collection burden standards based on a common set of activities can be both created and implemented.

The obvious consequence of not having such standards is minimal reporting that too often omits activities that impose a great deal of time and financial costs on schools. Many of these information collection and reporting activities, particularly in the case of federal financial aid, are seasonal. However, compliance is not the kind of activity that tends to be, nor should be, assigned to temporary work staff. Document collection and retention pose time/resource commitments that frequently do not get accounted for, such as having to account for the diversity with which institutions tend to receive information (e.g., fax, email, paper) versus how it eventually must be stored. Timing is even important as things like study abroad, transient students, and diploma verification can potentially become flags in automated systems because they do not fall into traditional reporting slots.

What seems to frustrate many financial aid office staff is the serious underestimation of time needed to adjust when standards change. Adding data points to be collected or reviewed or reported is not limited to the simple 
inclusion of more fields. Schools may be pulling new data in from different sources, which taxes their IT infrastructure. Staff members need to be updated or, in some cases, trained. Forms (electronic and paper) need to be updated. Most importantly, these processes then need to be tested and validated, especially at institutions that work with large volumes of information.

The greatest challenge though, according to financial aid professionals, is in providing consumer support. Schools see ED craft information collection estimates that suggest staff members are capable of resolving issues with students in mere minutes when the consistent public message from the Department is that financial aid is too complex and that students and parents are easily confused. In a number of instances, for example, the financial aid administrators who were contacted for this paper pointed out the challenge of helping students provide the kind of verification information institutions need without looking like the administrators were actually recommending responses.

While the intuitive answer is a call for greater automation, individualized interactions will still be needed and they will slow down the process. In fact, it was actually the financial aid staff in the larger more automated institutions that were most likely to point out how manual processes that are consequences of data collection, data reporting, consumer communication and file rejections problems are what create the massive burdens they experience.

As a matter of best practice and fair standards of regulatory engagement, policymakers should hold federal departments and agencies more accountable for aspects of information collection burden that receive only minimal attention. Data collection and storage, data validation, and internal training are all components that create real financial costs and greatly increase the amount of time that schools need to properly address reporting, disclosure and record-keeping requirements.

In the absence of standards, the quality of estimates becomes very important and it is evident that, at least in certain cases, a good deal of false precision may exist. Where reporting and recordkeeping efforts can require tens of thousands of interactions per school, even a fractional increase in time spent on a given activity can quickly create a resource shortage. This is bound to either adversely affect quality or pull resources away from other, possibly more important core tasks. A one- or two-minute addition to a phone call with an uninformed borrower is not unreasonable by any measure, nor is the notion that regulatory burden changes need to be shared with everyone in a financial aid office.

To the extent that the alternative burden estimates in the findings section of this paper are more apt to reflect the reality that higher education institutions face, the magnitude of the differences between what ED assumes and what actually occurs is cause for more than just concern. The available evidence already suggests that college financial aid offices have borne the brunt of considerable additional work without a commensurate addition in resources. ${ }^{9}$

It is logical to conclude that better communication between the Department and higher education institutions is needed, but so too is greater awareness and action from OIRA when information collection burdens seem to grossly underestimate actual effort. Policymaking in this area needs to focus more on creating ways for the Department to more highly value the observations of the institutions that it regulates. Yes, there are options for higher education institutions to express concern about unfair estimates, including filing public comments and

9 In that study, see Figures 5 and 6, which document the general growth in the number of financial aid applicants and lack of commensurate budget increase during the same time period. 
even petitioning OIRA directly. Nevertheless, casual observation suggests that institutions are not necessarily aware of their ability to appeal directly to OIRA on such matters and financial aid offices have already indicated that time constraints make drafting comments to regulatory proposals a very low priority. ${ }^{10}$

Any number of options could be explored. One, for example, might be to emulate the White House's "We the People" petition process and develop a system where, provided that enough comments or concerns are raised, ED becomes obligated to articulate how it will address any differences between its own estimates and those developed by institutions. Another alternative could involve the establishment of a standing group of college and university experts that can inject a formal position into the regulatory process at the point where information collection burden is being established.

Another area where a policy change could be of great assistance to information collection efforts is accounting for operational scale economies. Colleges and universities are not single-sized organizations. At their largest, they can enroll up to 60,000 students at a single campus and have student support offices (like admissions and financial aid) employing up to 40 or 50 individuals. At the other end of the spectrum are many institutions that enroll less than 1,000 students and where the financial aid director is the financial aid office, with perhaps a part-time student worker. ${ }^{11}$

In this regard, the "average" incremental burden increase discussed in the last section can be deceiving, since small institutions will, by design, be reviewing smaller numbers of applications. Still, this is offset by the fact that smaller offices do not enjoy the scale economies of automation or data retrieval/validation and may still be doing compliance on an Excel spreadsheet or even by hand. The nominal number of hours needed to meet regulatory compliance may be lower at smaller institutions. But there are thousands of small institutions, and when individuals at those institutions are also tasked with performing the counseling function and aid disbursement, one can see how information collection burdens that assume greater resource availability are not capturing the true nature of the effort. In the same vein, large institutions have the ability to leverage more staff and more technology to meet the same burden but scale economies can work against them because a much greater up-front investment is necessary. In some cases these larger offices can have upwards of five to 10 dedicated compliance staff and within this office maintain an additional degree of hyper-specialization.

In other words, simply disaggregating institutions by public, private nonprofit and for-profit status, as is the current Department practice, misses a great deal of underlying infrastructure variation that shapes the ability of colleges and universities to meet regulatory compliance. Policymaking in this area needs to rethink the standards by which affected institutions are grouped. Strategies might include classifying information collection burden estimates by institution size or by technological capacity. They may also be grouped by the size of the office affected (e.g., utilizing ratios of financial aid office staff to students served as a baseline for several burden "buckets").

On a much larger level, forging a policy focusing on consistent review of existing regulations is warranted. Efforts to simplify the Free Application for Federal Student Aid (FAFSA) seek to minimize applicant burden and increase individuals' ability to get financial resources to support an education. Yet the simplification debate has not addressed the back-end cost to verification because far less information is flowing to the schools up front.

10 See the NASFAA Administrative Burden Survey. Nearly half of all school respondents indicated that office resource shortages greatly affected their ability to respond to Notices of Proposed Rulemaking.

11 The more useful metric would be median financial aid office staff size; however, this information is not readily collected. For further information see NASFAA's staffing and administrative burden reports, which are available on NASFAA's website. 
Less information is likely to lead to even more time spent on verification, since schools will need to request more information from students and families as part of the process. That may actually end up complicating students' financial aid packages.

Which leads to two very obvious questions: why is verification only done on a third of all aid recipients, and why is it a school process and not one conducted by ED? Today the Department of Education owns all of the federal loans currently disbursed. Since verification is technically a loan underwriting process, all recipients should be verified and it is not entirely clear why schools should still be doing this. Private sector companies such as Campus Logic already offer solutions that specifically address many of the data collection and reporting challenges behind verification. They could theoretically save the higher education sector millions of hours of staff time and also do so for a fraction of the current cost. ${ }^{12}$ In light of the data collection, storage, validation and transfer challenges, policymakers should consider how private sector technologies could help reduce information collection burden.

This paper starts a much-needed conversation on information collection burden by highlighting the challenges and shortcomings to the existing regulatory framework. A more in-depth and rigorous analysis would do much to strengthen that conversation and provide policymakers with the kind of analysis that can help craft meaningful change. To that end, it makes good sense for Congress to consider asking the Government Accountability Office to conduct more in-depth research on the extent to which the Department of Education's information collection request estimates are consistent with the time spent by higher education institutions' professionals who perform such activities.

\section{APPENDIX A}

List of Information Collection Requests Reviewed

\begin{tabular}{|c|c|c|c|c|c|}
\hline $\begin{array}{c}\mathrm{OMB} \\
\text { Control No }\end{array}$ & Agency/Sub & Title & $\begin{array}{l}\text { Date } \\
\text { Received }\end{array}$ & $\begin{array}{l}\text { Concluded } \\
\text { Date }\end{array}$ & $\begin{array}{c}\text { Current } \\
\text { Expiration Date }\end{array}$ \\
\hline$\underline{1405-0138}$ & STATE/AFA & $\begin{array}{l}\text { DOS-Sponsored Academic Exchange Program Applica- } \\
\text { tion }\end{array}$ & $9 / 20 / 11$ & $2 / 5 / 12$ & $2 / 28 / 15$ \\
\hline$\underline{1840-0550}$ & $\mathrm{ED} / \mathrm{OPE}$ & $\begin{array}{l}\text { Application for Grants Under the Upward Bound Pro- } \\
\text { gram }\end{array}$ & $10 / 31 / 11$ & $12 / 8 / 11$ & $12 / 31 / 14$ \\
\hline$\underline{1840-0744}$ & $\mathrm{ED} / \mathrm{OPE}$ & $\begin{array}{l}\text { Higher Education Act (HEA) Title II Report Cards on } \\
\text { State Teacher Credentialing and Preparation }\end{array}$ & $9 / 19 / 12$ & $12 / 6 / 12$ & $12 / 31 / 15$ \\
\hline$\underline{1840-0821}$ & $\mathrm{ED} / \mathrm{OPE}$ & GEAR UP Applications for Partnership and State Grants & $7 / 19 / 12$ & $8 / 24 / 12$ & $8 / 31 / 15$ \\
\hline$\underline{1840-0826}$ & $\mathrm{ED} / \mathrm{OPE}$ & Talent Search (TS) Annual Performance Report & $7 / 26 / 12$ & $10 / 11 / 12$ & $10 / 31 / 15$ \\
\hline$\underline{1840-0828}$ & $\mathrm{ED} / \mathrm{OPE}$ & $\begin{array}{l}\text { Assessing Program Performance, National Resource Cen- } \\
\text { ter, Business and International Education, and Undergrad- } \\
\text { uate International Studies and Foreign Language Programs } \\
\text { Phone Interviews }\end{array}$ & $9 / 5 / 12$ & $12 / 6 / 12$ & $12 / 31 / 15$ \\
\hline$\underline{1840-0829}$ & $\mathrm{ED} / \mathrm{OPE}$ & $\begin{array}{l}\text { Survey of Post-Graduate Outcomes for International } \\
\text { Education Fellowship Recipients }\end{array}$ & $10 / 9 / 12$ & $12 / 21 / 12$ & $12 / 31 / 15$ \\
\hline$\underline{1845-0011}$ & $\mathrm{ED} / \mathrm{FSA}$ & $\begin{array}{l}\text { William D. Ford Federal Direct Loan Program Deferment } \\
\text { Request Forms }\end{array}$ & $5 / 21 / 12$ & $7 / 23 / 12$ & $7 / 31 / 15$ \\
\hline
\end{tabular}

12 Campus Logic estimates that it can provide all aspects of the verification process for approximately $\$ 1$ per student. 


\begin{tabular}{|c|c|c|c|c|c|}
\hline $\begin{array}{l}\text { OMB } \\
\text { Control No }\end{array}$ & Agency/Sub & Title & $\begin{array}{l}\text { Date } \\
\text { Received }\end{array}$ & $\begin{array}{l}\text { Concluded } \\
\text { Date }\end{array}$ & $\begin{array}{l}\text { Current } \\
\text { Expiration Date }\end{array}$ \\
\hline$\underline{1845-0015}$ & $\mathrm{ED} / \mathrm{FSA}$ & $\begin{array}{l}\text { Federal Family Education Loan, Direct Loan, and Perkins } \\
\text { Loan Discharge Applications }\end{array}$ & $10 / 28 / 13$ & $12 / 3 / 13$ & $12 / 31 / 14$ \\
\hline$\underline{1845-0018}$ & $\mathrm{ED} / \mathrm{FSA}$ & $\begin{array}{l}\text { William D. Ford Federal Direct Loan (Direct Loan) } \\
\text { Program: Internship/Residency and Loan Debt Burden } \\
\underline{\text { Forbearance Forms }}\end{array}$ & $5 / 21 / 12$ & $7 / 23 / 12$ & $7 / 31 / 15$ \\
\hline$\underline{1845-0035}$ & $\mathrm{ED} / \mathrm{FSA}$ & National Student Loan Data System (NSLDS) & $3 / 27 / 13$ & $5 / 13 / 13$ & $5 / 31 / 16$ \\
\hline$\underline{1845-0052}$ & $\mathrm{ED} / \mathrm{FSA}$ & $\begin{array}{l}\text { Student Assistance General Provision-Subpart I-Immi- } \\
\text { gration Status Confirmation }\end{array}$ & $4 / 5 / 13$ & $4 / 17 / 13$ & $4 / 30 / 15$ \\
\hline$\underline{1845-0059}$ & $\mathrm{ED} / \mathrm{FSA}$ & $\begin{array}{l}\text { Federal Direct Loan Program and Federal Family Educa- } \\
\text { tion Loan Program Teacher Loan Forgiveness Forms }\end{array}$ & $5 / 27 / 14$ & $7 / 21 / 14$ & $7 / 31 / 17$ \\
\hline$\underline{1845-0083}$ & $\mathrm{ED} / \mathrm{FSA}$ & $\begin{array}{l}\text { Teacher Education Assistance for College and Higher } \\
\text { Education (TEACH) Grant Program Agreement to Serve }\end{array}$ & $12 / 19 / 11$ & $2 / 16 / 12$ & $2 / 28 / 15$ \\
\hline$\underline{1845-0102}$ & $\mathrm{ED} / \mathrm{FSA}$ & $\begin{array}{l}\text { Federal Family Education Loan (FFEL) Program Income } \\
\text { Based Repayment (IBR) Plan Request and Alternative } \\
\text { Documentation of Income }\end{array}$ & $2 / 19 / 14$ & $3 / 18 / 14$ & $11 / 30 / 15$ \\
\hline$\underline{1845-0107}$ & $\mathrm{ED} / \mathrm{FSA}$ & $\begin{array}{l}\text { Student Assistance General Provisions_-Subpart A- } \\
\text { General }\end{array}$ & $8 / 19 / 13$ & $9 / 10 / 13$ & $3 / 31 / 15$ \\
\hline$\underline{1845-0110}$ & $\mathrm{ED} / \mathrm{FSA}$ & $\begin{array}{l}\text { Employment Certification for Public Service Loan For- } \\
\text { giveness }\end{array}$ & $3 / 7 / 12$ & $3 / 19 / 12$ & $11 / 30 / 14$ \\
\hline$\underline{2900-0073}$ & VA & $\underline{\text { VA Enrollment Certification }}$ & $3 / 8 / 12$ & $7 / 5 / 12$ & $7 / 31 / 15$ \\
\hline$\underline{2900-0156}$ & VA & Notice of Change in Student Status & $3 / 13 / 12$ & $6 / 19 / 12$ & $6 / 30 / 15$ \\
\hline$\underline{2900-0718}$ & VA & $\underline{\text { Yellow Ribbon Program Agreement }}$ & $6 / 12 / 12$ & $7 / 16 / 12$ & $7 / 31 / 15$ \\
\hline$\underline{2900-0794}$ & VA & $\underline{\text { Post-9/11 GI Bill Longitudinal Study }}$ & $11 / 6 / 12$ & $5 / 30 / 13$ & $5 / 31 / 16$ \\
\hline$\underline{2900-0797}$ & VA & Principles of Excellence Complaint System Intake & $10 / 28 / 13$ & $12 / 13 / 13$ & $12 / 31 / 16$ \\
\hline$\underline{3137-0086}$ & IMLS & $\begin{array}{l}\text { Laura Bush 21st Century Librarian Grant Program Eval- } \\
\text { uation }\end{array}$ & $7 / 19 / 12$ & $12 / 20 / 12$ & $12 / 31 / 15$ \\
\hline$\underline{3145-0035}$ & NSF & $\underline{\text { National Science Foundation Science Honor Awards }}$ & $6 / 24 / 11$ & $8 / 10 / 11$ & $10 / 31 / 14$ \\
\hline$\underline{3145-0062}$ & NSF & $\begin{array}{l}\text { Survey of Graduate Students and Postdoctorates in Sci- } \\
\text { ence and Engineering }\end{array}$ & $5 / 17 / 13$ & $5 / 31 / 13$ & $10 / 31 / 14$ \\
\hline$\underline{3145-0100}$ & NSF & $\underline{\text { Higher Education R\&D and FFRDC R\&D Surveys }}$ & $6 / 25 / 13$ & $9 / 16 / 13$ & $9 / 30 / 16$ \\
\hline$\underline{3145-0174}$ & NSF & $\begin{array}{l}\underline{\text { SRS-Generic Clearance of Survey Improvement Projects }} \\
\text { for the Division of Science Resources Statistics }\end{array}$ & $5 / 30 / 13$ & $5 / 31 / 13$ & $5 / 31 / 16$ \\
\hline$\underline{3145-0217}$ & NSF & $\begin{array}{l}\text { Evaluation of the Robert Noyce Teacher Scholarship } \\
\underline{\text { Program }}\end{array}$ & $12 / 13 / 11$ & $4 / 4 / 12$ & $4 / 30 / 15$ \\
\hline$\underline{3145-0223}$ & NSF & $\begin{array}{l}\text { Grantee Reporting Requirements for the Graduate } \\
\text { Research Fellowship Program. }\end{array}$ & $9 / 11 / 12$ & $12 / 6 / 12$ & $12 / 31 / 15$ \\
\hline$\underline{3145-0227}$ & NSF & $\begin{array}{l}\text { Office of Inspector General Review of Awardee Imple- } \\
\text { mentation of NSF's Requirement for a Responsible } \\
\text { Conduct of Research Program }\end{array}$ & $5 / 31 / 13$ & $8 / 2 / 13$ & $8 / 31 / 16$ \\
\hline$\underline{3145-0229}$ & NSF & $\begin{array}{l}\text { Grantee Reporting Requirements for Nanoscale Science } \\
\text { and Engineering Centers (NSECs) }\end{array}$ & $8 / 20 / 13$ & $9 / 19 / 13$ & $9 / 30 / 16$ \\
\hline
\end{tabular}




\begin{tabular}{|c|c|c|c|c|c|}
\hline $\begin{array}{l}\text { OMB } \\
\text { Control No }\end{array}$ & Agency/Sub & Title & $\begin{array}{l}\text { Date } \\
\text { Received }\end{array}$ & $\begin{array}{l}\text { Concluded } \\
\text { Date }\end{array}$ & $\begin{array}{l}\text { Current } \\
\text { Expiration Date }\end{array}$ \\
\hline$\underline{3145-0230}$ & NSF & $\begin{array}{l}\text { Grantee Reporting Requirements for Materials Research } \\
\underline{\text { Science and Engineering Centers (MRSECs) }}\end{array}$ & $9 / 20 / 13$ & $12 / 6 / 13$ & $12 / 31 / 16$ \\
\hline$\underline{3145-0233}$ & NSF & $\begin{array}{l}\text { Grantee Reporting Request for Emerging Frontiers in } \\
\text { Research and Innovation (EFRI) Program }\end{array}$ & $12 / 5 / 13$ & $3 / 20 / 14$ & $3 / 31 / 17$ \\
\hline$\underline{3145-0234}$ & NSF & $\begin{array}{l}\text { Grantee Reporting Requirements for National Facilities } \\
\text { Managed by the NSF Division of Materials Research }\end{array}$ & $12 / 30 / 13$ & $3 / 27 / 14$ & $3 / 31 / 17$ \\
\hline
\end{tabular}

\section{APPENDIX B}

\section{Supplementary Statement Answers to Question \#12 (calculation of burden estimates) for Department of Edu- cation's SSSP and CATEF programs}

\section{Student Support Services (SSS) Program Annual Performance Report (APR)}

Estimated burden hours for this collection of information are 15,405 hours. We estimate approximately 1,027 respondents x 1 (one) APR each @ 15 hours per respondent. The APR will be submitted once a year (annually).

\begin{tabular}{ll} 
Estimated number of respondents & 1027 \\
Estimated preparation time & 15 hours \\
\hline Total estimated burden hours & $\mathbf{1 5 , 4 0 5}$
\end{tabular}

(Estimated Burden: 15,405 hrs. Total number of hours [preparation time] multiplied by the total number of respondents equals estimated burden hours).

Most of the costs of this data collection are those of the federal government, since the respondents are project staff paid for the most part with Federal grant funds. Nonetheless, the annual cost to the grantees to respond to this data collection is estimated as follows:

Estimated annual costs to respondents:

Professionals (1,027 personnel x 12 hours @ \$35 per hour) \$431,340

\begin{tabular}{ll} 
Clerical $\quad(1,027$ clerical $x 3$ hours @ $\$ 18$ per hour $)$ & $\$ 55,458$ \\
\hline Total estimated cost to respondents & $\$ 486,798$
\end{tabular}

\section{College Affordability and Transparency List Explanation Form (CATEF)}

The estimated time burden to respondents for the College Affordability and Transparency Explanation Form (CATEF) is three hours on average. The form will be completed by the top 5 percent of institutions in each sector with the largest increases in tuition and fees and/or net prices to students. Thus, the exact number of institutions that will be included in the collection may vary slightly from year to year based on the number of institutions in each sector. The number of respondents may also vary depending on how many institutions are included on both the tuition and fees and net price increase lists, as that overlap would limit the number of other institutions included in the top 5 percent that would have to report data. The 2011-12 collection will have 528 institutions, leading to an estimated total burden of 1,584 hours per year for all respondents.

In all cases, if the data are readily accessible, then the time required is less than the estimated burden hours. 
Estimates include the time for reviewing instructions, gathering and maintaining the institution's general purpose financial statements for the two necessary years and completing and reviewing the required information. This time burden was reviewed by those people noted in section A.8 and B.5 that provided consultation on the survey. This time amount is the total of the following estimates by section of the proposed survey form:

Table 1: Detailed calculations for the CATEF data collection time burden estimate

\begin{tabular}{|c|c|c|}
\hline Section & Time Estimate & Section Requirements \\
\hline 1 & 10 to 20 minutes & $\begin{array}{l}\text { Two paragraphs of instructions to read. Information on the institution } \\
\text { and respondent are pre-loaded. The respondent has one or two "yes or } \\
\text { no" questions to respond to, depending on which CATC list they were } \\
\text { on. If the institution responds affirmatively they will have to enter an } \\
\text { explanation that is expected to take } 10 \text { minutes. For those institutions } \\
\text { that respond affirmatively to either question, this will be the end of the } \\
\text { survey with a total burden estimate of } 20 \text { minutes. }\end{array}$ \\
\hline 2 & 45 minutes & $\begin{array}{l}\text { One paragraph of instructions and up to twenty definitions to read. } \\
\text { The respondent will need to have their financial statements for the first } \\
\text { year and last year of the three-year period covered. The respondent will } \\
\text { need to enter selected amounts for expenses from their financial state- } \\
\text { ment into the survey. The reporting of revenue amounts is optional and } \\
\text { those amounts will be available from the same financial statements as } \\
\text { the expense amounts. The collection system will calculate the percent } \\
\text { change for the amounts and the per FTE student amounts from existing } \\
\text { information. }\end{array}$ \\
\hline 3 & 10 to 50 minutes & $\begin{array}{l}\text { One sentence of instructions to read. Respondent will need to provide } \\
\text { an explanation for each of the cost increases they indicated in section } 2 . \\
\text { It is estimated that each explanation will take } 10 \text { minutes. Respondents } \\
\text { will have a minimum of one and a maximum of five explanations to } \\
\text { provide. }\end{array}$ \\
\hline 4 & 10 to 50 minutes & $\begin{array}{l}\text { Two sentences of instructions to read. Respondent will need to describe } \\
\text { the steps the institution has taken to reduce the costs for each of the cost } \\
\text { increases they indicated in section } 2 \text {. It is estimated that each description } \\
\text { will take } 10 \text { minutes. Respondents will have a minimum of one and a } \\
\text { maximum of five descriptions to provide. }\end{array}$ \\
\hline 5 & 5 to 30 minutes & $\begin{array}{l}\text { Up to five sentences of instructions to read. The respondent will need to } \\
\text { respond to a "yes or no" screening question. If the institutions responds } \\
\text { "no" they will have to enter two short responses (expected to take } 10 \\
\text { minutes total). The respondent has the option to enter any additional } \\
\text { information they would like to be included in their submission. }\end{array}$ \\
\hline 6 & 5 minutes & $\begin{array}{l}\text { The respondent answers "yes" or "no" to whether they found the burden } \\
\text { estimate for the survey to be accurate. If they indicate "no," then they } \\
\text { must enter in how long the survey took them to complete. }\end{array}$ \\
\hline Total & 20-190 minutes & $\begin{array}{l}\text { The variance depends on: 1) whether the respondent enters "yes" to } \\
\text { either of the questions in the first section, which end the survey; 2) the } \\
\text { number of cost areas that have increased over the three year period; } \\
\text { and 3) the amount of additional information the respondent decides to } \\
\text { include }\end{array}$ \\
\hline
\end{tabular}

The total cost to respondents is based on the estimated response burden (hours) multiplied by $\$ 42$ (in 2011-12), 
which includes average data analyst and associated computer costs (for running programs to extract data). The hourly wage is increased by an assumed 2 percent cost-of-living adjustment for subsequent years. Because the institutions that will be on the College Affordability and Transparency Lists in subsequent years have not yet been identified, we will use the 2011-12 hour burden estimate for subsequent years. Total estimated costs to respondents for the 2011-12, 2012-13, and 2013-14 collections are:

Table 2: Estimated costs to respondents, by collection year

\begin{tabular}{|crrrrr|}
\hline Collection year & $\begin{array}{c}\text { Number of } \\
\text { Respondents }\end{array}$ & $\begin{array}{c}\text { Average Burden } \\
\text { Hours Per Insti- } \\
\text { tution }\end{array}$ & $\begin{array}{c}\text { Estimated Total } \\
\text { Burden Hours for } \\
\text { All Institutions }\end{array}$ & $\begin{array}{c}\text { Average Esti- } \\
\text { mated Costs Per } \\
\text { Institution }\end{array}$ & $\begin{array}{c}\text { Estimated Cost to } \\
\text { All Institutions }\end{array}$ \\
\hline $2011-12$ & 528 & 3 & 1,584 & $\$ 126$ & $\$ 66,528$ \\
\hline $2012-13$ & 528 & 3 & 1,584 & $\$ 151$ & $\$ 79,728$ \\
\hline $2013-14$ & 528 & 3 & 1,584 & $\$ 181$ & $\$ 95,568$ \\
\hline
\end{tabular}




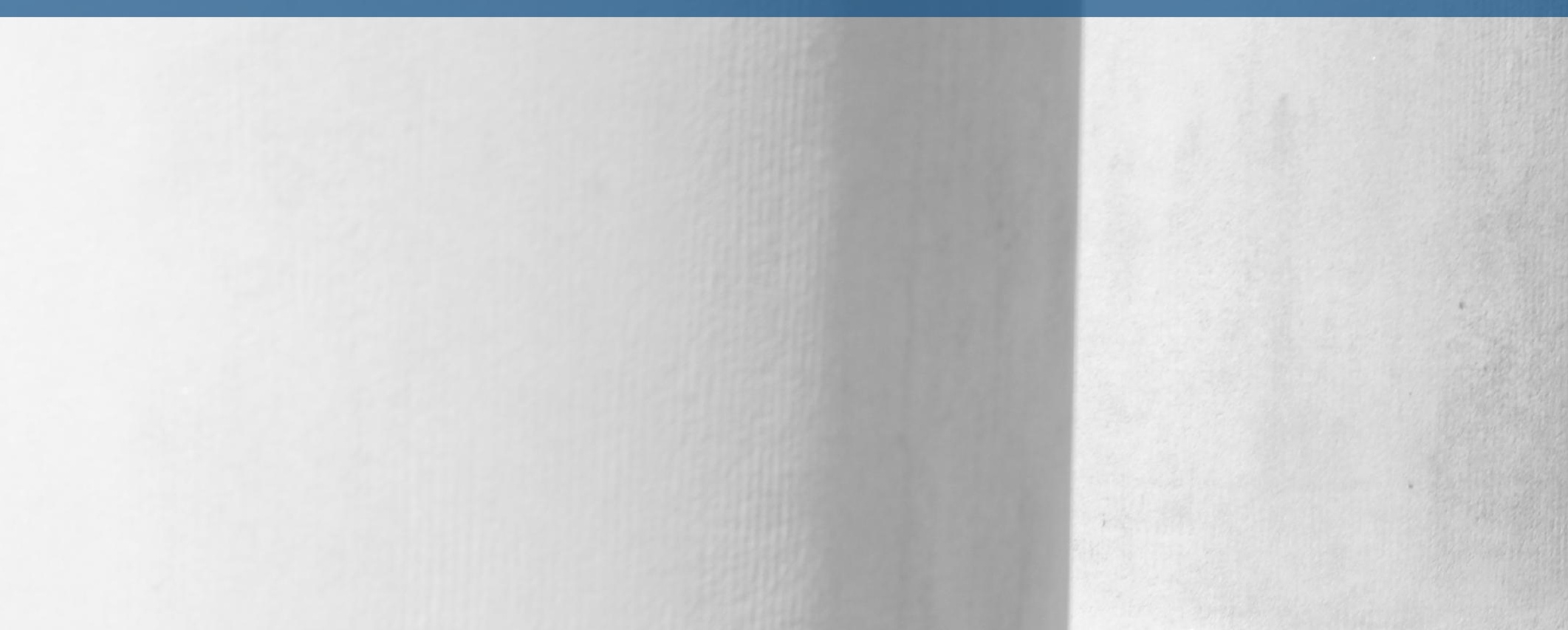

